\title{
The use of pulsed radiofrequency in the management of chronic lumbosacral radicular pain
}

Citation for published version (APA):

van Boxem, K. D. M. (2014). The use of pulsed radiofrequency in the management of chronic lumbosacral radicular pain. [Doctoral Thesis, Maastricht University]. Maastricht University. https://doi.org/10.26481/dis.20140605kb

Document status and date:

Published: 01/01/2014

DOI:

$10.26481 /$ dis.20140605kb

Document Version:

Publisher's PDF, also known as Version of record

\section{Please check the document version of this publication:}

- A submitted manuscript is the version of the article upon submission and before peer-review. There can be important differences between the submitted version and the official published version of record.

People interested in the research are advised to contact the author for the final version of the publication, or visit the DOI to the publisher's website.

- The final author version and the galley proof are versions of the publication after peer review.

- The final published version features the final layout of the paper including the volume, issue and page numbers.

Link to publication

\footnotetext{
General rights rights.

- You may freely distribute the URL identifying the publication in the public portal. please follow below link for the End User Agreement:

www.umlib.nl/taverne-license

Take down policy

If you believe that this document breaches copyright please contact us at:

repository@maastrichtuniversity.nl

providing details and we will investigate your claim.
}

Copyright and moral rights for the publications made accessible in the public portal are retained by the authors and/or other copyright owners and it is a condition of accessing publications that users recognise and abide by the legal requirements associated with these

- Users may download and print one copy of any publication from the public portal for the purpose of private study or research.

- You may not further distribute the material or use it for any profit-making activity or commercial gain

If the publication is distributed under the terms of Article $25 \mathrm{fa}$ of the Dutch Copyright Act, indicated by the "Taverne" license above, 


\section{The use of pulsed radiofrequency in the management of chronic lumbosacral radicular pain}

KOEN VAN BOXEM 


\section{The use of pulsed radiofrequency in the management of chronic lumbosacral radicular pain}

Proefschrift

Ter verkrijging van de graad van doctor aan de Universiteit Maastricht, op gezag van de Rector Magnificus, Prof. dr. L. Soete. Volgens het besluit van het College van Decanen

Printed at: Geers Offset- Oostakker

Koen D. M. Van Boxem Geboren te Antwerpen op 6 april 1970 
Beoordelingscommissie

Prof. dr. R. van Oostenbrugge (Voorzitter)

Prof. dr. W. Buhre

Prof. dr. G. Hans (Universiteit Antwerpen, België)

Prof. dr. K. van Overbeeke

Prof dr K. Vissers (Radboud universiteit Nijmegen)

\section{GHAPTER II}

Evidence-based Interventional Pain Medicine according to clinical diagnoses: Lumbosacral Radicular Pain

\section{GHAPTER III}

Pulsed Radiofrequency: A Review of the Basic Science as Applied to the

Pathophysiology of Radicular Pain: A Call for Clinical Translation

\section{GHAPTER IV}

Clinical trials in interventional pain management: optimizing chances for succes.

\section{GHAPTER V}

Pulsed radiofrequency treatment adjacent to the lumbar dorsal root ganglion for the management of lumbosacral radicular syndrome: A clinical audit

GHAPTER VI

Pulsed radiofrequency for chronic intractable lumbosacral radicular pain:

a six-month cohort study.

\section{CHAPTER VII}

Predictive factors for successful outcome of pulsed radiofrequency treatment in patients with intractable lumbosacral radicular pain

CHAPTER VIII

General discussion

\section{GHAPTER IX}

Summary

CO-AUTHORS AND AFFILIATIONS

BIBLIOGRAPHY

\section{DANKWOORD}

GV AND PUBLIGATIONS

LIST OF ABBREVIATIONS 
Chapter I

Introduction 


\section{Historical aspects}

The first reports on lumbosacral radicular pain go back to Hippocrates. It was initially described as sciatica in Greek (literally "hip pain")' and ischialgia in Latin.

The derived term "ischias" refers to the distribution according to the sciatic nerve (nervus ischiadicus), for until the $19^{\text {th }}$ century it was believed that this type of nerve pain was caused by an inflammatory process at the sciatic nerve due to a rheumatic condition ${ }^{2}$ or according to Lasègue - Forst by a muscular compression at the buttocks. ${ }^{3}$ It lasted until the 20th century before the intervertebral disc was consid-

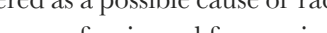
inflammation, ischemia ${ }^{6,7}$ and probably to a lesser extent pressure ${ }^{8}$ not only initiates but also maintains radicular pain.

This historical overview explains the wide range in terminology currently used: sciatica, ischias, nerve root entrapment, radicular pain, radiculopathy, pain that goes down the leg,...

Up till now no consensus has been reached, ${ }^{9}$ although it has been recommended to use the terms nerve root pain, or lumbosacral radicular pain which is more accurate and explanatory of the presenting condition. ${ }^{10-12}$ Radiculopathy is frequently used in literature, although strictly speaking this can only be used when there is an objective loss of sensory and/or motor function..$^{13}$ In this thesis the term lumbosacral radicular pain will be consistently used for pain radiating into the leg and originating from an inflammatory process at the nerve root.

The latter can lead to a state of neuropathic pain as described in basic science ${ }^{6}$ as well as in clinical data.

Epidemiology of lumbosacral radicular pain

In the general population older than 30 years of age, up to $5 \%$ suffer from low back pain radiating into the leg, ${ }^{14-16}$ making it probably the most commonly occurring form of neuropathic pain. ${ }^{17-19}$ Acute lumbosacral radicular pain, caused by disc herniation and/or nerve root entrapment, improves considerably in the short-term. About three quarters of patients will recover after three months, ${ }^{12,20-22}$ however a high recurrence rate is reported. ${ }^{23}$ Furthermore when pain persists after this recovery pe(1) fem (in patients referred for secondary care and receiving conservative care or surgery if necessary, about $40 \%$ to $45 \%$ report unsuccessful outcomes at respectively 1 and 2 years' follow-up. ${ }^{25}$ Patients suffering from lumbosacral radicular pain often experience a reduced functionality leading to an incapacity to work. A quarter of these patients are still out of work 2 years after onset. ${ }^{27}$ These patients are characterized by lower levels of health-

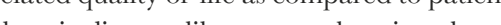
The high prevalence of lumbosacral radicular pain in the general population combined with a decreased quality of life therefore creates a major health care problem with great economic impact.

\section{Available treatments for lumbosacral radicular pain}

Because the prognosis of lumbosacral radicular pain during the first months is favorable for the majority of patients an initial conservative approach with medication or physiotherapy is recommended. Pharmacological treatment remains the first treatment option for the management of patients with lumbosacral radicular pain. The neuropathic character of chronic lumbosacral radicular pain justifies 
the use of medication such as tricyclic antidepressants or anti-epileptics. The efficacy and tolerability of these drugs for lumbosacral radicular pain in primary care is however unclear, ${ }^{29}$ as the majority of clinical trials have been performed in patients with painful diabetic polyneuropathy or post herpetic neuralgia. Based on the published randomized controlled trials in patients with chronic lumbosacral radicular pain no superiority of pregabalin, morphine, nortryptiline or topiramate over placebo could be noted. $17,30,31$

Exercise therapy seems to have a favorable influence ${ }^{33}$ but its value still has to be determined. ${ }^{34}$

Interventional pain management techniques are used when the pain proves to be refractory to conservative treatment. Interventional therapies are mainly aimed at targeting the specific structures thought to be causing the lumbosacral radicular pain. In the sub-acute phase of lumbosacral radicular pain the inflammation of the spinal nerve is mostly treated by injecting corticosteroids around the nerve. A systematic review on the effect of corticosteroid injection in lumbosacral radicular pain included 25 published reports on 23 clinical trials. According to the GRADE classification the overall quality of the included trials was rated as high. There was a significant effect of epidura corticosteroids over placebo on leg pain and disability in the short-term, however in the long-term no difference could be discerned.

The effect of corticosteroid injections at the nerve root in patients with chronic lumbosacral radicular pain still is unclear. It should be recognized that experimental work has shown that chronic lumbosacral radicular pain is characterized by an inflammatory process with a continuous nociceptive afferent firing input leading to a chronic neuropathic state with a consequent and robust central sensitization at the spinal pain gate. ${ }^{35,36}$

As an alternative to reduce the continuous afferent nociceptive input in patients with chronic lumbosacral radicular pain, a small part of the ganglion spinale [dorsal root ganglion (DRG)] can be coagulated by a selective heat lesion..$^{37}$ The effect of this radiofrequency treatment (RF) adjacent to the dorsal root ganglion in patients suffering from chronic lumbosacral radicular pain, was studied in a well-designed randomized clinical trial. ${ }^{38}$ The active treatment did not show superiority over sham intervention. Moreover the potential risk of inducing deafferentation pain by the heat lesion compromises the attractiveness of this treatment option.

On the other hand two RCT's demonstrated the efficacy of RF adjacent to the cervical DRG in the management of cervical radicular pain. ${ }^{37,39}$

In order to minimize heat induced side-effects commonly reported after the use of RF a technique of pulsed radiofrequency (PRF) was developed. With PRF, high frequency current is administered whereby pulses of current are followed by a silent period thus allowing the generated heat to be washed out. ${ }^{40}$ In this way PRF results in an increased output as compared to RF, due to a larger electromagnetic fields which is capable of disrupting the neuronal membranes and thereby interfering with the generation of action potentials and ectopic firing. ${ }^{41}$

PRF for the management of cervical radicular pain was studied in both a clinical audit and in a RCT and was reported to reduce the pain over a longer period of time. ${ }^{42,43}$

Pulsed radiofrequency treatment for lumbar radicular pain was assessed in retrospective and prospective studies. In a retrospective study of 13 patients who were scheduled for surgery, PRF adjacent to the DRG precluded the intervention in 11 patients. ${ }^{44}$ The effect of PRF adjacent to the DRG in patients with herniated disc, spinal canal stenosis or failed back surgery syndrome (FBSS) was assessed in a retrospective study of 54 patients. PRF resulted in a significant reduction in pain and in analgesic (a) FBSS 45
A RCT aimed at identifying the potential additional effect of a conventional RF treatment immediately after a PRF treatment adjacent to the lumbar DRG for patients with chronic lumbosacra pain, demonstrated no additional pain reduction strongly suggesting that the additional RF intervention does not yield a better treatment outcome. ${ }^{46}$

Hence PRF treatment is a potential treatment option for patients with chronic lumbosacral radicular pain, but evidence is still limited. In order to optimize treatment outcome, insights into the pathophysiology of lumbosacral radicular pain are necessary to maximally interfere with the underlying mechanism including the continuous afferent nociceptive firing. $.55,36$

Nevertheless, although the role of the DRG in the pathophysiology of cervical radicular pain was described earlier ${ }^{47}$ and a continuous afferent nociceptive firing is involved, the underlying pathophysiological mechanisms in lumbosacral radicular pain are still poorly understood.

As it is generally accepted that the understanding of the molecular, cellular and system's mechanisms of pain has important implications for its diagnosis and management, ${ }^{48}$ a mechanism based treatment can only be achieved with a better understanding of the pathophysiology of lumbosacral radicular pain. When interventional pain management techniques, such as PRF, are used, the optimal use depends equally on the understanding of the mechanisms that are initiated and/or influenced by the interventional procedure. The present insights into the mechanisms underlying lumbosacral radicular pain are far from complete and this hinders optimal use and application of therapeutic intervention including PRF. Therefore more research on the pathophysiology of lumbosacral radicular pain and possible interference of this process with PRF treatment is justified.

Basic science, however, is not a substitute for well controlled clinical trials. ${ }^{49}$ Experience learns that performing an interventional randomized controlled trial with patients who suffer severe pain with high disability and low quality of life may be complicated by several factors such as patient selection, comparator and rescue medication, and patient withdrawal/refusal to sign informed consent when confronted with sham procedures in studies with long-term follow-up..$^{50}$ This often leads to limited study populations and consequently limited evidence of efficacy. Alternative study designs are therefore worth exploring in order to minimize these confounding factors.

\section{AIM OF THE THESIS AND RESEARGH OUESTIONS}

The aim of this thesis was to evaluate and understand the potential role of pulsed radiofrequency treatment adjacent to the DRG in patients with chronic lumbosacral radicular pain. In view of this aim we addressed the following research questions:

What is the current knowledge on epidemiology, diagnosis and management of lumbosacral radicular pain?

2. Which pathophysiological processes underlie acute and chronic lumbosacral radicular pain and how might pulsed radiofrequency modulate these processes?

3. Is it possible to further improve the design of clinical studies on interventional pain therapy and how?

4. Does pulsed radiofrequency treatment adjacent to the DRG in patients with refractory lumbosacral radicular pain result in pain relief?

5. Is it possible to determine predictive factors for successful outcome of pulsed radiofrequency treatment adjacent to the DRG in chronic lumbosacral radicular pain patients? 
In this thesis, the management of lumbosacral radicular pain is addressed in chapter II. Research question 2 is addressed in chapter III. We reviewed the literature on the pathophysiology of lumbosacral radicular pain and the research that was designed to elucidate the mechanism of action of pulsed radiofrequency.

Research question 3 is addressed in chapter IV where problems with interventional clinical pain research are formulated and an alternative clinical study design is proposed.

The results of our clinical studies on the effect of PRF in patients with lumbosacral radicular pain deal with research question 4 and are presented in Chapters V, VI and VII. The findings of a clinical audit (chapter V) led to the development of a study protocol whereby the inclusion criteria were suc that a strictly selected homogeneous patient population with refractory lumbosacral radicular pain was included. The effect of PRF on pain relief in this selected patient population with lumbosacral radicular pain is studied and details are presented in chapter VI.

In order to improve the treatment outcome of pulsed radiofrequency treatment adjacent to the DRC in chronic lumbosacral radicular pain patients possible predictive factors for a positive treatment were analyzed (chapter VII, research question 5).

The general discussion (chapter VIII) summarizes the major findings as related to our research questions Suggestions for improvement of patient selection and treatment parameters of PRF in chronic lumbosacral radicular pain and future research are presented. The thesis ends with a summary of the findings (chapter IX)
References

1. Adams F. Hippocrates. (460-370 BV). The Genuine Works of Hippocrates. Translation F A ed. London: Sydenham Society; 1849

2. Fuller H. On Rheumatism, Rheumatic Gout and Sciatica: The Phatology, Symptoms and Treatment. London: John Churchill; 1852

3. Forst J. Contribution a l'étude clinique de la sciatique. Paris: Université de Paris; 1881

4. Eslberg C. The extradural ventral on ondromas (eccondroses) their favourite sites, the spinal cord and root symptoms they produce and their surgical treatment. Bull Neurosurg Inst New York. 193I; I:350-366.

5. Mixter W, Barr J. Rupture of the intervertebral dics with involvement of the spinal canal. New Engl J Med 1934:210-215.

6. Yabuki S, Kikuchi S, Olmarker K, Myers RR. Acute effects of nucleus pulposus on blood flow and endoneurial fluid pressure in rat dorsal root ganglia. Spine (Phila Pa 1976). 1998; 23:2517-2523.

7. Kobayashi S, Shizu N, Suzuki Y, Asai T, Yoshizawa H. Changes in nerve root motion and intraradicular blood flow during an intraoperative straight-leg-raising test. Spine (Phila Pa 1976). 2003; 28:14271434.

8. el Barzouhi A, Vleggeert-Lankamp CL, Lycklama a Nijeholt GJ, Van der Kallen BF, van den Hout WB, Jacobs WC, Koes BW, Peul WC. Magnetic resonance imaging in follow-up assessment of sciatica. N Engl J Med. 2013: 368:999-1007.

9. Lin CW, Verwoerd AJ, Maher CG, Verhagen AP, Pinto RZ, Luijsterburg PA, Hancock MJ. How is radiating leg pain defined in randomized controlled trials of conservative treatments in primary care? A systematic review. Eur J Pain. 2013.

10. Waddell G. The Back Pain Revolution. New York: Churchill Livingstone; 2004

11. Fairbank JC. Sciatic: An archaic term. BMJ. 2007: 335:112.

12. Peul WC, Brand R, Thomeer RT, Koes BW. Influence of gender and other prognostic factors on outcome of sciatica. Pain. 2008; 138:180-191.

13. Merskey H, Bogduk N. Classification of Chronic Pain: Descriptions of Chronic Pain Syndromes and Definitions of Pain Terms. Merksey H, BogdukN ed. Seattle: Wash: IASP Press; 1994

14. Younes M, Bejia I, Aguir Z, Letaief M, Hassen-Zrour S, Touzi M, Bergaoui N. Prevalence and risk factors of disk-related sciatica in an urban population in Tunisia. Joint Bone Spine. 2006; 73:538-542.

15. Heliovaara M, Impivaara O, Sievers $K$, Melkas T, Knekt P, Korpi J, Aromaa A. Lumbar disc syndrome in Finland. J Epidemiol Community Health. 1987; 41:251-258.

16. Savettieri G, Salemi G, Rocca WA, Meneghini F, D'Arpa A, Morgante L, Coraci MA, Reggio A, Grigoletto F, Di Perri R. Prevalence of lumbosacral radiculopathy in two Sicilian municipalities. Sicilian Neuro-Epidemiologic Study (SNES) Group. Acta Neurol Scand. 1996; 93:464-469.

17. Khoromi S, Patsalides A, Parada S, Salehi V, Meegan JM, Max MB. Topiramate in chronic lumbar radicular pain.J Pain. 2005; 6:829-836.

18. Dworkin RH, O'Connor $A B$ Backonja M, Farrar JT, Finnerup NB, Jensen TS, Kalso EA, Loeser ID, Miaskowski C, Nurmikko TJ, Portenoy RK, Rice AS, Stacey BR, Treede RD, Turk DC, Wallace MS. Pharmacologic management of neuropathic pain: evidence-based recommendations. Pain. 2007; 132:237-251.

19. Bala M, Bekkering T, Riemsma R, Harker J, Huygen F, Kleijnen J. Epidemiology of chronic pain in the Netherlands Rotterdam Centrum voor pijngeneeskunde van Erasmus Medisch Centrum - Rotterdamed. York-United Kingdom: Kleinen Systematic Reviews Ltd: 2011

20. Vroomen PC, de Krom MC, Knottnerus JA. Predicting the outcome of sciatica at short-term follow-up. Br J Gen Pract. 2002; 52:119-123. 
21. Pinto RZ, Maher CG, Ferreira ML, Hancock M, Oliveira VC, McLachlan AJ, Koes B, Ferreira $P H$. Epidural corticosteroid injections in the management of sciatica: a systematic review and meta-analysis. Ann Intern Med. 2012; 157:865-877.

22. Balague F, Nordin M, Sheikhzadeh A, Echegoyen AC, Brisby H, Hoogewoud HM, Fredman P, Skovron ML. Recovery of severe sciatica. Spine (Phila Pa 1976). 1999; 24:2516-2524.

23. Suri P, Rainville J, Hunter DJ, Li L, Katz JN. Recurrence of radicular pain or back pain after nonsurgical treatment of symptomatic lumbar disk herniation. Arch Phys Med Rehabil. 2012, 93:690-695.

24. Weber H, Holme I, Amlie E. The natural course of acute sciatica with nerve root symptoms in a double-blind placebo-controlled trial evaluating the effect of piroxicam. Spine. 1993; 18:14331438 .

25. Haugen AJ, Brox JI, Grovle L, Keller A, Natvig B, Soldal D, Grotle M. Prognostic factors for non-success in patients with sciatica and disc herniation. BMC Musculoskelet Disord. 2012; 13:183

26. Tubach F, Beaute J, Leclerc A. Natural history and prognostic indicators of sciatica. J Clin Epidemiol. 2004; 57:174-179.

27. Grovle L, Haugen AJ, Keller A, Ntvig B, Brox JI, Grotle M. Prognostic factors for return to work in patients with sciatica. Spine J. 2013; 13:1849-1857.

28. Doth AH, Hansson PT, Jensen MP, Taylor RS. The burden of neuropathic pain: a systematic review and meta-analysis of health utilities. Pain. 2010; 149:338-344

29. Pinto RZ, Maher CG, Ferreira ML, Ferreira PH, Hancock M, Oliveira VC, McLachlan AJ, Koes $B$. Drugs for relief of pain in patients with sciatica: systematic review and meta-analysis. BMJ. 2012; 344:e497.

30. Baron R, Freynhagen R, Tolle TR, Cloutier C, Leon T, Murphy TK, Phillips K. The efficacy and safety of pregabalin in the treatment of neuropathic pain associated with chronic lumbosacral radiculopathy. Pain. 2010; 150:420-427.

31. Khoromi S, Cui L, Nackers L, Max MB. Morphine, nortriptyline and their combination vs. placebo in patients with chronic lumbar root pain. Pain. 2007; 130:66-75.

32. Vroomen PC, de Krom MC, Knottnerus JA. Diagnostic value of history and physical examination in patients suspected of sciatica due to disc herniation: a systematic review. J Neurol. 1999; 246:899-906.

33. Albert HB, Manniche C. The efficacy of systematic active conservative treatment for patients with severe sciatica: a single-blind, randomized, clinical, controlled trial. Spine (Phila Pa 1976). 2012; 37:531-542.

34. Luijsterburg PA, Lamers LM, Verhagen AP, Ostelo RW, van den Hoogen HJ, Peul WC, Avezaa $C J$, Koes BW. Cost-effectiveness of physical therapy and general practitioner care for sciatica. Spine. 2007; 32:1942-1948

35. Kobayashi S, Uchida K, Kokubo Y, Takeno K, Yayama T, Miyazaki T, Nakajima H, Nomura E, $M$ waka $E, B a b a H$. Synapse involvement of the dorsal horn in experimental lumbar nerve root compression: a light and electron microscopic study. Spine (Phila Pa 1976). 2008; 33:716-723.

36. Terashima Y, Kawamata M, Takebayashi T, Tanaka S, Tanimoto K, Yamashita T. Changes in synaptic transmission of substantia gelatinosa neurons in a rat model of lumbar radicular pain revealed by in vivo patch-clamp recording. Pain. 2011; 152:1024-1032.

37. van Kleef M, Liem L, Lousberg $R$, Barendse G, Kessels $F$, Sluijter M. Radiofrequency lesion adjacent to the dorsal root ganglion for cervicobrachial pain: a prospective double blind randomized study. Neurosurgery. 1996; 38:1127-1131.
38. Geurts JW, van Wijk RM, Wynne HJ, Hammink E, Buskens E, Lousberg R, Knape JT, Groen GJ. Radiofrequency lesioning of dorsal root ganglia for chronic lumbosacral radicular pain: a randomised, double-blind, controlled trial. Lancet. 2003; 361:21-26.

39. Slappendel R, Crul BJ, Braak GJ, Geurts JW, Booij LH, Voerman VF, de Boo T. The efficacy of radiofrequency lesioning of the cervical spinal dorsal root ganglion in a double blinded randomized study: no difference between 40 degrees $C$ and 67 degrees $C$ treatments. Pain. 1997; 73:159-163.

40. Sluijter ME, Cosman ER, Rittman IIWB, van Kleef M. The effects of pulsed radiofrequency field applied to the dorsal root ganglion - a preliminary report. The Pain Clinic. 1998; 11:109-117.

41. Cosman EJ, Cosman ES. Electric and thermal field effects in tissue around radiofrequency electrodes. Pain Medicine. 2005; 6:405-424.

42. Van Zundert J, Lamé IE, de Louw A, Jansen J, Kessels F, Patijn J, van Kleef M. Percutaneous Pulsed Radiofrequency Treatment of the Cervical Dorsal Root Ganglion in the Treatment of Chronic Cervical Pain Syndromes: A Clinical Audit. Neuromodulation. 2003; 6:6-14.

43. Van Zundert J, Patijn J, Kessels A, Lame I, van Suijlekom H, van Kleef M. Pulsed radiofrequency adjacent to the cervical dorsal root ganglion in chronic cervical radicular pain: a double blind sham controlled randomized clinical trial. Pain. 2007; 127:173-182.

44. Teixeira A, Grandinson M, Sluijter M. Pulsed Radiofrequency for radicular pain due to a herniated intervertebral disc - an initial report. Pain Pract. 2005; 5:111-115.

45. Abejon D, Garcia-del-Valle S, Fuentes ML, Gomez-Arnau JI, Reig E, van Zundert J. Pulsed radiofrequency in lumbar radicular pain: clinical effects in various etiological groups. Pain Pract. 2007; 7:21-26.

46. Simopoulos TT, Kraemer J, Nagda JV, Aner M, Bajwa ZH. Response to pulsed and continuous radiofrequency lesioning of the dorsal root ganglion and segmental nerves in patients with chronic lumbar radicular pain. Pain Physician. 2008; 11:137-144.

47. Van Zundert J, Harney D, Joosten EA, Durieux ME, Patijn J, Prins MH, Van Kleef M. The role of the dorsal root ganglion in cervical radicular pain: diagnosis, pathophysiology, and rationale for treatment. Reg Anesth Pain Med. 2006; 31:152-167.

48. Woolf CJ, Bennett GJ, Doherty M, Dubner R, Kidd B, Koltzenburg M, Lipton R, Loeser JD, Payne R, Torebjork E. Towards a mechanism-based classification of pain? Pain. 1998; 77:227229.

49. Richebe P, Rathmell JP, Brennan TJ. Immediate early genes after pulsed radiofrequency treatment: neurobiology in need of clinical trials. Anesthesiology. 2005; 102:1-3.

50. Van Zundert J, Van Boxem K, Joosten EA, Kessels A. Clinical trials in interventional pain management: Optimizing chances for success? Pain. 2010; 151:571-574. 


\section{Chapter II}

Evidence-based Interventional Pain Medicine according to clinical diagnoses:

Lumbosacral Radicular Pain

Koen Van Boxem, M.D., FIPP a,b; Jianguo Cheng, MD, PhD c; Jacobus Patijn, MD, PhD ${ }^{a}$; Maarten van Kleef, MD, PhD, FIPP a; Arno Lataster, MSc ${ }^{\text {; }}$; Nagy Mekhail, MD, PhD, FIPP c. Jan Van Zundert, M.D., Ph.D., FIPP e,a.

a. Department of Anesthesiology and Pain Medicine, Maastricht University Medical Centre, Maastricht, The Netherlands. b. Department of Anesthesiology - Critical Care and Multidisciplinary Pain Centre, Sint-Jozefkliniek, Bornem and Willebroek, Bornem, Belgium. c. Department of Pain Management, Cleveland Clinic, Cleveland Ohio, USA. d. Department of Anatomy and Embryology, Maastricht University, Maastricht, the Netherlands. e. Department of Anatomy and Embryology, Maastricht University, Maastricht, the Netherlands. e. Department of
Anesthesiology, Critical Care, Emergency Medicine and Multidisciplinary Pain Centre, Ziekenhuis Oost-Limburg, Genk/Lanaken, Belgium

Published in Pain Practice: 2010; 10:339-358

Reprinted with permission of the publisher 


\section{ABSTRACT}

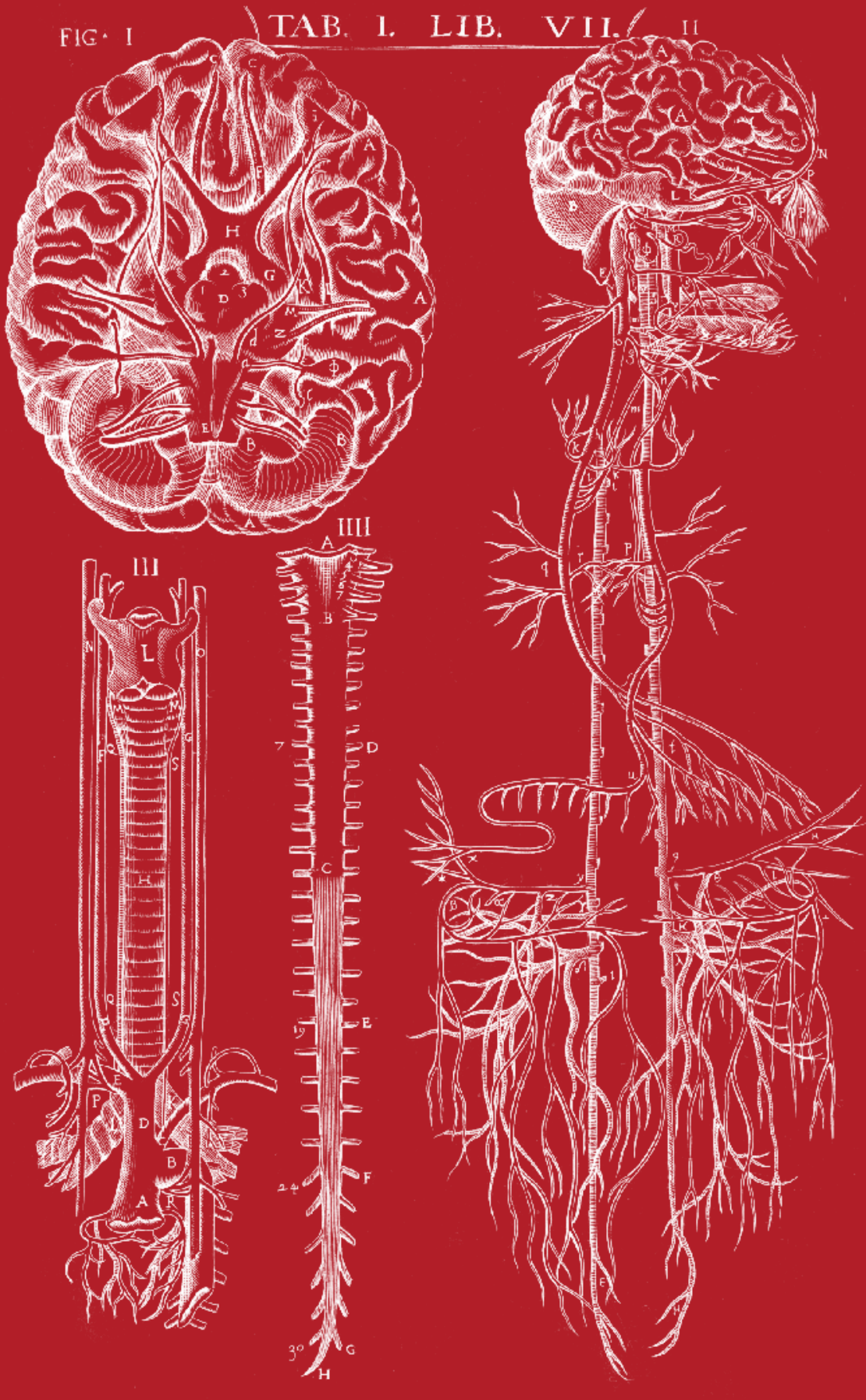

Lumbosacral radicular pain is characterized by a radiating pain in one or more lumbar or sacral dermatomes; it may or may not be accompanied by other radicular irritation symptoms and/or symptoms of decreased function. The annual prevalence in the general population, described as low back pain with leg pain traveling below the knee, varied from $9.9 \%$ to $25 \%$, which means that it is presumably the most commonly occurring form of neuropathic pain.

The patient's history may give a suggestion of lumbosacral radicular pain. The best known clinical examination and potentially additional tests. Medical imaging studies are indicated to exclude possible serious pathologies and to confirm the affected level in patients suffering lumbosacral radicular pain for longer than 3 months. Magnetic resonance imaging is preferred. Selective diagnostic blocks help confirming the affected level.

There is controversy concerning the effectiveness of conservative management (physical therapy, exercise) and pharmacological treatment.

When conservative treatment fails, in sub-acute lumbosacral radicular pain under the level L3 as the result of a contained herniation, transforaminal corticosteroid administration is recommended (2 B+). In chronic lumbosacral radicular pain, PRF treatment adjacent to the spinal ganglion (DRG) can be considered $(2 \mathrm{C}+)$. For refractory lumbosacral radicular pain, adhesiolysis and epiduroscopy can be considered (2 $\mathrm{B} \pm$ ), preferentially study related.

In patients with a therapy-resistant radicular pain in the context of a Failed Back Surcery Syndrome, spinal cord stimulation is recommended $(2 \mathrm{~A}+)$. This treatment should be performed in specialized centres.

Key words: Lumbosacral radicular pain, epidural corticosteroids, radiofrequency treatment, pulsed radiofrequency treatment, Evidence-based Medicine 


\section{INTRODUGTION}

This review on lumbosacral radicular pain is part of the series "Evidence-based Interventional Pain Medicine according to clinical diagnoses". Recommendations formulated in this article are based on "Grading strength of recommendations and quality of evidence in clinical guidelines" described by Guyatt et al. ${ }^{1}$, and adapted by van Kleef et al. in the editorial accompanying the first article of thi series. ${ }^{2}$ (Table 1)

The latest literature update was performed in December 2009.

Table 1: Summary of evidence scores and implications for recommendation:

\begin{tabular}{|c|c|c|}
\hline Score & Description & Implication \\
\hline $1 \mathrm{~A}+$ & $\begin{array}{l}\text { Effectiveness demonstrated in various RCTs of good quality. The } \\
\text { benefits clearly outweigh risk and burdens }\end{array}$ & \multirow{3}{*}{$\begin{array}{l}\text { Positive } \\
\text { recommendation }\end{array}$} \\
\hline $1 \mathrm{~B}+$ & $\begin{array}{l}\text { One RCT or more RCTs with methodological weaknesses, } \\
\text { demonstrate effectiveness. The benefits clearly outweigh risk and } \\
\text { burdens }\end{array}$ & \\
\hline $2 \mathrm{~B}+$ & $\begin{array}{l}\text { One or more RCTs with methodological weaknesses, demon- } \\
\text { strate effectiveness. Benefits closely balanced with risk and } \\
\text { burdens }\end{array}$ & \\
\hline $2 \mathrm{~B} \pm$ & $\begin{array}{l}\text { Multiple RCTs, with methodological weaknesses, yield con- } \\
\text { tradictory results better or worse than the control treatment. } \\
\text { Benefits closely balanced with risk and burdens, or uncertainty in } \\
\text { the estimates of benefits, risk and burdens. }\end{array}$ & \multirow{2}{*}{$\begin{array}{l}\text { Considered, } \\
\text { preferably study- } \\
\text { related }\end{array}$} \\
\hline $2 \mathrm{C}+$ & $\begin{array}{l}\text { Effectiveness only demonstrated in observational studies. Given } \\
\text { that there is no conclusive evidence of the effect, benefits closely } \\
\text { balanced with risk and burdens }\end{array}$ & \\
\hline 0 & $\begin{array}{l}\text { There is no literature or there are case reports available, but } \\
\text { these are insufficient to prove effectiveness and/or safety. These } \\
\text { treatments should only be applied in relation to studies }\end{array}$ & Only study-related \\
\hline $2 \mathrm{C}-$ & $\begin{array}{l}\text { Observational studies indicate no or too short-lived effectiveness. } \\
\text { Given that there is no positive clinical effect, risk and burdens } \\
\text { outweigh the benefit }\end{array}$ & \multirow{2}{*}{$\begin{array}{l}\text { Negative } \\
\text { recommendation }\end{array}$} \\
\hline $2 \mathrm{~B}-$ & $\begin{array}{l}\text { One or more RCTs with methodological weaknesses, or large } \\
\text { observational studies that do not indicate any superiority to the } \\
\text { control treatment. Given that there is no positive clinical effect, } \\
\text { risk and burdens outweigh the benefit }\end{array}$ & \\
\hline $2 \mathrm{~A}-$ & $\begin{array}{l}\text { RCT of a good quality which does not exhibit any clinical effect. } \\
\text { Given that there is no positive clinical effect, risk and burdens } \\
\text { outweigh the benefit }\end{array}$ & \\
\hline
\end{tabular}

A lumbosacral radicular syndrome (LSR) is characterized by a radiating pain in one or more lumbar or sacral dermatomes; it may or may not be accompanied by other radicular irritation symptoms and/ or symptoms of decreased function. In the literature, this disorder can also be referred to as sciatica, clearly highlights huge differences in the description of low back pain, which makes comparison of epidemiological data extremely difficult. ${ }^{3}$ The terms radicular pain and radiculopathy are also sometimes used interchangeably, although they certainly are not synonyms. In the case of radicular pain, only radiating pain is present, while in the case of radiculopathy, sensory and/or motor loss that can be objectified can be observed. Both syndromes frequently occur together and radiculopathy can be a continuum of radicular pain. In this review lumbosacral radicular pain is considered as pain radiating

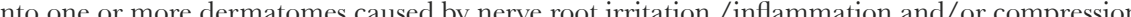

The annual prevalence in the general population, described as low back pain with leg pain traveling below the knee, varied from $9.9 \%$ to $25 \%$. Also the point prevalence $(4.6$ to $13.4 \%)$ and lifetime prevalence $(1.2$ to $43 \%)$ are very high, ${ }^{4}$ which means that lumbosacral radicular pain is presumably the most commonly occurring form of neuropathic pain. ${ }^{5,6}$ The most important risk factors are: being male, obesity, smoking, history of lumbalgia, anxiety and depression, work which requires lengthy periods of standing and bending forward, heavy manual labor, lifting heavy objects and being exposed to vibration.

Pain completely or partially resolves in $60 \%$ of the patients within 12 weeks of onset. ${ }^{8}$ However about $30 \%$ of the patients still have pain after 3 months to 1 year. Apparently the female population with LSR has a considerably worse outcome compared to the male population. The estimated unadjusted odd for a long-term poor outcome was 3.3 times higher for female patients than for males. ${ }^{9}$

In patients under 50 years of age, a herniated disc is the most frequent cause of a lumbosacral radicular syndrome. After the age of 50, radicular pain is often caused by degenerative changes in the spine (e.g., stenosis of the foramen intervertebrale)..$^{10}$

\section{DIAGNOSIS}

\section{I.A. History}

The patient mav experience the radiating pain as sharp, dull, piercing, throbbing or burning. Pain caused by a herniated disc classically increases by bending forward, sitting, coughing or (excessive) stress on the lumbar discs and can be avoided by lying down or sometimes by walking. Inversely, pain from a lumbar spinal canal stenosis can typically increase when walking and improve immediately upon bending forward. ${ }^{10}$ In addition to the pain, the patients also often report paresthesia in the nation of the level involved, there is however a large variation in radiation pattern. The $\mathrm{S} 1$ dermatome seems the most reliable. ${ }^{11}$ If present, the dermatomal distribution of paresthesia is more specific. ${ }^{10}$

\section{I.B. Physical Examination}

The diagnostic value of anamnesis and physical examination has as yet been insufficiently studied. Only pain distribution is considered to be a meaningful parameter from anamnesis..$^{12}$ The clinical test described most often for the lumbosacral radicular syndrome is the Lasègue test. If radicular pain can be elicited under $60^{\circ}$, there is a large chance that a lumbar herniated disc is present. However, the sensitivity of this test for the detection of lumbosacral radicular syndrome due to a herniated disc 
varies sharply: the global sensitivity is 0.91 with a specificity of $0.26 .{ }^{13}$ This specificity drops even more when the test is positive above $60^{\circ}$. The crossed Lasègue test is the only examination with good specificity $(0.88)$, but this comes at the expense of the sensitivity $(0.29) .{ }^{13}$ Both tests are described in table 2 .

Table 2: Lasègue and crossed Lasègue test

The Lasègue test is performed by placing the patient in a supine position and having the patient lift up the affected leg (with a straight knee). The test is positive if this maneuver reproduces the symptoms Rotation, abduction and adduction in the hip should be avoided, since these movements can have an effect on the result

The crossed Lasègue test is performed by a patient in the supine position lifting up the contralatera leg. The test is positive if lifting is accompanied by a pain reaction in the affected leg which follows the same pattern that appeared in the regular Lasègue test.

There is no consensus about the specificity of the other neurological signs (paresis, sensory loss or los of reflexes). ${ }^{12}$ In practice, the presence of signs that are indicative of an L4 involvement (patellar reflex, foot inversion) or a L5-S1 hernia (Achilles tendon reflex) are checked in a neurological examination. . dorsiffexion and/or extension of the toes and an S1 paresis due to a decrease in plantar flexion, among other things. ${ }^{10}$ (Table 3$)$

In summary, a diagnosis of lumbosacral radicular syndrome appears to be justified if the patien reports radicular pain in one leg, combined with one or more positive neurological signs that indicate a nerve root irritation or neurological loss of function.

Table 3: Neurological examination of the lumbosacral radicular syndrome

\begin{tabular}{l|l|l|l|l} 
Level & Pain & $\begin{array}{l}\text { Sensory Loss } \\
\text { Paresthesia }\end{array}$ & $\begin{array}{l}\text { Motor Disturbances or } \\
\text { Weakness }\end{array}$ & $\begin{array}{l}\text { Disturbances } \\
\text { in Reflexes }\end{array}$ \\
\hline L3 & $\begin{array}{l}\text { Front of the } \\
\text { thigh to the knee }\end{array}$ & $\begin{array}{l}\text { medial portion thigh } \\
\text { and knee }\end{array}$ & $\begin{array}{l}\text { quadriceps femoris, iliopsoas, hip } \\
\text { adductors }\end{array}$ & $\begin{array}{l}\text { patellar reflex, } \\
\text { adductor reflex }\end{array}$ \\
\hline L4 & $\begin{array}{l}\text { Medial portion } \\
\text { leg }\end{array}$ & medial portion leg & $\begin{array}{l}\text { anterior tibialis, quadriceps, hip } \\
\text { adductors }\end{array}$ & patellar reflex \\
\hline L5 & $\begin{array}{l}\text { Lateral portion } \\
\text { thigh and leg, } \\
\text { dorsum of the } \\
\text { foot }\end{array}$ & $\begin{array}{l}\text { lateral portion leg, } \\
\text { dorsum of foot, first } \\
\text { toe }\end{array}$ & $\begin{array}{l}\text { toe extensors and flexors, ankle } \\
\text { dorsiflexors, eversion and inver- } \\
\text { sion of the ankle, hip abductors }\end{array}$ & \\
\hline S1 & $\begin{array}{l}\text { Posterior portion } \\
\text { thigh, calf and } \\
\text { heel }\end{array}$ & $\begin{array}{l}\text { sole of the foot, } \\
\text { lateral portion foot } \\
\text { and ankle, two most } \\
\text { lateral toes }\end{array}$ & $\begin{array}{l}\text { gastrocnemius, biceps femoris, } \\
\text { gluteus maximus, toe flexors }\end{array}$ & Achilles reflexes \\
\hline
\end{tabular}

Adapted from: Tarulli AW, Raynor EM: Lumbosacral radiculopathy. Neurol Clin. 2007; 25, (2): 387-405.

\section{I.C Additional tests}

Imaging studies - Given that the natural course of lumbosacral radicular pain is favorable in $60-80 \%$ of patients and that the pain improves spontaneously or even disappears completely after 6-12 weeks, additional examination has little value in the acute phase. ${ }^{8,15}$ Medical imaging, primarily magnetic resonance imaging (MRI), can confirm the presence of a herniated disc; this technique is preferred because of the better visualization of soft tissues and the lower radiation dose. ${ }^{14}$ The specificity of MRI and computer tomography (CT) is very low given that a herniated disc was identified by CT or MRI in $20-36 \%$ of the asymptomatic population, ${ }^{16}$ and there is little correlation between the severity of a possible radiculopathy and the magnitude of the spinal disc herniation. Incidentally, the symptoms can disappear after a conservative therapy without a corresponding decrease in the volume of the herniated disc $17-19$

In addition to this, a hernia could not be demonstrated on the scans of some patients with clinical symptoms of a radicular syndrome. ${ }^{20,21}$ In the event of an unclear clinical picture or in the absence of radiological arguments for radicular complaints, electromyography (EMG)/nerve conduction studies (NCS) can be performed to differentiate lumbar radicular syndrome from peripheral neuropathy (sensitivity 0.45 to 0.65$)^{22}$ Other common causes of lumbar radicular pain, such as stenosis of the foramen intervertebrale, may be revealed by MRI or CT. Entrapment of the sciatic nerve such as piriformis syndrome is not included in this chapter

Selective segmental nerve blocks • Although the diagnostic nerve root block is a commonly used technique for determining the level of the radicular pain, there is uncertainty concerning its sensitivity and specificity. In a lumbosacral radicular syndrome without clear signs of a focal neurological deficit, there appears to have been a variable hypoesthesia already present in the majority of the patients before the execution of a diagnostic nerve root block. ${ }^{23}$ These changes in sensory function can also vary in time and location.

With an intraforaminal block, there is also a real chance of a simultaneous block of the nervus sinuvertebralis. This nerve is responsible for the afferent input of the nearby disci intervertebrales (superficial annulu fibrosus), ligamentum longitudinale posterius, and the ventral dura mater and nerve root sleeve. In addition, the sensory fibers of the ramus dorsalis of the segmental nerve pass through the ganglion spinale (dorsal root ganglion, DRG) which is also blocked. This nerve innervates local back muscles and nearby facet joints. De be reduced by a peripheral nerve block. As a result, pain that originates from proximal spinal nerve root irritation with corresponding pain in the leg and back can in fact be influenced by a more peripheral block. ${ }^{24}$ This was confirmed in a study by North ${ }^{25}$ in which patients with radicular pain as their chief complaint had in a randomized sequence 4 different blocks with local anesthetic. Paraspinal lumbosacral root blocks and medial branch posterior primary ramus blocks (at the same level or proximally) as well as nervus ischiadicus (sciatic nerve) blocks (collaterally or distal to the pathology) with $3 \mathrm{ml}$ bupivacaine $0.5 \%$ provide a temporary greater pain reduction in the majority of cases, in comparison with a lumbar subcutaneous administration of the same product in an identical volume. The specificity of a single level diagnostic block is further influenced by the injected volume, as $0.5 \mathrm{ml}$ of contrast already reaches the adjacent level in $30 \%$ of cases, and $1.0 \mathrm{~m}$ even in $67 \%$ of cases..$^{26} \mathrm{As}$ a result, it appears that the specificity of diagnostic nerve root blocks is limited: a negative block has a specific predictive value, but isolated positive blocks are non-specific. ${ }^{2}$

An example of the variability of the effect of nerve root blocks in patients with lumbar radicular syndrome without neurological deficit is the incidence, location and extent of the dermatomal areas with a hypoeshesia. Namely, the total area in which hypoesthesia can be found is very extensive, yet it is exceptional that in some patients absolutely no hypoesthesia develops even though the technique performed is identical..$^{27}$ This 
pattern of hypoesthesia and radicular pain usually surpasses the boundaries of standard dermatomal charts but is better understood if an overlap with the adjacent dermatomes is taken into account. The resulting adapted dermatomes are twice as large as those in standard dermatomal charts, but as a result, the sensory effects of diagnostic nerve root blocks lie more within the limits of the (adapted) dermatomal charts. ${ }^{2}$

Conversely, the variability of paresthesia as a result of electro-stimulation appears to be much smaller; it i usually registered in the central sections of the standard dermatomes. The reproducibility of paresthesia by electro-stimulation also appears to be high: $80 \%$ of the paresthesia can be traced to within the borders of the standard dermatomal charts, and $98 \%$ to within the borders of the adapted dermatomal charts. In spite of this, the relationship to pain remains unclear. When pain is reported in an "adapted" dermatome, in only $1 / 3$ of cases can a corresponding reduction in pain, paresthesia and hypoesthesia be induced by electrostimulation and nerve root blocks.

After a nerve root block, the average muscle force is reduced within the corresponding myotome, but the muscle force within the myotome is increased if the block has reduced the pain. ${ }^{28} \mathrm{~A}$ possible explanation for the increase in muscle force in patients with a chronic lumbar radicular syndrome is the finding that pain ha an inhibiting effect on the muscle force (diffuse noxious inhibitory control or DNIC). ${ }^{29}$ After pain reduction, the inhibition lessens which results in a normalization of the muscle force. ${ }^{30}$

In practice, the most rational method used to confirm the suspected level of radicular complaints is still the use of one or more selective diagnostic blocks. These selective infiltrations must occur with a limited amoun of local anesthetic (max. $1 \mathrm{ml}$ ) per level and in separate sessions.

\section{I.D Differential Diagnosis}

In cases of acute low back pain, physical abnormalities which can account for the complaints are ruled out first on the basis of the so-called "red flags"; yet in cases of chronic low back pain, we recommend also checking whether there are signs which could indicate underlying pathology such as tumors and infections, among others (table 4). When making a differential diagnosis, inflammatory/metabolic causes (diabetes, ankylosing spondylitis, Paget's disease, arachnoiditis, sarcoidosis) must also be taken into account; these must be ruled out first. ${ }^{10}$

The acute cauda equina syndrome is usually the result of a large, central disc herniation with compression of the low lumbar and sacral nerve roots, usually at the L4-L5 level. As a result of the sacral polyradiculopathy, a significant bowel and micturition dysfunction can arise with a characteristic saddle anesthesia. If the lumber

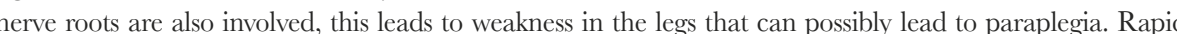
recognition of these symptoms and referral for emergency surgery is recommended. ${ }^{10}$

\section{Table 4: Red Flags}

- First appearance of back complaints before 20th or after the 55th year

- Trauma

- Constant progressive back pain

- Malignant disorder in the medical history

- Long-term use of corticosteroids

- Drug use, immunosupression, HIV

- (Frequent) general malaise

- Unexplained weight los

- Structural deformities of the spinal column

- Infectious disorders (e.g., herpes zoster, epidural abscess, HIV, Lyme disease)

- Neurological loss of function (motor weakness, sensory disturbances, and/or micturition disturbances)

\section{TREATMENT OPTIONS}

II.A Conservative management

(Sub)acute radicular complaints • Controversy exists concerning the conservative approach to lumbosacral radicular syndrome since there is no strong evidence of the effectiveness of most treatments. ${ }^{31}$ Providing adequate information to the patient about the causes and prognosis of lumbosacral radicular syndrome can be a logical step in the management of this problem, but this has not yet been studied in randomized, controlled studies. ${ }^{14}$

There is no difference between the advice for bed rest when compared to the advice to remain active. ${ }^{32}$ The use of NSAIDs (Non-Steroidal Anti-Inflammatory Drugs) or Cox-2 inhibitors can have a significant effect on acute radicular pain compared to placebo. ${ }^{33,34}$ There are however no long-term results on the evolution of LSR.

Exercise therapy can possibly have a beneficial effect. For this reason, it is often considered a first-line treatment. However, until now, evidential value for this is lacking. ${ }^{12,31} \mathrm{~A}$ randomized study was able to demonstrate a better outcome after 52 weeks in patients who received physiotherapy in the form of exercise therapy combined with a conservative therapy from the general practitioner in comparison to patients who received only the conservative therapy $(79 \%$ versus $56 \%$ Global Perceived Effect, respectively). However, this does not appear to be cost effective. ${ }^{35}$ For a selected population, a surgical intervention results in a more rapid lessening of the acute radicular complaints in comparison with a conservative approach, but the outcomes after 1 to 2 years are equivalent. ${ }^{8,36,37}$

Furthermore, the effect of surgery on the natural course of the herniated disc disease is unclear and there are no proven arguments for an optimal time period for surgery. 38,39

For patients with a neurological loss of function due to a herniated disc, immediate surgical treatment is usually recommended. From the available studies, it appears that this loss of function remains steady initially, but after surgery it can still regress (up to $50 \%$ of the patients). ${ }^{40,41}$ It can therefore be stated that the outcome in cases of herniated disc with regard to neurological loss of function is determined by the severity of the lesion at the outset and not by whether an intervention occurs sooner or later. ${ }^{42}$ In patients with a spinal canal stenosis with secondary neurological loss of function on which surgery has been performed, reflex disturbances and sensory and motor deficits will be permanent or will only very slowly be partially restored. Up to $70 \%$ of the patients will continue to have residual neurological abnormalities after decompression, ${ }^{43}$ and the risk of permanent neuropathy is larger in central spinal canal stenosis in comparison with lateral spinal canal stenosis."

Chronic radicular complaints • The place of physiotherapy in these cases is also unclear, since there are no randomized studies available ${ }^{45}$ For chronic lumbosacral radicular syndrome, a trial period with medication is indicated. Classically, neuropathic pain is treated by prescribing tricyclic antidepressants (TCAs) such as amitriptyline. ${ }^{46}$ Although a medicinal treatment policy is still in the foreground, in practice, this is not always evident. Thus, for these neurogenic conditions, less than $1 / 3$ of the patients will experience a reduction in pain that is better than "moderate" ${ }^{46}$ Furthermore, various reviews were performed concerning the place of the TCAs ${ }^{47}$ and anticonvulsants ${ }^{6,47}$ in the treatment of neuropathic pain. It is striking that the included studies were mostly performed in patients with diabetic neuropathy and post-herpetic neuralgia. The extension of these results to patients with LSR, with a physiopathology based more on compression and inflammation of the nerve root and the ganglion spinale (DRG) has not yet been scientifically proven. ${ }^{5}$ 
Anticonvulsants are a possible alternative for the treatment of neuropathic pain if tricyclic antidepressants cannot be tolerated or are contraindicated. Gabapentin has been studied most often in this indication and is supported by an RCT. ${ }^{48}$ The results are variable and optimization of the dosage long been considered controversial. Recent guidelines concerning the treatment of neuropathic pain mention tramadol and oxycodone as possible therapeutic options. ${ }^{6}$ In an open-label trial using transdermal fentanyl in 18 patients with radicular pain, an average pain reduction of $32 \%$ was achieved. ${ }^{4}$

II.B Interventional management

Anesthesiological treatment techniques are indicated for patients with radicular pain. Epidura administration of corticosteroids is generally indicated in cases of subacute radicular pain. In patients with chronic radicular complaints, corticosteroids will not provide any improvement in the outcome in comparison to local anesthetics alone. This indicates that epidural corticosteroids are more effective for (sub)acute radicular pain where a significant inflammatory pain component is present..$^{50}$ (Pulsed) radiofrequency $(\mathrm{PRF})$ treatment is a treatment option for chronic radicular pain.

\section{Epidural corticosteroid administration}

The logic of epidural corticosteroid administration rests on the anti-inflammatory effect of the corticosteroids, which are administered directly onto the inflamed nerve root. There are three approaches: interlaminar, transforaminal, and caudal.

Interlaminar corticosteroids • The available evidence concerning interlaminar corticosteroid administration has been studied in systematic reviews. The conclusions of these reviews are divergen to Treat (NNT) To achieve 50\% pain reduction in the short term ( 1 day to 3 months), an NNT of 3 is obtained and an NNT of 13 for long-term pain relief ( 3 months to 1 year). ${ }^{51} \mathrm{~A}$ systematic review of RCTs concluded that there is insufficient proof of the efficacy of this technique. If there are benefit, then they are of short duration. ${ }^{52}$ A recent systematic review of RCTs showed that among the 11 RCTs of interlaminar steroid injection for radiculopathy, four trials are rated high quality. ${ }^{53}$ Three of the four trials used ligamentum interspinale (interspinous ligament) saline injection as control interfits ( $\leq 1$ months) ${ }^{54-56}$ The other used epidural saline injection as control and did not show any benefit ${ }^{57}$

Transforaminal corticosteroids • The variable results of corticosteroids administered interlaminarly are ascribed to the fact that there is no certainty that the needle reaches the epidura space and even if it did, there is no certainty that the medication reaches the ventral section of the epidural space. ${ }^{58}$ Transforaminal administration allows a more precise application of the corticosteroids at the level of the inflamed nerve root. Three high quality, placebo controlled trial evaluating transforaminal approach reported mixed results. ${ }^{53}$ One showed long-term benefits in one year ${ }^{59}$, one showed mixed short-term benefits ${ }^{61}$, and one showed no benefit. ${ }^{50}$

In a double blind, randomized study, patients who were scheduled for a surgical intervention received an epidural injection with local anesthetic only or local anesthetic with corticosteroid at random. At the follow-up (13 to 28 months), 20/28 patients in the local anesthetic with corticosteroid group had decided not to undergo surgery, while in the local anesthetic only group, 9/27 decided to forego a surgical intervention. ${ }^{59}$ The majority $(81 \%)$ of the patients who had not yet had surgery 1 year after infiltration were able to avoid the operation after 5 years. ${ }^{61}$ A prospective controlled study of transforaminal epidural corticosteroids showed superiority of this procedure over trigger-point injection in patients with disc herniation ${ }^{62}$. Karpinnen's group ${ }^{60}$ carried out a randomized, controlled study in patients with radicular pain and disc herniation documented compared with transforaminal injections of normal saline solution. Two wecks after the treatment, the clinical result in the corticosteroid group was better than that of the group treated with normal saline solution. After 3 to 6 months, on the other hand, patients in the group with normal saline were in better condition owing to a rebound effect that was noted in the corticosteroid group. A sub-analysis in which the results of patients with a "contained" herniation were compared with those of patients with an "extruded" herniation showed that in the first group, corticosteroid injecfound. ${ }^{63}$ In this study "contained herniation" was defined as a herniation with a broad base which is still contained within the ligamentum longitudinale posterius. "Extruded herniation" is a herniation that breaks through the ligamentum longitudinale posterius.

In a comparative study, the effectiveness of caudal, interlaminar and transforaminal corticosteroid administration in the epidural space was compared in patients with radicular pain as a result of disc herniation. The transforaminal approach gave the best clinical results. ${ }^{64} \mathrm{~A}$ double blind, randomized study compared the efficacy of interlaminar and transforaminal corticosteroid administration in patients with lumbar radicular pain as a result of CT- or MRI-confirmed herniated disc that lasted ess than 30 days. Six months after the treatment, the results in the transforaminal-treatment group was significantly better than that of the group that was treated interlaminarly in the areas of pain reduction, daily activity, free-time and work activities and anxiety and depression. ${ }^{6 .}$

Gaudal corticosteroids $•$ Four placebo-controlled trials were conducted, but none were rated high quality.$^{53}$ The results are mixed and no definitive conclusions can be drawn from these studies.

In summary, one can state that the transforaminal epidural corticosteroid administration is preferable In practice, due to the not yet completely elucidated, rare neurological complications associated with the transforaminal administration route, the interlaminar and caudal approaches can also still be considered.

\section{II. (Pulsed) radiofrequency treatment}

The application of conventional radiofrequency $(\mathrm{RF})$ treatment $\left(\right.$ at $\left.67^{\circ} \mathrm{C}\right)$ adjacent to the lumbar ganglion spinale (DRG) has lost interest because no extra value could be shown in comparison with a sham procedure in a randomized, double blind, sham-controlled study. ${ }^{66}$

Pulsed radiofrequency (PRF) treatment adjacent to the lumbar ganglion spinale (DRG) was studied in a retrospective study. In a group of 13 patients for which a surgical intervention was planned, the PRF treatment adjacent to the ganglion spinale (DRG) of the nerve involved precluded the intervention in 11 patients. One patient had a disc operation and 1 underwent a spinal fusion 1 year after the treatment without having radicular pain at the time of the operation ${ }^{67}$ In another retrospective study, PRF treatments were carried out in patients with a radicular syndrome as a result of disc herniation, spinal canal stenosis, or failed back surgery syndrome (FBSS). A significant reduction in pain and in analgesic consumption was attained in the patients with a disc herniation and spinal canal stenosis, but not in those with FBSS. ${ }^{68}$ A randomized controlled trial aimed at identifying the potential additional effect of a conventional RF treatment directly after a PRF treatment adjacent to the lumbar ganglion spinale (DRG). Thirty-seven patients were treated with PRF and 39 patients with PRF and RF. A marked decrease in VAS pain score was observed in both groups, but no significant difference between groups in pain reduction and duration of action could be identified. ${ }^{69}$ 


\section{Adhesiolysis and epiduroscopy}

The goal of lysis of epidural adhesions is to remove barriers in the epidural space that may contribute to pain generation and prevent delivery of pain relieving drugs to target sites.

The development of a navigable, radio-opaque, kink-resistant, soft tipped catheter has allowed placement at or near this target site in most patients. In the literature adhesiolysis with or without endoscopic control is sometimes assessed together. There are 2 RCT's on fluoroscopic guided adhesiolysis. Patients included in the RCT's suffered chronic low back pain and sciatica and might have undergone previous back surgery, furthermore the treatment protocols differed. Heavner et al. ${ }^{70}$ compared the effect of mechanical adhesiolysis with (1) a combination of hyaluronidase and hypertonic saline; (2) hypertonic saline solution; (3) isotonic saline solution; and (4) hyaluronidase and isotonic saline solution. The treatment consisted of a 3-day procedure where the catheter was inserted and the drugs were injected on three consecutive days. Manchikanti et al. ${ }^{71}$ assessed one-day procedure in 3 patient groups: a control group treated with injection of local anesthetic corticosteroid and normal saline without adhesiolysis; the second group consisting of patients undergoing adhesiolysis, with injection of local anesthetic, steroid, and normal saline; and the third group consisting of patients undergoing adhesiolysis, with an injection of $10 \%$ sodium chloride solution, in addition to local anesthetic and steroid. The third trial compared the effect of adhesiolysis and injection of corticosteroid and local anesthetic followed, 30 minutes later, by an injection of hypertonic saline $(10 \%)$ with conservative treatment. ${ }^{72}$ These trials and all the observational trials but on found positive short- and long-term outcome. The trial on the effect of adhesiolysis with hypertonic saline found only short term positive outcome. ${ }^{73}$

Epiduroscopy, which is also called spinal endoscopy, is an alternative way to perform adhesiolysis under visual control. It couples the possibility of diagnostic and therapeutic interventions in one sescion.

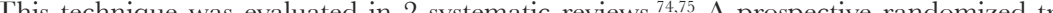
significant improvement without adverse effects in $80 \%$ of the patients receiving epiduroscopy at 3 months, $56 \%$ at 6 months, and $48 \%$ at 12 months, compared to $33 \%$ of the patients in the contro group showing improvement at one month and none thereafter. ${ }^{76}$ In a randomized controlled trial 60 patients with a 6-18 months history of sciatica received either targeted epidural local anesthetic and steroid placement with manipulation of the adhesions using a spinal endoscope or caudal epidura local anesthetic and steroid treatment. No significant differences were found between the groups for any of the measures at any timen Observational stuies showed rood short and long-term pain relief $75,78-8$

\section{Spinal cord stimulation in failed back surgery syndrom}

Failed back surgery syndrome (FBSS) is a persistent back pain that may or may not include pain radiating to the leg after one or more back operations. Spinal cord stimulation (SCS) consists of the percutaneous application of electrodes at the level of the spinal cord segment involved. These electrodes are then connected to a generator that delivers electrical pulses to stimulate the painfu dermatome and to induce altered pain conductivity, transmissibility, and perception. A systematic review of the effectiveness of SCS for the treatment of chronic low back and leg pain in patien with FBSS included an RCT, a cohort study and 72 case reports. The RCT demonstrated clear advantage of SCS in comparison with repeat surgery. However, the results of the case reports are very heterogeneous. ${ }^{84}$ A randomized study that compared SCS with conventional treatment in FBSS patients showed that fewer patients from the SCS group switched over to conventional treatment than did patients who initially received a conventional treatment and then switched over to SCS. The number of patients satisfied with the treatment was higher in the SCS group. ${ }^{85}$

\section{II.G Complications of interventional management}

Complications and side effects of epidural corticosteroids

Interlaminar epidural corticosteroids • The most frequent side effect is a dural puncture $(2.5 \%)$ with or without a transient headache $(2.3 \%)^{86}$ Minor side effects, such as transient increase in complaints or the appearance of new neurological symptoms more than 24 hours after the infiltration, occur in $4 \%$ of the patients; the median duration of the complaints was 3 days (1-20 days). ${ }^{88}$ In a study examining side effects in 4722 infiltrations with betamethasone dipropionate and betamethasone sodium phosphate, $14(0.7 \%)$ serious side effects were reported (cardiovascular gastrointestinal, allergy), 7 of which were attributed to the product. ${ }^{88}$ More serious complications are cases of aseptic meningitis, arachnoiditis and conus medullaris syndrome, but this typically occurs after multiple accidental subarachnoidal injections. Two cases of epidural abscess, 1 case of bacterial meningitis and 1 case of aseptic meningitis were also reported. ${ }^{89}$

Transforaminal epidural corticosteroids • At the time of preparing this manuscript 7 publicaions report 9 cases of neurological complications such as paraplegia following lumbar transforaminal epidural corticosteroid administration ${ }^{90-96}$ The probable mechanism is an injury to an unusully low dominant radiculomedullary artery $y^{90}$ The largest radicular artery is the arteria radicularis magna (artery of Adamkiewicz); in 80\% of the population, this artery is present in the spinal canal between T9 and L1. However, in a minority of cases it can occur between T7 and L4 which results in the possibility that the artery is in the vicinity of the end position of the needle in a transforaminal infiltration. Depot injections can then mimic an embolism; if this occurs in a critical artery which supplies the anterior spinal artery, spinal cord ischemia may result. ${ }^{97}$ Of the reported cases of neurologic complications, 1 occurred after Th12-L1, 1 case at L1-L2, 2 cases at L 2-L3, 3 cases at L3-L4, 1 after L3-4 and $\mathrm{L} 4-5$ injection and finally 1 case after a $\mathrm{S} 1$ injection.

A retroperitoneal hematoma was reported in a patient having anticoagulant therapy who received a transforaminal injection. ${ }^{60}$ Two cases of dural puncture ${ }^{98}$, one disc entry ${ }^{99}$, one case of cauda equina ${ }^{100}$ and one case of transient blindness attributed to the temporarily intra-epidural pressure increase ${ }^{101}$. Infectious complications such as epidural abscess caused by MRSA (1 case) ${ }^{102}$, discitis (1 case) ${ }^{103}$ and one case of vertebral osteomyelitis ${ }^{104}$ are reported.

The recently reported cases of serious complication with the transforaminal approach warrant a cautious policy. It is recommended to only perform transforaminal infiltrations under the L3 level and to always administer the injection fluid during real-time imaging, the additional use of digital subtraction angiography may be of value. It is also recommended to first administer a test dosage of local anesthetic before infiltrating the depot corticosteroid after waiting 1 to 2 minutes to observe potential neurologic signs. ${ }^{105}$ Neurological complications rarely occur when using the correct technique and when sedation is avoided. If a significant increase in pain is reported during the injection of contrast agent, local anesthetic and/or corticosteroids, the procedure must be immediately stopped in order to ascertain the cause of the pain.

Endocrine side effects • Cushing's syndrome was reported in the prospective study of the side effect of epidurally administered betamethasone dipropionate and betamethasone sodium phosphate ${ }^{89}$ 
Side effects and complications of radiofrequency treatments

Conventional radiofrequency treatment $(\mathbf{R F}) \cdot$ A burning pain was found to occur in $60 \%$ of RF-treated patients, and a hyposensitivity in the associated dermatome in $35 \%$ of RF-treated effects disappeared spontaneousy a was no difference in side effects and complications between a classic RF group and a sham group ${ }^{66}$

Pulsed radiofrequency treatment (PRF) • In an extensive review of the literature on the use of PRF covering over 1200 patients no neurological complication was identified. ${ }^{107}$ Twelve publication are currently available regarding PRF treatment adjacent to the ganglion spinale (DRG). Eight of those publications specifically report PRF treatment adjacent to the lumbar ganglion spinale (DRG). 67-69, 108-112 In totat if are mentioned.

Side effects and complications of SCS

In a review of the complications of SCS, 18 studies on 112 patients receiving SCS for FBSS were identified. Forty eight patients $(42 \%)$ reported a side effect or complication. Complications can be subdivided in: technical, biological (post-operative) and other. The majority (> 25\%) of the complications are of technical order such as lead migration, lead breakage, hardware malfunction, battery failure and loose connection. Postsurgical complications can be infection, cerebrospinal fluid leakage and hematoma. Undesirable stimulation, pain over the implant, skin erosion and allergy have also been reported. ${ }^{11}$

Side effects and complications of epidural adhesiolysis and epiduroscopy

Four studies look specifically into the complications of epidural adhesiolysis. ${ }^{114-117}$ The most commonly reported complications of percutaneous adhesiolysis are dural puncture, catheter shearing, an infection. Other potential complications include intravascular injection, vascular injury, cerebra vascular or pulmonary embolus, reaction to the steroids, hypertonic saline, or hyaluronidase, and administration of high volumes of fluids potentially, resulting in excessive epidural hydrostatic pressures, brain damage and death.

Talu and Erdine ${ }^{114}$ reviewed percutaneous adhesiolysis complications in 250 patients. Three patients $(1.2 \%)$ developed epidural abscesses, and 1 patient developed a severe headache. Retained sheared adhesiolysis catheter was described in a patient who underwent percutaneous adhesiolysis to treat persistent back and leg pain after 2 previous lumbar surgeries. ${ }^{115}$

Unintended subarachnoid or subdural puncture with injection of local anesthetic or hypertonic saline is one of the major complications of the procedure with catheter adhesiolysis.

For epiduroscopy side effects and complications are comparable to those of adhesiolysis without endoscopic control. There is however an additional potential of increased pressure in the epidural space due to the continuous pressurized liquid injection, necessary to obtain a clear image. Up till now only one report of visual disturbances due to increased liquor pressure has been reported. Careful monitoring of pressure fluctuations is warranted to reduce the risk of prolonged increased liquor pressur and the duration of the procedure should be limited to maximum 60 minutes.
II.D. Evidence for interventional management

The summary of the evidence for interventional management of lumbosacral radicular pain is given in table 5

Table 5: Summary of the evidence for interventional management

Technique

\begin{tabular}{l|l} 
Interlaminar corticosteroid administration & $2 \mathrm{~B} \pm$ \\
\hline Transforaminal corticosteroid administration in "contained herniation" & $2 \mathrm{~B}+$ \\
\hline Transforaminal corticosteroid administration in "extruded herniation" & $2 \mathrm{~B}-$ \\
\hline Radiofrequency lesioning at the level of the spinal ganglion (DRG) & $2 \mathrm{~A}-$ \\
\hline Pulsed radiofrequency treatment at the level of the spinal ganglion & $2 \mathrm{C}+$ \\
\hline Spinal cord stimulation (FBSS only) & $2 \mathrm{~A}+$ \\
\hline Adhesiolysis - epiduroscopy & $2 \mathrm{~B} \pm$
\end{tabular}

\section{RECOMMENDATIONS}

Based on the evidence available regarding effects and complications, we recommend the following techniques for the treatment of LSR:

- Since epidural corticosteroid injections have mainly short-term effects; these techniques are recommended for patients with subacute radicular pain symptoms.

- In patients with pain at the lumbosacral level (L4, L5, S1) as a result of a "contained herniation", a transforaminal epidural injection with local anesthetic and corticosteroids is recommended. A preference seems to exist for transforaminal epidural corticosteroid administration over caudal and interlaminar corticosteroids below level L3.

- Radiofrequency treatment adjacent to the ganglion spinale (DRG) is not recommended. A pulsed radiofrequency treatment adjacent to the ganglion spinale (DRG) can be considered.

- Spinal cord stimulation is recommended for patients with a therapy-resistant radicular syndrome, but only in specialized centres.

Epiduroscopy and adhesiolysis can be considered in the context of research and only in specialized centres. 
III. A Glinical practice algorithm

Figure 1 represents the treatment algorithm based on the available evidence

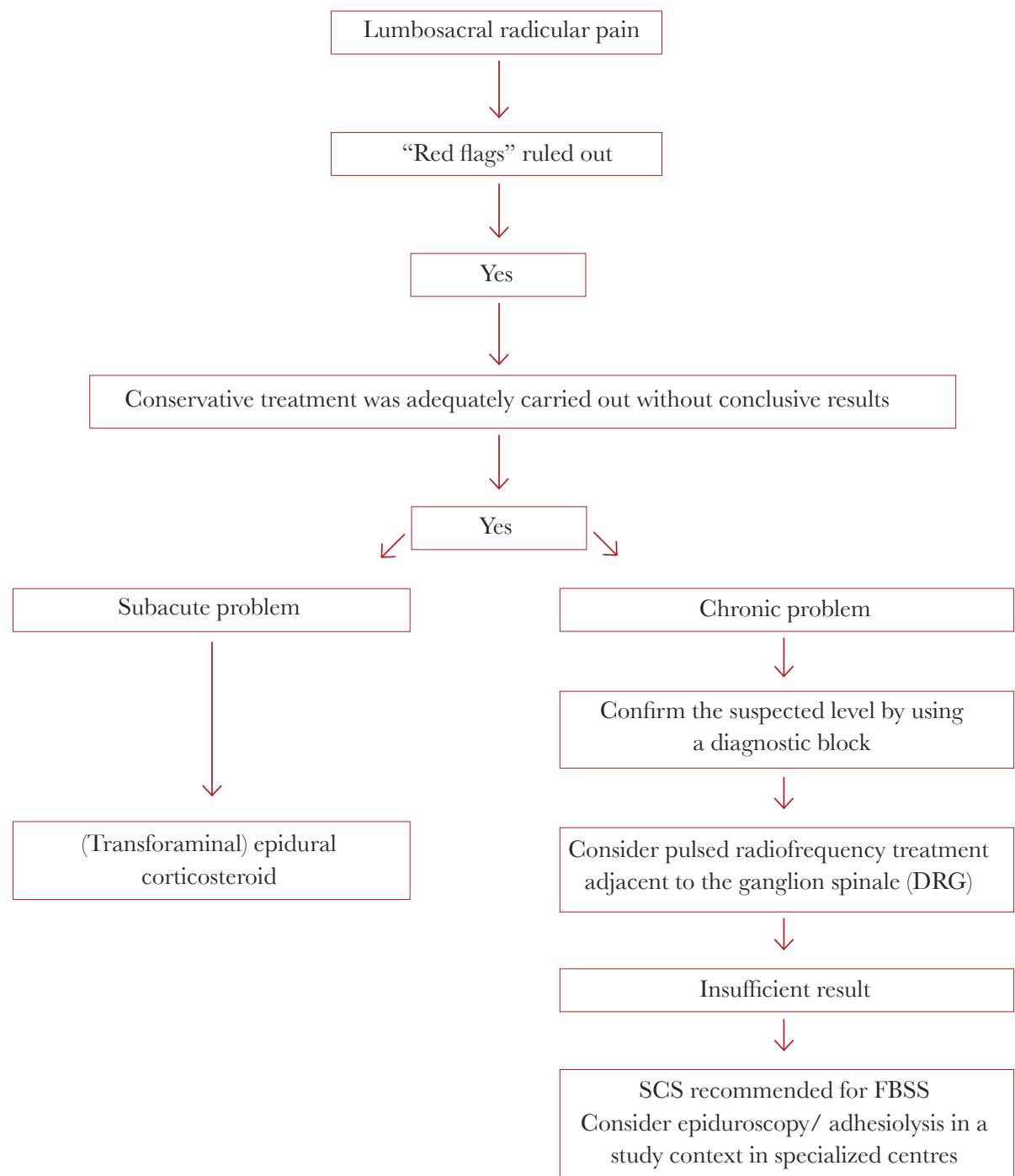

Figure 1: Treatment algorithm for lumbosacral radicular pain.

\section{III.B Techniques}

Practical recommendations epidural corticosteroid administration

There are 7 systematic reviews concerning epidural corticosteroid administration for the treatment of LSR. With regard to short-term effectiveness, 6 of the 7 systematic reviews give a positive assessment and 1 gives a negative assessment (conflicting evidence) ${ }^{87,119-122}$ There are no comparative studies available for the effectiveness and/or complications of the various depot corticosteroids, which means that a distinction between these products cannot be verified.

It is possible that the particle size of the depot corticosteroid is related to the reported neurological complications, but the literature concerning this possibility is also inconclusive. ${ }^{123}$ Up till now, no reported neurologic complications were noted with the non-particulate corticosteroid dexamethasone. One abstract has prospectively compared the transforaminal use of triamcinolone with dexamethasone in 50 patients. ${ }^{124} \mathrm{~A}$ significant greater reduction in pain was noted after 2 weeks in patients treated with triamcinolone, so this far evidence about its efficacy at the lumbar level is lacking. Currently, there is no evidence that a higher corticosteroid dosage produces a better clinical effect ${ }^{125}$, yet the risk of endocrine side effects is substantially higher. It is for this reason that the lowest dosage of depot corticosteroid is currently recommended.

With regard to the number of infiltrations, there are no comparative studies that have shown that the systematic implementation of 3 infiltrations would result in superior outcome ${ }^{126}$ From the RCTs available concerning the transforaminal administration of corticosteroids, one finds an average of 1 to 2 infiltrations. Considering the potential endocrine side effects, adhering to an interval of at least 2 weeks between two infiltrations is recommended.

Interlaminar epidural corticosteroid administration • This technique can be carried out with the patient in a prone position, lying on the side or sitting; in the two latter postures, place the patient in flexion or in the "fetal" position. ${ }^{127}$ The sitting posture is considered to be the most comfortable for the patient as well as for the pain physician. This position allows a correct assessment of the midline and avoids the rotation of a lateral decubitus position.

Determination of the correct level can occur with reference to the cresta illiaca (iliac crest) or via fluoroscopy. In the medial approach, first a local anesthetic will be infiltrated in the middle of the processus spinosi, thereafter, the subcutaneous tissue and the ligamentum supraspinosi are approached with an epidural needle. The latter offers enough resistance that the epidural needle remains in position when the needle is released. Subsequently, the needle enters the ligamentum interspinale and the ligamentum flavum, which both provide additional resistance. A false sensation of loss of resistance may occur upon entering the space between the ligamentum interspinale and the ligamentum flavum. The ligamentum flavum provides the greatest resistance to the epidural needle since it is almost entirely composed of collagenous fibers. Breaking through this ligament to the epidural space is accompanied by

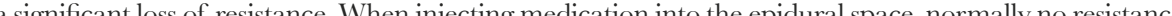
hould be felt since it is filled with fat, blood vessels, lymph tissue and connective tissue. The epidural space is 5 to $6 \mathrm{~mm}$ wide at the L2-L3 level in a patient in a flexion position. In addition, the injection of contrast agent can verify the correct positioning in the epidural space.

In the case of aspiration of blood, the needle must be reoriented; in the case of aspiration of cerebrospinal fluid, the procedure must be repeated at another level. In the latter case, an overflow to the cerebrospinal fluid is possible; therefore, this procedure must be carried out with caution.

Classically, an infiltration consists of an injection of a local anesthetic with a corticosteroid. There is a tendency to perform this procedure under fluoroscopy, yet thus far, no advantages of fluoroscopic control have been demonstrated. ${ }^{128,129}$ 
Transforaminal epidural corticosteroid administration - In a transforaminal approach, the $\mathrm{C}$-arm is adjusted in such a way that the $\mathrm{X}$-rays run parallel to the cover plates of the relevant level. Thereafter, the $\mathrm{C}$-arm is rotated until the processus spinosus projects over the contralateral facet over the me aris superius (superior articular process) or the undenlying joint, he C-arm must be rotated cranially. A 10-cm long, 25-G or 22-G needle with connection tubing that is first flushed with contrast mediun is inserted here locally in the direction of the radiation beam (Figure 2). Thereafter, the direction is corrected such that the needle is projected as a point on the screen. Then, in a lateral view, the depth of the needle tip is checked. A classical approach is in the dorsocranial quadrant, care should be taken

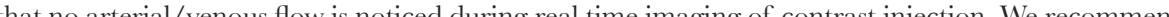
avoiding that the needle elicits paresthesia in the patient. Paresthesia is considered unpleasant by the patient and, in addition, segmental medullary blood vessels may be hit. ${ }^{91,130}$ Therefore the "safe triangle" should be taken into account (Figure 3).

This triangle is formed cranially by the underside of the upper pediculus, laterally by a line between the lateral edges of the upper and lower pediculus and medially by the spinal nerve root (as the during the procedure, the needle must be pulled back several millimeter.

The direction of the radiation beam is now modified to forward-backward (A-P view); as a result, the point of the needle should be located between the lateral edge and the middle of the facet column After the injection of a small quantity of contrast agent during real-time imaging, the course of the ramus anterior (spinal nerve), in the epidural or laterocaudal direction becomes visible. If this image is not attained due to a position that is too lateral, the needle must be more deeply inserted toward the ganglion spinale (DRG). The execution of this procedure during real-time imaging allows the distinction to be made between an accidental intrathecal, intra-arterial or intravenous injection.

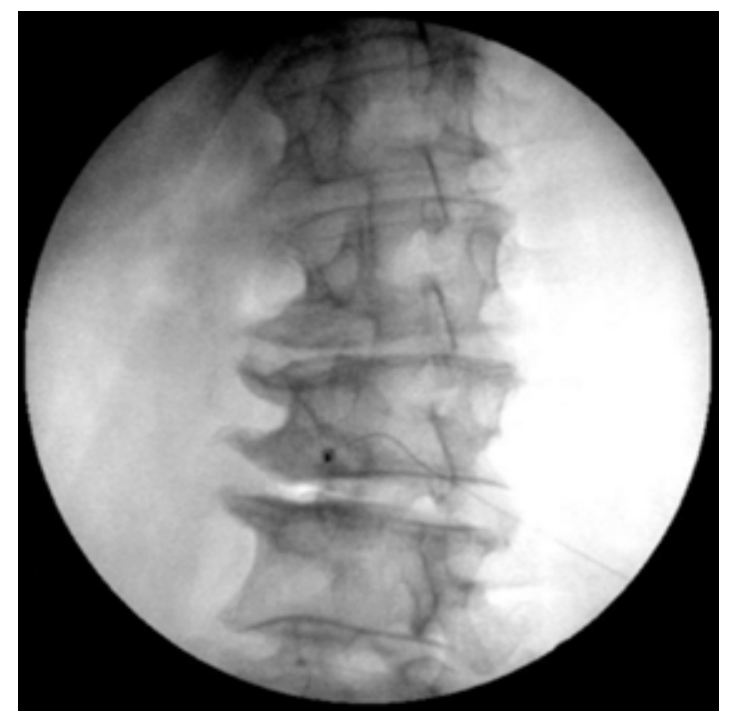

Figure 2: Lumbar transforaminal epidural injection: injection point (oblique insertion)

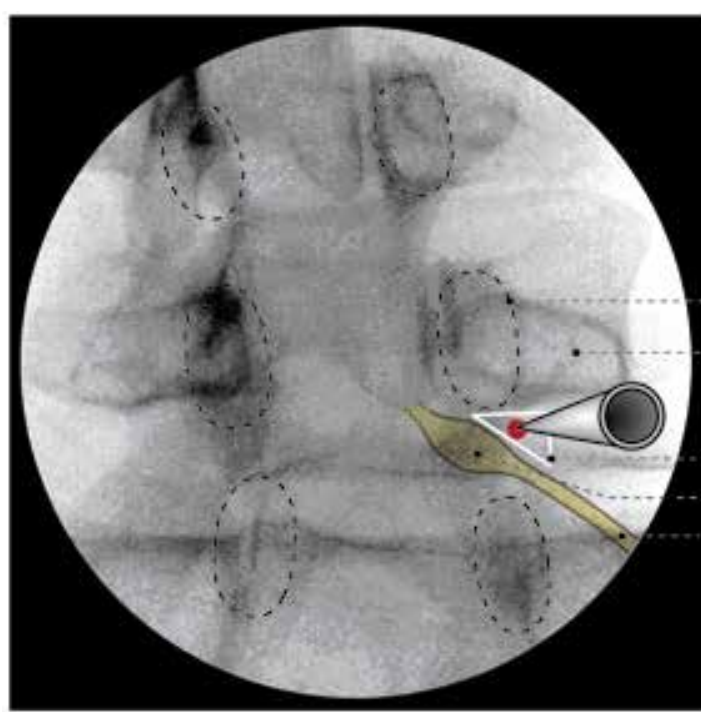

Pediculus

Processus transversus

'Save' triangle

Ganglion spinale (DRG) Ramus ventralis

igure 3: "Safe triangle" for the insertion of the needle in transforaminal epidural injectio

After a correct visualization of the ramus anterior (spinal nerve), a test is carried out with $1 \mathrm{ml}$ bupivacaine $0.5 \%$ or xylocaine $1-2$ minutes thereafter the patient is asked to move the leos to rule out a

S1 transforaminal epidural procedure $\bullet$ The technique used at the S1 level is analogous with that used for the lumbar levels; however, this time the needle is positioned through the foramen sacrale dorsale of S1 on the S1 pedicle. For this, the target lies on the caudal edge of the S1 pediculus on a location homologous to that in the case of the lumbar transforaminal infiltrations. Radiologically, this foramen cannot be that clearly distinguished, but by reorinting the C-arm cephalo-caudally and rotating it ipsilaterally one can cause the foramen sacrale ventrale and the foramen sacrale dorsale of S1 to overlap. The puncture point is chosen at the level of the lateral edge of the dorsal sacral foramen of S1. In an optimal position, the needle point is positioned at $5 \mathrm{~mm}$ from the floor of the canalis sacralis in a lateral view.

(Pulsed) radiofrequency treatment

Diagnostic block • In a diagnostic block, the C-arm is adjusted in such a way that the $\mathrm{X}$-ravs run parallel to the end-plates of the relevant level. Thereafter, the C-arm is rotated until the processus spinosus projects over the contralateral facet column. With the $\mathrm{C}$-arm in this projection, the injection point is found by projecting a metal ruler over the lateral part of the foramen intervertebrale. A 10-cm long, 22-G needle is inserted here locally in the direction of the rays. Thereafter, the direction is corrected such that the needle is projected as a point on the screen (Figure 4). The direction of the radiation beam is now modified to a profile (lateral) view, and the needle inserted until the point is located in the craniodorsal part of the foramen intervertebrale (Figure 5). 


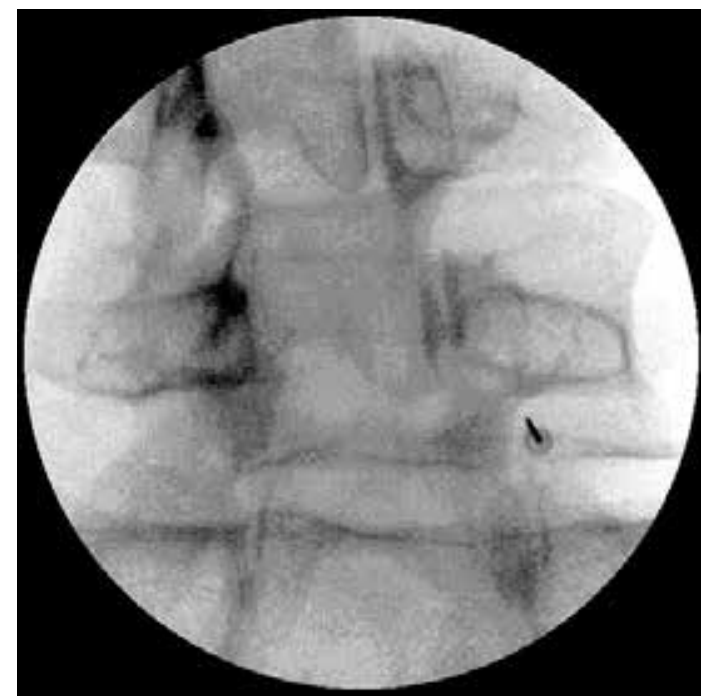

Figure 4: Lumbar DRG: oblique insertion.

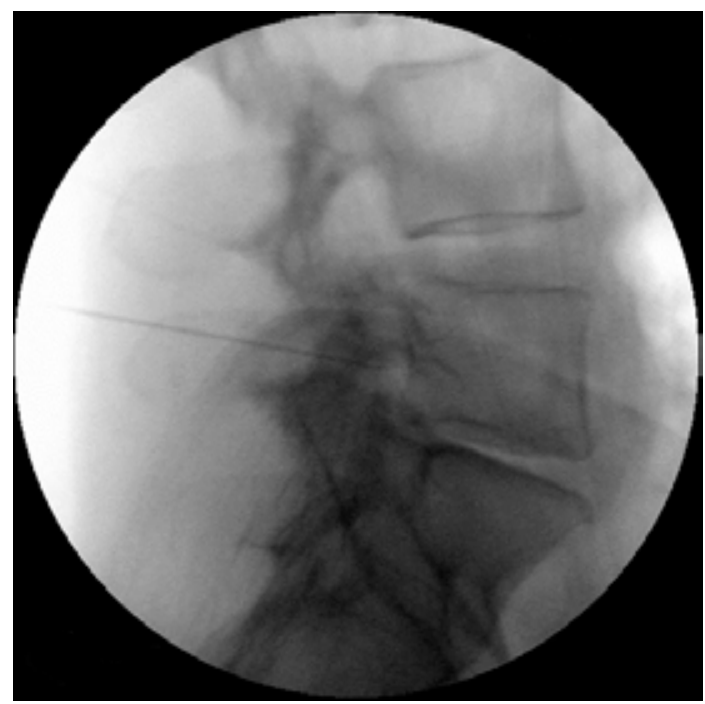

Figure 5: Lumbar DRG: lateral insertion.

In an AP view, the course of a small amount of contrast agent is followed with "real-time imaging"; it spreads out laterocaudally along the spinal nerve (Figure 6 ). Finally a maximum of $1 \mathrm{ml}$ lidocaine $2^{\circ}$ or bupivacaine $0.5 \%$ is injected.

A prognostic block is considered positive if there is a $50 \%$ reduction in symptoms $20-30$ minutes after the intervention. The level that best satisfies the aforementioned criteria is chosen for PRF treatment.

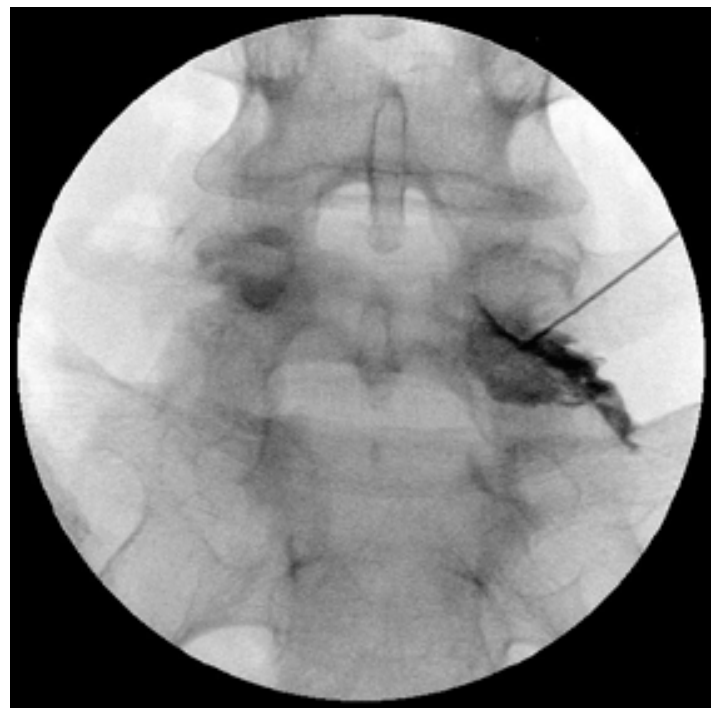

Figure 6: Lumbar DRG: Spread of contrast fluid along the segmental nerve

Lumbar percutaneous pulsed radiofrequency treatment - The insertion point for PRF reatment is determined in the same way as for the diagnostic block; this time, the projection is kept . in the direction of the radiation beam. While the cannula is still located in the superficial layers, the direction is corrected so that the cannula is projected as a point on the screen. Thereafter, the cannula is carefully inserted further until the point is located in the middle on the foramen intervertebrale in lateral view.

The stylet is removed and exchanged for the radiofrequency probe. The impedance is checked, and thereafter, stimulation at $50 \mathrm{~Hz}$ is done. The patient should now feel tingling at a voltage of $<0.5 \mathrm{~V}$. are met, the position of the cannula is recorded in two directions Thereafter, a pulsed current (routinely $20 \mathrm{~ms}$ current and $480 \mathrm{~ms}$ without current) is applied for $120 \mathrm{~s}$ with an output of $45 \mathrm{~V}$; during this procedure, the temperature at the tip of the electrode may not surpass $42^{\circ} \mathrm{C}$. The output may need to be reduced.

The target is an impedance of less than $500 \Omega$. If it is higher, fluid injection can reduce this value. There are reports that the injection of a contrast agent can paradoxically increase the impedance. After repositioning, one can search for a lower stimulation threshold for additional treatment.

Adhesiolysis ${ }^{131}$ • Under fluoroscopic control the target level is identified. The $\mathrm{C}$-arm is then rotated $15-20^{\circ}$ oblique to the ipsilateral side of the targeted foramen intervertebrale. Once a "Scotty dog" image is obtained, the fluoroscope is rotated in a caudal-cephalad direction for 15 to $20^{\circ}$. A caudalcephalad rotation elongates the superior articular process ("ear of the Scotty dog"). The tip of the ear, or superior articular process, in the "oun barrel" technique is marked on the skin as entry point. An (8) needle is advanced anteriorly until bone is contacted. A lateral fluoroscopic image is obtained before further introduction of the needle. To facilitate passage of the needle past the articular process, the 
epidural needle is turned laterally to slide past the bone and stop just after a "pop" is felt. The needle tip on a lateral view should be in the posterior aspect of the foramen. An Epimed Tun-L-XL epidura catheter is then inserted through the epidural needle. Occasionally, the epidural needle must be tilted at the hub laterally to aid entry of the epidural catheter into the anterior epidural space. The catheter is advanced medial to the pedicle. After catheter placement is confirmed to be in the anterior epidural space under anteroposterior and lateral views, the stylet is removed from the catheter and a connector is placed on the proximal end of the epidural catheter.

Aspiration should be negative before $3 \mathrm{ml}$ radiographic contrast is injected. The contrast injection should show opening of the entered neuroforamen, with contrast exiting along the path of the nerve root.

Lysis is commonly performed with hypertonic saline but remains controversial due to its potential neurotoxocity should intrathecal spread occur.

After performing the lysis local anesthetic and corticosteroid is injected.

When performing adhesiolysis according to the Racz procedure the catheter is kept in place and lysis is repeated on 3 consecutive days. ${ }^{132}$ Manchikanti on the other hand advocates a one-day procedure. ${ }^{13}$

Epiduroscopy $\mathbf{y}^{80}$ Epiduroscopy is performed with the patient in the prone position on a translucent table. Intravenous access, electrocardiographic, blood pressure, and oxygen saturation monitoring must be established. The patient is lightly sedated, making sure that communication is possible throughout the procedure.

The sacral cornua are identified. When this proves to be difficult, internal rotation of the feet will widen the gluteal cleft, thus facilitating the identification of the sacral hiatus. After anesthesia of the skin and underlying tissues a $18 \mathrm{G}$ Tuohy needle is advanced 2 to $3 \mathrm{~cm}$ into the sacral canal. Care must be taken not to exceed the level of $\mathrm{S} 3$ to prevent intradural placement of the needle and subsequent equipment. Through the Tuohy needle a guide-wire is directed cranially, as close as possible to the target area. The Manchikanti group recommends not to position the guidewire beyond the S3 level. In this case, however, there is an increased risk of dislocation when placing the introducer and performin dilation. A small incision is made at the introduction site and after removal of the Tuohy needle, a dilator is passed over the guide wire followed by the introducer sheath. The side arm of the introducer sheath is left open to allow drainage of excess saline. A flexible $0.9 \mathrm{~mm}$ (outer diameter) fiberoptic endocscope (magnification X 45) is introduced through one of two main access ports of a disposable $2.2 \mathrm{~mm}$ (outer diameter) steering catheter. The steering catheter also contains 2 side channels for fluid instillation. One side channel of the steering catheter is used for the intermittent flush of norma saline. The other side channel is connected to an automatic monitoring system by means of a standard arterial pressure monitoring system, to allow for continuous monitoring of epidural/saline delivery pressure. After distention of the sacral epidural space with normal saline the steering catheter with the fiberoptic endoscope is slowly advanced to the target area. The epidural space is kept distended with normal saline, but the pressure should be limited to minimize the risks of compromised perfusion. Total saline volume ranges between 50 and $250 \mathrm{ml}$. When fibrosis or adhesions become visible during epiduroscopy these can be mobilized with the tip of the endoscope. It is recommended to limit the duration of the procedure to maximum 60 minutes.

\section{SUMMARY}

- There is no gold standard for the diagnosis of lumbosacral radicular pain

- History and clinical examination are the cornerstones of the diagnostic process.

- In case red flags are present or if an interventional treatment is being considered, medical imaging is recommended with a slight preference for MRI

- When conservative treatment fails:

- In (sub)acute lumbosacral radicular pain under the L3 level as a result of a contained herniation, transforaminal corticosteroid administration is recommended.

- In chronic lumbosacral radicular pain, PRF treatment at the level of the spinal ganglion can be considered.

- For refractory lumbosacral radicular pain, adhesiolysis and epiduroscopy can be considered (2 B \pm ), preferentially study related.

- In patients with a therapy-resistant radicular pain in the context of a FBSS, spinal cord stimulation is recommended. Adhesiolysis and epiduroscopy can be considered in a study design.

Aknowledgements • This review was initially based on practice guidelines, written by Dutch and Flemish (Belgian) experts that are assembled in a handbook for the Dutch-speaking pain physicians. After translation, the manuscript was updated and edited in cooperation with U.S./International pain specialists. The authors thank Nicole Van den Hecke for coordination and suggestions regarding the manuscrip 


\section{References}

Guyatt G, Gutterman D, Baumann MH et al. Grading strength of recommendations and quality of evidence in clinical guidelines: report from an american college of chest physicians task force. Chest 2006:129:174-81.

2. van KleefM, Mekhail N, van Zundert J.Evidence-based guidelines for interventional pain medicine accordin to clinical diagnoses. Pain Pract 2009;9:247-51.

Dionne CE, Dunn KM, Croft PR et al. A consensus approach toward the standardization of back pain definitions for use in prevalence studies. Spine 2008;33:95-103.

4. Konstantinou K, Dunn KM. Sciatica: review of epidemiological studies and prevalence estimates. Spine (Phila Pa 1976) 2008;33:2464-72.

5horomi S, Patsalides A, Parada S et al. Topiramate in chronic lumbar radicular pain.J Pain 2005;6:829-36.

6. Dworkin RH, O'Connor AB, Backonja $M$ et al. Pharmacologic management of neuropathic pain: evidence-based recommendations. Pain 2007:132:237-51.

7. Younes M, Bejia I, Aguir Z et al. Prevalence and risk factors of disk-related sciatica in an urban population in Tunisia. Joint Bone Spine 2006;73:538-42.

8. Weber H, Holme I, Amlie E. The natural course of acute sciatica with nerve root symptoms in a double-blind placebo-controlled trial evaluating the effect of piroxicam. Spine 1993;18:1433-8.

9. Peul WC, Brand R, Thomeer RT, Koes BW. Influence of gender and other prognostic factors on outcome of sciatica. Pain 2008:138:180-91.

10. Tarulli AW, Raynor EM. Lumbosacral radiculopathy. Neurol Clin 2007;25:387-405.

11. Murphy DR, Hurwitz EL, Gerrard JK, Clary R. Pain patterns and descriptions in patients with radicular pain: Does the pain necessarily follow a specific dermatome? Chiropr Osteopat 2009;17:9.

12. Vroomen PC, de Krom MC, Knottnerus JA. Diagnostic value of history and physical examination in patient suspected of sciatica due to disc herniation: a systematic review. J Neurol 1999;246:899-906.

13. Deville WL, van der Windt DA, Dzaferagic A, Bezemer PD, Bouter LM. The test of Lasegue: systematic review of the accuracy in diagnosing herniated discs. Spine 2000;25:1140-7.

14. Koes BW, van Tulder MW, Peul WC. Diagnosis and treatment of sciatica. BMJ 2007;334:1313-7.

15. Hofstee DJ, Gijtenbeek JM, Hoogland PH et al. Westeinde sciatica trial: randomized controlled study of bed rest and physiotherapy for acute sciatica. J Neurosurg 2002;96:45-9.

16. Jensen MC, Brant-Zawadzki MN, Obuchowski $N$ et al. Magnetic resonance imaging of the lumbar spine in people without back pain. N Engl J Med 1994;331:69-73.

17. Delauche-Cavallier MC, Budet C, Laredo JD et al. Lumbar disc herniation. Computed tomography scan changes after conservative treatment of nerve root compression. Spine 1992;17:927-33.

18. Wiesel SW, Tsourmas N, Feffer HL, Citrin CM, Patronas N. A study of computer-assisted tomography. I. The incidence of positive CAT scans in an asymptomatic group of patients. Spine 1984;9:549-51.

19. Maigne JY, Rime B, Deligne B. Computed tomographic follow-up study of forty-eight cases of nonoperatively treated lumbar intervertebral disc herniation. Spine 1992;17:1071-4.

20. Modic MT, Obuchowski NA, Ross JS et al. Acute low back pain and radiculopathy: MR imaging findings and their prognostic role and effect on outcome. Radiology 2005:237:597-604.

21. Modic MT, Ross JS, Obuchowski NA et al. Contrast-enhanced MR imaging in acute lumbar radiculopathy: a pilot study of the natural history. Radiology 1995;195:429-35.

22. Tullberg T, Svanborg E, Isaccsson J, Grane P. A preoperative and postoperative study of the accuracy and value of electrodiagnosis in patients with lumbosacral disc herniation. Spine 1993;18:837-42.

23. Wolff AP, Groen GJ, Wilder-Smith $\mathrm{OH}$. Influence of needle position on lumbar segmental nerve root block selectivity. Reg Anesth Pain Med 2006:31:523-30.

24. Xavier AV, Farrell CE, McDanal J, Kissin I. Does antidromic activation of nociceptors play a role in sciatic radicular pain? Pain 1990;40:77-9.
25. North RB, Kidd DH, Zahurak M, Piantadosi S. Specificity of diagnostic nerve blocks: a prospective, andomized study of sciatica due to lumbosacral spine disease. Pain 1996;65:77-85.

26. Furman MB, Lee TS, Mehta A, Simon JI, Cano WG. Contrast flow selectivity during transforaminal lumbosacral epidural steroid injections. Pain Physician 2008;11:855-61.

27. Wolff AP, Groen GJ, Crul BJ. Diagnostic lumbosacral segmental nerve blocks with local anesthetics: a prospective double-blind study on the variability and interpretation of segmental effects. Reg Anesth Pain Med 2001;26:147-55

28. Wolff AP, Wilder Smith $\mathrm{OH}$, Crul BJ, van de Heijden MP, Groen GJ. Lumbar segmental nerve blocks with local anesthetics, pain relief, and motor function: a prospective double-blind study between lidocaine and ropivacaine. Anesth Analg 2004;99:496-501, table of contents.

29. Le Bars D. The whole body receptive field of dorsal horn multireceptive neurones. Brain Res Brain Res Rev 2002:40:29-44.

30. Wolff A, Wilder-Smith O. Diagnosis in patients with chronic radiating low back pain without overt focal neurological deficits : what is the value of segmental nerve root blocks? Therapy 2005;2:577-85.

31. Luijsterburg PA, Lamers LM, Verhagen AP et al. Cost-effectiveness of physical therapy and general practitioner care for sciatica. Spine 2007;32:1942-8.

32. Hagen KB, Jamtvedt G, Hilde G, Winnem MF. The updated cochrane review of bed rest for low back pain and sciatica. Spine 2005;30:542-6.

33. Amlie E, Weber H, Holme I. Treatment of acute low-back pain with piroxicam: results of a double-blind placebo-controlled trial. Spine (Phila Pa 1976) 1987;12:473-6.

34. Dreiser RL, Le Parc JM, Velicitat P, Lleu PL. Oral meloxicam is effective in acute sciatica: two randomised, double-blind trials versus placebo or diclofenac. Inflamm Res 2001;50 Suppl 1:S17-23.

35. Luijsterburg PA, Verhagen AP. Ostelo RW et al. Physical therapy plus general practitioners' care versus general practitioners' care alone for sciatica: a randomised clinical trial with a 12-month follow-up. Eur Spine J 2008:17:509-17.

36. Atlas SJ, Keller RB, Wu YA, Deyo RA, Singer DE. Long-term outcomes of surgical and nonsurgical management of lumbar spinal stenosis: 8 to 10 year results from the maine lumbar spine study. Spine 2005;30:936-43.

37. Weinstein JN, Tosteson TD, Lurie JD et al. Surgical vs nonoperative treatment for lumbar disk herniation: the Spine Patient Outcomes Research Trial (SPORT): a randomized trial. JAMA 2006;296:2441-50.

38. Peul WC, van Houwelingen $H C$, van den Hout WB et al. Surgery versus prolonged conservative treatment for sciatica. N Engl J Med 2007:356:2245-56.

39. Gibson JN, Waddell G. Surgical interventions for lumbar disc prolapse: updated Cochrane Review. Spine 2007;32:1735-47

40. Jonsson B, Stromqvist B. Clinical characteristics of recurrent sciatica after lumbar discectomy. Spine 1996;21:500-5.

41. Postacchini F, Giannicola G, Cinotti G. Recovery of motor deficits after microdiscectomy for lumbar disc herniation. J Bone Joint Surg Br 2002;84:1040-5.

42. CBO. Het Lumbosacrale radiculaire syndroom. In: Toetsing CBvdI ed. Consensus richtlijnen. Utrecht: $C B O$, 1996.

43. Guigui P, Cardinne L, Rillardon Let al. [Per-and postoperative complications of surgical treatment of lumbar spinal stenosis. Prospective study of 306 patients]. Rev Chir Orthop Reparatrice Appar Mot 2002;88:669-77.

44. Jonsson B, Stromqvist B. Motor affliction of the L5 nerve root in lumbar nerve root compression syndromes. Spine 1995;20:2012-5.

45. Hahne AJ, Ford JJ. Functional restoration for a chronic lumbar disk extrusion with associated radiculopathy. Phys Ther 2006:86:1668-80.

46. Finnerup NB, Otto M, McQuay HJ, Jensen TS, Sindrup SH. Algorithm for neuropathic pain treatment: 
an evidence based proposal. Pain 2005;118:289-305.

47. Saarto T, Wiffen PJ.Antidepressants for neuropathic pain. Cochrane Database Syst Rev 2007:CD005454

48. Yildirim K, Kataray $S$. The effectiveness of gabapentin in patients with chronic radiculopathy. The Pain Clinic 2003;15:213-8.

Dellemijn $P L$, van Duijn $H$, Vanneste JA. Prolonged treatment with transdermal fentanyl in neuropathic pain. J Pain Symptom Manage 1998;16:220-9.

50. Ng L, Chaudhary N, Sell P. The efficacy of corticosteroids in periradicular infiltration for chronic radicular pain: a randomized, double-blind, controlled trial. Spine 2005;30:857-62.

51. McQuay HJ, Moore RA. Epidural corticosteroids for sciatica Oxford- New York- Tokyo: Oxford University Press, 1998.

52. Koes BW, Scholten RJPM, Mens JMA, Bouter LM. Epidural Steroid Injections for Low Back Pain and Sciatica: An updated Systematic Review of Randomized Clinical Trials. Pain Digest 1999;9:241-7.

53. Chou $R$, Atlas $S J$, Stanos $S P$, Rosenquist $R W$. Nonsurgical interventional therapies for low back pain: a review of the evidence for an American Pain Society clinical practice guideline. Spine (Phila Pa 1976) 2009;34:107893.

54. Arden NK, Price C, Reading I et al. A multicentre randomized controlled trial of epidural corticosteroid injections for sciatica: the WEST study. Rheumatology (Oxford) 2005;44:1399-406.

55. Dilke TF, Burry HC, Grahame R. Extradural corticosteroid injection in management of lumbar nerve root compression. BMJ 1973;2:635-7.

56. Wilson-MacDonald J, Burt G, Griffin D, Glynn C. Epidural steroid injection for nerve root compression. A randomised, controlled trial. J Bone Joint Surg Br 2005;87:352-5

57. Carette S, Leclaire R, Marcoux S et al.Epidural corticosteroid injections for sciatica due to herniated nucleus pulposus. N Engl J Med 1997;336:1634-40.

58. Bogduk N. Epidural steroids. Spine 1995;20:845-8.

59. Riew KD, Yin Y, Gilula L et al. The effect of nerve-root injections on the need for operative treatment of lumbar radicular pain. A prospective, randomized, controlled, double-blind study. J Bone Joint Surg Am 2000;82A:1589-93

60. Karppinen J, Malmivaara A, Kurunlahti $M$ et al. Periradicular infiltration for sciatica: a randomized controlled trial. Spine 2001;26:1059-67.

61. Riew KD, Park JB, Cho YS et al. Nerve root blocks in the treatment of lumbar radicular pain. A minimum five-year follow-up. J Bone Joint Surg Am 2006;88:1722-5.

62. Vad VB, Bhat AL, Lutz GE, Cammisa F. Transforaminal epidural steroid injections in lumbosacral radiculopathy: a prospective randomized study. Spine 2002;27:11-6.

63. Karppinen J, Ohinmaa A, Malmivaara A et al. Cost effectiveness of periradicular infiltration for sciatica: subgroup analysis of a randomized controlled trial. Spine 2001;26:2587-95.

64. Ackerman WE, 3rd, Ahmad M. The efficacy of lumbar epidural steroid injections in patients with lumbar disc herniations. Anesth Analg 2007;104:1217-22.

65. Thomas E, Cyteval C, Abiad L et al. Efficacy of transforaminal versus interspinous corticosteroid injectionin discal radiculalgia - a prospective, randomised, double-blind study. Clin Rheumatol 2003;22:299-304.

66. Geurts JW, van Wijk RM, Wynne HJ et al. Radiofrequency lesioning of dorsal root ganglia for chronic lumbosacral radicular pain: a randomised, double-blind, controlled trial. Lancet 2003;361:21-6.

67. Teixeira A, Grandinson M, Sluijter M. Pulsed Radiofrequency for radicular pain due to a herniated intervertebral disc - an initial report. Pain Practice 2005;5:111-5.

68. Abejon D, Garcia-del-Valle S, Fuentes ML et al. Pulsed radiofrequency in lumbar radicular pain: clinical effects in various etiological groups. Pain Pract 2007;7:21-6.

69. Simopoulos TT, Kraemer J, Nagda JV, Aner M, Bajwa ZH. Response to pulsed and continuous radiofrequency lesioning of the dorsal root ganglion and segmental nerves in patients with chronic lumbar radicular pain. Pain Physician 2008;11:137-44.

70. Heavner JE, Racz GB, Raj P. Percutaneous epidural neuroplasty: prospective evaluation of $0.9 \% \mathrm{NaCl}$ versus 10\% $\mathrm{NaCl}$ with or without hyaluronidase. Reg Anesth Pain Med 1999;24:202-7.

71. Manchikanti L, Rivera JJ, Pampati V et al. One day lumbar epidural adhesiolysis and hypertonic saline neurolysis in treatment of chronic low back pain: a randomized, double-blind trial. Pain Physician 2004;7:177-86

72. Veihelmann A, Devens $C$, Trouillier $H$ et al. Epidural neuroplasty versus physiotherapy to relieve pain in patients with sciatica: a prospective randomized blinded clinical trial.J Orthop Sci 2006;11:365-9.

73. Manchikanti L, Pakanati R, Bakhit CE, Pampati V. Role of adhesiolysis and hypertonic saline neurolysis in management of low back pain. Evaluation of modification of Racz protocol. Pain Digest 1999:91-6.

74. Gillespie G, MacKenzie P. Epiduroscopy--a review. Scott Med J 2004;49:79-81.

75. Boswell MV, Trescot AM, Datta S et al. Interventional techniques: evidence-based practice guidelines in the management of chronic spinal pain. Pain Physician 2007;10:7-111

76. Manchikanti L, Boswell MV, Rivera JJ et al. [ISRCTN 16558617] A randomized, controlled trial of spinal endoscopic adhesiolysis in chronic refractory low back and lower extremity pain. BMC Anesthesiol 2005;5:10.

77. Dashfield AK, Taylor MB, Cleaver JS, Farrow D. Comparison of caudal steroid epidural with targeted steroid placement during spinal endoscopy for chronic sciatica: a prospective, randomized, double-blind trial. Br J Anaesth 2005:94:514-9.

78. Manchikanti L, Pampati V, Bakhit CE, Pakanati RR. Non-endoscopic and endoscopic adhesiolysis in post-lumbar laminectomy syndrome: a one-year outcome study and cost effectiveness analysis. Pain Physician 1999;2:52-8.

79. Geurts JW, Kallewaard JW, Richardson J, Groen GJ. Targeted methylprednisolone acetate/hyaluronidase/ clonidine injection after diagnostic epiduroscopy for chronic sciatica: a prospective, 1-year follow-up study. Reg Anesth Pain Med 2002;27:343-52.

80. Ruetten S, Meyer O, Godolias G. Endoscopic surgery of the lumbar epidural space (epiduroscopy): results of therapeutic intervention in 93 patients. Minim Invasive Neurosurg 2003;46:1-4.

81. Igarashi T, Hirabayashi $Y$, Seo $N$ et al. Lysis of adhesions and epidural injection of steroid/local anaesthetic during epiduroscopy potentially alleviate low back and leg pain in elderly patients with lumbar spinal stenosis. Br J Anaesth 2004:93:181-7.

82. Raffaeli W, Righetti D. Surgical radio-frequency epiduroscopy technique (R-ResAblator) and FBSS treatment: preliminary evaluations. Acta Neurochir Suppl 2005;92:121-5.

83. Sakai T, Aoki $H$, Hojo M et al. Adhesiolysis and targeted steroid/local anesthetic injection during epiduroscopy alleviates pain and reduces sensory nerve dysfunction in patients with chronic sciatica. $J$ Anesth 2008;22:242-7.

84. Taylor RS, Van Buyten JP, Buchser E. Spinal cord stimulation for chronic back and leg pain and failed back surgery syndrome: a systematic review and analysis of prognostic factors. Spine 2005;30:152-60.

85. Kumar K, Taylor RS, Jacques $L$ et al. Spinal cord stimulation versus conventional medical management for neuropathic pain: a multicentre randomised controlled trial in patients with failed back surgery syndrome. Pain 2007;132:179-88.

86. Watts RW, Silagy CA. A Meta-Analysis on the efficacy of epidural corticosteroids in the treatment of sciatica. Anaesth Intens Care 1995;23:564-9.

87. Armon C, Argoff CE, Samuels J, Backonja MM. Assessment: use of epidural steroid injections to trea radicular lumbosacral pain: report of the Therapeutics and Technology Assessment Subcommittee of the American Academy of Neurology. Neurology 2007;68:723-9.

88. Van Zundert J, le Polain de Waroux B. Safety of epidural steroids in daily practice: evaluation of more than 
4000 administrations. In: Monitor TI ed. XX Annual ESRA Meeting. Rome: ESRA, 2000: 122.

89. Abram SE, O'Connor TC. Complications associated with epidural steroid injections. Reg Anesth 1996;21:149-

90. Houten JK, Errico TJ. Paraplegia after lumbosacral nerve root block: report of three cases. The Spine Journal 2002;2:70-5.

91. Huntoon MA, Martin DP. Paralysis after transforaminal epidural injection and previous spinal surgery. Reg Anesth Pain Med 2004;29:494-5.

92. Glaser SE, Falco F. Paraplegia following a thoracolumbar transforaminal epidural steroid injection. Pain Physician 2005;8:309-14.

93. Somayaji HS, Saifuddin A, Casey AT, Briggs TW. Spinal cord infarction following therapeutic computed tomography-guided left L2 nerve root injection. Spine (Phila Pa 1976) 2005;30:E106-8.

94. Quintero N, Laffont I, Bouhmidi L et al. [Transforaminal epidural steroid injection and paraplegia: case report and bibliographic review]. Ann Readapt Med Phys 2006;49:242-7.

95. Kennedy DJ, Dreyfuss P, Aprill CN, Bogduk N. Paraplegia Following Image-Guided Transforaminal Lumba Spine Epidural Steroid Injection: Two Case Reports. Pain Med 2009; 10:1389-1394.

96. Lyders EM, Morris PP. A case of spinal cord infarction following lumbar transforaminal epidural steroid injection: MR imaging and angiographic findings. AJNR Am J Neuroradiol 2009;30:1691-3.

97. Rathmell JP, Benzon HT. Transforaminal injection of steroids: should we continue? Reg Anesth Pain Med 2004:29:397-9.

98. Goodman BS, Bayazitoglu M, Mallempati S, Noble BR, Geffen JF. Dural puncture and subdural injection: complication of lumbar transforaminal epidural injections. Pain Physician 2007;10:697-705

99. Finn KP, Case JL. Disk entry: a complication of transforaminal epidural injection--a case report. Arch Phys Med Rehabil 2005;86:1489-91.

100. Bilir A, Gulec S. Cauda equina syndrome after epidural steroid injection: a case report. J Manipulative Physiol Ther 2006;29:492 el-3.

101. Young WF. Transient blindness after lumbar epidural steroid injection: a case report and literature review. Spine 2002;27:E476-7.

102. Kabbara A, Rosenberg SK, Untal C. Methicillin-resistant Staphylococcus aureus epidural abscess after transforaminal epidural steroid injection. Pain Physician 2004;7:269-72.

103. Hooten WM, Mizerak A, Carns PE, Huntoon MA. Discitis after lumbar epidural corticosteroid injection: case report and analysis of the case report literature. Pain Med 2006;7:46-51

104. Simopoulos TT, Kraemer JJ, Glazer P, Bajwa ZH. Vertebral osteomyelitis: a potentially catastrophic outcome after lumbar epidural steroid injection. Pain Physician 2008;11:693-7.

105. Bogduk N. Lumbar transforaminal injections of corticosteroids. In: Bogduk N, ed. International Spine Intervention Society Practice Guidelines for Spinal Diagnoses and Treatment San Francisco, USA: ISIS, 2004.

106. van Kleef M, Spaans $F$, Dingemans $W$ et al. Effects and side effects of a percutaneous thermal lesion of the dorsal root ganglion in patients with cervical pain syndrome. Pain 1993;52:49-53.

107. Cahana A, Van Zundert J, Macrea L, van Kleef M, Sluijter M. Pulsed Radiofrequency: Current Clinical and Biological Literature Available. Pain Medicine 2006;7:411-23.

108. Sluijter ME, Cosman ER, Rittman IIWB, van Kleef M. The effects of pulsed radiofrequency field applied to the dorsal root ganglion - a preliminary report. The Pain Clinic 1998;11:109-17.

109. Munglani $R$. The longer term effect of pulsed radiofrequency for neuropathic pain. Pain 1999;80:437-9.

110. Pevzner E, David R, Leitner Y et al. [Pulsed radiofrequency treatment of severe radicular pain]. Harefuah 2005; 144:178-80, 231.

111. Ramanavarapu V, Simopoulos TT. Pulsed radiofrequency of lumbar dorsal root Ganglia for chronic postamputation stump pain. Pain Physician 2008;11:561-6.
112. Chao SC, Lee HT, Kao TH et al. Percutaneous pulsed radiofrequency in the treatment of cervical and lumbar radicular pain. Surg Neurol 2008;70:59-65.

113. Kumar K, Buchser E, Linderoth B, Meglio M, Van Buyten JP. Avoiding Complications from spinal cord stimuLation: Practical recommendations from an international panel of experts. Neuromodulation 2007:10:24-33.

14. Talu G. Erdine S. Complications of epidural neuroplasty: a retrospective evaluation. Neuromodulation 2003:237-347.

115. Perkins WJ,Davis DH, Huntoon MA, Horlocker TT.Aretained Raczcatheter fragment after epidural neurolysis: implications during magnetic resonance imaging. Anesth Analg 2003;96:1717-9, table of contents.

116. Wagner KJ, Sprenger T, Pecho C et al. [Risks and complications of epidural neurolysis -- a review with case report]. Anasthesiol Intensivmed Notfallmed Schmerzther 2006;41:213-22.

117. Richter H. Is the so-called epidural neuroplasty (Racz catheter) a harmless procedure? In: Neurochirurgie DGfed.Deutsche Gesellschaft fur Neurochirurgie Strasbourg, Germany: Deutsche Gesellschaft fur Neurochirurgie 2005

118. Luijsterburg PA, Verhagen AP, Ostelo RW et al. Effectiveness of conservative treatments for the lumbosacral radicular syndrome: a systematic review. Eur Spine J 2007;16:881-99.

119. Abdi S, Datta S, Trescot AM et al. Epidural steroids in the management of chronic spinal pain: a systematic review. Pain Physician 2007:10:185-212.

120. DePalma MJ, Bhargava A, Slipman CW. A critical appraisal of the evidence for selective nerve root injection in the treatment of lumbosacral radiculopathy. Arch Phys Med Rehabil 2005;86:1477-83.

121. Vroomen PC, de Krom MC, Slofstra PD, Knottnerus JA. Conservative treatment of sciatica: a systematic review. J Spinal Disord 2000;13:463-9.

122. Koes B, Scholten RJ, Mens JMA, Bouter LM. Efficacy of epidural steroid injections for low-back pain and sciatica: a systematic review of randomized clinical trials. Pain 1995;63:279-88.

123. Benzon HT, Chew TL, McCarthy RJ, Benzon HA, Walega DR. Comparison of the particle sizes of different steroids and the effect of dilution: a review of the relative neurotoxicities of the steroids. Anesthesiology 2007; 106:331-8.

124. O'Donnell C, Cano W, D'Eramo G. Comparison of triamcinolone to dexamethasone in the treatment of low back and leg pain via lumbar transforaminal epidural steroid injection. In: ISIS ed. North American Spine Society 23rd Annual Meeting. Toronto: ISIS, 2008.

125. Owlia MB, Salimzadeh A, Alishiri G, Haghighi A. Comparison of two doses of corticosteroid in epidural steroid injection for lumbar radicular pain. Singapore Med J 2007:48:241-5.

126. Novak S, Nemeth WC. The basis for recommending repeating epidural steroid injections for radicular low back pain: a literature review. Arch Phys Med Rehabil 2008;89:543-52.

127. Waldman. Interventional Pain Management: Saunders, W.B, 2001

128. Merrill DG, Rathmell JP, Rowlingson JC. Epidural steroid injections. Anesth Analg 2003;96:907-8.

129. Cluff R, Mehio AK, Cohen SP et al. The technical aspects of epidural steroid injections: a national survey. Anesth Analg 2002;95:403-8.

130. Botwin K, Gruber R, Bouchlas C, et al. Complications of fluoroscopically guided transforaminal lumbar epidural injections. Arch Phys Med Rehabil 2000;81:1045-50.

131. Lou L, Racz G. Spinal Decompressive Neuroplasty via the Caudal and Cervical Approaches In: Beltrutti D Benzon HT, Erdine S, Heavner JE, Niv D, Racz GB, Rauck RL, Staats PS, Warfield CA, Wells C, Raj PP, eds. Raj: Textbook of Regional Anesthesia, 1st ed Philadelphia, Pennsylvania, US, Churchill Livingstone, 2002.

132. Heavner I, Chokhavatia S, Kizelshteyn G. Percutaneous evaluation of the epidural and subarachnoid space with a flexible fiberscope. Reg Anesth 1991:15(S):85.

133. Manchikanti L, Pampati V. Role of One Day Epidural Adhesiolysis in Managemnt of Chronic Low Back Pain: A radomized Clinical Trial. Pain Physician 2001;4:153-66. 


\section{Chapter III}

Pulsed Radiofrequency: A Review of the Basic

Science as Applied to the Pathophysiology of

Radicular Pain: A Call for Clinical Translation

Koen Van Boxem, MD, FIPP a,b; Marc Huntoon, MD c; Jan Van Zundert MD, PhD, FIPP d; Jacob Patijn, MD, PhD a; Maarten van Kleef, MD, PhD, FIPP a; Elbert A Joosten PhD a,e.

a Department of Anesthesiology and Pain Medicine, Maastricht University Medical Centre, Maastricht, the Netherlands. b Department of Anesthesiology - Critical Care and Multidisciplinary Pain Centre, Sint Jozefkliniek, Bornem and Willebroek, Bornem, Belgium. c Division of Pain

Management, Vanderbilt University, Nashville, USA. d Department of Anesthesiology Critical Care, Emergency Medicine and Multidisciplinary pain Centre, Ziekenhuis Oost-Limburg, Genk/ Lanaken, Belgium. e School of Mental Health and Neuroscience, University Maastricht, the Netherlands

Published in Regional Anesthesia and Pain Medicine: 2014; 39 (2):149-159 Reprinted with permission of the publisher 


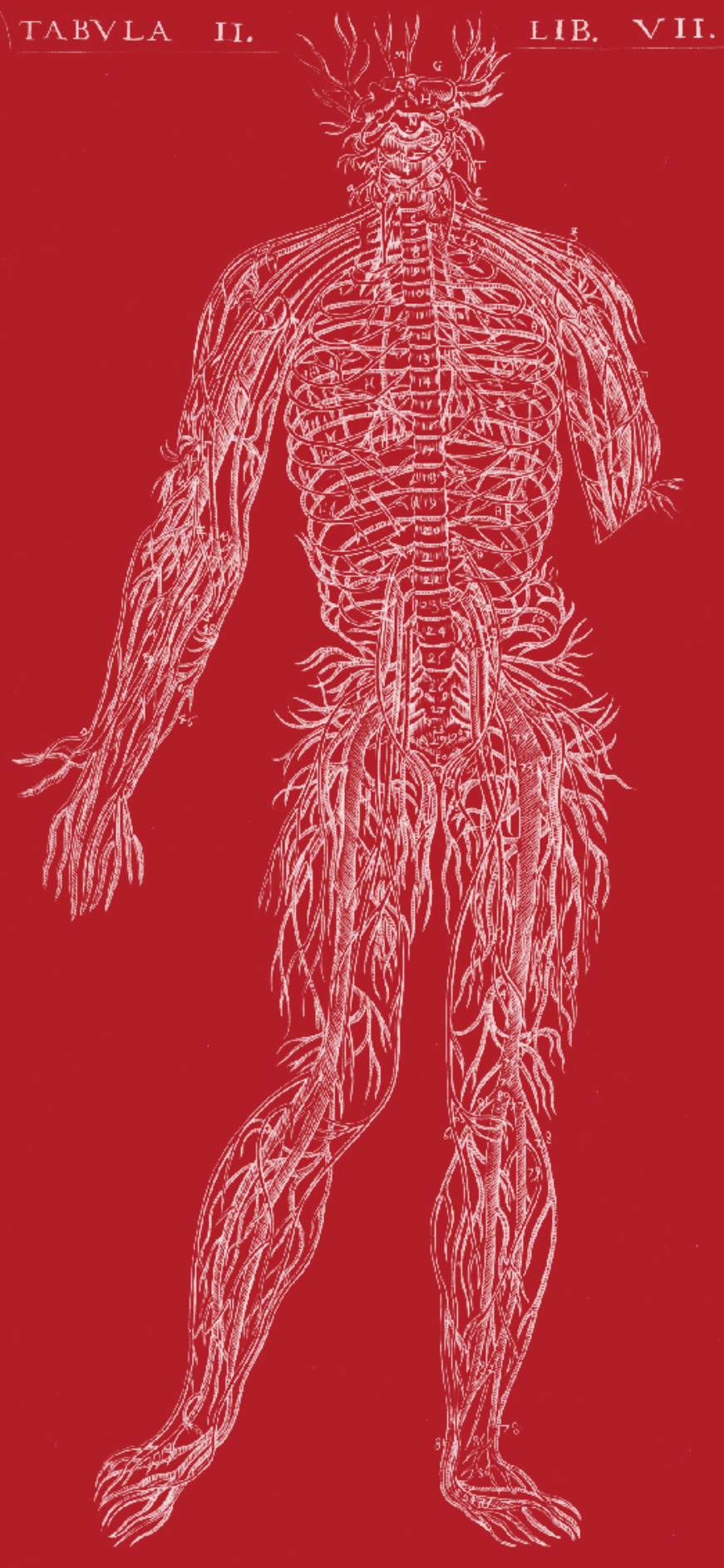

ABSTRACT

Radicular pain is an important health care problem, with only limited evidence-based treatments available Treatment selection should ideally target documented pathophysiological pathways. In herniated discs, a sequence in the inflammatory cascade can be observed that initiates and maintains increased nociceptive signal input. Inflammatory mediators including tumor necrosis factor a are released from the nucleus pulposus and the degenerating peripheral nerve, which, in turn, induces production of neurotrophins like nerve growth factor and brain-derived neurotrophic factor. Neurotrophins interfere not only with the generation of ectopic firing of nociceptive neuronsin the dorsal root ganolion but also with the excitability and sensitization of neuronal transmission in the dorsal spinal horn. Radicular pain is further characterized by the electrophysiological spreading of the afferent nociceptive input over different spinal nerve roots. Both the complex pathophysiological pathways involved and the spreading of the nociceptive signal make radicular pain difficult to treat. Pulsed radiofrequency (PRF) is considered an option in treatment of radicular pain. To understand and increase the efficiency of PRF interventional treatments in radicular pain, both in vitro and in vivo studies aiming at elucidating part of the mechanism of action of PRF are described. Potential factors that may improve the efficacy of PRF treatment in radicular pain are discussed. 


\section{RADICULAR PAIN}

Radicular pain is defined as "pain perceived as arising in a limb or the trunk wall caused by ectopic activation of Radicular pain is defined as "pain perceived as arising in a limb or the trunk wall caused by ectopic activation of nociceptive afferent fibers in a spinal nerve or its roots or other neuropathic mechanisms" (International Association
for the Study of Pain). ${ }^{1}$ Although the pathophysiology is not fully understood, radicular pain is related to lesions that either directly compromise the dorsal root ganglion (mechanically) or indirectly compromise the spinal nerve and its roots by causing ischemia or inflammation of the axons. ${ }^{1}$ In radiculopathy, there is an objective loss of sensory and/or motor function.

\section{Epidemiology of radicular pain}

Cervical radicular pain affects approximately 1 of 1000 adults $(0.1 \%)^{2}$ Lumbosacral radicular pain, described as low back pain with leg pain extending below the knee, occurs at an annual prevalence in the general population of $9.9 \%$ to $25 \% .{ }^{3}$ The point prevalence $(4.6 \%-13.4 \%)$ and lifetime prevalence $(1.2 \%-43 \%)$ are also very high, ${ }^{3}$ which means that lumbosacral radicular pain is presumably the most commonly occurring form of neuropathic pain. ${ }^{4}$ The health burden for patients with painful radiculopathy/failed back surgery is higher relative not only to othe types of neuropathic pain but also to major diseases including diabetes, heat failure, and cancer 6 Lumbosctol redicular pain completely or partially resolves in $60 \%$ of patients within 12 weeks of onset. ${ }^{7}$ However, $20 \%$ to $30 \%$ of patients have ongoing pain 3 months to 1 year after onset.

Treatment of radicular pain

Although many treatment modalities have been described for radicular pain, the available evidence is insufficient to allow recommendations about optimal therapy. At present, the conservative treatment of radicular pain combines pharmacological management and physiotherapy.-14

Interventional pain management techniques are commonly reserved for patients whose pain is refractory to conservative treatment. Evidence strongly suggests that lumbar epidural corticosteroid injections provide short-term relief of leg pain and disability following acute disc herniation. ${ }^{15}$ However, vascular complications are not uncommo and the efficacy of epidural injections for providing long-term pain relief or relief of chronic lumbosacral radicula pain is debated. Radiofrequency $(\mathrm{RF})$ may provide a good treatment option.

Two small randomized controlled trials (RCTs) have demonstrated the efficacy of RF treatment ${ }^{17}$ From these studies, one cancc results in similar pain relief as $R F$ at $40^{\circ} \mathrm{C} . .^{17}$

However, a well-designed RCT comparing RF adjacent with the lumbar DRG with a sham intervention did not demonstrate significant pain reduction for the management of lumbosacral radicular pain. ${ }^{18}$ This lack of efficacy of RF for lumbosacral radicular pain, combined with a potential risk for deafferentation pain at electrode tip temperatures above $42^{\circ} \mathrm{C},{ }^{19}$ helps explain the ongoing search for safer and more efficient techniques in clinical practice. In order to enhance therapeutic treatment options in the management of chronic pain, including radicular pain, pulsed radiofrequency (PRF) was developed. ${ }^{20}$
PRF in the management of radicular pain

The clinical pain-relieving effect of RF may arise from a number of different mechanisms, ${ }^{21}$ including heat generation and generation of an electric field that may induce changes in the neuronal cells. ${ }^{20}$ The effect 作 pates between these bursts or "pulses" of treatment. In this way, PRF treatment allows for application of the same high-voltage, fluctuating electrical fields as used during conventional RF treatment, but without electrode tip temperatures exceeding the neurodestructive temperature level of $42^{\circ} \mathrm{C} . .^{20}$

Since initial reports of PRF 15 years ago, ${ }^{20,22}$ more than 120 publications have reported on the use of this modality for the management of pain, including cervical and lumbar radicular pain. Unfortunately, most of these reports are of poor methodologic quality. The use of PRF adjacent to the cervical DRG was documented in a clinical audit, and an RCT. 2324 Both of these studies demonstrated pain reduction. In the clinical audit, the mean duration of action was 9.2 months. ${ }^{23}$ In the RCT, $82 \%$ of patients in the active treatment group reported more than $50 \%$ improvement of the global perceived effect at 3 months compared with $33 \%$ of patients in the sham group. Similarly, a 20-point pain reduction was noted in $82 \%$ and $25 \%$ of active and sham patients respectively. At 6 months, the statistical significance between groups was lost, but the need for pain medication remained significantly reduced in the active treatment group. ${ }^{24}$

Several retrospective and prospective clinical studies on the use of PRF applied adjacent to the lumbar DRG suggest an effect on pain reduction. ${ }^{25} \mathrm{~A}$ recent clinical audit noted that a single PRF treatment adjacent to a single lumbar DRG reduced both pain and the need for pain medication for $29.5 \%$ of all the patients at 2 months. After 12 months $13.1 \%$ still reported > 50\% pain reduction. ${ }^{2 .}$

In summary, despite the large number of publications on the use of PRF, the clinical evidence for the use of PRF for the management of cervical and lumbosacral radicular pain remains limited. This is due not only to the lack of large RCTs but also to an inadequate understanding of underlying pain and treatment mechanisms. In order to improve existing treatments for radicular pain, it is of pivotal importance to understand the mechanism of action of PRF. The cellular and molecular changes induced by PRF and their relationship to the development of radicular pain should be investigated and may, in turn, lead to more effective clinical use of PRF in the management of radicular pain. Mechanistically, radicular pain is characterized by spreading of the afferent nociceptive input (see Radicular Pain: Spreading of the Nociceptive afferent Signal section) combined with complex cellular and molecular processes (see Radicular Pain: Cellular and Molecular Mechanisms section) that initiate and maintain the increased nociceptive signal input. 


\section{GELLULAR AND MOLECULAR CHANGES IN RADICULAR PAIN}

Radicular Pain: Spreading of the Nociceptive Afferent Signal

The spread of radicular pain to adjacent spinal segments has been demonstrated in human studies. ${ }^{26}$ Quantitative sensory testing (QST) was performed in patients with lumbar radiculopathy, using vibrametry and thermal threshold detection. Thi allowed study of sensory nerve function in not only the compressed nerve root or DRG but also in neighboring uncompressed nerve roots (Fig. 1). No significant differences between the dermatome of the involved nerve root and the ipsilateral neighboring dermatome were noted, despite significant differences from a contro group. ${ }^{26}$ These findings suggest involvement of adjacent nerve roots in the pathophysiology of radicular pain in human.

The complexity of lumbar radicular pain signaling was further demonstrated based on electrophysiological recordings of nociceptive specific neurons in Lamina I of the dorsal horn and of neurons related to the lateral spinal nucleus neurons (located in the dorsolateral funiculus). At spin segments L3 and L4, both Lamina I and lateral spinal nucleus neurons received mixed excitatory $\mathrm{A} \delta$-fiber and C-fiber nociceptive afferent input from up to 6 dorsa roots, with less than one-third arising from the corresponding segmental root. ${ }^{27}$

To summarize, both anatomical 28,29 and electrophysiological studies ${ }^{27}$ suggest that the spreading of radicular pain to involve adjacent spinal segments is a well-recognize phenomenon (Fig. 1). This supports the common clinical observation of involvement of multiple nerve roots, despite single level of pathology. The involvement of adjacent areas also has profound implications for targeted therapies.

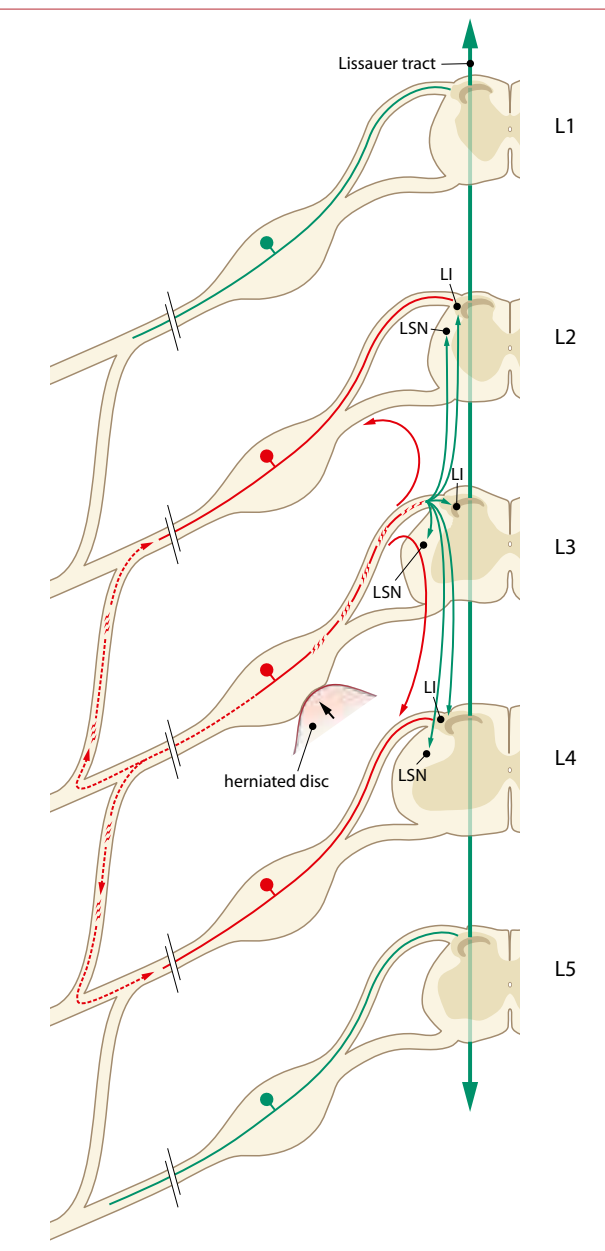

\section{$\longrightarrow$ Centrally mediated antidromic A.P. in adjacent dorsal roo}

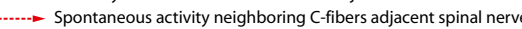

LI through possible nevily

Normal anatom
Activated DRG

Figure 1: Schematic representation of the electrophysiologic spreading of the pain signal from a nerve root.

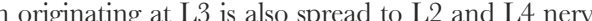
Poots and to different levels of the spinal cord. Illustration: Rogier Trompert, Medical Art, www.medical-art.eu.
Radicular Pain: Cellular and Molecular Mechanisms

Peripheral injury to the sensory axons leads to major molecular and cellular changes, not only at the level of the axon but also within cells of origin in the DRG. Using whole genome expreshanges in gene expesion in the L5 and L4 DRGs occul ${ }^{30}$ In this SNL mouse model of neuropathic pain, a total of 2552 transcripts were significantly up-regulated in the axotomized L5 DRG 3 days postoperatively. A few genes in the uninjured L4 DRG also showed altered expression. These genes may be associated with pain-related sprouting but also regeneration and apoptosis. Further study is needed to determine which genes and proteins are associated with pain behavior. Although the spreading of the radicular afferent signal is a complex phenomPence a the inflammatory cascade is apparent (Fir. 2). Beginning with the disc degenerating nerve, pro-inflammatory cytokines are released at the site of lesion and at a distance through Wallerian Degeneration (WD) (See The Herniated Disc, the Degenerative Nerve Root, and the Role of Tumor Necrosis Factor a and Neurotrophins section). This causes ectopic firing at the DRG (see At the DRG: Ectopic Firing section), leading to an increased release of neurotrophins and ectopic firing at the dorsal horn, eventually leading to central sensitization (see In the Dorsal Horn: Central Sensitization and the Role of BDNF section).

The herniated disc, the degenerating nerve root, and the role of TNF-alpha and neurotrophins $\bullet$ The cellular-molecular cascade may either start from the herniated disc (a), or the degenerating peripheral nerve (b). (Fig. 2). In both cases, the inflammatory cascade is initiated by the release of specific inflammatory mediators. Cytokines, in particular tumor necrosis factor-a (TNF-a), are thought to play an important and initiating role, especially in the induction of neurotrophin production and/or release. Increased local neurotrophin concentrations activate satellite glial cells and attract adjoining immune modulating cells, which changes the local micro-environment of the DRG neurons and those in the spinal dorsal horn but also directly interferes with the sensitization of synaptic transmission (for review see ${ }^{31}, 32$ ). Following disc herniation, the site of injury as related to the DRG is also of significant importance (c).

Herniated disc, nucleus pulposus and TNF-a. • The extrusion of material from the nucleus pulposus onto the spinal nerve leads to edema and ischemia. Experimental work has shown that exposure of nerve root (proximal to the DRG) to material from the nucleus pulposus material increased endoneurial fluid pressure and decreased blood flow into the DRG with secondary edema. ${ }^{33}$ Clinical confirmation was lacking until further study examined the effect of intraoperative straight-legraising test (SLR) after lumbar disc herniation. ${ }^{34}$ A direct correlation was established between a sharp decrease in S1 spinal nerve blood flow during SLR, and deterioration of compound muscle action potential amplitudes from the gastrocnemicus muscle. Hence, mechanical compression or stretching of affected spinal nerves clearly causes conduction disturbances.

A key mediator released after disc herniation, is the pro-inflammatory cytokine TNF-a. When TNF-a reaches the nerve root, production of the neurotrophic factor Nerve Growth Factor (NGF) in the surrounding inflamed tissue is initiated. ${ }^{32,35,36}$ This, in turn, induces the production of another neurotrophin, brain-derived neurotrophic factor (BDNF), in the DRG. ${ }^{36,37}$ Besides their neurotrophic qualities, such as the induction of nerve sprouting, both NGF and BDNF are also recoonized as important factors in the development of central sensitization ${ }^{38}$ and may play an important role in the pathophysiology of radicular pain. The release of cytokines may also directly interfere with both activity and expression of various ion-channels in the DRG. ${ }^{39}$ 
Degenerating peripheral nerve, Wallerian Degeneration and TNF-a $\cdot$ The developmen of radicular pain may also involve the degenerating peripheral nerve. During degeneration of the distal axon by Wallerian Degeneration,TNF- $a$ is released by Schwann cells, endothelial cells, mas cells, and resident macrophages at the site of nerve injury. TNF-a modulates NGF signaling, ${ }^{40}$ which can be transported retrogradely to ascending neurons and glia along the sensory pathway, thereby sensitizing the nervous system. ${ }^{41}$ NGF has been proposed as an important "guidance" molecule for the sympathetic invasion and sprouting of sympathetic axons into the DRG. ${ }^{42,43}$ How thi sympathetic sprouting contributes to the clinical symptoms of radicular pain remains unknown. Increased levels of cytokines including TNF-a and neurotrophins including BDNF within the DRG, produce a state of increased excitability and ectopic firing. (See At the DRG: Ectopic Firing section)

Site of injury as related to the DRG: transport of neurotrophins • The site of injury (or compression) of the nerve root in relation to the DRG plays an important role in the pathophysiology of radicular pain. Lumbar disc herniation can be categorized as (para)central, sub-articula (lateral recess), foraminal, or extraforaminal. Herniated discs in these regions, therefore, will mainly interfere with nerve roots proximal to the DRG. To produce compression of the DRG against the pedicle, the annulus fibrosus must be breached laterally in a location that allows migration of extruded material upward from the disc level to the infrapedicular level (upper foraminal) level to compress the ganglion; this does occur but is uncommon. ${ }^{4}$

As discussed, interference of NGF and/or BDNF with local sprouting ${ }^{42}$ and the neurotrophic factor-induced modulation of synaptic transmission in the spinal cord is only possible through retrograde transport of these factors in uninjured sensory afferent axons. ${ }^{45-47} \mathrm{It}$ is thus understandable that a nerve root injury proximal to the DRG (a routine herniated disc) as compared with an injury distal to the DRG may interfere with the retrograde and anterograde transport of neurotrophic factors. Experimental work has shown that neurotrophins and the transport of neurotrophin significantly interferes with sprouting (formation of functional connections after damage to neighboring axons) of uninjured (sympathetic) fibers as well as the state of excitability of neurons in the $D_{R G}^{47-51}$ (Fig. 2, also see At the DRG Ectopic Firing section).

In summary in the common conditions that lead to radicular pain, inflammatory mediators like TNF- $a$ are released from the nucleus pulposus and the degenerating peripheral nerve. This induces production of neurotrophins, including NGF and BDNF. The axonal transport of these neurotrophins is related to the site of injury of the nerve root in relation to the DRG. Neurotrophin interfere with the excitability and sensitization of neuronal transmission in the dorsal spinal horn and in the generation of ectopic firing of nociceptive neurons in the DRG.

\section{At the DRG: ectopic firing}

In radicular pain, ectopic discharges can be generated at different locations of the nervous system. Based on a selected experimental lesion model, (modified spinal nerve ligation), ${ }^{52}$ the primary lesion (L5 spinal nerve section) resulted in generation of discharges originating not only at the site of nerve injury but also in the somata of cell bodies of the axotomized DRG neurons ${ }^{53}$ From electrophysiological analysis it was calculated that about $75 \%$ of the overall ectopic firing was generated a the DRG and only $25 \%$ at the lesion or neuroma. ${ }^{54}$ This finding, currently only documented for the SNL model, requires confirmation in other animal models before it can be generalized. Importantly if this concept is replicated, it may have important clinical ramifications for targeted interventional pain treatment.

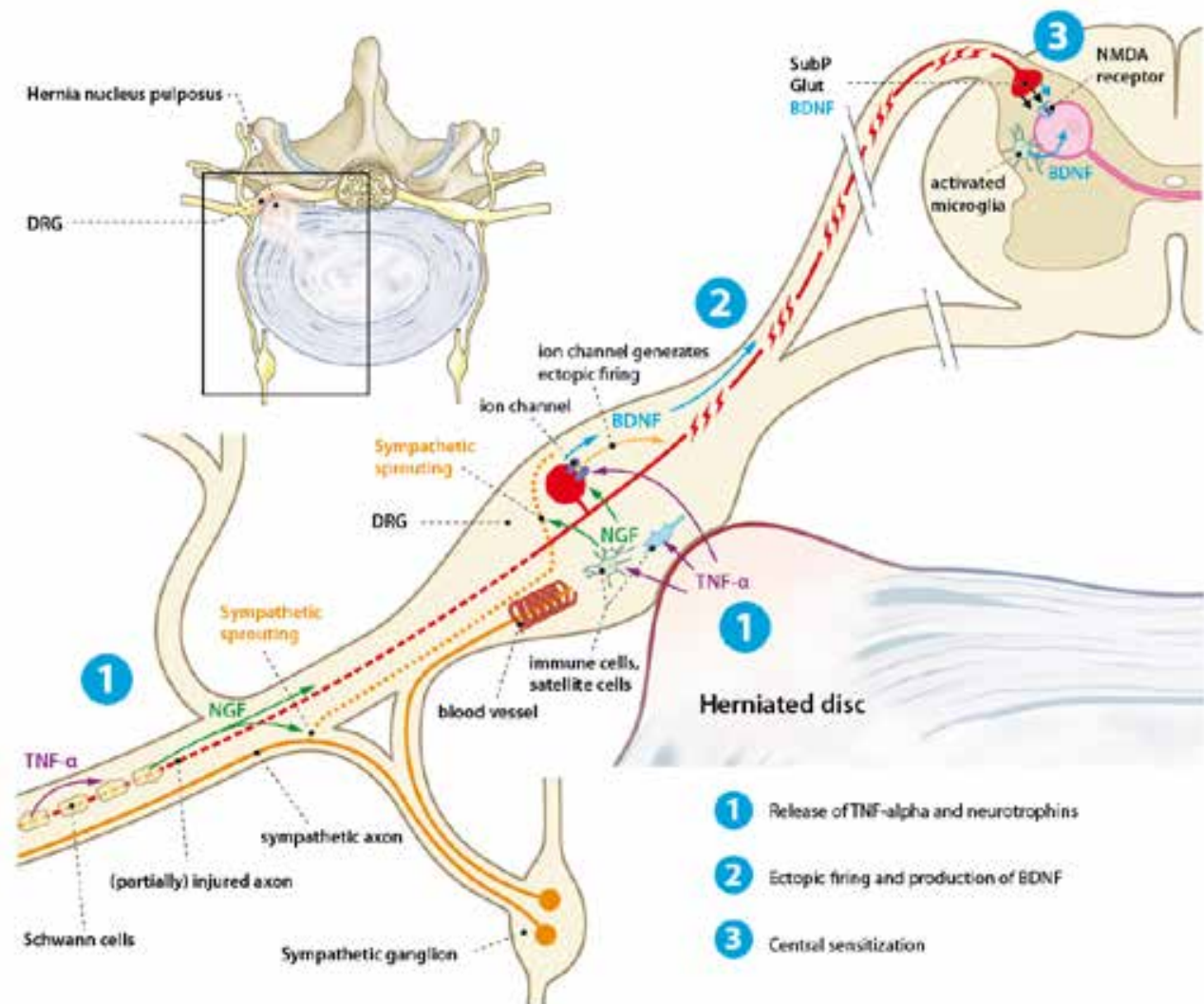

Figure 2: Schematic representation of the inflammatory cascade starting from herniated disc and/or degenerating nerve. Illustration: Rogier Trompert, Medical Art, www.medical-art.eu.

Correspondingly, the failure of L5 dorsal rhizotomy to prevent or reverse the hyperalgesia associated with a L5 spinal nerve ligation indicates that ectopic discharges from uninjured DRG neurons and not those of injured ones are possibly important in the development of neuropathic pain. ${ }^{53}$

Cytokines and neurotrophins can initiate modulation and phosphorylation of ion channels, which forms the basis for generation of ectopic action potentials or ectopic firing ${ }^{55,56}$ and this, in turn, is causally related to the pain-related behavioral changes in the operated animals. ${ }^{56}$ Since repetitive firing of the pain afferents forms the physiological reason for central sensitization ${ }^{57}$ (see section 2.2.3), this clearly contributes to the clinical syndrome of radicular pain.

In summary, trauma to nerve roots and the DRG lead to significant changes in ion-channels at both injured and adjacent uninjured DRGs, leading to ectopic firing and evidence of central sensitization. In the dorsal horn: central sensitization and the role of BDNF • Ectopic discharges that reach the dorsal horn can activate postsynaptic pain neurons due to an increase in synaptic efficacy ${ }^{58}$ via modulation of the neurotransmitter glutamate and the neuromodulators substance-P and BDNF. ${ }^{45}$ 
Furthermore, ectopic firing induces microglia activation, leading to the production of spinal microglial-derived BDNF. Hence, increased levels of BDNF at the nociceptive synapse in the spinal dorsa horn are due to both direct release of neuronal BDNF and additional release of microglial BDNF. Mechanistically, the binding of BDNF with its receptor, tyrosine kinase receptor B $(\operatorname{trkB}){ }^{46}$ results in interference with the opening of the NMDA channels important for the process of central sensitization, ${ }^{45,57,59-61}$ and, furthermore, regulates neuronal survival, differentiation, dendritic morphology, and synaptic plasticity.

After experimental compression of the nerve root, electrophysiological changes are found in the spinal dorsal horn, with edema formation noted in the upper spinal dorsal horn laminae. The latter phenomenon, in conjunction with damage to the spinal cord-blood barrier, leads to shrinkage of the axon terminals in these dorsal horn laminae. ${ }^{47}$ This degenerative process is characterized by ongoing ectopic firing and enhanced excitatory synaptic transmission in neurons in these dorsal horn laminac at each segmental level ${ }^{63}$ and has been shown to contribute to further spreading of the incoming afferent nociceptive signal.

In summary, ectopic firing from the DRG and increased neurotrophin (eg, BDNF) in the spinal dorsa horn induce a cascade of mechanisms that sensitize the transmission of afferent nociceptive input.

Radicular pain: distinctive features?

Although medical evidence supports the routine use of medications including tricyclic antidepressants and gabapentin/pregabalin for peripheral neuropathy, ${ }^{64}$ the evidence is far less clear fo radicular pain. ${ }^{8}, 65$ Different hypotheses can be formulated to address the question of why (lumbosacral) radicular pain is relatively refractory to existing first- and second-line neuropathic pain medications. ${ }^{14}$ First, the anatomic location of the DRG relative to a herniated disc is likely crucial, with secondary inflammation, localized compression, and/or ischemia of the DRG. The DRG may be particularly vulnerable to mechanical compression, due to specific leakage of inflammatory material from the disc (see Herniated disc, nucleus pulposus, and TNF-a section) and abundant blood vessels nourishing the nerve cells..$^{66,6}$

As mentioned, the foraminal localization of a herniated disc, with inhibition of retrograde transport of neurotrophins (see Site of injury as related to the DRG: transport of neurotrophins section) can influence a "normal" evolution of neuropathic pain. The exact site of pathology relative to the DRG further affects the type of sympathetic basket formation ${ }^{43}$ (abnormal sympathetic terminal arborizations around some DRG neurons) and the intensity of ectopic firing ${ }^{54}$ (see Degenerating peripheral nerve, WD, And TNF-a section), although it must be noted that the latter has been demonstrated only in a spinal nerve injury model. In what way the type of sympathetic basket formation influences the clinical picture of radicular pain is not known. The intensity of ectopic firing may explain the clinical picture, since an axotomy close to the DRG creates more intense firing of the DRG compared with burden of painful radiculopathy/failed back surgery patients compared with other types of neuropathic pain. ${ }^{6}$ Conversely, the potential for ectopic firing in the presence of an external stimulus is large after a distal lesion than a proximal injury. This may explain the clinical observation that in cases of peripheral neuropathy, allodynia and hyperalgesia are common but are less frequently documented in cases of lumbosacral radicular pain.68,

Collectively factors including: the specific location of the lesion relative to the DRG and/or herniated disc; interference with neurotrophin transport; and differences in expression of ion channels create a distinctive pathophysiology that may explain why treatment focusing on a single inflammatory proces may fail. ${ }^{65}$ To improve pharmacological and interventional treatments in radicular pain, we must improve our knowledge of the underlying mechanisms in relation to the spreading of the signal and how these treatments may interfere with the nociceptive afferent signal. PRF is an interventional treatment that creates a stronger electro-magnetic field than conventional RF, potentially disrupting the pathophysiological processes underlying radicular pain in a large area. In the following section, the scientific studies that partly elucidate the mechanism of action of PRF in experimental radicular and neuropathic pain models are discussed and suggestions for future studies are presented.

\section{MEGHANISM OF AGTION OF PRF AND RADICULAR PAIN}

PRF was developed to reduce or even avoid neuronal damage, making it potentially suitable for patients with neuropathic pain. ${ }^{20} \mathrm{~A}$ computer modeling study based on data obtained in ex vivo tissue showed that PRF does, however, produce heat bursts with temperature peaks that may induce neurodestruction. Furthermore, PRF produces strong electro-magnetic fields that may be capable of disrupting the neuronal membranes, thereby interfering with the generation of action potentials and ectopic firing. ${ }^{70}$ The mechanisms underlying PRF therapy in neuropathic pain have been determined

\section{In vitro studies}

Studies on hippocampal slice cultures compared conventional $\mathrm{RF}$ at $42^{\circ} \mathrm{C}$ with PRF. PRF was found to be less neurodestructive than conventional RF with a limited and temporary effect on impulse propagation in the nerve tissue.

\section{In vivo studies}

Anatomical • Increased expression of c-Fos, an immediate early gene used as a marker for neuronal activity, was detected in the dorsal horn 3 hours after PRF treatment adjacent to the DRG, but not after $\mathrm{RF}^{72}$ This differential response in c-Fos expression after PRF treatment adjacent to the DRG as compared with RF-treatment disappeared after 7 days. $^{73}$ These findings suggest that early-phase, but not late-phase, effects of RF and PRF on neuronal activation in the spinal cord differ. It should be noted that c-Fos is a limited marker of neuronal activity and does not differentiate the possible effects of RF and/or PRF on afferent pain signaling.

Application of PRF adjacent to the DRG but not at the sciatic nerve resulted in an up-regulation of activating transcription factor 3 (ATF-3), a marker of cellular stress, in both small and medium caliber neurons of the DRG.7. Immunochemical observations suggest that the application of PRF adjacent to the DRG is related to a short- and a long-term increase in neuronal markers in the DRG and the dorsal horn.

Electron microscopic studies demonstrated only small histological changes after use of PRF adjacent to the DRG: the changes included enlarged endoplasmic reticulum cisterns or increased cytoplasm vacuoles. Conversely, $\mathrm{RF}$ at $67^{\circ} \mathrm{C}$ resulted in significant changes, e.g. mitochondrial degeneration and a loss of nuclear membrane integrity. ${ }^{756}$

An effect was seen on myelinated nerve fibers after the application of RF or PRF on the sciatic nerve. RF resulted in severe Wallerian degeneration of the distal peripheral nerve, in contrast to the PRF group, where only changes in myelin configuration were observed. ${ }^{77}$ Nevertheless, small electron microscopic changes have also been observed after application of PRF on the sciatic nerve, although mainly restricted to the unmyelinated C-fibers and the thinly myelinated A- $\delta$ fibers ${ }^{78}$ This preferential effect of PRF on the nociceptive $\mathrm{C}$ - and $\mathrm{A}-\delta$ fibers might explain differential analgesic effects without greatly interfering with the tactile sensory input. 
In summary, the histological data suggest that PRF is less neurodestructive than RF. PRF targets primarily the nociceptive $\mathrm{C}$ and $\mathrm{A}-\delta \mathrm{\delta}$ axons, and immunochemistry reveals short- and long-term changes in neuron markers in the dorsal horn and DRG.

Behavioral studies • Various experimental neuropathic pain models show the pain-relieving effect of PRF on mechanical hypersensitivity, and sometimes on thermal allodynia ${ }^{79,80-84}$ (Table 1 ).

There are indications that these behavioral responses are accompanied by a glial response at the dorsa horn, since a reduction of OX42, a microglial marker, was reported. ${ }^{82,84}$ Additionally, the level of MetEnkephalin in the dorsal horn was significantly increased in the spinal cord in the first 24 hours after PR application, suggesting a possible role for endogenous opioids ${ }^{85}$

PRF effects on thermal allodynia have been shown to be attenuated through not only the intrathecal administration of an alpha2-adrenoceptor antagonist, but also application of a selective 5-HT3 serotoni receptor antagonist and a nonselective serotonin receptor antagonist. These observations suggest that the analgesic effect of PRF may involve descending noradrenergic and serotonergic inhibitory pathways. ${ }^{85}$ The latter pathways are known to be involved in the modulation of neuropathic pain. ${ }^{82,85,86}$

A critical factor in behavioral pain assessment in these experimental animal studies and their use for clinical translation is the problem of evoked and reflexive assessments. This method of assessment clearly differs from clinical assessment of pain sensitivity in humans and may partially explain the relatively limited translation of experimental animal findings into clinical breakthroughs. It must be stressed that effects on pain sensitivity analyzed in animal models based on cortically dependent operant testing may well become the new gold-standard and finally result in increased translation of results from the laboratory into the clinic. In summary, the number of publications on PRF in animal models is limited, with a large variability in location and timing of PRF and similar variability in outcomes. Behavioral studies demonstrate reduction in pain behavior after PRF treatment in chronic neuropathic pain animal studies. The magnitude and duration of effect is equally variable in these models and remains unclear

\section{Summary conclusions: mechanism of action of PRF and radicular pain}

Although our understanding of the pathophysiology and mechanisms of radicular pain have improved, see Cellular and molecular changes in radicular pain section), further study is needed to evaluate potential interference and modulation from PRF interventional techniques. Limited data surgest that PR results in behaviorally detectable pain relief in experimental radicular and neuropathic pain models, which is accompanied by cellular changes at the DRG and spinal horn. However the precise interference of PRF with:1) inflammatory responses induced by a herniated disc and WD (seeThe Herniated Disc, the Degenerating Nerve Root and the Role of Tumor Necrosis Factor a and Neurotrophins section); 2 enhanced ectopic firing at the DRG (see At the DRG: Ectopic Firing section); 3) central sensitization and release of BDNF in the spinal dorsal horn (see In the dorsal Horn: Central sensitization and the Role of BDNF section) and other mechanisms of radicular neuropathic pain are not clear. Future research should systematically analyze the experimental effects of PRF on these distinct cellular-molecular processes underlying radicular pain. Currently, most experimental studies on PRF in radicular and neuropathic pain have focused on optimization of the behavioral pain-relieving effect of PRF based on finite and discrete anatomic locations, on temporal features, and on the use of different pulse stimulation-parameters. ${ }^{82,88,89}$ 
IMPROVEMENT OF PRF TREATMENT EFFICACY IN RADIGULAR PAIN:

EXTRAPOLATION OF BASIC SCIENCE INTO CLINICALLY MEANINGFUL RESULTS

Given the heterogeneity of the published PRF studies, advancing the field will require improving ou research efficiency. Toward that goal, let us critically look at the newly presented evidence, specifically the issues of location, timing, and optimal parameters of PRF.

Location • The spreading of the signal to adjacent segments challenges the concept of PRF applied at adjacent to the $\mathrm{DRG}$ at the involved level, is based on conventional radiofrequency treatment with the reduction of nociceptive input of the primary sensory neuron by coagulation and WD of a small par of the DRG.$^{18}$ From animal experiments however, this approach is questionable since a selective L dorsal rhizotomy does not prevent or reverse neuropathic behavior after a L5 Spinal Nerve Ligation. ${ }^{9}$ This implies that reducing the nociceptive input at the concerned level is not enough, probably due to the spreading of the afferent nociceptive signal over different adjacent levels. Therefore, performing (pulsed) radiofrequency treatment at multiple adjacent levels might be required to improve efficacy.

The precise way in which PRF interacts with the afferent nociceptive signaling in lumbosacral radicular pain remains unclear. On the basis of the cellular and molecular mechanism underlyin radicular pain as discussed in Radicular Pain: Cellular and Molecular Mechanisms section (see also Fig. 2) it can be hypothesized that PRF, even if applied at 1 defined location, may act at various level in the system, including 1) the direct activation of cells in the DRG or spinal cord; 2) interference with retrograde transport of neurotrophins at the level of the dorsal root secondary to edema; and 3 ) interference with processes in the dorsal spinal horn that minimize microglial activity/stimulation and enhancement of endogenous opioids which inhibit the nociceptive incoming signal. Consequently the optimal location for PRF treatment (percutaneous, sciatic nerve, DRG) is not yet established.79,85

Timing • Experimental and clinical data regarding the timing of the effect of PRF in the treatmen of neuropathic and radicular pain are not conclusive but strongly sugest that this effect is temporay. persistent inflammation in radicular pain.

Parameters • PRF parameters such as voltage, frequency, and duration of treatment have been empirically selected. Information on the effect of various parameters can, as yet, not be derived from the published animal studies because the treatment protocols vary without exception, hindering both interpretation of the data and verification. Moreover, some results seem contradictory. Hence, it is recommended to analyze the effect of PRF treatment parameters through mechanism-based experimental study. Standardization among the various animal models used in PRF studies would greatly benefit the interpretation

\section{GONGLUSION}

Afferent signaling in radicular pain is complex, but important events in the inflammatory cascade can be noted. The specific location of the lesion relative to the DRG and/or herniated disc, interference with neurotrophin transport and differences in expression of ion channels create a distinctive pathophysiology. Furthermore, there are strong indications that adjacent levels contribute to pain conduction. Findings in basic science provide a basis for investigating the value of treatment at different levels in future clinical research. This finding is important when target-specific interventional treatment approaches, such as PRF, are used.

The potential effect on multiple levels of afferent pain signaling, together with its lack of reported side effects, creates opportunities for PRF in treating radicular pain. With respect to the underlying mechanism of action of PRF in relation to the cellular and molecular changes in radicular pain, future research is needed. Determining the exact impact of PRF on radicular pain signaling requires systematic analysis and use of standardized PRF parameters in order to document the effects of stimulation intensity, frequency, and duration in treatment of radicular pain. Well-designed randomized controlled trials are required to identify the beneficial effect of PRF arjacent to the DRG for radicular pain. 
References

1. Merksey, Bogduk N. Descriptions of Chronic Pain Syndromes and Definitions of Pain Terms. Seattle, Washington: IASP Press; 1994

2. Radhakrishnan K, Litchy WJ, O'Fallon WM, Kurland LT. Epidemiology of cervical radiculopathy. population-based study from Rochester, Minnesota, 1976 through 1990. Brain. 1994: 117 (Pt 2):325335 .

3. Konstantinou K, Dunn KM. Sciatica: review of epidemiological studies and prevalence estimates. Spine (Phila Pa 1976). 2008; 33:2464-2472

4. Khoromi S, Patsalides A, Parada S, Salehi V, Meegan JM, Max MB. Topiramate in chronic lumbar radicular pain. J Pain. 2005;6:829-836.

5. Dworkin RH, O'Connor AB, Backonja M, Farrar JT, Finnerup NB, Jensen TS, Kalso EA, Loeser JD, Miaskowski C, Nurmikko TJ, Portenoy RK, Rice AS, Stacey BR, Treede RD, Turk DC, Wallace MS. Pharmacologic management of neuropathic pain: evidence-based recommendations. Pain. 2007; 132:237-251

6. Doth AH, Hansson PT, Jensen MP, Taylor RS. The burden of neuropathic pain: a systematic review and meta-analysis of health utilities. Pain. 2010; 149:338-344.

7. Weber H, Holme I, Amlie E. The natural course of acute sciatica with nerve root symptoms in a double-blind placebo-controlled trial evaluating the effect of piroxicam. Spine. 1993: 18:1433-1438.

8. Pinto RZ, Maher CG, Ferreira ML, Ferreira PH, Hancock M, Oliveira VC, McLachlan AJ, Koes B. Drugs for relief of pain in patients with sciatica: systematic review and meta-analysis. BMJ. 2012, 344:e497.

9. Luijsterburg PA, Verhagen AP, Ostelo RW, van Os TA, Peul WC, Koes BW. Effectiveness of conservative treatments for the lumbosacral radicular syndrome: a systematic review. Eur Spine J. 2007; 16:881-899.

10. Luijsterburg PA, Verhagen AP, Ostelo RW, van den Hoogen HJ, Peul WC, Avezaat CJ, Koes BW. Physical therapy plus general practitioners'care versus general practitioners'care alone for sciatica: randomised clinical trial with a 12-month follow-up. Eur Spine J. 2008; 17:509-517.

11. Albert HB, Manniche $C$. The efficacy of systematic active conservative treatment for patients with severe sciatica: a single-blind, randomized, clinical, controlled trial. Spine (Phila Pa 1976). 2012; 37:531-542.

12. Thoomes EJ, Scholten-Peeters W, Koes B, Falla D, Verhagen AP. The Effectiveness of Conservative Treatment for Patients With Cervical Radiculopathy: A Systematic Review. Clin J Pain.2013. Feb 26 [Epub ahead of print]

13. Jacobs WC, van Tulder M, Arts M, Rubinstein SM, van Middelkoop M, Ostelo R, Verhagen A, Koes $B$, Peul WC. Surgery versus conservative management of sciatica due to a lumbar herniated disc: systematic review. Eur Spine J. 2011; 20:513-522.

14. Dworkin RH, O'Connor AB, Audette J, Baron R, Gourlay GK, Haanpaa ML, Kent JL, Krane EJ Lebe $A A$, Levy RM, Mackey SC, Mayer J, Miaskowski C, Raja SN, Rice AS, Schmader KE, Stacey B, Stanos $S$, Treede RD, Turk DC, Walco GA, Wells CD. Recommendations for the pharmacological management of neuropathic pain: an overview and literature update. Mayo Clin Proc. 2010; 85:S3-14

15. Pinto RZ, Maher CG, Ferreira ML, Hancock M, Oliveira VC, McLachlan AJ, Koes B, Ferreira PH. Epidural corticosteroid injections in the management of sciatica: a systematic review and metaanalysis. Ann Intern Med. 2012; 157:865-877.

16. van Kleef M, Liem L, Lousberg $R$, Barendse G, Kessels F. Sluijter M. Radiofrequency lesion adjacent to the dorsal root ganglion for cervicobrachial pain: a prospective double blind randomized study. Neurosurgery. 1996; 38:1127-1131.
17. Slappendel R, Crul BJ, Braak GJ, Geurts JW, Booij LH, Voerman VF, de Boo T. The efficacy of radiofrequency lesioning of the cervical spinal dorsal root ganglion in a double blinded randomized study: no difference between 40 degrees $C$ and 67 degrees C treatments. Pain. 1997;73:159-163.

18. Geurts JW, van Wijk RM, Wynne HJ, Hammink E, Buskens $E$, Lousberg R, Knape JT, Groen GJ. Radiofrequency lesioning of dorsal root ganglia for chronic lumbosacral radicular pain: a randomised, double-blind, controlled trial. Lancet. 2003;361:21-26.

19. Sluijter ME. Radiofrequency part I: Flivopress, Meggen, Switzerland; 2001

20. Sluijter ME, Cosman ER, Rittman IIWB, van Kleef M. The effects of pulsed radiofrequency field applied to the dorsal root ganglion - a preliminary report. The Pain Clinic. 1998;11:109-117.

21. van Kleef M, Spaans F, Dingemans W, Barendse GAM, Floor E, Sluijter ME. Effects and side effects of a percutaneous thermal lesion of the dorsal root ganglion in patients with cervical pain syndrome. Pain. 1993: 52:49-53.

22. Munglani R. The longer term effect of pulsed radiofrequency for neuropathic pain. Pain. 1999; 80:437-439

23. Van Zundert J, Lamé IE, de Louw A, Jansen J, Kessels F, Patijn J, van Kleef M. Percutaneous Pulsed Radiofrequency Treatment of the Cervical Dorsal Root Ganglion in the Treatment of Chronic Cervical Pain Syndromes: A Clinical Audit. Neuromodulation. 2003; 6:6-14.

24. Van Zundert J, Patijn J, Kessels A, Lame I, van Suijlekom H, van Kleef M. Pulsed radiofrequency adjacent to the cervical dorsal root ganglion in chronic cervical radicular pain: a double blind sham controlled randomized clinical trial. Pain. 2007; 127:173-182.

25. Van Boxem K, van Bilsen J, de Meij N, Herrler A, Kessels F, Van Zundert J, van Kleef M. Pulsed radiofrequency treatment adjacent to the lumbar dorsal root ganglion for the management of lumbosacral radicular syndrome: a clinical audit. Pain Med. 2011; 12:1322-1330.

26. Nygaard OP, Mellgren SI. The function of sensory nerve fibers in lumbar radiculopathy. Use of quantitative sensory testing in the exploration of different populations of nerve fibers and dermatomes. Spine. 1998; 23:348-352.

27. Pinto V, Szucs P, Lima D, Safronov BV. Multisegmental A\{delta $\}$ - and C-fiber input to neurons in lamina I and the lateral spinal nucleus. J Neurosci. 2010; 30:2384-2395.

28. Wall PD, Lidierth M, Hillman P. Brief and prolonged effects of Lissauer tract stimulation on dorsal horn cells. Pain. 1999; 83:579-589.

29. Lidierth M. Long-range projections of Adelta primary afferents in the Lissauer tract of the rat. Neurosci Lett. 2007; 425:126-130.

30. Persson AK, Gebauer M, Jordan S, Metz-Weidmann C, Schulte AM, Schneider HC, Ding-Pfennigdorff $D$, Thun J, Xu XJ, Wiesenfeld-Hallin Z, Darvasi A, Fried K, Devor M. Correlational analysis for identifying genes whose regulation contributes to chronic neuropathic pain. Mol Pain. 2009; 5:7.

31. Klusakova I, Dubovy P. Experimental models of peripheral neuropathic pain based on traumatic nerve injuries - an anatomical perspective. Ann Anat. 2009;191:248-259.

32. Woolf CJ, Allchorne A, Safieh-Garabedian B, Poole S. Cytokines, nerve growth factor and inflammatory hyperalgesia: the contribution of tumour necrosis factor alpha. Br J Pharmacol. 1997;121:417-424.

33. Yabuki S, Kikuchi S, Olmarker K, Myers RR. Acute effects of nucleus pulposus on blood flow and endoneurial fluid pressure in rat dorsal root ganglia. Spine (Phila Pa 1976). 1998; 23:2517-2523.

34. Kobayashi S, Shizu N, Suzuki Y, Asai T, Yoshizawa H. Changes in nerve root motion and intraradicular blood flow during an intraoperative straight-leg-raising test. Spine (Phila Pa 1976). 2003; 28:14271434

35. Onda A, Murata Y, Rydevik B, Larsson K, Kikuchi S, Olmarker K. Immunoreactivity of brain-derived neurotrophic factor in rat dorsal root ganglion and spinal cord dorsal horn following exposure to 
the rat is not dependent on input from injured nerve fibers. Pain. 2000; 85:493-502.

herniated nucleus pulposus. Neurosci Lett. 2003; 352:49-52

36. Obata K, Tsujino H, Yamanaka H, Yi D, Fukuoka T, Hashimoto N, Yonenobu K, Yoshikawa H, Noguchi K. Expression of neurotrophic factors in the dorsal root ganglion in a rat model of lumbar disc herniation. Pain. 2002; 99:121-132.

37. Matsuoka Y, Yang J. Selective inhibition of extracellular signal-regulated kinases 1/2 blocks nerve growth factor to brain-derived neurotrophic factor signaling and suppresses the development of and reverses already established pain behavior in rats. Neuroscience. 2012; 206:224-236.

38. Van Zundert J, Harney D, Joosten EA, Durieux ME, Patijn J, Prins MH, Van Kleef M. The role of the dorsal root ganglion in cervical radicular pain: diagnosis, pathophysiology, and rationale for treatment. Reg Anesth Pain Med. 2006;31:152-167.

39. Bauer CS, Nieto-Rostro M Rahman W, Tran-Van-Minh A, Ferron L, Douglas L, Kadurin I, Sri Ranjan $Y$, Fernandez-Alacid L, Millar NS, Dickenson AH, Lujan R, Dolphin AC. The increased trafficking of the calcium channel subunit alpha2delta-1 to presynaptic terminals in neuropathic pain is inhibited by the alpha2delta ligand pregabalin. J Neurosci. 2009; 29:4076-4088.

40. Takei $Y$, Laskey R. Interpreting crosstalk between TNF-alpha and NGF: potential implications for disease. Trends Mol Med. 2008;14:381-388.

41. Myers RR, Shubavev VI. The ology of neuropathy: an integrative review of the role of neuroinflammation and TNF-alpha axonal transport in neuropathic pain.J Peripher Nerv Syst. 2011; 16:277-286

42. Ramer MS, French GD, Bisby MA. Wallerian degeneration is required for both neuropathic pain and sympathetic sprouting into the DRG. Pain. 1997; 72:71-78.

43. Ramer MS, Thompson SW, McMahon SB. Causes and consequences of sympathetic basket formation in dorsal root ganglia. Pain. 1999; Suppl 6:S111-120.

44. Wilmink J. In: Lumbar spinal imaging in radicular pain and related conditions, Vol. ed. Berlin Heidelberg: Springer-Verlag; 2010.79

45. Ji RR, Kohno T, Moore KA, Woolf CJ. Central sensitization and LTP: do pain and memory share similar mechanisms? Trends Neurosci. 2003; 26:696-705.

46. Michael GJ, Averill S, Nitkunan A, Rattray M, Bennett DL, Yan Q, Priestley JV. Nerve growth fac tor treatment increases brain-derived neurotrophic factor selectively in TrkA-expressing dorsal roo ganglion cells and in their central terminations within the spinal cord. J Neurosci. 1997;17:8476-8490.

47. Kobayashi S, Uchida K, Kokubo Y, Takeno K, Yayama T, Miyazaki T, Nakajima H, Nomura E, Mwaka $E, B a b a H$. Synapse involvement of the dorsal horn in experimental lumbar nerve root compression: a light and electron microscopic study. Spine (Phila Pa 1976). 2008; 33:716-723.

48. Song XJ, Hu SJ, Greenquist KW, Zhang JM, LaMotte RH. Mechanical and thermal hyperalgesia and ectopic neuronal discharge after chronic compression of dorsal root ganglia. J Neurophysiol. 1999; 82:3347-3358.

49. Hu SJ, Xing JL. An experimental model for chronic compression of dorsal root ganglion produced by intervertebral foramen stenosis in the rat. Pain. 1998; 77:15-23.

50. Chien SO, Li C, Li H, Xie W, Pablo CS, Zhang JM. Sympathetic Fiber Sprouting in Chronically Compressed Dorsal Root Ganglia Without Peripheral Axotomy. J Neuropathic Pain Symptom Palliation.2005; 1:19-23.

51. Abe M, Kurihara T, Han W, Shinomiya K, Tanabe T. Changes in expression of voltage-dependent ion channel subunits in dorsal root ganglia of rats with radicular injury and pain. Spine. 2002; 27:15171524.

52. Kim SH, Chung JM. An experimental model for peripheral neuropathy produced by segmental spinal nerve ligation in the rat. Pain. 1992; 50:355-363.

53. Li Y, Dorsi MJ, Meyer RA, Belzberg AJ. Mechanical hyperalgesia after an L5 spinal nerve lesion in
4. Liu CN, Wall PD, Ben-Dor E, Michaelis M, Amir R, Devor M. Tactile allodynia in the absence of $C$-fiber activation: altered firing properties of DRG neurons following spinal nerve injury. Pain. 2000 , 85:503-521

55. Zang R, Muller HJ, Kielbassa K, Marks F, Gschwendt M. Partial purification of a type eta protein kinase $C$ from murine brain: separation from other protein kinase $C$ isoenzymes and characterization. Biochem J. 1994; 304 ( Pt 2):641-647.

56. Fan N, Sikand P, Donnelly DF, Ma C, Lamotte RH. Increased Na+ and K+ currents in small mouse dorsal root ganglion neurons after ganglion compression. J Neurophysiol. 2011; 106:211-218.

57. You HJ, Morch CD, Arendt-Nielsen L. Electrophysiological characterization of facilitated spinal withdrawal reflex to repetitive electrical stimuli and its modulation by central glutaciliate receptor in spinal anesthetized rats. Brain Res. 2004;1009:110-119.

58. Woolf CJ, King AE. Dynamic alterations in the cutaneous mechanoreceptive fields of dorsal horn neurons in the rat spinal cord. J Neurosci. 1990;10:2717-2726.

59. Kerr BJ, Bradbury EJ, Bennett DL, Trivedi PM, Dassan P, French J, Shelton DB, McMahon SB, Thompson SW. Brain-derived neurotrophic factor modulates nociceptive sensory inputs and NMDAevoked responses in the rat spinal cord. J Neurosci. 1999;19:5138-5148.

60. Geng SJ, Liao FF, Dang WH, Ding X, Liu XD, Cai J, Han JS, Wan Y, Xing GG. Contribution of the spinal cord BDNF to the development of neuropathic pain by activation of the NR2B-containing NMDA receptors in rats with spinal nerve ligation. Exp Neurol. 2010; 222:256-266.

61. Janssen SP, Truin M, Van Kleef M, Joosten EA. Differential GABAergic disinhibition during the development of painful peripheral neuropathy. Neuroscience. 2011; 184:183-194.

62. Rong $R$, Meng BL, Jiang $N, H u L Q$, Wang $T H$. Roles of BDNF in spinal neuroplasticity in cats subjected to partial dorsal ganglionectomy. Growth Factors. 2011;29:263-270.

63. Terashima Y Kawamata M, Takebayashi $T$, Tanaka S, Tanimoto $K$, Yamashita $T$ Changes in synaptic transmission of substantia gelatinosa neurons in a rat model of lumbar radicular pain revealed by in vivo patch-clamp recording. Pain. 2011; 152:1024-1032.

64. Finnerup NB, Sindrup SH, Jensen TS. The evidence for pharmacological treatment of neuropathic pain. Pain. 2010;150:573-581.

65. Baron R, Freynhagen R, Tolle TR, Cloutier C, Leon T, Murphy TK, Phillips $K$. The efficacy and safety of pregabalin in the treatment of neuropathic pain associated with chronic lumbosacral radiculopathy. Pain. 2010;150:420-427

66. Kobayashi S, Mwaka ES, Baba H, Kokubo Y, Yayama T, Kubota M, Nakajima H, Meir A. Microvascular system of the lumbar dorsal root ganglia in rats. Part II: neurogenic control of intraganglionic blood flow. J Neurosurg Spine. 2010;12:203-209.

67. Kobayashi S, Mwaka ES, Baba H, Takeno K, Miyazaki T, Matsuo H, Uchida K, Meir A. Microvascular system of the lumbar dorsal root ganglia in rats. Part I: a 3D analysis with scanning electron microscopy of vascular corrosion casts. J Neurosurg Spine. 2010; 12:197-202.

68. Bouhassira D, Attal N, Alchaar $H$, Boureau F, Brochet B, Bruxelle J, Cunin G, Fermanian J, Ginies P, Grun-Overdyking A, Jafari-Schluep H, Lanteri-Minet M, Laurent B, Mick G, Serrie A, Valade D, Vicaut E. Comparison of pain syndromes associated with nervous or somatic lesions and developmen of a new neuropathic pain diagnostic questionnaire (DN4). Pain. 2005; 114:29-36.

69. Attal N, Perrot S, Fermanian J, Bouhassira D. The neuropathic components of chronic low back pain: a prospective multicenter study using the DN4 Questionnaire. J Pain. 2011: 12:1080-1087.

70. Cosman EJ, Cosman ES. Electric and thermal field effects in tissue around radiofrequency electrodes. Pain Medicine. 2005; 6:405-424 
71. Cahana A, Vutskits L, Muller D. Acute differential modulation of synaptic transmission and cell survival during exposure to pulsed and continuous radiofrequency energy. J Pain. 2003; 4:197-202.

72. Higuchi Y, Nashold BS, Sluijter ME, Cosman E, Pearlstein RD. Exposure of the dorsal root ganglion in rats to pulsed radiofrequency currents activates dorsal horn lamina I and II neurons. Neurosurgery. 2002;50:850-856.

73. Van Zundert J, de Louw AJ, Joosten EA, Kessels AG, Honig W, Dederen PJ, Veening JG, Vles JS, van Kleef M. Pulsed and continuous radiofrequency current adjacent to the cervical dorsal root ganglion of the rat induces late cellular activity in the dorsal horn. Anesthesiology. 2005;102:125-131.

74. Hamann W, Abou-Sherif S, Thompson S, Hall S. Pulsed radiofrequency applied to dorsal root ganglia causes a selective increase in ATF3 in small neurons. Eur J Pain. 2006; 10:171-176.

75. Erdine S, Yucel A, Cimen A, Aydin S, Sav A, Bilir A. Effects of pulsed versus conventional radio frequency current on rabbit dorsal root ganglion morphology. Eur J Pain. 2005; 9:251-256.

76. Protasoni $M$, Reguzzoni $M$, Sangiorgi S, Reverberi C, Borsani E, Rodella LF, Dario A, Tomei $G$ Dell'Orbo C. Pulsed radiofrequency effects on the lumbar ganglion of the rat dorsal root: a morphological light and transmission electron microscopy study at acute stage. Eur Spine J. 2009; 18:473 478.

77. Tun K, Cemil B, Gurcay AG, Kaptanoglu E, Sargon MF, Tekdemir I, Comert A, Kanpolat Y. Ultrastructural evaluation of pulsed radiofrequency and conventional radiofrequency lesions in rat sciatic nerve. Surg Neurol. 2009; 72:496-500

78. Erdine S, Bilir A, Cosman ER, Cosman ER, Jr. Ultrastructural changes in axons following exposure to pulsed radiofrequency fields. Pain Pract. 2009; 9:407-417.

79. Ozsoylar O, Akcali D, Cizmeci P, Babacan A, Cahana A, Bolay H. Percutaneous pulsed radiofrequency reduces mechanical allodynia in a neuropathic pain model. Anesth Analg. 2008; 107:14061411

80. Aksu R, Ugur F, Bicer C, Menku A, Guler G, Madenoglu H, Canpolat DG, Boyaci A. The efficiency of pulsed radiofrequency application on $L 5$ and 16 dorsal roots in rabbits developing neuropathic pain. Reg Anesth Pain Med. 2010; 35:11-15.

81. Perret DM, Kim DS, Li KW, Sinavsky K, Newcomb RL, Miller JM, Luo ZD. Application of pulsed radiofrequency currents to rat dorsal root ganglia modulates nerve injury-induced tactile allodynia. Anesth Analg. 2011;113:610-616.

82. Park HW, Ahn SH, Son JY, Kim SJ, Hwang SJ, Cho YW, Lee DG. Pulsed radiofrequency application reduced mechanical hypersensitivity and microglial expression in neuropathic pain model. Pain Med. 2012; 13:1227-1234

83. Wu B, Ni J, Zhang C, Fu P, Yue J, Yang L. Changes in spinal cord met-enkephalin levels and mechanical threshold values of pain after pulsed radio frequency in a spared nerve injury rat model. Neurol Res. 2012; 34:408-414.

84. Cho HK, Cho YW, Kim EH, Sluijter ME, Hwang SJ, Ahn SH. Changes in pain behavior and glial activation in the spinal dorsal horn after pulsed radiofrequency current administration to the dorsal root ganglion in a rat model of lumbar disc herniation. J Neurosurg Spine. 2013; 19:256-263.

85. Hagiwara S, Iwasaka H, Takeshima N, Noguchi T. Mechanisms of analgesic action of pulsed radiofrequency on adjuvant-induced pain in the rat: roles of descending adrenergic and serotonergic systems. Eur J Pain. 2009; 13:249-252.

86. Millan MJ. Descending control of pain. Prog Neurobiol. 2002; 66:355-474.

87. Yezierski RP. The effects of age on pain sensitivity: preclinical studies. Pain Med. 2012; 13 Suppl 2:S27-36.

88. Tanaka N, Yamaga M, Tateyama S, Uno T, Tsuneyoshi I, Takasaki M. The effect of pulsed radio- frequency current on mechanical allodynia induced with resiniferatoxin in rats. Anesth Analg. 2010, 111:784-790.

89. Laboureyras E, Rivat C, Cahana A, Richebe P. Pulsed radiofrequency enhances morphine analgesia in neuropathic rats. Neuroreport. 2012;23:535-539.

90. Sheth RN Dorsi MJ Li Y Murinson BB, Belzberg AJ Griffin JW, Meyer RA. Mechanical hyperalgesia after an L5 ventral rhizotomy or an L5 ganglionectomy in the rat. Pain. 2002; 96:63-72. 


\section{Ghapter IV}

Clinical trials in interventional pain management: optimizing chances for success.

Jan Van Zundert ${ }^{\text {a,b; }}$;oen Van Boxem ${ }^{\text {b,c, }}$ Elbert A. Joosten ${ }^{\text {b; }}$ Alfons Kessels ${ }^{\text {d. }}$.

a Department of Anesthesiology, Critical Care, Emergency Medicine and Multidisciplinary Pain Centre, Ziekenhuis Oost-Limburg, Genk/Lanaken, Belgium. b Department of Anesthesiology and Pain Medicine, Maastricht University Medical Centre, Maastricht, Netherland. c Department of Anesthesiology - Critical Care and Multidisciplinary Pain Centre, Sint-Jozefkliniek, Bornem en Willebroek, Belgium. d Clinical Epidemiology and Medical Technology Assessment, Maastricht University Medical Centre, Maastricht, Netherland

Published in Pain: 2010; 15; (3) :571-574.

Reprinted with permission of the publisher 


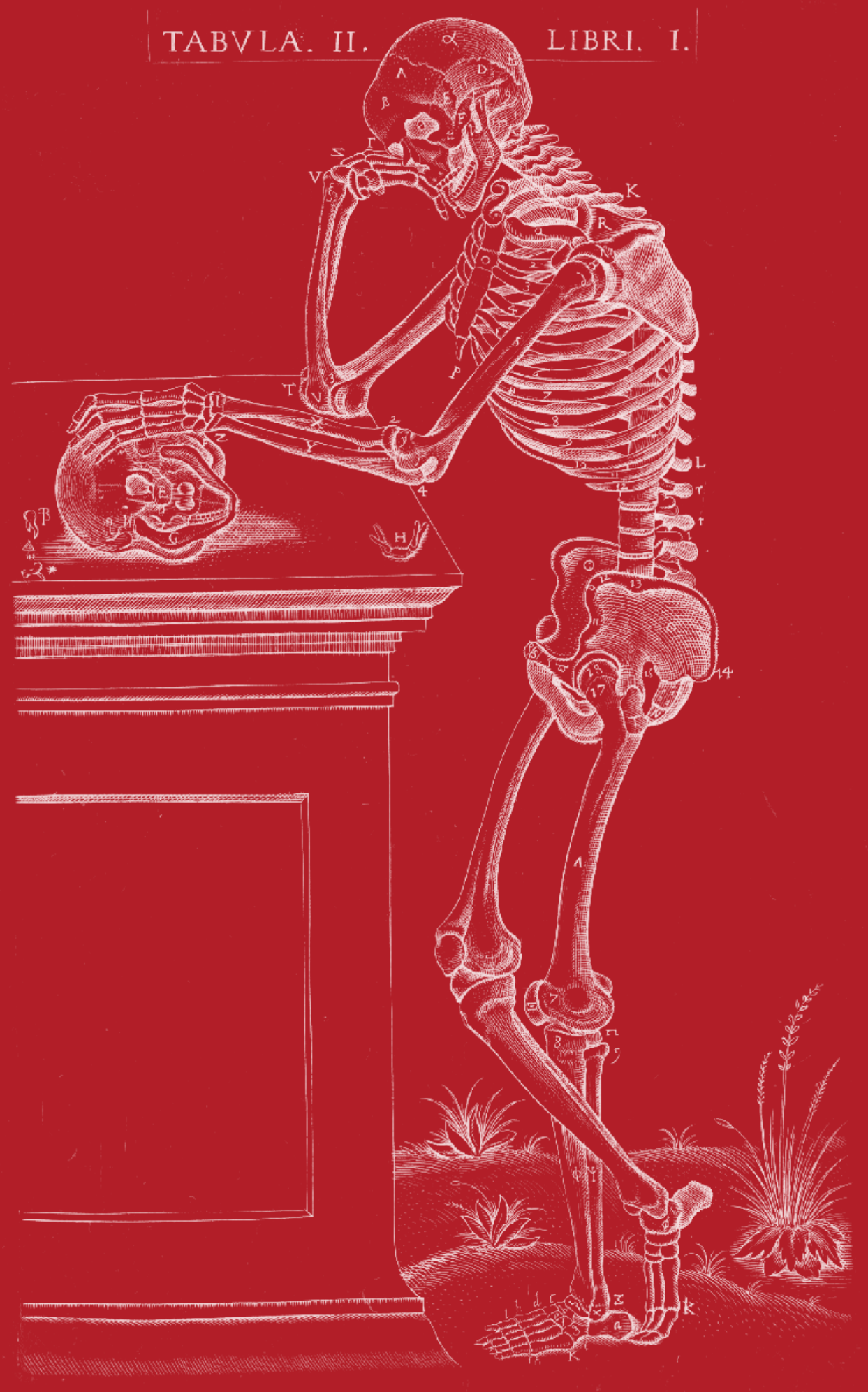

\section{INTRODUCTION}

Interventional pain management techniques consisting of minimal invasive percutaneous interventions such as: spinal injection therapy, (pulsed) radiofrequency $[\mathrm{P}) \mathrm{RF}]$ treatment, neurolytic techniques and spinal cord stimulation as part of a multidisciplinary approach for the management of chronic (spinal) pain, have gained more interest. The most important indications are chronic radicular pain, chronic pain due to degenerative disease of the facet joints and cancer pain. Scientific evidence is necessary to identify and substantiate the specific role of these techniques. ${ }^{1}$ According to the Evidence Based Medicine (EBM) guidelines, randomized controlled trials (RCTs) have the highest scientific value.' However, RCTs on interventional pain management techniques face methodological problems often leading to power problems because inadequate number of subjects can be recruited. Unfortunately the results of those underpowered studies are included in systematic reviews and meta-analyses and they may negatively influence the general recommendations. This subject was also described in a recent review on methodological issues in non-pharmacological trials for chronic pain. ${ }^{3}$

Clinical trials in interventional pain management techniques may encounter problems related to; patient selection, comparator and rescue medication, and patient withdrawal/refusal to sign informed consent.

Alternative study designs will be discussed.

Table 1: Factors influencing research on interventional pain management techniques

Patient selection:

- Better diagnosis leads to more homogeneous patient population and improves treatment outcome

Comparator and escape/rescue treatment

- Sham intervention does not reflect natural history of disease

- Sham intervention is ethically not justifiable

- Current best medical management is the preferred comparator

- Use of escape/rescue treatment should be considered a secondary outcome parameter

Patient refusal to sign informed consent or withdrawal from study

- A substantial part of the patients receiving ineffective treatment hinders obtaining informed consent

and keeping patients in the study for the entire follow-up period

- Slow inclusion and withdrawal may influence statistical significance significantly

Pre-randomization or Zelen design (see fig. 1)

- Patients are randomized prior to asking informed consent

- Patients in investigational group receive full information and informed consent is asked

- No informed consent in the comparative group and consequently no drop out

- Effect measurement using medical registration or informed consent at the end of the study

- Comparison of treatment under investigation with best medical practice 


\section{PATIENT SELEGTION}

Lack of a diagnostic gold standard for chronic (spinal) pain will lead to inclusion of patients who may not benefit from the treatment. Patient groups will be heterogeneous, which prohibits the comparison of outcome between studies. The importance of patient selection on the study outcome became evident when comparing between studies. The importance of patient selection on the study outcome became evident when comparing
the results of 5 RCTs on percutaneous RF thermo-coagulation of the innervations of the lumbar facet joint..$^{-{ }^{-8}}$ the results of 5 RCins on percutaneous RF thermo-coagulation of the innervations of the lumbar facetjoint. sometimes medical imaging is required. Additionally, selective diagnostic blocks can confirm the working diagnosis before offering a RF technique to the patient. In the above mentioned RCTs the diagnostic block were performed in different ways, which resulted in a prevalence of 'facet joint pain' ranging from $10 \%$ to $90 \%$. In earlie epidmiologicats whe Closer examination of two studies clearly illustrates the impact of patient selection on the treatment outcome. In one study the diagnosis was confirmed with 1 diagnostic block of a very limited amount of local anesthetic at the innervations the facet joint. The diagnosis was judged positive when the patient, with the assistance of an independent data manager, scored pain relief to be at least $50 \%$ during the first hour after the block. By this criterion, $31 \%$ of the referred patients were judged to suffer facet joint pain and be eligible to enter the study. The number needed to treat (NNT) for a significant pain reduction in the RF group was 1.6. ${ }^{7}$ In intertect of an intra-articular injection of local anesthetic was judged positive when the patien and the physiatrist reported significant relief of low back pain at least of $24 \mathrm{hrs}$ duration during the week after infiltration. Approximately $90 \%$ of the referred patients were included in the study. The NNT for R was 11 and consequently it was concluded that RF was not effective. ${ }^{5}$ The wide variations in NNT for RF in the different RCT's are the reason why the conclusions of systematic reviews differ. ${ }^{10,1}$

\section{COMPARATOR AND ESCAPE/RESCUE INTERVENTION}

An RCT is an experiment designed to determine the influence of an intervention on the natural histor of the disease ${ }^{2}$. In interventional trials patients in the control group receive a sham intervention, this is equivalent to the placebo in pharmacological trials, therefore most often the needle is placed on the same target structure as in the active group but no active treatment is offered. A major question regarding the use of sham intervention in pain management RCTs is raised: "Does sham intervention correctly represent the natural history of the disease?" ${ }^{12}$ It was advocated that placebo surgery or sham intervention is a medical act, hence compromising the researched natural course of the disease. ${ }^{13}$ The intervention generates an expectation that can induce placebo analgesia or even nocebo hyperalgesia (worsening of symptoms after an iner intervention). ${ }^{14}$ Moreover a systematic review reported that placebo had a significant effect as compared to no treatment on pain or phobia measured on continuous scales. ${ }^{15-18}$ Also many ethical concerns were raised offering placebo. ${ }^{19}$ Ethical ouidelines on the use of placebo in drug trials have been formulated. The use of sham surgery is intuitively considered questionable. Therefore this comparator encountered much opposition..$^{20,21}$ The ethics on sham surgery or sham intervention are described to focus around two issues: does a sham intervention represents a minimal risk for the patient and is a sham intervention justifiable in relation to the potential value of the scientific knowledge? $?^{2}$

For ethical reasons every study design should foresee an escape/rescue treatment for patients suffering intractable pain. The selection of the rescue treatment may pose a problem and interfere with the outcome. This may lead to inconoruous situations as is illustrated by Wong et al ${ }^{22}$ who compared neurolytic celiac plexus block with optimized systemic analgesic therapy alone for patients with unresectable pancreatic cancer All patients received analgesic treatment, including opioids, prior to inclusion. They were randomly assigned to neurolytic or sham celiac plexus block. The control group received best medical treatment available: an analgesic regimen, but for ethical reasons escape treatment was offered with additional pain medication according to the WHO pain ladder in both groups. Moreover, for ethical reasons a neurolytic celiac plexus block could be used as rescue treatment in both groups although this was the procedure under investigation In the results section the need for escape/rescue treatment was not mentioned as an outcome parameter. It is unclear what is measured in this RCT and how the conclusions can be supported.

\section{PATIENT WITHDRAWAL/REFUSAL TO SIGN INFORMED CONSENT}

The information provided to potential participants in a randomized sham controlled trial also describes the substantial chance of receiving an ineffective treatment. This results in a proportion of alerted patients, who do not agree to provide consent. Or even worse, some patients who signed the informed consent will leave the trial and go for "shopping" in other pain centres.

The effect of RF treatment at the lumbar dorsal root ganglion (DRG) for lumbar radicular pain was studied in a well-designed RCT. ${ }^{23}$ From the 1001 patients referred with low back pain, only 201 were eligible for a diagnostic block and 32 patients refused to give the informed consent. Finally only 83 out of the 1001 screened patients $(8 \%)$ could be enrolled and randomized to either active treatment or to sham intervention. A similar observation was made in an RCT evaluating the efficacy of PRF treatment at the cervical DRG for cervical radicular pain. ${ }^{24}$ Of the 256 patients referred, 114 were considered candidates for participation in the study and received a diagnostic block, but 63 refused signing the informed consent. Twenty three out of the 256 screened patients $(9 \%)$ were randomized to PRF or sham treatment. These data clearly indicate the patients' reluctance to signing consent with the risk of receiving a sham intervention, certainly because they have severe refractory symptoms. Also the referring physician, often a believer in interventional pain treatment, may negatively advice the patient. ${ }^{25}$

\section{GAN WE OPTIMIZE THE STUDY DESIGN OF GLINICAL TRIALS IN} INTERVENTIONAL PAIN MANAGEMENT?

As discussed above, conducting randomized controlled trials in interventional pain management is hindered by several factors. Patient inclusion in a RCT can be hindered by the reluctance for signing informed consent. The selected comparative treatment may not be appealing to patients.

Several alternative trial designs have been proposed. Well-conducted, prospective studies do not assign patients randomly to a treatment group. High-quality observational studies tend to overestimate treatment effect. Expertise-based or centre randomization have been proposed to overcome the impact of the operator's expertise on the outcome. These designs require a high patients' mobility to attend the centre they are assigned to. ${ }^{26}$

The pre-randomization design (or Zelen or post-consent design) is a way of avoiding contamination by blinding the control group and may offer an alternative that may be worth testing in interventional pain management. It implies that randomization takes place prior to seeking informed consent. ${ }^{27}$ All patients are told that efforts are made to find the optimal treatment, which requires close monitoring of the results. They are asked to sign a consent to attend the clinic at reoular time points for evaluation. Patients assigned The study, and written informed consent is obtained. It is assumed that the great majority of patients referred to a pain clinic for interventional pain management technique will accept to sign the informed consent 
because of the attractiveness of the treatment option. Patients in the control/ standard treatment group will receive the best available standard treatment and are blinded for the experimental treatment. They will be informed at the end of the study that their results will be compared to those obtained from patients who received another (interventiona) treatment. Consent to use their data will be asked. Patients in the control/ standard treatment group with the best medical treatment available regularly consult the pain physician who will adjust the treatment to optimize pain control and mobility, without, however using interventional pain management. Patients in the experimental/interventional group had optimized medical managemen prior to signing informed consent. The interventional pain management technique is performed and patient consult with the pain physician for adjustment of the conservative treatment. Besides, all patients consul with the blinded evaluator at the pre-defined evaluation points for collecting the information for the standardized evaluation (See Figure 1). Several modifications on the desion are possible ${ }^{28}$ Although the design is still controversial in many countries it is now accepted by most medical ethical committees in the UK and the Netherlands. ${ }^{29}$ It may be more challenging to accept the prerandomization design in the USA given the more strict regulatory control over human subject research. In October 2006 the Dutch State Secretary of health, Welfare and Sport announced that the application of pre-randomisation in study designs is admissible and not in conflict with the Medical Research Involving Human Subjects Act. ${ }^{30}$ Methodologically the pre-randomization design reduces the chance of withdrawal in the control/ standard treatment group after inclusion and therefore seems preferable when an attractive experimental treatment is involved, the reference is the standard treatment and a sham procedure or placebo cannot be used. ${ }^{28}$ Successful use of the prerandomization design may be limited to studies concerning minimal invasive interventional pain managemen techniques, that may already routinely be used in pain centers. Outcome assessment should be possible by means of non-invasive tests that are easy to perform, and do not require invasive tests for data collection.

In a recent review of randomized trials using the pre-randomization design it was concluded that this design if carefully used can avoid 'resentful demoralization' and other negative effects biasing trials."

\section{Conventional study design}

potential participants

informed consent $\rightarrow$ refuse to participate

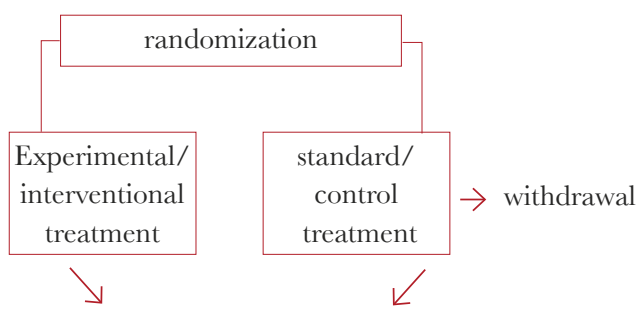

Effect measurement

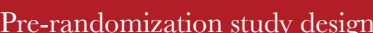

potential participant

$\downarrow$

agreement to attend the study site at predefined time point

\begin{tabular}{|c|c|}
\hline \multicolumn{2}{|c|}{ randomization } \\
\hline informed \\
consent + \\
experimental/ \\
interventional \\
treatment
\end{tabular}$\quad$\begin{tabular}{c} 
standard/ \\
control \\
treatment \\
\hline
\end{tabular}

treatment for data analysis

Effect mestichent

\begin{tabular}{|c|c|c|c|c|}
\hline \multicolumn{2}{|c|}{ Conventional study design } & & \multicolumn{2}{|c|}{ Pre-randomization design } \\
\hline \multicolumn{2}{|c|}{ v } & Patients screened for diagnosis & \multicolumn{2}{|c|}{$\mathrm{V}$} \\
\hline \multicolumn{2}{|c|}{ v } & Informed consent asked & \multicolumn{2}{|c|}{ no } \\
\hline \multicolumn{2}{|c|}{ yes } & Potential refusal to participate & \multicolumn{2}{|c|}{ not applicable } \\
\hline \multicolumn{2}{|c|}{ yes } & Randomization & \multicolumn{2}{|c|}{ yes } \\
\hline experimental/ & $\begin{array}{l}\text { standard/con- } \\
\text { trol treatment }\end{array}$ & & $\begin{array}{c}\text { experimental/ } \\
\text { interventional } \\
\text { treatment }\end{array}$ & $\begin{array}{c}\text { standard/ } \\
\text { control treat- } \\
\text { ment }\end{array}$ \\
\hline $\begin{array}{c}\text { interventional } \\
\text { treatment }\end{array}$ & not applicable & informed consent & yes & no \\
\hline not applicable & high & risk for early withdrawl & & $\begin{array}{l}\text { unlikely, } \\
\text { patient is not } \\
\text { aware of an } \\
\text { alternative }\end{array}$ \\
\hline $\mathrm{v}$ & v & effect measurement & $\mathrm{v}$ & v \\
\hline not applicable & not applicable & consent to analyse data & not applicable & yes \\
\hline
\end{tabular}

Figure 1: Schematic diagrams showing the difference between the conventional design and the pre-randomization design with an attractive experimental treatmen

\section{CONCLUSIONS}

Improvement of research in interventional pain medicine has the ultimate goal to provide Evidence-Based Medicine supported recommendations for accurate pain-patient care in daily practice, considering the balance between benefits, risks and burdens. ${ }^{32}$ In research and in clinical practice patient selection influences the outcome of the intervention. Therefore evidence based practice guidelines for interventional pain management techniques should be based on specific clinical diagnoses. ${ }^{33}$ The pre-randomization design could be an alternative in future trials on interventional pain management techniques to increase the number of participating patients and dealing with issues of the comparator group.

In conclusion: the pre-randomization can be considered in clinical trials on interventional pain management for techniques that are minimal invasive and mostly routinely used. The tools used for assessing efficacy and safety of the treatment should be easy to handle and may not be invasive, thus allowing compliance with good clinical practice

\section{Acknowledgements}

The authors thank Michael Rowbotham and Maarten van Kleef for their constructive discussions and remarks on the manuscript and Nicole Van den Hecke for coordination. No support was received for this work. None of the authors has a conflict of interest regarding treatment options discussed 
References

1. Dworkin RH, Turk DC, Peirce-Sandner S, Baron R, Bellamy N, Burke LB, Chappell A, Chartier K, Cleeland CS, Costello A, Cowan P, Dimitrova R, Ellenberg S, Farrar JT, French JA, Gilron I, Hert $S$, Jadad AR, Jay GW, Kalliomaki J, Katz NP, Kerns RD, Manning DC, McDermott MP, McGrath PJ, Narayana A, Porter L, Quessy S, Rappaport BA, Rauschkolb C, Reeve BB, Rhodes T, Sampaio C, Narayana A, Porter L, Quessy S, Rappaport BA, Rauschkolb C, Reeve BB, Rhodes T, Sampaio C,
Simpson DM, Stauffer JW, Stucki G, Tobias J, White RE, Witter J. Research design considerations for confirmatory chronic pain clinical trials: IMMPACT recommendations. Pain. 2010; 149:177-193.

2. McGovern D, Summerskill W, Levi M. Evidence-based medicine in general practice. Oxford: Bios Scientific Publishers; 2001

3. Bennett MI, Closs J. Methodological issues in nonpharmacological trials for chronic pain. PAIN: Clinical updates. 2010; XVIII:1-6.

4. Gallagher J, Vadi PLP, Wesley JR. Radiofrequency facet joint denervation in the treatment of low back pain-a prospective controlled double-blind study in assess to efficacy. Pain Clinic. 1994; 7:193-198.

5. Leclaire R, Fortin L, Lambert R, Bergeron YM, Rossignol M. Radiofrequency facet joint denervation in the treatment of low back pain: a placebo-controlled clinical trial to assess efficacy. Spine. 2001, 26:1411-1416.

6. Nath S, Nath CA, Pettersson K. Percutaneous lumbar zygapophysial (Facet) joint neurotomy using radiofrequency current, in the management of chronic low back pain: a randomized double-blind trial. Spine. 2008; 33:1291-1297.

7. van Kleef M, Barendse GA, Kessels F, H.M.Voets, Weber WE, de Lange S. Randomized trial of radiofrequency lumbar facet denervation for chronic low back pain. Spine. 1999; 24:1937-1942.

8. van Wijk RM, Geurts JW, Wynne HJ, Hammink E, Buskens E, Lousberg R, Knape JT, Groen GJ. Radiofrequency denervation of lumbar facet joints in the treatment of chronic low back pain: a randomized, double-blind, sham lesion-controlled trial. Clin J Pain. 2005; 21:335-344.

9. Schwarzer AC, Wang SC, Bogduk N, McNaught PJ, Laurent R. Prevalence and clinical features of lumbar zygapophysial joint pain: a study in an Australian population with chronic low back pain. Ann Rheum Dis. 1995; 54:100-106.

10. Geurts JW, van Wijk RM, Stolker RJ, Groen GJ. Efficacy of radiofrequency procedures for the treatment of spinal pain: a systematic review of randomized clinical trials. Reg Anesth Pain Med. 2001; 26:394-400.

11. Niemisto L, Kalso E, Malmivaara A, Seitsalo S, Hurri H. Radiofrequency denervation for neck and back pain: a systematic review within the framework of the cochrane collaboration back review group. Spine. 2003; 28:1877-1888.

12. Van Zundert J. Clinical research in interventional pain management techniques: the clinician's point of view. Pain Pract. 2007; 7:221-229.

13. Polgar S, Ng J. Ethics, methodology and the use of placebo controls in surgical trials. Brain Res Bull. 2005; 67:290-297.

14. Petrovic P. Placebo analgesia and nocebo hyperalgesia--two sides of the same coin? Pain. 2008; 136:5-6.

15. Hrobjartsson A, Gotzsche PC. Is the placebo powerless? Update of a systematic review with 52 new randomized trials comparing placebo with no treatment.J Intern Med. 2004; 256:91-100.

16. Finniss DG, Kaptchuk TJ, Miller F, Benedetti F. Biological, clinical, and ethical advances of placebo effects. Lancet. 375:686-695.

17. Enck P, Benedetti F, Schedlowski M. New insights into the placebo and nocebo responses. Neuron. 2008; 59:195-206.
18. Benedetti F, Carlino E, Pollo A. How Placebos Change the Patient's Brain. Neuropsychopharmacology 2010.

19. World Medical Association. World Medical Association Declaration of Helsinki: ethical principles for medical research involving human subjects. JAMA. 2000; 284:3043-3045.

20. Albin RL. Sham surgery controls are mitigated trolleys. J Med Ethics. 2005; 31:149-152.

21. Horng S, Miller FG. Is placebo surgery unethical? N Engl J Med. 2002; 347:137-139.

22. Wong GY, Schroeder DR, Carns PE, Wilson JL, Martin DP, Kinney MO, Mantilla CB, Warner DO. Effect of neurolytic celiac plexus block on pain relief, quality of life, and survival in patients with unresectable pancreatic cancer: a randomized controlled trial. JAMA. 2004; 291:1092-1099.

23. Geurts JW, van Wijk RM, Wynne HJ, Hammink E, Buskens E, Lousberg R, Knape JT, Groen GJ Radiofrequency lesioning of dorsal root ganglia for chronic lumbosacral radicular pain: a randomised, double-blind, controlled trial. Lancet. 2003; 361:21-26.

24. Van Zundert J, Patijn J, Kessels A, Lame I, van Suijlekom H, van Kleef M. Pulsed radiofrequency adjacent to the cervical dorsal root ganglion in chronic cervical radicular pain: a double blind sham controlled randomized clinical trial. Pain. 2007; 127:173-182.

25. Sackett $D L$. Why randomized controlled trials fail but needn't: 1. Failure to gain "coal-face" commitment and to use the uncertainty principle. CMAJ. 2000; 162:1311-1314.

26. Morshed S, Bhandari M. Clinical trial design in fracture-healing research: meeting the challenge. Bone Joint Surg Am. 2008; 90 Suppl 1:55-61.

27. Zelen M. A new design for randomized clinical trials. N Engl J Med. 1979; 300:1242-1245.

28. Schellings R, Kessels AG, ter Riet G, Sturmans F, Widdershoven GA, Knottnerus JA. Indications and requirements for the use of prerandomization. J Clin Epidemiol. 2009; 62:393-399.

29. Schellings $R$, Kessels AG, Ter Riet G, Kleijnen J, Leffers P, Knottnerus JA, Sturmans F. Members of research ethics committees accepted a modification of the randomized consent design. J Clin Epidemiol. 2005: 58:589-594.

30. Tweede kamer der Staten-Generaal TLCotDP. Evaluatie Wet medisch-wetenschappelijk onderzoek met mensen [Evaluation of The Medical Research Involving Human Subjects Act]. In, Vol.29963 The Hague; 2006-2007.

31. Adamson J, Cockayne S, Puffer S, Torgerson DJ. Review of randomised trials using the postrandomised consent (Zelen's) design. Contemp Clin Trials. 2006; 27:305-319.

32. Guyatt G, Gutterman D, Baumann MH, Addrizzo-Harris D, Hylek EM, Phillips B, Raskob G, Lewis SZ, Schunemann H. Grading strength of recommendations and quality of evidence in clinical guidelines: report from an american college of chest physicians task force. Chest. 2006; 129:174-181.

33. van Kleef M, Mekhail N, van Zundert J. Evidence-based guidelines for interventional pain medicine according to clinical diagnoses. Pain Pract. 2009; 9:247-251. 


\section{Ghapter V}

Pulsed radiofrequency treatment adjacent to the lumbar dorsal root ganglion for the management of lumbosacral radicular syndrome:

A clinical audit

Koen Van Boxem, MD, FIPP a,b; Joselien van Bilsen, BSc ${ }^{\text {a }}$; Nelleke de Meij, MSc ${ }^{\text {a }}$; Andreas Herrler, MSc ${ }^{c}$; Fons Kessels, MD, MSc ${ }^{\mathrm{d}}$; Jan Van Zundert, MD, PhD, FIPP a,c, Maarten van Kleef, MD, PhD, FIPP a.

a Department of Anesthesiology and Pain Medicine, Maastricht University Medical Centre, Maastricht, Netherland. b Department of Anesthesiology - Critical Care and Multidisciplinary Pain Centre, Sint-Jozefkliniek, Bornem en Willebroek, Belgium. c Department of Anatomy and Embryology, Maastricht University, Maastricht, the Netherlands. d Clinical Epidemiology and Medical Technology Assessment, Maastricht University Medical Centre, Maastricht, Netherland. Medical Technology Assessment, Maastricht University Medical Centre, Maastricht, Netherland.
e Department of Anesthesiology, Critical Care, Emergency Medicine and Multidisciplinary Pain Centre, Ziekenhuis Oost-Limburg, Genk/Lanaken, Belgium

Published in Pain Medicine : 2011; 12: 1322-1330 Reprinted with permission of the publisher 


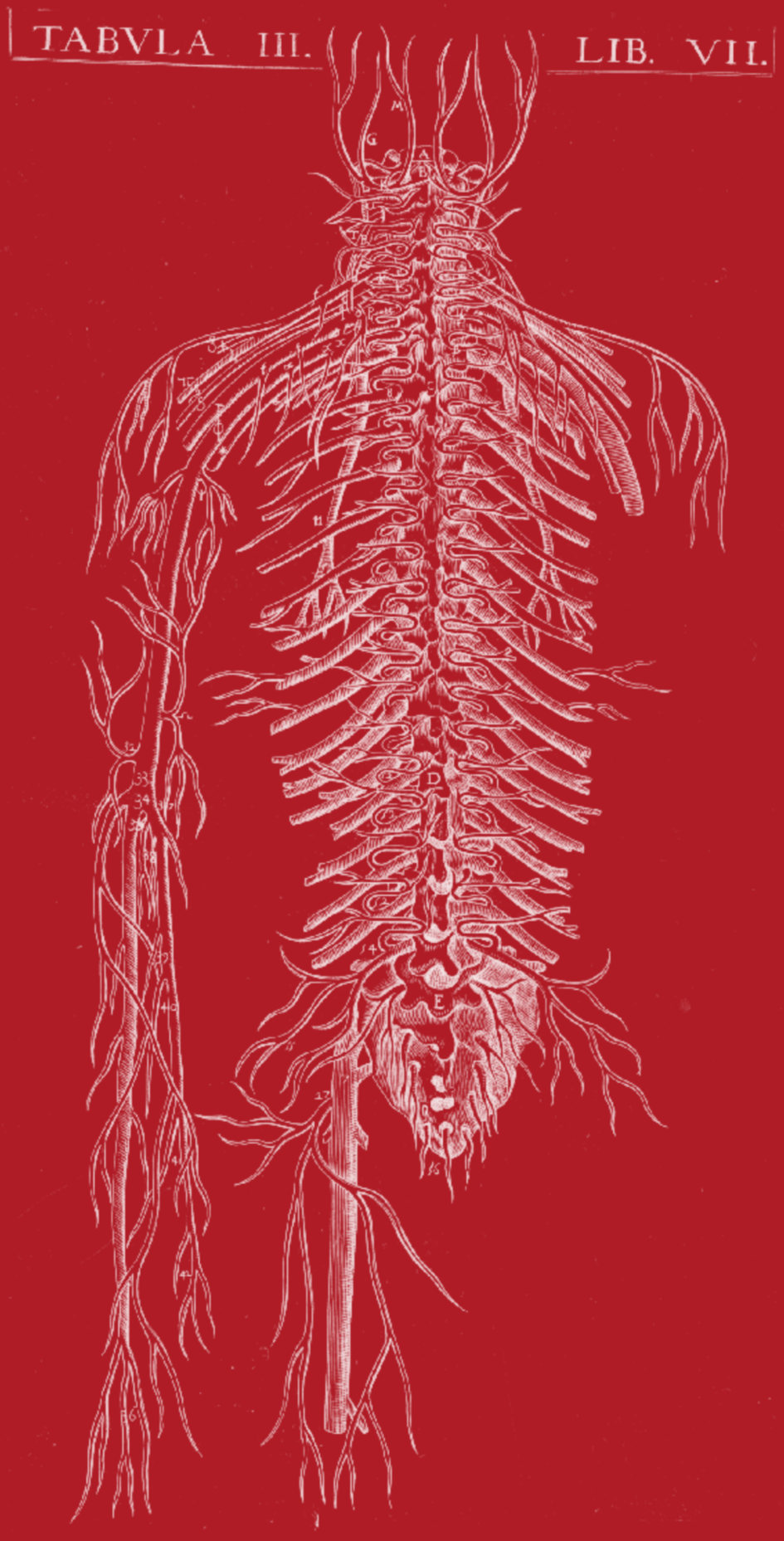

ABSTRACT

\section{Introduction}

Lumbosacral radicular syndrome (LSR) is probably the most frequent neuropathic pain syndrome. Three months to 1 year after onset, $30 \%$ of the patients still experience ongoing pain. The management of those patients is complex and treatment success rates are rather low. The beneficial effect of pulsed radiofrequency therapy (PRF) has been described for the treatment of LSR in case reports and in retrospective and prospective studies. Up till now, no neurological complications have been reported after PRF treatment. The current clinical audit has been performed to assess the amount of pain relief after a single PRF treatment.

Methods

Sixty consecutive patients who received a PRF treatment adjacent to the lumbar dorsal root ganglion for the management of lumbosacral radicular syndrome in the period 2007-2009 were included. The main study objective was to measure the reduction of pain after the pulsed radiofrequency treatment by using the Global Perceived Effect. The primary endpoint was defined as at least 50\% pain relief for a period of 2 months or longer

Results

The primary endpoint was achieved in $29.5 \%$ of all the PRF-interventions. After 6 months $50 \%$ pain relief was still present in $22.9 \%$ of the cases and after 12 months in $13.1 \%$ of the cases. The need for pain medication was significantly lower after pulsed radiofrequency treatment in the success group compared to the non-success group.

Gonclusions

PRF treatment can be considered for the management of ISR patients. These results need to be confirmed in a randomized clinical trial.

Key words: pulsed radiofrequency, dorsal root ganglion, lumbosacral radicular syndrome, effect 


\section{INTRODUCTION}

A lumbosacral radicular syndrome (LSR) is characterized by a radiating pain in one or more lumbar tit may or may not be accompanied by ohe and/or symptoms of decreased function. The annual prevalence in the general population, described as low back pain with leg pain traveling below the knee, lies between $9.9 \%$ to $25 \% .{ }^{1}$ Also, the poin prevalence ( 4.6 to $13.4 \%$ ) and lifetime prevalence (1.2 to $43 \%$ ) are very high ${ }^{1}$, which means that lumbosacral radicular pain is presumably the most commonly occurring form of neuropathic pain. ${ }^{2,}$ Acute lumbosacral radicular pain completely or partially resolves in $60 \%$ of the patients within 12 weeks of onset ${ }^{4}$ However, about $30 \%$ of the patients are still suffering from pain after 3 months to lyear.

Although the prevalence of lumbosacral radicular pain is very high, there are only few pharmacological studies performed in this specific patient population. Recent trials suggest that lumbosacral radiculopathy might not be responsive to nortriptyline and morphine, pregabalin and topiramate drug regimen. For exercise or physical treatment a better outcome compared to conservative therapy could only be noted after 52 weeks. ${ }^{5}$ When conservative treatment fails to provide satisfactory pain relief and/or restoration of functional capacity interventional pain management techniques may be considered.

Pulsed radiofrequency (PRF) treatment uses intermittent administration of high frequency current, thus avoiding temperature rise above the critical level of $42^{\circ} \mathrm{C}$, described as the temperature that cause neuronaldamage. ${ }^{6,7}$ ThereforePRFisassumedtobesaferthanconventionalRFwherethetemperatureatthe electrodetiprisesabove $67^{\circ} \mathrm{C}$. Thesafety of $\mathrm{PRF}$ canbederivedfromthefactthatsinceitsintroductionin $1998^{\circ}$ no neurological complications were reported ${ }^{9}$, even in the numerous reports of PRF adjacent to the dorsal root ganglion (DRG) only minor post-procedural discomfort was mentioned ${ }^{8,10-16}$ (See table 1). The beneficial effect of PRF adjacent to the lumbar DRG has been described for the treatment of LSR in case reports and in retrospective and prospective studies. ${ }^{8,10-16}$ These studies include a limited number of patients in some cases with various clinical subdiagnoses. Moreover the treatment could be repeated at the same or an adjacent level in most of the trials, making it difficult to draw conclusion (See also table 1).

We report here the results of the first clinical audit on the long-term effect of 1 single PRF treatment adjacent to 1 level lumbar DRG in 60 consecutive patients

\section{METHODS}

The primary objective of this study was to test the hypothesis that PRF produces satisfactory pain relief. As a secondary objective the predictive outcome value of gender and FBSS patients were relief. As a scolo
analyzed.

\section{Patients}

Between 2007 and 2009 more than 200 patients clinically diagnosed with a chronic lumbosacra radicular syndrome were treated in the multidisciplinary pain centre of the Maastricht University Hospital. Before treatment with PRF, the patients received medical therapy to manage their pain, minimally consisting of physical therapy and the use of NSAID's if not contra-indicated. In case of insufficient pain relief (NRS score $>5$ on an 11- point scale), patients were judged eligible for PRF treatment. Diagnosis in our centre was made based on the patient's pain description. Pain should be radiating into the leg below the knee. If back pain is present it should be less intensive than leg pain. Pain should be radiating under the knee, with a dermatomere distribution L5 (lateral part of the lower leg up to the big toe) or S1 (calf up to lateral side of the foot). ${ }^{17,18}$ The assumed causative level identified by the clinical diagnosis was confirmed in all patients by means of a selective diagnostic segmental block. The clinical picture should be concordant with the observation on CT-scan or MRI. Patients experiencing at least $50 \%$ pain reduction in the leg for the duration of action of the administered local anesthetic, received PRF treatment. Eventually, 60 patients were treated with PRF adjacent to the lumbar DRG at level L4, L5 or S1.

Patients were eligible for the study if they were 18 years or older and could speak, read and understand the Dutch language properly. Patients were excluded if they had malignant disorders or previous lumbar fractures.

The 60 patients, identified through the record card, and who underwent PRF at level L4, L5 or S1 were sent an information letter about this study. Two weeks later they were contacted by phone by a medical student (JvB), independent evaluator who was not involved in diagnosis or treatment of the patients. According to the recommendations of the Medical Ethical guidelines of the MUMC informed consent was first obtained. Thereafter the medical student conducted a structured interview.

\section{Outcome Measures}

The primary outcome measure was the degree of pain reduction as assessed by the Global Perceived Effect (GPE) for pain, measured on a 7-point Likert scale (table 2). ${ }^{19}$ Success was defined as at least $50 \%$ improvement on the GPE (score 6 or 7 ).$^{20}$

Another outcome measure was the change in need of pain medication according to the Medication Quantification Scale III (MQS) after treatment. ${ }^{21}$

Demographic factors and the influence on treatment outcome were separately analyzed.

Table 2. Likert scale 7-point scoring system: global perceived effect

\begin{tabular}{l|l|l|} 
Score & \% Change & Description \\
\hline 7 & $75 \%$ improvement & Very good \\
\hline 6 & $50-74 \%$ improvement & Good \\
\hline 5 & $25-49 \%$ improvement & Fairly good \\
\hline 4 & $0-24 \%$ improvement or worse & Same as before \\
\hline 3 & $25-49 \%$ worse & Fairly bad \\
\hline 2 & $50-74 \%$ worse & Bad \\
\hline 1 & $75 \%$ worse & Very bad \\
\hline
\end{tabular}

The Procedure

Diagnostic Block • For the diagnostic block, the $\mathrm{C}$-arm is adjusted in such a way that the X-rays run parallel to the end plates of the relevant level. Thereafter, the C-arm is rotated until the processus spinosus projects over the contralateral facet column. With the $\mathrm{C}$-arm in this projection, the insertion point is found by projecting a metal ruler over the lateral part of the foramen intervertebrale. A $10 \mathrm{~cm}$ long, 22-G needle is inserted here locally in the direction of the rays. Thereafter, the direction is corrected such that the needle is projected as a point on the screen. The direction of the radiation beam is now modified to a profile (lateral) view, and the needle inserted until the point is located in the craniodorsal part of the foramen intervertebrale. In an AP view, the course of a small amount 
Table 1: Study details on PRF adjacent to the lumbar DRG

\begin{tabular}{|c|c|c|c|c|c|c|c|c|}
\hline Study & Type & $\begin{array}{l}\text { Number of pa- } \\
\text { tients }\end{array}$ & Indication & Diagnosis & Treatment & Follow-Up & Outcome & Side Effects \\
\hline $\begin{array}{l}\text { Sluijter } 1998 \\
\text { part } 1[8]\end{array}$ & $\mathrm{P}$ & $\begin{array}{l}\mathrm{RF}=24 \\
\mathrm{PRF}=36\end{array}$ & $\begin{array}{l}\text { Lumbar radicular } \\
\text { pain }\end{array}$ & & $\begin{array}{l}\mathrm{RF} 42^{\circ} \mathrm{C} 60 \mathrm{~s} \\
\text { vs PRF } 120 \mathrm{~s}\end{array}$ & $\begin{array}{l}\text { If after } 6 \text { weeks not } \\
\text { effective RF heat lesion }\end{array}$ & $\begin{array}{l}6 \text { weeks } \\
\text { GPE }>50 \% \\
\text { RF } 12 \% \\
\text { PRF } 86 \%\end{array}$ & $\begin{array}{l}\text { Post-operative discomfort not } \\
\text { uncommon but no neuritis like } \\
\text { reaction }\end{array}$ \\
\hline $\begin{array}{l}\text { Sluijter } 1998 \\
\text { part } 2[8]\end{array}$ & $\mathrm{P}$ & 15 & FBSS & $\begin{array}{l}3 \text { segmental nerve blocks } \\
\text { at L4-S2 }\end{array}$ & $\begin{array}{l}\text { Best responding level } \\
\text { PRF } 120 \text { s } \\
5 \text { pts not treated nega- } \\
\text { tive diagnostic block }\end{array}$ & $\begin{array}{l}\text { After } 6 \text { weeks if un- } \\
\text { satisfactory result PRF } \\
\text { at different segmental } \\
\text { level }\end{array}$ & $\begin{array}{l}\text { Pain reduction } \geq 2 \\
\text { points (VAS) } \\
6 \text { months } 53 \% \\
12 \text { months } 40 \%\end{array}$ & None \\
\hline $\begin{array}{l}\text { Teixeira } 2005 \\
{[11]}\end{array}$ & $\mathrm{R}$ & 13 & $\begin{array}{l}\text { Subacute or chronic } \\
\text { radicular pain : } \\
\text { disc herniation } \\
\text { pts scheduled for } \\
\text { surgery }\end{array}$ & $\begin{array}{l}\text { CT or MRI confirmation } \\
\text { of involved level(s) }\end{array}$ & $\begin{array}{l}\text { PRF DRG 180s at } \\
\text { involved level } \\
\text { if two levels involved } \\
\text { both are treated }\end{array}$ & $\begin{array}{l}\text { Regular visits during } \\
\text { mean period of } 15.8 \\
\text { months NRS }\end{array}$ & $\begin{array}{l}\text { Significant decrease } \\
\text { in NRS at } 4 \text { weeks, } \\
\text { continuous decrease } \\
\text { until end of fol- } \\
\text { low-up. } \\
1 \text { pt disc surgery at } \\
\text { week } 9\end{array}$ & $\begin{array}{l}\text { There were no residual } \\
\text { neurological signs, except in } \\
\text { one patient who had residual } \\
\text { decreased sensibility in an area } \\
\text { of about } 12 \mathrm{~cm}^{2} \text { in the L3 } \\
\text { dermatome }\end{array}$ \\
\hline $\begin{array}{l}\text { Pevzner } 2005 \\
{[16]}\end{array}$ & $\mathrm{P}$ & $28 \mathrm{pts}$ & Radicular pain & $\begin{array}{l}\text { Medical history and clini- } \\
\text { cal examination }\end{array}$ & $\begin{array}{l}\text { PRF DRG after } \\
\text { corticosteroid and LA } \\
\text { injection }\end{array}$ & $\begin{array}{l}3,6 \text { and } 12 \text { months } \\
\text { GPE }\end{array}$ & $\begin{array}{l}\geq 50 \% \text { pain relief } \\
3 \text { months } 50 \% \\
6 \text { months } 32 \% \\
12 \text { months } 29 \%\end{array}$ & $\begin{array}{l}\text { No complications. Post proce- } \\
\text { dure discomfort in } 21 \% \text { (no } \\
\text { differentiation between cervical } \\
\text { and lumbar) }\end{array}$ \\
\hline $\begin{array}{l}\text { Shabat } 2006 \\
{[15]}\end{array}$ & $\mathrm{P}$ & $28 \mathrm{pts}$ & $\begin{array}{l}\text { Neuropathic spinal } \\
\text { pain } \\
20 \mathrm{pt} \text { lumbar region }\end{array}$ & & $\begin{array}{l}\text { PRF after corticoster- } \\
\text { oid and LA injection }\end{array}$ & $\begin{array}{l}1,3 ; 6 \text { and } 12 \text { months } \\
\text { GPE and VAS }\end{array}$ & $\begin{array}{l}\geq 50 \% \text { pain relief } \\
3 \text { months } 50 \% \\
6 \text { months } 32 \% \\
12 \text { months } 29 \%\end{array}$ & $\begin{array}{l}\text { No complications. Post proce- } \\
\text { dure discomfort in } 21 \% \text { which } \\
\text { resolved spontaneously within } \\
3 \text { weeks (no differentiation } \\
\text { between cervical and lumbar) }\end{array}$ \\
\hline $\begin{array}{l}\text { Abejon } 2007 \\
{[12]}\end{array}$ & $\mathrm{R}$ & $\begin{array}{l}54 \text { pts }-75 \text { proce- } \\
\text { dures }\end{array}$ & $\begin{array}{l}\mathrm{SS}=12 \\
\mathrm{FBSS}=13 \\
\mathrm{HD}=29\end{array}$ & Selective nerve block & $\begin{array}{l}\text { PRF at } 1 \text { or more } \\
\text { adjacent levels } 120 \mathrm{~s}\end{array}$ & $\begin{array}{l}\text { PRF repeated in pts } \\
\text { who at } 60 \mathrm{~d} \text { had NRS } \\
>5 \text { if }>50 \% \text { pain } \\
\text { reduction at } 30 \mathrm{~d} \\
\text { NRS and GPE at } 1,2,3 \\
\text { and } 6 \text { months } \\
\end{array}$ & $\begin{array}{l}\text { GPE } \geq 50 \% \\
\text { at } 3 \text { months } 52 \% \\
(\mathrm{HD}), 58 \% \text { (SS), } \\
15 \% \text { (FBSS) }\end{array}$ & None \\
\hline $\begin{array}{l}\text { Simopoulos } \\
2008 \\
{[13]}\end{array}$ & $\mathrm{P}$ & $\begin{array}{l}76 \mathrm{pts} \\
37 \mathrm{PRF} \\
39 \mathrm{PRF}+\mathrm{CRF}\end{array}$ & $\begin{array}{l}\text { Segmental pain of } \\
\text { lumbar or sacral } \\
\text { origin }\end{array}$ & $\begin{array}{l}\text { Clinical examination, } \\
\text { complete but temporary } \\
\text { relief radicular pain after } \\
3 \text { diagnostic/ therapeutic } \\
\text { blocks (LA + corticosteroid) }\end{array}$ & $\begin{array}{l}\text { PRF } 120 \mathrm{~s} \\
\text { or PRF } 120 \text { s followed } \\
\text { by CRF at max tolerat- } \\
\left.\text { ed temp (mean } 54^{\circ} \mathrm{C}\right) \\
\text { for } 60 \mathrm{~s} \text {. } \\
\text { Resp } 32 \% \text { and } 26^{\circ} \% \\
\text { of patients treated at } \\
2 \text { levels. }\end{array}$ & $\begin{array}{l}\text { Monthly evaluation, up } \\
\text { to } 1 \text { year, } \\
\text { Successful outcome : } \\
\text { VAS reduction of } 2 \\
\text { points or more }\end{array}$ & 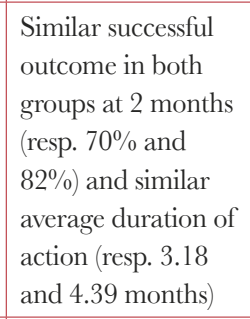 & None though screened for \\
\hline $\begin{array}{l}\text { Chao } 2008 \\
{[14]}\end{array}$ & $\mathrm{R}$ & $\begin{array}{l}116 \text { pts at lumbar } \\
\text { level }\end{array}$ & $\begin{array}{l}\text { Lumbar radicular } \\
\text { pain }\end{array}$ & $\begin{array}{l}\text { Clinical examination nerve } \\
\text { root compromise to mild or } \\
\text { moderate bulging disk }\end{array}$ & $\begin{array}{l}\text { PRF 120s }, 2 \text { to } 4 \text { levels, } \\
\text { repeat procedure } \\
\text { allowed }\end{array}$ & $\begin{array}{l}\text { lwk, } 1,3,6,9 \mathrm{mo} 1 \\
\text { year }\end{array}$ & $\begin{array}{l}>50 \% \text { pain reduc- } \\
\text { tion } 3 \mathrm{mo:} 45 \% \\
1 \text { year: } 23 \%\end{array}$ & None \\
\hline
\end{tabular}




\section{RESULTS}

terocaudally along the spina nerve. Finally, a maximum of $1 \mathrm{~mL}$ lidocaine $2 \%$ or bupivacaine $0.5 \%$ is injected. A prognostic block is considered positive if there is a 50\% reduction in symptoms 20 to 30 minutes after the intervention. The level that best satisfies the aforementioned criteria is chosen for PRF treatment.

Lumbar Percutaneous PRF • The insertion point for PRF treatment is determined in the same way as for the diagnostic block; this time, the projection is kept as medial as possible in order to maximally reach the ganglion spinale (DRG). The cannula is inserted in the direction of the radiation beam. While the cannula is still located in the superficial layers, the direction is corrected so that the cannula is projected as a point on the screen. Thereafter, the cannula is carefully inserted further until the point is located in the middle on the foramen intervertebrale in lateral view. The stylet is removed and exchanged for the RF probe (Cotop Amsterdam, Netherlands) 22G 100mm probe with a $5 \mathrm{~mm}$ active tip. The probe is connected to the radiofrequency generator (Neurotherm NT1 100, Massachusetts, USA). The impedance is checked, and thereafter, the sensory threshold. The patient should now feel tingling at a voltage of $<0.5 \mathrm{~V}$. If these criteria are met, the position of the cannula is recorded in two directions on a video printer. Thereafter, a pulsed current (routinely $20 \mathrm{~ms}$ current and $480 \mathrm{~m}$ without current) is applied for $120 \mathrm{~s}$ with an output of $45 \mathrm{~V}$; during this procedure, the temperature at the tip of the electrode may not surpass $42^{\circ} \mathrm{C}$.

\section{Statistical analysi}

Data were analyzed using SPSS 15.0. Baseline characteristics (age, gender, duration of pain, level an side of PRF) were assessed. Inferences about means from continuous data were based on standard parametric statistics. Success was defined by the GPE and VAS score (a score of 6 or 7 or $\pm 50 \%$ pain relief). Success rates for pain relief with a 95\%-confidence interval were determined and differences in proportion were tested.

Influence of age on success rate was examined using the t-test. For the influence of sex, level treated (L4, L5 or S1), side, duration of pain (<6 months, 6-24 months and >24 months) and FBSS status the Chi-square test was used.

Change in need of pain medication was tested by the paired sample test. A p-value of $\leq 0.05$ was considered statistically significant.

A Kaplan-Meier curve was constructed to determine the time-dependent success rate. ${ }^{22}$

Two out of the 60 included patients received a second PRF treatment in the period 2007-2009. In one case, the time elapsed between the 2 interventions was 1 year, which justified considering it as two separate cases. In another case a repeat intervention was carried out after 3 months because of lack of success. This patient finally had a positive result after a year. Because of the initial negative result, this patient was regarded as a failure and the second treatment was excluded.

Information on 61 PRF treatments adjacent to the lumbar DRG in 29 men and 31 women was retrieved. The mean age of the study population was 58 years and the mean duration of complaints was 8.9 months (SD 8). (Table 3$)$

Table 3 : Baseline characteristics in patients with successful treatment and in patients with unsuccessful treatment

\begin{tabular}{|c|c|c|c|c|c|}
\hline \multirow{2}{*}{$\begin{array}{l}N=61 \\
\text { Age (mean) }\end{array}$} & \multicolumn{2}{|c|}{$\begin{array}{l}\text { Pain reduction successful } \\
N=18\end{array}$} & \multicolumn{2}{|c|}{$\begin{array}{l}\text { Pain reduction not successful } \\
\mathrm{N}=43\end{array}$} & \multirow{2}{*}{\begin{tabular}{|l|} 
P value \\
0.93 \\
\end{tabular}} \\
\hline & $58($ SD 12.9) & & $58($ SD 12) & & \\
\hline \multicolumn{6}{|l|}{ Gender } \\
\hline Male & 9 & $30 \%$ & 21 & $70 \%$ & \\
\hline Female & 9 & $29 \%$ & 22 & $71 \%$ & \\
\hline $\begin{array}{l}\text { (Mean) Change in } \\
\text { Medication(MQS) }\end{array}$ & 2.4 (SD3.6) & & $0.7(\mathrm{SD} 2,1)$ & & 0.003 \\
\hline PRF level & & & & & 0.63 \\
\hline L4 & 5 & $33 \%$ & 10 & $66 \%$ & \\
\hline L5 & 11 & $27 \%$ & 30 & $73 \%$ & \\
\hline $\mathrm{S} 1$ & 2 & $40 \%$ & 3 & $60 \%$ & \\
\hline Side & & & & & 0.34 \\
\hline right & 8 & $24 \%$ & 25 & $76 \%$ & \\
\hline left & 10 & $36 \%$ & 18 & $64 \%$ & \\
\hline Duration of Pain & & & & & 0.76 \\
\hline $0-5$ & 9 & $30 \%$ & 21 & $68 \%$ & \\
\hline $6-24$ & 7 & $28 \%$ & 18 & $72 \%$ & \\
\hline$>25$ & 2 & $33 \%$ & 4 & $67 \%$ & \\
\hline FBSS & & & & & 0.55 \\
\hline yes & 6 & $35 \%$ & 11 & $65 \%$ & \\
\hline no & 12 & $27 \%$ & 32 & $73 \%$ & \\
\hline
\end{tabular}

Two-tailed test. SD: standard deviation, PRF: pulsed radiofrequency, FBSS: failed back surgery syndrome

The evolution of the GPE for the total patient population is shown in figure 1. The primary endpoint defined as at least $50 \%$ pain relief for a period of 2 months or more, was achieved in 18 cases $(29.5 \%)$ of all the PRF-interventions. After 6 months pain relief was still present in 14 cases $(22.9 \%)$ and after 12 months in 8 cases $(13.1 \%$. 


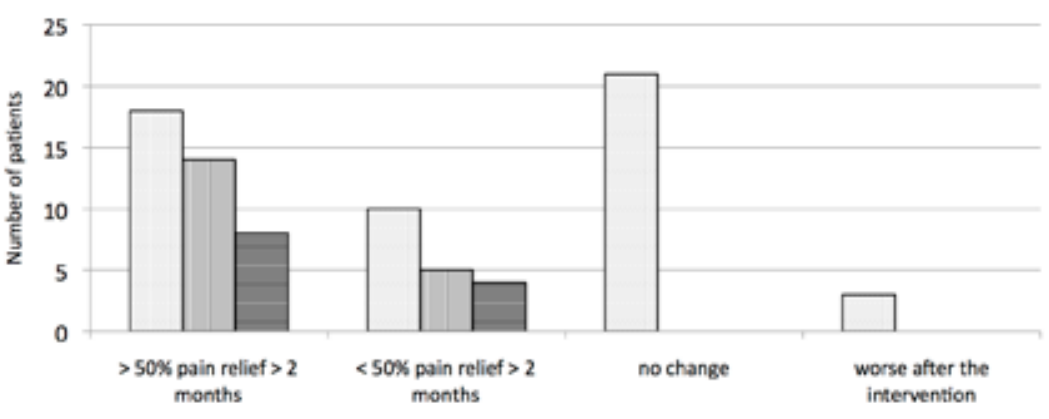

22 months 06 months 812 months

\section{Figure 1: Evolution of the Global Perceived Effect}

No significant differences in outcome were found when analyzed by age, sex, and level or side of PR treatment. The group of patients without previous surgery did not show a significant difference in treatment outcome compared to the FBSS patients. In the group having successful PRF treatment, the duration of pain relief ranged from 2 to 22 months, with a mean of 9.89 months. Furthermore, the need for analgesic medication after the PRF intervention according to the MQS was significantly more reduced in the success-group compared to the non-success-group (resp. 2.4 and 0.7$)(\mathrm{p}=0.003$ (table 3).

A Kaplan-Meier curve was constructed to examine the duration of satisfactory pain relief in the patients who had initial treatment success at 2 months (figure 2). ${ }^{22}$ At 6 months, there were 14 cases with significant pain reduction left ( $77.8 \%$ survival rate ), and 8 cases $(44.4 \%)$ at one year.

No complications were observed.

\section{Survival Function}

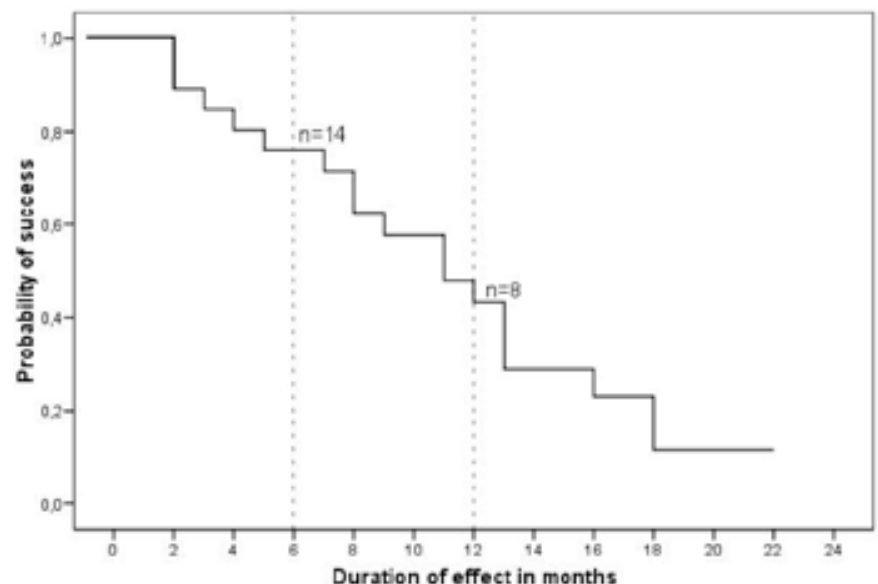

Figure 2: Kaplan-Meier curve estimating the duration of effect in patients with successful treatment at 2 months.
Our study indicates that $29.5 \%$ of the patients experience at least $50 \%$ pain reduction for minimally 2 months after a single PRF treatment adjacent to one level lumbar DRG There is a significant lesser need for pain medication in the group of patients having a successful treatment compared to those who are not successfully treated with PRF. Although in the general population the long-term outcome for radicular pain is much worse for the female population ${ }^{23}$, gender apparently does not influence the outcome of a PRF treatment.

In our study the duration of the beneficial effect of PRF in the success group varies from 2 to more than 22 months with a mean of 9.89 months. According to the Kaplan-Meier curve of our study $44.4^{\circ}$ of the patients who responded still have beneficial effect after one year.

The Medication Quantification Scale was used to evaluate the change in need of pain medication after the PRF treatment. Normally, the medication dosage is also used for calculating a particular MQS-score. ${ }^{21}$ Because of difficulties in collecting exact medication dosages in many patients, scoring of the medication was based upon the class. Despite this limitation the MQS seems to be the best option to estimate the change in need for medication. A significant reduction in MQS represents a reduced need for medication and consequently a potential reduction in side effects, which may represent an improvement in the patient's quality of life.

Side effects are often the reason for stopping the pharmacological treatment but also the in the literature published success rates regarding LSR are relatively low. A randomized controlled trial published in a non-PubMed indexed journal suggests a positive effect for the management of LSR for gabapentin, an anti-epileptic drug. ${ }^{24}$ Other studies were negative, showed only short term results or reported considerable side effects compared to the limited results., 25-28

The success rate obtained in our study is slightly lower than those of previously published reports on PRF adjacent to the lumbar DRG, ${ }^{8,11-14}$ There are, however, factors that may explain those differences such as repeat procedures in patients with unsatisfactory pain relief ${ }^{3,14}$ and the concomitant treatment of two adjacent levels. ${ }^{11-13}$ (see table 1

These clinical observations suggest that performing a repeat procedure at the same or an adjacent level might increase the likelihood of success. Also findings from animal experiments provide justification for a repeat intervention.

The dorsal root ganglion has a pivotal role in the pathophysiology of radicular pain. 29, 30 Animal experiments illustrated early and late induction of c-Fos expression in the dorsal horn after PRF application adjacent to the DRG. ${ }^{31,32}$ Furthermore PRF application was shown to induce cell stress as indicated by an increase in ATF3 in the DRG. ${ }^{33}$ These processes are likely to be temporary after a single treatment.

Not only the repetition of treatments at a single spinal level is possibly important, also animal research on afferent signaling suggests involvement of multiple spinal segments, obscuring the result of a single level treatment. Due to the Lissauer tract signals from propriospinal axons which arise from cells in the substantia gelatinosa can project to the substantia of neighboring spinal segments. ${ }^{34}$ In rat studies A delta fibres can project rostrally for 2 to up to 7 spinal segments (L2-S2) ${ }^{35}$, causing a possible multilevel excitation. There is evidence that some C-fibres may also have long-range projections in this tract. The central effects of sustained activation of nociceptive neurons in the compressed DRG might produce a centrally mediated chronic abnormal nerve impulse activity in the adjacent noncompressed Dent reflexes, i.e. centrally mediated antidromic action potentiab in an ac In a chronic compression model of the DRG L4 and L5, chronic inflammation responses by chemo- 
kines were monitored by the beta chemokine receptor 2 (CCR2). A significant up-regulation of CCR2 was noted in both compressed DRG's and non-compressed ("uninjured") adjacent DRG's. ${ }^{36}$ This confirmed by another paper where lumbosacral DRG's at some distance from a thoracic spinal cord injury exhibit a persistent inflammatory response involving macrophages and $\mathrm{T}$ lymphocytes. ${ }^{38}$

In an animal model of spinal nerve transection, a spontaneous activity in neighboring, intact C-fiber nociceptors of adjacent spinal nerves was noted. ${ }^{39,40} \mathrm{It}$ is possible that this C-fiber spontaneous activity produces a central sensitization.

In summary, anatomical information and animal data suggest that performing a repeat procedure at the same and/or other spinal levels would potentially have a more profound effect on this complex pathophysiology.

PRF is considered a safe procedure. In our study no complications were reported, also in the other studies on PRF adjacent to the DRG there was no mention of neurological complications (see table 1). In this study very basic inclusion and exclusion criteria were used for patient selection, resulting in a study population comparable to common medical practice. Stricter inclusion and exclusion criteri are recommended when selecting patients for a randomized controlled trial in order to be certain that the right group is being treated and evaluated and to make sure outcome is not confounded by other factors.

\section{CONGLUSIONS}

The results of this retrospective study suggest that a single PRF treatment adjacent to the lumbar DRC of patients suffering lumbosacral radicular pain reduces pain and the need for analgesic medication in approximately 1 out of 3 patients during a mean period of more than 9 months. The better results reported in other studies may be attributed to the fact that the intervention was repeated at the same or an adjacent level. Therefore a prospective randomized trial that has the objective of confirming ou results should allow the possibility for a repeat intervention. Future studies may additionally to pain reduction capture more detailed information on medication use and functional outcome.
References

1. Konstantinou K, Dunn KM. Sciatica: review of epidemiological studies and prevalence estimates. Spine Phila Pa 1976). 2008; 33:2464-2472.

2. Khoromi S, Patsalides A, Parada S, Salehi V, Meegan JM, Max MB. Topiramate in chronic lumbar radicular pain. J Pain. 2005; 6:829-836.

3. Dworkin RH, O'Connor AB, Backonja M, Farrar JT, Finnerup NB, Jensen TS, Kalso EA, Loeser JD, Miaskowski C, Nurmikko TJ, Portenoy RK, Rice AS, Stacey BR, Treede RD, Turk DC, Wallace MS. Pharmacologic management of neuropathic pain: evidence-based recommendations. Pain. 2007; 132:237-251.

4. Weber H, Holme I, Amlie E. The natural course of acute sciatica with nerve root symptoms in a double-blind placebo-controlled trial evaluating the effect of piroxicam. Spine. 1993; 18:1433-1438.

5. Luijsterburg PA, Verhagen AP Ostelo RW, van den Hoogen HJ. Peul WC, Avezaat CJ, Koes BW. Physical therapy plus general practitioners' care versus general practitioners' care alone for sciatica: a randomised clinical trial with a 12-month follow-up. Eur Spine J. 2008; 17:509-517.

6. Hildebrandt B, Wust P, Ahlers $O$, Dieing A, Sreenivasa $G$, Kerner $T$, Felix $R$, Riess $H$. The cellular and molecular basis of hyperthermia. Crit Rev Oncol Hematol. 2002; 43:33-56.

7. Yonezawa M, Otsuka T, Matsui N, Tsuji H, Kato KH, Moriyama A, Kato T. Hyperthermia induces apoptosis in malignant fibrous histiocytoma cells in vitro. Int J Cancer. 1996; 66:347-351.

8. Sluijter ME, Cosman ER, Rittman IIWB, van Kleef $M$. The effects of pulsed radiofrequency field applied to the dorsal root ganglion - a preliminary report. The Pain Clinic. 1998; 11:109-117.

9. Cahana A, Van Zundert J, Macrea L, van Kleef M, Sluijter M. Pulsed Radiofrequency: Current Clinical and Biological Literature Available. Pain Medicine. 2006; 7:411-423.

10. Munglani R. The longer term effect of pulsed radiofrequency for neuropathic pain. Pain. 1999; 80:437-439.

11. Teixeira A, Grandinson M, Sluijter M. Pulsed Radiofrequency for radicular pain due to a herniated in tervertebral disc - an initial report. Pain Practice. 2005; 5:111-115.

12. Abejon D, Garcia-del-Valle S, Fuentes ML, Gomez-Arnau JI, Reig E, van Zundert J.Pulsed radiofrequency in lumbar radicular pain: clinical effects in various etiological groups. Pain Pract. 2007; 7:21-26.

13. Simopoulos TT, Kraemer J, Nagda JV, Aner M, Bajwa ZH. Response to pulsed and continuous radiofrequency lesioning of the dorsal root ganglion and segmental nerves in patients with chronic lumbar radicular pain. Pain Physician. 2008; 11:137-144.

14. Chao SC, Lee HT, Kao TH, Yang MY, Tsuei YS, Shen CC, Tsou HK. Percutaneous pulsed radiofrequency in the treatment of cervical and lumbar radicular pain. Surg Neurol. 2008; 70:59-65.

15. Shabat S, Pevsner Y, Folman Y, Gepstein R. Pulsed radiofrequency in the treatment of patients with chronic neuropathic spinal pain. Minim Invasive Neurosurg. 2006; 49:147-149.

16. Pevzner E, David R, Leitner Y, Pekarsky I, Folman Y, Gepstein R. [Pulsed radiofrequency treatment of severe radicular pain]. Harefuah. 2005; 144:178-180, 231.

17. Vroomen PC, de Krom MC, Knottnerus JA. Diagnostic value of history and physical examination in patients suspected of sciatica due to disc herniation: a systematic review. J Neurol. 1999; 246:899-906.

18. Kerr RS, Cadoux-Hudson TA, Adams CB. The value of accurate clinical assessment in the surgical management of the lumbar disc protrusion. J Neurol Neurosurg Psychiatry. 1988; 51:169-173.

19. Likert R. A technique for the measurement of attitudes. Archives of Psychology. 1932; 22:140.

20. Kamper SJ, Ostelo RW, Knol DL, Maher CG, de Vet HC, Hancock MJ. Global Perceived Effect scales provided reliable assessments of health transition in people with musculoskeletal disorders, but ratings are strongly influenced by current status. J Clin Epidemiol. 2010; 63:760-766 e761.

21. Gallizzi M, Gagnon C, Harden RN, Stanos S, Khan A. Medication Quantification Scale Version III: internal validation of detriment weights using a chronic pain population. Pain Pract. 2008; 8:1-4.

22. Bland J, Altman D. Survival probabilities (the Kaplan-Meier method). BMJ. 1998; 317:1572. 
23. Peul WC, Brand R, Thomeer RT, Koes BW. Influence of gender and other prognostic factors on outcome of sciatica. Pain. 2008; 138:180-191.

24. Yildirim K, Kataray $S$. The effectiveness of gabapentin in patients with chronic radiculopathy. The Pain Clinic. 2003; 15:213-218.

25. Baron R, Freynhagen R, Tolle TR, Cloutier C, Leon T, Murphy TK, Phillips K. The efficacy and safety of pregabalin in the treatment of neuropathic pain associated with chronic lumbosacral radiculopathy. Pain. 2010; 150:420-427

26. Khoromi S, Cui L, Nackers L, Max MB. Morphine, nortriptyline and their combination vs. placebo in patients with chronic lumbar root pain. Pain. 2007; 130:66-75.

27. Finckh A, Zufferey $P$, Schurch MA, Balague F, Waldburger M, So AK. Short-term efficacy of intravenous pulse glucocorticoids in acute discogenic sciatica. A randomized controlled trial. Spine (Phila Pa 1976). 2006; 31:377-381.

28. Friedman BW, Esses D, Solorzano C, Choi HK, Cole M, Davitt M, Bijur PE, Gallagher EJ. A randomized placebo-controlled trial of single-dose IM corticosteroid for radicular low back pain. Spine (Phila Pa 1976). 2008; 33:E624-629.

29. Van Zundert J, Harney D, Joosten EA, Durieux ME, Patijn J, Prins MH, Van Kleef M. The role of the dorsa root ganglion in cervical radicular pain: diagnosis, pathophysiology, and rationale for treatment. Reg Anesth Pain Med. 2006; 31:152-167.

30. Abram SE. Pain mechanisms in lumbar radiculopathy. Anesth Analg. 1988; 67:1135-1137.

31. Van Zundert J, de Louw AJ, Joosten EA, Kessels AG, Honig W, Dederen PJ, Veening JG, Vles JS, van Kleef M. Pulsed and continuous radiofrequency current adjacent to the cervical dorsal root ganglion of the rat induces late cellular activity in the dorsal horn. Anesthesiology. 2005; 102:125-131.

32. Higuchi $Y$, Nashold BS, Sluijter ME, Cosman E, Pearlstein RD. Exposure of the dorsal root ganglion in rats to pulsed radiofrequency currents activates dorsal horn lamina I and II neurons. Neurosurgery. 2002, 50:850-856

33. Hamann W, Abou-Sherif S, Thompson S, Hall S. Pulsed radiofrequency applied to dorsal root ganglia causes a selective increase in ATF3 in small neurons. Eur J Pain. 2006; 10:171-176.

34. Wall PD, Lidierth M, Hillman P. Brief and prolonged effects of Lissauer tract stimulation on dorsal horn cells. Pain. 1999; 83:579-589.

35. Lidierth M. Long-range projections of Adelta primary afferents in the Lissauer tract of the rat. Neurosci Lett. 2007; 425:126-130.

36. White FA, Sun J, Waters SM, Ma C, Ren D, Ripsch M, Steflik J, Cortright DN, Lamotte RH, Miller RJ Excitatory monocyte chemoattractant protein-1 signaling is up-regulated in sensory neurons after chronic compression of the dorsal root ganglion. Proc Natl Acad Sci U S A. 2005; 102:14092-14097.

37. Lin $Q$, Zou X, Willis WD. Adelta and C primary afferents convey dorsal root reflexes after intradermal injection of capsaicin in rats. J Neurophysiol. 2000; 84:2695-2698.

38. McKay SM, McLachlan EM. Inflammation of rat dorsal root ganglia below a mid-thoracic spinal transection. Neuroreport. 2004: 15:1783-1786.

39. Ali Z, Ringkamp M, Hartke TV, Chien HF, Flavahan NA, Campbell JN, Meyer RA. Uninjured C-fiber nociceptors develop spontaneous activity and alpha-adrenergic sensitivity following L6 spinal nerve ligation in monkey. J Neurophysiol. 1999; 81:455-466.

40. Wu G, Ringkamp M, Hartke TV, Murinson BB, Campbell JN, Griffin JW, Meyer RA. Early onset of spontaneous activity in uninjured C-fiber nociceptors after injury to neighboring nerve fibers. J Neurosci. 2001; $21: R C 140$

41. Sheth RN, Dorsi MJ, Li Y, Murinson BB, Belzberg AJ, Griffin JW, Meyer RA. Mechanical hyperalgesia after an L5 ventral rhizotomy or an L5 ganglionectomy in the rat. Pain. 2002; 96:63-72.

\section{Chapter VI}

Pulsed radiofrequency for chronic intractable lumbosacral radicular pain: a six-month cohort study.

Van Boxem Koen, MD, FIPP a,b; de Meij Nelleke, MSc a; Kessels Alfons, MD, MSc c; van Kleef Maarten, MD, PhD, FIPP a,d; Van Zundert Jan, MD, PhD, FIPP e.

\begin{abstract}
a Department of Anesthesiology and Pain Medicine Maastricht University Medical Centre MUMC, The Netherlands. b Department of Anesthesiology - Critical Care and Multidisciplinary Pain Centre, Sint-Jozefkliniek Bornem \& Willebroek, Beloium. c Clinical Epidemiology and Medical Technology Assessment, University Hospital Maastricht, The Netherlands. d Department of Anesthesiology and Pain management VUMC Amsterdam, The Netherlands. e Department of Anesthesiology, Critical Care, Emergency Medicine and Multidisciplinary Pain Centre, ZOL, Genk/ Lanaken, Belgium
\end{abstract}

Submitted 


\section{ABSTRAGT}

Background and objectives

There is little evidence concerning the medical management of lumbosacral radicular pain. The prognosis for patients suffering pain for more than 3 months is poor. Pulsed radiofrequency treatment of the dorsal root ganglion has been suggested as a minimally invasive treatment. We studied the effect on pain and quality of life of pulsed radiofrequency treatment of the dorsal root ganglion in patients with chronic, severe lumbosacral radicular pain.

\section{Methods}

Patients with lumbosacral radicular pain were screened to select a homogeneous population. Pulsed radiofrequency treatment of the dorsal root ganglion was performed at L5 or S1. Evaluation was carried out at 6 weeks, 3 and 6 months. Pain reduction and "fully recovered" or "much improvement" in terms of the global perceived effect were the primary outcomes. Quality of life (RAND-36), disability (Oswestry Disblity Index), and the neuropathic pain sales LANSS and DN4 were registered at each time point. Medication use was scored with the Medication Quantification Scale (MOSIII).

\section{Results}

Out of 461 screened patients, 65 were included. According to the intention to treat analysis, clinical success was achieved in $56.9 \%, 52.3 \%$ and $55.4 \%$ of the patients at respectively 6 weeks, 3 and 6 D-36 quality of life improved significantly while the mental component remained unchanged. The number of patients on opioids was reduced.

\section{Conclusions}

Pulsed radiofrequency treatment of the dorsal root ganglion may be considered for patients with chronic, severe lumbosacral radicular pain refractory to conventional medical management. 


\section{INTRODUCTION}

Lumbosacral radicular pain is an important healthcare problem. In the general population older than 30 years of age, up to $5 \%$ suffer low back pain radiating into the leg, making it probably the most commonly years of age, up to $5 \%$ suffer low back pain radiating into the leg, making it probably the most commonly
occurring form of neuropathic pain. ${ }^{1}$ Acute lumbosacral radicular pain, caused by disc herniation and/ or nerve root entrapment, improves considerably in the short-term. About three quarters of patient will have symptoms of recovery after three months, however there is a high recurrence rate, and when pain persists after this period the prognosis is rather unfavorable, especially in the female population. Of all patients referred for secondary care and receiving conservative care or surgery if necessary about Or reduced functionality leading to incapacily to work. A quarter of patients are still out of work 2 years after onset. ${ }^{4}$ They have lower levels of health-related quality of life (HRQoL) than patients suffering other types of neuropathic pain, or other chronic disease like cancer, chronic pulmonary disease, type 2 diabetes, stroke and heart failure.

Despite its high prevalence and significant impact on quality of life, the optimal conservative treatmen for patients with radicular pain is not known. Considering the moderate quality of published evidence, the efficacy and tolerability of pharmacological treatment in primary care for patients with lumbosacra radicular pain is unclear. Pulsed radiofrequency (PRF) treatment uses high-frequency current intermittently and its use adjacent to the dorsal root ganglion (DRG) has been suggested for the treatment of radicular pain..$^{6-12}$ The optimal settings for PRF (parameters, location, number of treatments...) have not been fully elucidated. In several studies a repeat procedure was performed when the pain reduction of the first intervention was not clinically satisfactory, $6,9,15$

We performed this observational study to determine the effect of PRF adjacent to the DRG on pain and quality of life, in a strictly selected population of patients suffering chronic and severe lumbosacral radicular pain at 6 weeks, at 3 and 6 months' follow-up.

\section{MATERIALS AND METHODS}

\section{Participants}

All consecutive patients with lumbosacral radicular pain were screened in the multidisciplinary pai centres of the Maastricht University Medical Centre, the Netherlands; Sint-Jozefkliniek, Bornem, Belgium; Ziekenhuis Oost-Limburg, Genk/Lanaken, Belgium; and Klinieken Noord-Antwerpen, Brasschaat, Belgium. The pain physicians in each centre have at least 5 years' experience (KVB, JVZ, MvK, Koen Lauwers). Most of the patients were referred by medical specialists (neurologists, neurosurgeons, orthopedic surgeons, and rehabilitation physicians).

The institutional Ethics Review Board of each of the participating centres approved the trial and all patients signed an informed consent form. The trial was registered as NCT00991237 (ClinicalTrials. gov).

Patients were eligible for the study if they reported a unilateral and monosegmental radiating pain down the leg, into the foot to the hallux (L5) or lateral side of the foot (S1), suggesting involvement of the lumbar spinal nerve along the affected nerve root concordant with the MRI or CT scan findings. The radicular syndrome should have been present for at least 3 months, despite conservative treatment consisting of medication and physical therapy. The leg pain should be the primary complaint with an average pain score of at least 5 on the Numerical Rating Scale (NRS, $0=$ no pain and $10=$ the worst pain imaginable)

The patients' pain had to be therapy-resistant despite the conventional medical management (CMM) that was optimized (e.g. acetaminophen, tramadol, amitryptiline, gabapentin, pregabalin). In patient with a degree of pan reduction that was not atifoctory however, the medical promegemt tained. The treating physician could adapt the dose and type of medical management based on the patient's report on pain relief.

Exclusion criteria were: younger than 18 and older than 80, an atypical radiation pattern, bilatera symptoms or involvement of more than 1 segment (L5 and S1 radiation), a history of cancer, fractures of the lumbar vertebrae, myelopathy, systemic diseases or connective tissue diseases, diabetes mellitus type I, coagulation disorders and use of anticoagulants, multiple sclerosis, pregnancy, the presence of a cardiac pacemaker or spinal cord stimulator and RF or PRF treatment of the lumbar dorsal root ganglion (DRG) in the last year. When the patient had a score higher than 45 on the Pain Catastrophizing Scale, he/she was first referred to a psychologist for further evaluation. Referred leg pain due to localized hip, knee or back pain pathology was excluded during the standardized physical and neurological examination.

Patients first received a nerve root block at L5 or S1, depending on the typical radiation pattern and consisting of $0.7 \mathrm{~mL}$ of $2 \%$ lidocaine. Independent of the result of thi block, a PRF treatment at the same level concordant with clinical symptoms and adjacent to the DRG was performed within a week At 6 weeks, 3 months and 6 months after the procedure the outcome was evaluated.

If patients at the 6-week evaluation reported clinically insufficient pain relief, defined as less than $50^{\circ}$ pain relief and less than 2 points reduction on the NRS, an additional single repeat PRF procedure was proposed at the same or an adjacent level according to clinical symptoms. A single repeat PRF procedure was also performed if the patient considered the effect of the first PRF intervention was not sufficient. Conventional medical management (e.g. acetaminophen, tramadol, amitryptiline, gabapentin or pregabalin) was further allowed if pain was not adequately controlled. All medication use was recorded.

ntervention technique

The technique used has been described previously. ${ }^{1}$ The procedures were performed by experienced pain specialists (MvK, JVZ, KVB, KL).

In short: the patient is placed in a prone position on the translucent operation table. The C-arm is adjusted to parallel the X-rays with the end plates of the relevant level. The C-arm is then rotated until the processus spinosus projects over the contralateral facet column. The injection point is found by projecting a metal ruler over the medial part of the intervertebral foramen in order to maximally reach the DRG. In this tunnel view the cannula $(10 \mathrm{~cm}$ long, $22 \mathrm{G}$ straight $\mathrm{RF}$ cannula with $5 \mathrm{~mm}$ active tip ,SMK, Neurotherm Inc. USA) is carefully inserted further until the point is located in the middle of the intervertebral foramen in lateral view. The stylet is removed and exchanged for the RF probe Stimulation at $50 \mathrm{~Hz}$ should produce a tingling sensation at a voltage of less than $0.5 \mathrm{~V}$. In case of a threshold above $0.5 \mathrm{~V}$, the cannula is carefully advanced further until a correct sensory stimulation is found. The target was an impedance of less than $500 \Omega$; this was achieved by injecting $0.5 \mathrm{~mL}$ to $1 \mathrm{~mL}$ of saline $(0.9 \% \mathrm{NaCl})$ through the needle into each patient prior to PRF treatment. The PRF treatment was performed with an RF generator (Neurotherm NT1100, Neurotherm Inc. USA) with a 20 ms current, $2 \mathrm{~Hz}, 45 \mathrm{~V}, 2$ times for 2 minutes with a small interval in between. During the treatment the temperature at the electrode did not surpass $42{ }^{\circ} \mathrm{C}$. 


\section{RESULTS}

Outcome measurements

Evaluations were performed by an independent research nurse not involved in the treatment of the patients at 4 time points: after inclusion, at 6 weeks, at 3 months, and at 6 months. Pain intensity was assessed by measuring the pain in the leg according to the Numerical Rating Scale (NRS 11-point scale) 3 times a day, at predefined time points, for 4 consecutive days during the week prior to the control visits. Global perceived effect (GPE) was scored on a 7-point Likert Scale (Table 1). The primary outcome wa the success or failure of the treatment at 6 weeks and 3 and 6 months. Success was defined as a reductio in NRS of at least 2 points, or a GPE of 1 or 2 (fully recovered or much improvement).

Table 1 Likert scale 7-point scoring system: global perceived effect

\begin{tabular}{l|l} 
Score & Description \\
\hline 1 & fully recovered \\
\hline 2 & much improvement \\
\hline 3 & little improvement \\
\hline 4 & unchanged \\
\hline 5 & little worse \\
\hline 6 & much worse \\
\hline 7 & very bad \\
\hline
\end{tabular}

The quality of life was measured by RAND-36 and disability was assessed with the Oswestry Disability Index (ODI).

The neuropathic pain scales LANSS and DN4 (threshold resp. 12 and 4) were registered at each time point. Conventional medical management was continued for all patients; when necessary the dose of analgesics was adapted or switched to other medications for treating neuropathic pain (e.g. tramadol, opioids, amitryptiline, gabapentin, pregabalin). The use of medication was scored with the Medication Quantification Scale (MQSIII) using weights determined by surveying physician members of the American Pain Society. Medication that is considered as well tolerated is given a low weight (e.g. acetaminophen and tramadol: 2.4) while medication with more side effects is given a higher weight (e.g. tricyclic antidepressants: 2.7 , anticonvulsants-sodium channel blockers: 2.8; NSAIDs: 4; and corticosteroids: 4.9).

\section{Statistics}

Sample size • Based on literature we assumed that the success rate of PRF is $45 \%{ }^{6,13}$ To exclude with a power of $80 \%$ and $95 \%$ certainty that the success rate is lower than $25 \%, 38$ patients were needed. To take into account a loss at follow-up of $15 \%$, a total of 45 patients were planned to be included.

Analysis • Data were analyzed using SPSS 20.0 (IBM SPSS statistics). Analysis of the primary outcome measurement was by intention to treat, in which drop-outs were classified as failures.

Interval scaled variables were described with mean and standard deviation and nominal variables a percentages. For each patient it was determined whether the treatment was successful according to the definition above. Patients lost at follow-up were defined as a failure. The GPE was dichotomized (1-2 v 3-7), and based on the RAND parameters a Mental and a Physical Component Scale were calculated. The differences in the baseline values and outcome measurement were analyzed, using the Student's t-test. Changes over time of the outcome measures NRS, ODI, DN4, and MOSIII were analyzed using a linear multilevel mixed model analysis. The same methodology was used for missing values at specific time points. Significance was reached if $\mathrm{P}$ was less than 0.05
Between January 2010 and September 2012, all consecutive patients referred to the participating pain centres with presumed chronic lumbosacral radicular pain were screened for participation. Al patients were referred by specialists in physical medicine and rehabilitation, neurologists, orthopedic surgeons and neurosurgeons. Sixty-five patients out of a total of 461 screened were included in the study. Thirteen patients withdrew from the study before the 6 months evaluation point, of which 7 because of referral to back surgery, 4 received another treatment, such as surgery for another problem, during the trial period and were therefore excluded. Two patients were lost-to-follow up: one moved to another country and despite several trials to contact the 2nd patients could no longer be localized. They were all considered as failures, and intention-to-treat analysis was performed on 65 patients. The patient baseline characteristics are shown in Table 2.

Table 2: Baseline patient characteristics (SD)

\begin{tabular}{llr}
\hline Patient characteristics & $\mathbf{1 0 0} \%(\mathbf{n}=\mathbf{6 5})$ & mean (SD) \\
Age $\geq 55$ & $43.1(28)$ & \\
Gender & & \\
$\quad$ male & $27.7(18)$ & \\
$\quad$ female & $72.3(47)$ & \\
Duration of pain & & \\
$\quad$ 3-6 months & $27.7(18)$ & \\
$\quad$ 6-12 months & $29.2(19)$ & \\
$\quad$ 1 year & $43.1(28)$ & \\
Dermatome & & \\
$\quad$ L5 & $60.0(39)$ & \\
$\quad$ S1 & $40.0(26)$ & \\
Side & & \\
$\quad$ Left & $55.4(36)$ & \\
$\quad$ Right & $45.0(29)$ & \\
FBSS & $23.1(15)$ & \\
Age & & $51.80(14.3)$ \\
NRS & & $7.06(1.3)$ \\
Physical component scale (RAND-36) & & $33.40(6.7)$ \\
Mental component scale (RAND-36) & & $45.00(12.2)$ \\
ODI & & $43.11(14.0)$ \\
LANSS & & $8.80(5.0)$ \\
DN4 & & $4.50(2.0)$ \\
MQSIII & & $20.50(22.0)$
\end{tabular}

SD: standard deviation; FBSS: failed back surgery syndrome; NRS: numerical rating scale; RAND-36: quality of life measurement tool; ODI: Oswestry Disability Index; MQSIII: medication quantification scale version III

Primary outcome

At the different time points respectively $56.9 \%, 52.3 \%$, and $55.4 \%$ of a total of 65 included patients had clinical success on the GPE or NRS (intention-to-treat analysis). Thirteen patients had incomplete data, as already mentioned missing data were calculated with the linear multilevel mixed model 
analysis. To allow a graphical representation in time of the subpopulation with a NRS of 5 or more Fig. 1), patients with incomplete data were all considered as having an NRS of at least 7 (worst-case scenario). At the 6 -month evaluation 31 patients experienced a clinically relevant pain reduction mean 7.06 at baseline, 3.94 at 6 months) was observed (Fig. 2).

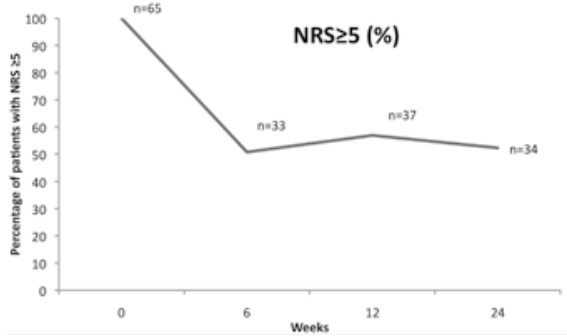

Figure 1: Evolution over time of percentage of patients with NRS of at least 5

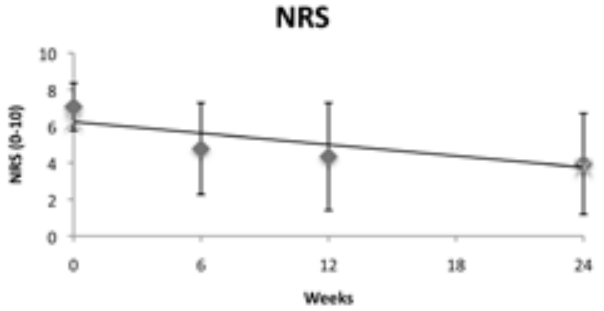

Fioure 2: Evolution over time of the mean Numerical Rating Scale (NRS) with standard deviation. The linear line represents linear regression after multilevel analysis
Secondary outcome

At 6 weeks 4 patients had withdrawn and 24 patients had no clinical success according to the primary outcome parameter (GPS and NRS). Five patients agreed with a second PRF and only one of these 5 patients was successful at 6 months.

The proportion of patients with a GPE reporting "fully recovered" or "much improved" of the total of 65 included patients was $35.4 \%, 33.8 \%$, and $47.7 \%$ (resp. 6 weeks, 3 months, and 6 months).

A significant change for the DN4 was observed with a reduction from 4.5 at baseline to 3.2 at 6 months ( $<0.001$, Fig. 3). The proportion of patients with a high probability of having neuropathic pain on the DN4 diminished from $73.0 \%$ at baseline to $53.0 \%$ at 6 months ( $\mathrm{p}=0.09$, worst-case scenario: all missing data considered as having neuropathic pain on DN4). The LANSS registered $30.8 \%$ as having neuropathic pain at baseline.

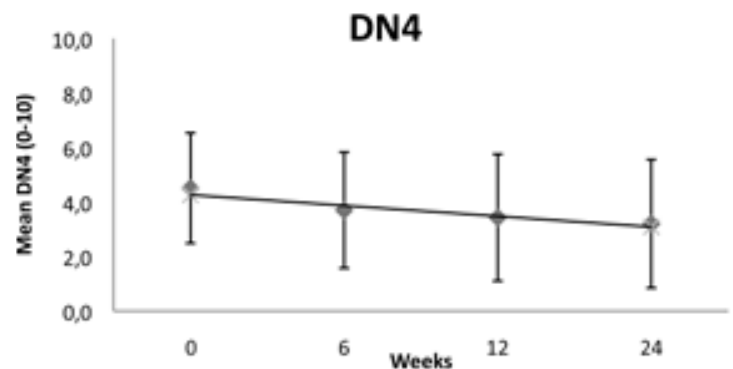

Figure 3: Evolution over time of the mean DN4 with standard deviation. The linear line represents linear regression after multilevel analysis.
A significant change for the RAND-36 quality of life could be seen in the Physical Component Scale at 3 and 6 months (resp. $p=0.008$ and $p<0.001$ ). The Mental Component Scale remained unchanged $(\mathrm{p}=0.23)$ (Fig. 4).

There was a significant reduction in the Oswestry Disability Index ( $p<0.05$, mean 43.11 at baseline, 35.06 at 6 months), although an 8 point reduction is considered as not clinically significant.

RAND 36

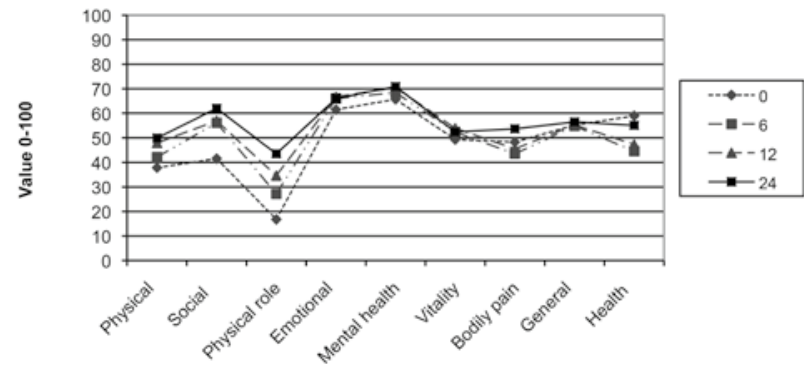

Figure 4: Evolution of different parameters of RAND-36 at baseline, 6, 12 and 24 weeks after PRF reatmen

No significant reduction in medication use could be seen, although a trend towards less consumption was shown ( $\mathrm{p}=0.112$ ). The number of patients on opioids was reduced from 10 at baseline to 2 at final evaluation. A decrease in the number of patients on tramadol and NSAIDs was also noted (Table 3).

Table 3: Number of patients on medication, divided into categories

\begin{tabular}{l|c|c|c|c}
$\mathrm{N}=65$ & 0 & $6 \mathrm{w}$ & $12 \mathrm{w}$ & $24 \mathrm{w}$ \\
\hline No medication & 15 & 31 & 31 & 26 \\
\hline Antidepressants/anticonvulsants & 23 & 16 & 10 & 9 \\
\hline acetaminophen/NSAIDs & 43 & 23 & 23 & 17 \\
\hline Opioids & 10 & 5 & 4 & 2 \\
\hline Other & 15 & 11 & 6 & 8 \\
\hline
\end{tabular}

No neurological side effects were noted, but $26.1 \%$ of the patients at 6 months' evaluation rated their pain as worse on GPE (worst-case scenario, including missing data and patients who received suroical intervention during the study period). 


\section{DISGUSSION}

\section{Principal findings}

This study shows that PRF for patients with chronic lumbosacral radicular pain results in clinical success in $55.4 \%$ of patients at 6 months using an intention-to-treat analysis. A significant reduction compared to baseline was noted in NRS and ODI. The DN4 showed a significant improvement, which is indicative of the fact that the neuropathic pain component disappears in some patients after PRF treatment. The RAND-36 showed significant improvement on the Physical Component Scale at 3 and 6 months. The MQSIII showed no significant reduction in medication use; however, the number of patients who needed additional opioids was reduced at 6 months. A second PRF showed only in one out of five patients a success.

\section{Strengths of the study}

This is the first study on PRF for lumbosacral radicular pain with strict clinical inclusion criteria, chronic pain radiating into the foot in a dermatomal distribution with high pain scores in the leg concordant with the observations of medical imaging (MRI or CT scan) in order to select a homogenous patient population. This is important since it has been observed that more accurate patient selection improves the outcome of interventional studies. ${ }^{14}$ More than $70 \%$ of this population suffered severe lumbosacral radicular pain for more than 6 months and $43 \%$ even suffered pain for more than 1 year. Over $70 \%$ of the patients were women. It has been documented that female gender and duration of the lumbosacral pain are two factors that are predictive of a negative natural evolution. Moreover, the prognosis for patients with lumbosacral radicular pain for more than 3 months, and high pain scores in the leg, was reported to be unfavorable ${ }^{15}$ and with a high recurrence rate. ${ }^{16}$

Both the DN4 and LANSS pain questionnaires were used to assess the presence of neuropathic pain. According to the LANSS, only $30.8 \%$ of the included patients suffered neuropathic pain. The DN4 however, showed that $73.8 \%$ of the patients were considered as having neuropathic pain at baseline This is in line with the $80 \%$ prevalence of a positive DN4 in patients with pain radiating toward the foot in a dermatomal distribution, if neurological signs are present (sensory deficits, muscular weakness, absent or reduced reflexes). ${ }^{17}$ The low incidence of neuropathic pain, according to the LANSS, is possibly due to the higher weight of autonomic clinical symptoms in its calculation. These sions seldom occur in clinical practice in patients with LSR; perhaps the LANSS is less suited to discriminating neuropathic pain in this specific population.

The use of DN4 as outcome measure for interventional pain therapy in patients with neuropathic pai may be considered in the future.

\section{Weaknesses/limitations of the study}

As is inherent with all nonrandomized prospective studies, there is no control group to eliminate the bias of a placebo or spontaneous resolution of symptoms. Two excellent studies demonstrated, however, that in patients with lumbosacral radicular pain lasting more than 3 months, there is little improvement. ${ }^{2,18}$ Performing a sham controlled randomized trial is difficult in interventional studie for patients with severe refractory symptoms like radicular pain. This is, amongst other reasons, due to the patients' reluctance to sign an informed consent when confronted with the risk of receiving a sham intervention. ${ }^{19}$

The low success rate after a second PRF could be due to selection mechanisms as only 5 of the 24 patents who did not experienced a success, agreed with a second PRF. A proportion of this subgroup were satisfied with a moderate clinical improvement and refused a repeat treatment.
The inclusion criteria were very specific to increase the likelihood of selecting patients with a clear chronic inflammation of the DRG. This is also the reason why only a L5 or S1 radicular pain distribution was included, because the $\mathrm{L} 4$ radiation is less specific. This resulted in a selection of patients highly refractory to conservative tratments and with a referrat rate to back surgery of $11 \%$ becilse of insufficient pain relief during the 6 month follow-up period. Patients with lumbosacral radicular pain randomized to surgery or conservative therapy have in general a high rate of nonadherence to the assigned treatment group. ${ }^{4}$ About 40 to $45 \%$ of patients randomized to a conservative group will receive surgery within a 2 years follow-up period, ${ }^{20}$ so this explains the proportion of patients withdrawn from the study protocol due to surgery.

\section{Working mechanism}

The mechanism of action of PRF adjacent to the DRG is far from being elucidated..$^{21}$ In vivo studies on nerve tissue showed that PRF induces a long-lasting inhibition of evoked synaptic activity. PRF induces changes in myelin configuration in animal experiments. After PRF, small electron microscopic changes were also observed in the sciatic nerve, although this was mainly restricted to the unmyelinated C-fibers and the thinly myelinated A- $\delta$ fibers.

Electron microscopic studies revealed that only small histological changes were present after use of PRF adjacent to the DRG. The expression of early gene c-Fos, a marker for neuronal activity, was rapidly increased (3hrs) at the dorsal horn after application of PRF adjacent to the DRG, but not after conventional radiofrequency.

Recent papers on the mechanism of action of PRF suggest further interference with the opioid system, noradrenaline and serotonin pathways, and microglia, all with behaviorally detectable pain relief in experimental radicular and neuropathic pain models.

The results show a relatively high proportion of females included in this study $(72.3 \%)$, which has not been observed in larger studies. ${ }^{22}$ The female population with lumbosacral radicular syndrome has a considerably worse outcome than the male population. The estimated unadjusted odds for a poor outcome after 1 year were 3.3 times higher for female patients than for males. ${ }^{2}$ Since $43 \%$ of the included patients had radicular symptoms for more than a year, the high proportion of females included in the study could possibly be explained by the less favorable spontaneous evolution.

\section{Meaning of the study: implications for clinicians}

Finding selection criteria to create homogenous study populations is particularly a challenge for studies on lumbosacral radicular pain. Anamnesis, clinical examination, imaging, electrophysiological testing or several combinations may help in clinical decision-making for the diagnosis of radicular pain, but each of these items lacks specificity to be considered as gold standard..$^{23}$ Since somatic referred pain is hardly reported to radiate to the hallux or to the lateral side of the foot, ${ }^{24}$ this specific feature was used to improve accuracy of inclusion. ${ }^{17}$ This is confirmed by the baseline patient characteristics: almost half of the patients had pain for more than a year, with a major disability (mean ODI 43.11), which is in line with a previous review on "sciatica" reporting a mean ODI of 44.65. A second item that improved homogenous patient inclusion was the presence of high pain scores in the leg at baseline (mean NRS at baseline 7.06). The latter is the only prognostic factor with strong evidence that predicts subsequent surgery ${ }^{25}$ suggesting a clear radicular involvement. To improve accuracy of inclusion for future studies on lumbosacral radicular pain, we suggest incorporating the inclusion criteria radiation into the hallux (L5) or lateral side of the foot (S1), together with high pain scores in the leg. 


\section{GONGLUSION}

This prospective study in patients with a chronic severe lumbosacral radicular syndrome reports a This prospective study in patients with a chronic severe lumbosacral radicular syndrome reports and on the physical component scale of quality of life was also observed. Radiation into the hallux (L5) or lateral side of the foot (S1), together with high pain scores in the leg, are inclusion criteria that could improve homogenous patient populations and are suggested for consideration in future studies on lumbosacral radicular pain.

These results will have to be confirmed in a prospective randomized trial.

Acknowledgments

The authors want to thank the cooperating physicians A. Balthasar MUMC, The Netherlands, K. Lauwers MD, KLINA Brasschaat Belgium, and P. Vanelderen, M. Puylaert, P. De Vooght, R. Mestrum, ZOL Genk/Lanaken, Belgium. The authors are grateful to Nicole Van den Hecke for administrative support.

\section{References}

1. Van Boxem K, Cheng J, Patijn J, van Kleef M, Lataster A, Mekhail N, Van Zundert J. 11. Lumbosacral radicular pain. Pain Pract. 2010; 10:339-358.

2. Peul WC, Brand R, Thomeer RT, Koes BW. Influence of gender and other prognostic factors on out come of sciatica. Pain. 2008; 138:180-191.

3. Haugen AJ, Brox JI, Grovle L, Keller A, Natvig B, Soldal D, Grotle M. Prognostic factors for non-success in patients with sciatica and disc herniation. BMC Musculoskelet Disord. 2012; 13:183.

4. Grovle L, Haugen AJ, Keller A, Ntvig B, Brox JI, Grotle M. Prognostic factors for return to work in patients with sciatica. Spine J.2013.

5. Doth AH, Hansson PT, Jensen MP, Taylor RS. The burden of neuropathic pain: a systematic review and meta-analysis of health utilities. Pain. 2010; 149:338-344.

6. Abejon D, Garcia-del-Valle S, Fuentes ML, Gomez-Arnau JI, Reig E, van Zundert J. Pulsed radiofrequency in lumbar radicular pain: clinical effects in various etiological groups. Pain Pract. 2007; 7:21-26.

7. Teixeira A, Grandinson M, Sluijter M. Pulsed Radiofrequency for radicular pain due to a herniated intervertebral disc - an initial report. Pain Pract. 2005; 5:111-115.

8. Munglani R. The longer term effect of pulsed radiofrequency for neuropathic pain. Pain. 1999, 80:437-439.

9. Sluijter ME, Cosman ER, Rittman IIWB, van Kleef $M$. The effects of pulsed radiofrequency field applied to the dorsal root ganglion - a preliminary report. The Pain Clinic. 1998; 11:109-117.

10. Simopoulos TT, Kraemer J, Nagda JV, Aner M, Bajwa ZH. Response to pulsed and continuous radiofrequency lesioning of the dorsal root ganglion and segmental nerves in patients with chronic lumbar radicular pain. Pain Physician. 2008; 11:137-144.

11. Van Boxem K, van Bilsen J, de Meij N Herrler A, Kessels $F$ Van Zundert J van Kleef M Pulsed radiofrequency treatment adjacent to the lumbar dorsal root ganglion for the management of lumbosacral radicular syndrome: a clinical audit. Pain Med.2011: 12:1322-1330.

12. Van Zundert J, Patijn J, Kessels A, Lame I, van Suijlekom H, van Kleef M. Pulsed radiofrequency adjacent to the cervical dorsal root ganglion in chronic cervical radicular pain: a double blind sham controlled randomized clinical trial. Pain. 2007; 127:173-182.

13. Chao SC, Lee HT, Kao TH, Yang MY, Tsuei YS, Shen CC, Tsou HK. Percutaneous pulsed radiofrequency in the treatment of cervical and lumbar radicular pain. Surg Neurol. 2008; 70:59-65.

14. Van Zundert J, Van Boxem K, Vanelderen P, Puylaert M, De Vooght P, Mestrum R, Heylen R, Visser $K$, Van Kleef M. Establishing the diagnosis of low back pain: patient selection for interventional pain medicine. Pain Manage. 2013; 3:1-8.

15. Vroomen PC, de Krom MC, Knottnerus JA. Predicting the outcome of sciatica at short-term follow-up. Br J Gen Pract. 2002; 52:119-123.

16. Suri P. Rainville J, Hunter DJ, Li L, Katz JN. Recurrence of radicular pain or back pain after nonsurgical treatment of symptomatic lumbar disk herniation. Arch Phys Med Rehabil 2012:93:690-695.

17. Attal N, Perrot S, Fermanian J, Bouhassira D. The neuropathic components of chronic low back pain a prospective multicenter study using the DN4 Questionnaire. J Pain. 2011; 12:1080-1087.

18. Freeman BJ, Ludbrook GL, Hall S, Cousins M, Mitchell B, Jaros M, Wyand M, Gorman JR. Randomized, Double-blind, Placebo-Controlled, Trial of Transforaminal Epidural Etanercept for the Treatment of Symptomatic Lumbar Disc Herniation. Spine (Phila Pa 1976). 2013; 38:1986-1994.

19. Van Zundert J, Van Boxem K, Joosten EA, Kessels A. Clinical trials in interventional pain management: Optimizing chances for success? Pain. 2010; 151:571-574

20. Weinstein JN, Lurie JD, Tosteson TD, Skinner JS, Hanscom B, Tosteson AN, Herkowitz H, Fischgrund 


\section{Ghapter VII}

(he Spine Patient Outcomes Research Trial (SPORT) observational cohort. JAMA. 2006; 296:2451-2459.

21. Van Boxem K, Huntoon M, Van Zundert J, Patijn J, van Kleef M, Joosten E. Pulsed radiofrequency: a review of the basic science as applied to the pathophysiology of radicular pain. A call for clinical translation Reg Anesth Pain Med. 2014; 39:149-159.

22. Pinto RZ, Maher CG, Ferreira ML, Hancock M, Oliveira VC, McLachlan AJ, Koes B, Ferreira PH. Epidural corticosteroid injections in the management of sciatica: a systematic review and metaanalysis. Ann Intern Med. 2012; 157:865-877.

23. el Barzouhi A, Vleggeert-Lankamp CL, Lycklama a Nijeholt GJ, Van der Kallen BF, van den Hout WB, Jacobs WC, Koes BW, Peul WC. Magnetic resonance imaging in follow-up assessment of sciatica. N Engl J Med. 2013; 368:999-1007.

24. Murphy DR, Hurwitz EL, Gerrard JK, Clary R. Pain patterns and descriptions in patients with radicular pain: Does the pain necessarily follow a specific dermatome? Chiropr Osteopat. 2009, 17:9.

25. Verwoerd AJ, Luijsterburg PA, Lin CW, Jacobs WC, Koes BW, Verhagen AP. Systematic review of prognostic factors predicting outcome in non-surgically treated patients with sciatica. Eur J Pain. 2013: 17:1126-1137.

Van Boxem Koen, MD, FIPP a,b; de Meij Nelleke, MSc a; Patijn Jacob, MD, PhD a; van Kleef Maarten, MD, PhD, FIPP a,c; Van Zundert Jan, MD, PhD, FIPP d; Kessels Alfons, MD, MSc e

a Department of Anesthesiology and Pain Medicine, Maastricht University Medical Centre, Maastricht, The Netherlands. b Department of Anesthesiology - Critical Care and Multidisciplinary Pain Centre, Sint-Jozefkliniek Bornem \& Willebroek, Belgium. c Department of Anesthesiology and Pain management VUMC Amsterdam, The Netherlands. d Department of Anesthesiology, Critical Care, Emergency Medicine and Multidisciplinary Pain Centre, Ziekenhuis Oost-Limburg Genk/Lanaken, Belgium. e Clinical Epidemiology and Medical Technology Assessment, University Hospital Maastricht, The Netherlands 


\section{ABSTRACT}

\section{Background}

In a previous prospective study on pulsed radiofrequency (PRF) treatment adjacent to the lumbar dorsal root ganglion (DRG) for patients with chronic lumbosacral radicular pain, we reported success in $55.4 \%$ of the patients at 6 months. Identification of predictors for success after PRF may improve outcome. We assessed the predictors of PRF in patients with chronic intractable lumbosacral radicular pain.

\section{Methods}

Patients with monosegmental chronic lumbosacral radicular pain of $\mathrm{L} 5$ or S1, first received a nerve root block at the corresponding level. Independent of the result of this block a PRF treatment at the same level was performed. At 6 weeks, 3 months and 6 months after the procedure the outcome was evaluated.

\section{Results}

Age $\geq 55$ was a predictive factor for successful outcome at 6 months while disability was a negative predictor.

The use of failed back surgery syndrome, gender, duration of pain, Numerical Rating Scale, level and side of treatment, DN4 and RAND-36 as predictor for success was not supported.

\section{Conclusions}

Successful outcome after PRF adjacent to the DRG, in patients with intractable chronic lumbosacral radicular pain is more likely in patients' $\geq 55$ years, whereas younger patients and those with a high disability probably will have a lower success rate. The diagnostic nerve root block has a limited predictive value. Combination of all these factors creates a fair predictive value. 


\section{INTRODUGTION}

Lumbosacral radicular pain can be considered as an important health care problem with the lowes quality of life compared to other types of neuropathic pain, or compared to other major chronic diseases. ${ }^{1}$ It is probably the most commonly occurring form of neuropathic pain ${ }^{2,3}$, thereby creating an important socio-economic problem. Although the majority of patients initially have a spontaneous recovery of symptoms, if severe pain persists after 3 months of onset, the long-term recovery unfavorable.- ${ }^{4-8}$ Two years after onset of lumbosacral radicular pain $25 \%$ of the patients are still unable to resume the professional activities. ${ }^{9}$ This high prevalence of chronic severe lumbosacral radicula pain may be attributed to 2 main factors. First the recurrence rate after an initial recovery within 3 months of onset is $40 \%$ of all patients referred for secondary care who were treated conservatively and/or were operated, report non-successful outcome at respectively 1 and 2 years follow-up. ${ }^{10}$

Pulsed radiofrequency (PRF) treatment uses high frequency current intermittently and its use adjacen to the dorsal root ganglion (DRG) has been suggested for the treatment of radicular pain. ${ }^{11-17}$ This target specific treatment obviously requires optimal identification of the causative level. Therefore a diagnostic block of the presumed causative dorsal root ganglion (DRG) has been sugested to determine the exact level of PRF treatment.

In a retrospective study at least 50\% pain relief after PRF of the lumbar DRG was achieved in $41 \%$ of the patients at 6 months. ${ }^{11}$ In patients with failed back surgery syndrome (FBSS) the use of PRF did not result in an improvement of pain. We conducted an outcome study to measure the effect of PRF a treatment option that can be considered in patients suffering chronic lumbosacral radicular pain refractory to conservative treatment. A good clinical outcome at 6 months was reported by $55.4 \%$ of

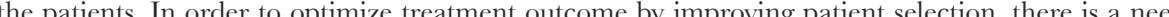
to identify those factors that may be predictive for the outcome of a PRF treatment. As part of the prospective outcome study, we assessed the parameters that could predict successful outcome of PRF adjacent to the DRG in patients with chronic intractable lumbosacral radicular pain.

All consecutive patients with lumbosacral radicular pain were screened in the multidisciplinary pain centres of the University Hospital Maastricht, Maastricht the Netherlands, Sint-Jozefkliniek, Bornem Belgium, Ziekenhuis Oost-Limburg, Genk/Lanaken Belgium and Klinieken Noord-Antwerpen, Brasschaat Belgium. The pain physicians in each centre have at least 5 years' experience (KVB, JVZ, $\mathrm{MvK}, \mathrm{KL}$ ). Most of the patients were referred by medical specialists (neurologists, neurosurgeons, orthopedic surgeons and rehabilitation physicians).

The institutional Ethics Review Board of each of the participating centres approved the trial and all patientssigned an informed consent form. The trial was registered as NCT00991237 (Clinical Trials.gov. Patients were eligible for the study if they reported a unilateral and monosegmental radiating pain down the leg, into the foot to the hallux (L5) or lateral side of the foot (S1), suggesting involvemen of the lumbar spinal nerve along the affected nerve root concordant with the MRI or CT-scan findings. ${ }^{18-21}$ The radicular syndrome should have been present for at least 3 months, despite conservative treatment consisting of medication and physical therapy, ${ }^{4,22}$ The leg pain should be the primary complaint with an average pain score of at least 5 on the Numerical Rating Scale (NRS - 11 point scale, $0=$ no pain and $10=$ the worst pain imaginable)

Exclusion criteria were: younger than 18 and older than 80, an atypical radiation pattern, bilateral symptoms or involvement of more than 1 seoment ( 5 and S1 radiation). A history of cancer, fracture of the lumbar vertebrae, myelopathy, systemic diseases or connective tissue diseases, diabetes mellitus type I, coagulation disorders and use of anticoagulants, multiple sclerosis, pregnancy, the presence of a cardiac pacemaker or spinal cord stimulator and RF or PRF treatment of DRG in the last year. When the patient had a score higher than 45 on the Pain Catastrophizing Scale (PCS), he/she was first referred to a psychologist for further evaluation. ${ }^{23}$

Patients first received a nerve root block at L5 or S1, depending on the typical radiation pattern and consisting of lidocaine $2 \% 0.7 \mathrm{~mL}$. Before performing the diagnostic block patients were asked to indicate the pain intensity in the leg on a NRS-11 point scale. Thirty minutes after the diagnostic block the patients were asked to rate again the pain intensity on the NRS. A reduction on the NRS of at least 2 points was considered a positive result. The patients' global perceived effect (GPE) was also assessed with a 7-point Likert scale. ${ }^{24}$ Patients reporting "full recovery" or "much improvement" were considered to have a positive result.

To allow assessment of the predictive value all patients, independent of the result of this block, received a PRF treatment at the same level concordant with clinical symptoms and adjacent to the L5 or S1 DRG within a week. At 6 weeks, 3 months and 6 months after the procedure the outcome was evaluated. If patients at the 6 -week evaluation reported clinically insufficient pain relief, defined as less than $50 \%$ pain relief and less than 2 points reduction on the NRS, an additional single repeat PRF procedure was proposed at the same or an adjacent level according to clinical symptoms. A single repeat PRF procedure was also performed if the patient considered the effect of the first PRF intervention was not sufficient. Conventional medical management (e.g. acetaminophen, tramadol, amitryptiline, gabapentin or pregabalin) was further allowed if pain was not adequately controlled.

\section{ntervention technique}

Diagnostic block • For the diagnostic block, the C-arm is adjusted in such a way that the X-rays run parallel to the end plates of the relevant level. Thereafter, the $\mathrm{C}$-arm is rotated until the processu spinosus projects over the contralateral facet column. With the $\mathrm{C}$-arm in this projection, the insertion point is found by projecting a metal ruler over the lateral part of the neuroforamen. This lateral approach reduces excesive overflow to adjacent level $\mathrm{A} 10-\mathrm{cm}$ long. 22-G needle is inserted here locally in the direction of the ravs. Thereafter, the direction is corrected such that the needle is projected as a point on the screen. The direction of the radiation beam is now modified to a profile (lateral) view, and the needle inserted until the point is located in the craniodorsal part of neurooramen. In an antero posterior (AP) view, the course of a small amount of contrast agent is followed with "real-time imaging"; it spreads out laterocaudally along the spinal nerve. If a correct imaging is not obtained, the needle is carefully advanced a little further. Finally, a small amount of contrast agent shows the course of the spinal nerve in an $\mathrm{AP}$ view. Lidocaine $2 \% 0.7 \mathrm{~mL}$ was then injected $0.2 \mathrm{~mL}$ stayed in the needle, $0.5 \mathrm{~mL}$ effectively injected). 
Lumbar Percutaneous PRF • The insertion point for PRF treatment is determined in the same way as for the diagnostic block; this time, the projection is kept as medial as possible in order to maximally reach the DRG. The cannula (22G $100 \mathrm{~mm}$ probe with a $5 \mathrm{~mm}$ active tip, Cotop Amsterdam,

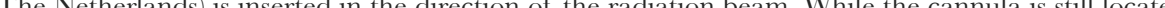
in the superficial layers, the direction is corrected so that the cannula is projected as a point on the screen. Thereafter, the cannula is carefully inserted further until the point is located in the middle on the neuroforamen in lateral view. The stylet is removed and exchanged for the RF probe. The probe is connected to the radiofrequency generator (Neurotherm NT1100, Massachusetts, MA, USA). The impedance is checked, and thereafter, the sensory threshold. The patient should now feel tingling at voltage of $<0.5 \mathrm{~V}$. In case of a threshold above $0.5 \mathrm{~V}$, the cannula is carefully advanced further until correct sensory stimulation is found. Thereafter, a pulsed current $(20 \mathrm{~ms}$ current, $2 \mathrm{~Hz})$ is applied for 2 times 120 seconds with an output of $45 \mathrm{~V}$, with a short interval between both treatments. During this procedure, the temperature at the tip of the electrode may not surpass $42^{\circ} \mathrm{C}$.

\section{Outcome measurements}

Patients' baseline characteristics: age, gender, duration of pain, and prior back surgery were noted. The affected side, level of pathology , pain intensity in the leg (NRS) measured according to the Jensen method ${ }^{25}$. quality of life (RAND 36$)^{26}$ and disability (Oswestry Disability index) ${ }^{27}$ were noted at baseline. The neuropathic character of pain was judged with DN-4 ${ }^{20,28}$ and LANSS. ${ }^{29}$

The use of medication at inclusion was scored with the Medication Quantification Scale (MQSIII) ${ }^{30}$. The primary aim of the analysis was to identify baseline variables that were indicators of success after PRF treatment.

Based on the RAND parameters a Mental and a Physical Component Scale were calculated. ${ }^{3}$ Success or failure of the PRF treatment was evaluated at 6 weeks and 6 months. Success was defined as a reduction in NRS of at least 2 points and a GPE of 1 or 2 (fully recovered or much improvement). Drop-outs were classified as failures.

\section{Statistics}

Possible predictors were the result of the diagnostic block, Failed Back Surgery Syndrome (FBSS), gender, age (dichotomized: $<55$ vs $\geq 55$ years), duration of complaints, level of PRF, side of PRF, DN4 (dichotomized : $<4$ vs $\geq 4$ ), Oswestry Disability Index (ODI), MOSIII, Physical Component Scale (CS) and Mental Component Scale of RAND-36 and use of opioids. Using a univariate logistic regression model the Odds Ratios and their Confidence Intervals were calculated. Those baselin characteristics were identified as predictors if the $\mathrm{P}$ - value was 0.1 or less. ${ }^{32} \mathrm{In}$ a second step all selected predictors were entered backward stepwise $(\mathrm{P}=0.1)$ in a multivariate logistic regression model. Receiver Operating Characteristics (ROC) curves were constructed and Area Under the Curve (AUC) were calculated of the selected predictors and the outcome of the multivariate regression model. To determine the influence of a second PRF on the performance of the diagnostic block, we also calculated the diagnostic Odds Ratio of the diagnostic block after one PRF treatment at 6 weeks. Data were analyzed using SPSS 20.0 (IBM SPSS statistics).

\section{RESULTS}

Between January 2010 and September 2012 all patients referred to the participating pain centres with Between January 2010 and September 2012 all patients referred to the participating pain centres with patients screened, 65 were included. Seven patients had to be referred for back surgery during the study period, 4 received another treatment such as surgery for another problem during the trial period and were therefore excluded. Two patients were lost-to-follow up at the 6 months evaluation. They were all considered as failures. Table 1 represents the baseline characteristics. None of the patients had to be excluded because of a score of more than 45 on PCS.

Twenty-four persons were not successful at 6 weeks and five of them received a second PRF.

The univariate analysis selected the results of the diagnostic block, age, MQSIII and ODI as predictors. The stepwise multivariate analysis with these predictors selected the diagnostic block, age and ODI as final predictors for a successful outcome at 6 months. The combination of all these final predictors gives an odds ratio of $83.2(\mathrm{p}=0.02,95 \% \mathrm{CI} 4.76-1454)$ for a successful outcome at 6 months. In table 2 the Diagnostic Odds Ratios (OR) and the OR of the stepwise multivariate regression analysis with their p-values and Confidence Interval are described.

Table 1. Baseline patient characteristics

\begin{tabular}{llr}
\hline Patient characteristics & $\mathbf{1 0 0} \%(\mathbf{n}=\mathbf{6 5})$ & mean (SD) \\
\hline Age $\geq 55$ & $43.1(28)$ & \\
$\quad$ Gender & & \\
$\quad$ male & $27.7(18)$ & \\
female & $72.3(47)$ & \\
Duration of pain & & \\
$\quad$ 3-6 months & $27.7(18)$ & \\
$\quad$ 6-12 months & $29.2(19)$ & \\
$\quad>1$ year & $43.1(28)$ & \\
Dermatome & & \\
$\quad$ L5 & $60.0(39)$ & \\
$\quad$ S1 & $40.0(26)$ & \\
Side & & \\
Left & $55.4(36)$ & \\
Right & $45.0(29)$ & \\
Failed Back Surgery & $23.1(15)$ & \\
Age & & $51.80(14.3)$ \\
NRS & & $7.06(1.3)$ \\
Physical CS (RAND-36) & & $33.40(6.7)$ \\
Mental CS (RAND-36) & & $45.00(12.2)$ \\
ODI & & $43.11(14.0)$ \\
LANSS & & $8.80(5.0)$ \\
DN4 & & $4.50(2.0)$ \\
MQSIII & & $20.50(22.0)$
\end{tabular}

$S D$ : standard deviation: FBSS: failed back surgery syndrome: NRS: numerical rating scale: RAND-36: quality of life measurement tool; ODI : Oswestry Disability Index; MQSIII: medication quantification scale version III; CS : Component Scale of RAND-36 
Table 2. The diagnostic Odds Ratios (OR) of all predictors as the results of the univariate regression analysis and the $\mathrm{OR}$ of the result of the stepwise multivariate regression analysis

\begin{tabular}{llll} 
& & & $95 \%$ C.I. \\
& OR & P & Lower - Upper \\
\hline Univariate model & & & \\
Gender & 0.52 & 0.26 & $0.17-1.62$ \\
Duration of symptoms in months & 0.72 & 0.29 & $0.40-1.32$ \\
Level diagnostic block & 0.61 & 0.33 & $0.22-1.64$ \\
Level PRF & 0.70 & 0.48 & $0.26-1.89$ \\
Side & 0.94 & 0.90 & $0.35-2.54$ \\
FBSS & 0.90 & 0.86 & $0.28-2.86$ \\
NRS & 0.82 & 0.32 & $0.56-1.21$ \\
DN4 & 0.91 & 0.44 & $0.71-1.16$ \\
DN4 $\geq 4$ & 1.14 & 0.81 & $0.38-3.47$ \\
LANSS & 1.30 & 0.62 & $0.45-3.82$ \\
MQSIII & 0.97 & 0.04 & $0.96-1.00$ \\
Opioid & 0.48 & 0.29 & $0.12-1.89$ \\
Physical CS (RAND-36) & 1.00 & 0.91 & $0.92-1.08$ \\
Mental CS (RAND-36) & 1.01 & 0.77 & $0.96-1.05$ \\
Age $\geq 55$ & 3.28 & 0.03 & $1.15-9.34$ \\
Diagnostic block & 3.26 & 0.06 & $0.97-11.00$ \\
ODI & -0.97 & 0.08 & $0.93-1.00$ \\
& & & \\
Multivariate model & & & \\
Predicted probability based on & 83.2 & 0.02 & $4.76-1454$ \\
Age $\geq 55$ & 3.78 & 0.02 & $1.22-11.63$ \\
Diagnostic block & 3.51 & 0.07 & $0.92-13.48$ \\
ODI & -0.96 & 0.07 & $0.92-1.00$
\end{tabular}

In fig 1 the ROC curves of these predictors are shown and Area Under the Curve is calculated. One possible cut-off would lead to a sensitivity of all predictors of $69 \%$ with a specificity of $59 \%$. The Odds Ratio of a positive diagnostic block in predicting the success at 6 weeks after one PRF treatment, is $3.2(p=0.072$, CI $0.9-11.375)$.

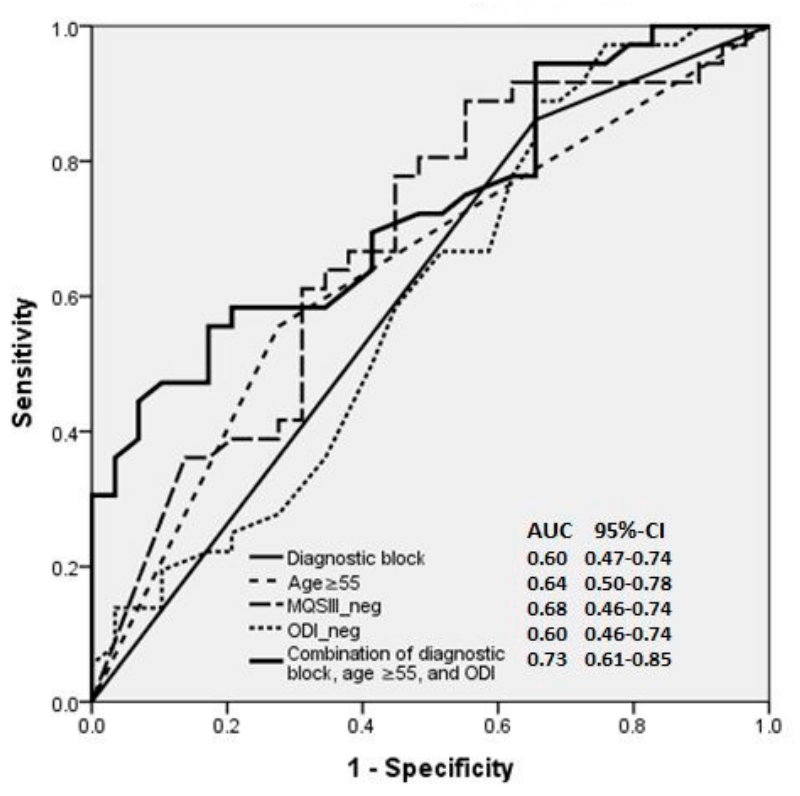

Figure 1: Receiver Operator Characteristic curves

$\mathrm{AUC}=$ Aera Under the Curve; MQSIII = Medication Quantification Scale ODI=Oswestry Disability Index

\section{DISCUSSION}

\section{Principal findings}

A positive diagnostic block of the corresponding nerve root is a predictor for success at 6 weeks and 6 months after PRF treatment adjacent to the DRG in chronic intractable lumbosacral radicular pain. Odds Ratios for a diagnostic block at 6 weeks and 6 months is similar, indicating the number of PRF treatments has no influence on the predictive value of the diagnostic block.

Older age (more than 55 years old) is also a predictor for clinical success at 6 months. A high disability acts as a negative predictor for a successful outcome. Each of these parameters have limited predictive value, combination of these predictors has a fair predictive value $(\mathrm{AUC}=0.73)$ for the 6 months outcome.

These results do not support the use of FBSS, gender, duration of pain, NRS, level and side of treatment, DN4 and RAND-36 as predictor for success.

Strength study

This is the first prospective study to evaluate potential factors that may predict the outcome of PRF adjacent to the lumbar DRG for the management of chronic intractable lumbosacral radicular pain. All patients were included according to strict selection criteria and treated regardless of the outcome of the selective diagnostic block, which allows judging the value of the block as predictive factor in a 
homogeneous patient population with dominant radicular symptoms in only one dermatome. The standardized inclusion and management also allows assessing other factors that may influence the treatment outcome.

\section{Relation with other studies}

Up till now only two studies assessed the influence of prior surgery on the outcome of PRF adjacen to the lumbar DRG. A retrospective analysis found that patients with FBSS had no beneficial effect of PRF treatment adjacent to the lumbar DRG. ${ }^{11}$ This observation was not confirmed in a clinical audit ${ }^{16}$ nor in the current study.

\section{How accurate is one single diagnostic block?}

There is a growing debate on the physiologic and anatomic selectivity of diagnostic "selective" nerve root blocks. According to the anatomy of the spinal nerve in the foramen, $7 \mu \mathrm{L}$ of local anesthetic should suffice for a nociceptive blockade. ${ }^{33}$ In practice 0.5 to $1 \mathrm{~mL}$ is used, with a risk of spreading to other structures like the nervus sinuvertebralis (innervation of nearby disci intervertebralis, ligamentum longitudinale posterius, ventral dura mater and nerve root sleeve) and sensory fibers of ramu dorsalis (local back muscles and facet joints) ${ }^{34}$ This interferes strongly with the anatomic selectivity of this diagnostic procedure. Furthermore the position of the needle tip during this procedure is normally located distal to the inflammatory process in case of a herniated disc (e.g. diagnostic block of nerve root L5 for a L4-5 herniated disc). Peripheral nerve blocks have the potential to induce adequat pain reduction even when the etiology is located more proximal. ${ }^{35,36}$

Ectopic firing and Wallerian degeneration potentiates afferent signaling in radicular pain, ${ }^{37,38}$ so it i possible that these distal secondary neurological events are interrupted by a diagnostic block ${ }^{33}$ The extent of the specificity of a nociceptive blockade of the nerve root distal to the etiology for the diagnosis of radicular pain is therefore unknown.

\section{Limitations}

The analysis of the predictive factors for clinical outcome was part of a prospective trial that also aimed at evaluating the effect of pulsed radiofrequency treatment adjacent to the dorsal root ganglion. Since the evidence for PRF in radicular pain is limited and ideal parameters for treatment not known, the objective was to first evaluate the effect of PRF at a single level. Moreover it is difficult to evaluate the diagnostic value of a single diagnostic nerve root block, if more than 1 nerve root is affected. For this reason patients with only one affected nerve root were selected. Since a large portion of the screened patients presented two or more affected nerve roots, this reduced significantly the inclusio rate. This is supported by electromyographical data where many patients have more than one affected nerve root ${ }^{39}$, so it is unclear how the information from our study can be extrapolated to situations were more than 1 nerve root is involved. The final position of the needle tip for PRF is based on sensory testing, and uses a threshold below $0.5 \mathrm{~V}$ as a benchmark. Due to the variability in the location of the DRG, the exact position of the needle-tip relative to the DRG is however uncertain. How this can influence the clinical result is unclear.

Psychosocial factors were used as exclusion criteria, but not as predictors for the outcome of PRF treatment adjacent to the DRG, this is another limitation of this study.

From the wide confidence intervals in table 2 it can be seen that a non-significant result does not mean that this variable has no predictive value especially when the distribution of that potential predictor is unbalanced. This may hold for the variable of FBSS. This is in agreement with another study where FBSS showed no significant influence on the outcome. ${ }^{16}$
Unanswered questions and future research

We noted that when the GPE was used to evaluate the diagnostic block, 14 patients with a negative result still had a good clinical outcome (false negative). This number of patients was reduced to 3 when using the NRS as cvalution mease. The combination $\mathrm{NRS}$ and $\mathrm{GPE}$ resulted in 5 patients a false negative block. This observation suggests that for future research preferable the NRS is used as an outcome parameter, or the combination of NRS and GPE.

It is possible that the number of false negative results can further be reduced by increasing the sensitivity of the diagnostic blockade. Targeting only one level of the spinal nerve may generate false negative results of the diagnostic block. Because of the described divergence and convergence of afferent radicular pain signaling different segmental levels are involved. $40-43$

Therefore the value of blocking more than 1 nerve root to predict more accurately outcome after PRF treatment is worth exploring

\section{GONGLUSION}

Successful outcome after PRF adjacent to the DRG, in patients with intractable chronic lumbosacra radicular pain is more likely in patients $\geq 55$ years, whereas younger patients and those with a high disability probably have a lower success rate. The diagnostic nerve root block has a limited predictive value. Combination of all these factors creates a fair predictive value.

Acknowledgements

The authors want to thank the cooperating physicians A. Balthasar MUMC, The Netherlands, K. Lauwers, (KL) KLINA Brasschaat, and P. Vanelderen ZOL, Belgium. The authors are grateful to Nicole Van den Hecke for administrative support. 


\section{References}

1. Doth AH, Hansson PT, Jensen MP, Taylor RS. The burden of neuropathic pain: a systematic review and meta-analysis of health utilities. Pain. 2010; 149:338-344.

2. Khoromi S, Patsalides A, Parada S, Salehi V, Meegan JM, Max MB. Topiramate in chronic lumbar radicular pain. J Pain. 2005; 6:829-836.

3. Dworkin RH, O'Connor AB, Backonja M, Farrar JT, Finnerup NB, Jensen TS, Kalso EA, Loeser JD, Miaskowski C, Nurmikko TJ, Portenoy RK, Rice AS, Stacey BR, Treede RD, Turk DC, Wallace MS. Pharmacelogic management of neuropathic pain: evidence-based recommendations. Pain. 2007; 132:237-251.

4. Weber H, Holme I, Amlie E. The natural course of acute sciatica with nerve root symptoms in a double-blind placebo-controlled trial evaluating the effect of piroxicam. Spine. 1993; 18:1433-1438.

5. Tubach F, Beaute J, Leclerc A. Natural history and prognostic indicators of sciatica.J Clin Epidemiol. 2004; 57:174-179.

6. Peul WC, Brand R, Thomeer RT, Koes BW. Influence of gender and other prognostic factors on outcome of sciatica. Pain. 2008; 138:180-191.

7. Suri P, Rainville J, Hunter DJ, Li L, Katz JN. Recurrence of radicular pain or back pain after nonsurgical treat ment of symptomatic lumbar disk herniation. Arch Phys Med Rehabil. 2012; 93:690-695.

8. Haugen AJ, Brox JI, Grovle L, Keller A, Natvig B, Soldal D, Grotle M. Prognostic factors for non-success in patients with sciatica and disc herniation. BMC Musculoskelet Disord. 2012; 13:183.

9. Grovle L, Haugen AJ, Keller A, Ntvig B, Brox JI, Grotle M. Prognostic factors for return to work in patients with sciatica. Spine J. 2013; 13:1849-1857.

10. Haugen AJ, Brox JI, Grovle L, Keller A, Natvig B, Soldal D, Grotle M. Prognostic factors for non-success in patients with sciatica and disc herniation. BMC Musculoskelet Disord. 2012; 13:183

11. Abejon D, Garcia-del-Valle S, Fuentes ML, Gomez-Arnau JI, Reig E, van Zundert J. Pulsed radiofrequency in lumbar radicular pain: clinical effects in various etiological groups. Pain Pract. 2007; 7:21-26.

12. Teixeira A, Grandinson M, Sluijter M. Pulsed Radiofrequency for radicular pain due to a herniated intervertebral disc - an initial report. Pain Pract. 2005; 5:111-115.

13. Munglani R. The longer term effect of pulsed radiofrequency for neuropathic pain. Pain. 1999; 80:437-439.

14. Sluijter ME, Cosman ER, Rittman IIWB, van Kleef M. The effects of pulsed radiofrequency field applied to the dorsal root ganglion - a preliminary report. The Pain Clinic. 1998; 11:109-117.

15. Simopoulos TT, Kraemer J Nagda JV Aner M Bajwa ZH. Response to pulsed and continuous radiofrequency lesioning of the dorsal root ganglion and segmental nerves in patients with chronic lumbar radicular pain. Pain Physician. 2008: 11:137-144.

16. Van Boxem K, van Bilsen J, de Meij N, Herrler A, Kessels F, Van Zundert J, van Kleef M. Pulsed radiofrequency treatment adjacent to the lumbar dorsal root ganglion for the management of lumbosacral radicular syndrome: a clinical audit. Pain Med.2011; 12:1322-1330.

17. Van Zundert J, Patijn J, Kessels A, Lame I, van Suijlekom H, van Kleef M. Pulsed radiofrequency adjacent to the cervical dorsal root ganglion in chronic cervical radicular pain: a double blind sham controlled randomized clinical trial. Pain. 2007; 127:173-182

18. Vroomen PC, de Krom MC, Knottnerus JA. Diagnostic value of history and physical examination in patient suspected of sciatica due to disc herniation: a systematic review. J Neurol. 1999; 246:899-906.

19. Kerr RS, Cadoux-Hudson TA, Adams CB. The value of accurate clinical assessment in the surgical managemen of the lumbar disc protrusion. J Neurol Neurosurg Psychiatry. 1988; 51:169-173.

20. Attal N. Perrot S, Fermanian J. Bouhassira D. The neuropathic components of chronic low back pain: prospective multicenter study using the DN4 Questionnaire. J Pain. 2011; 12:1080-1087.

21. Murphy DR, Hurwitz EL, Gerrard JK, Clary R. Pain patterns and descriptions in patients with radicular pain Does the pain necessarily follow a specific dermatome? Chiropr Osteopat. 2009; 17:9.
22. Hofstee DJ, Gijtenbeek JM, Hoogland PH, van Houwelingen HC, Kloet A, Lotters F, Tans JT. Westeinde sciatica trial: randomized controlled study of bed rest and physiotherapy for acute sciatica. J Neurosurg. 2002; 96:45-

23. Severeijns $R$, van den Hout MA, Vlaeyen JW, Picavet HS. Pain catastrophizing and general health status in a large Dutch community sample. Pain. 2002; 99:367-376.

24. Likert R. A technique for the measurement of attitudes. Archives of Psychology. 1932; 22:140

25. Jensen MP, McFarland CA. Increasing the reliability and validity of pain intensity measurement in chronic pain patients. Pain. 1993; 55:195-203

26. Ware JE, Jr. SF-36 health survey update. Spine (Phila Pa 1976). 2000; 25:3130-3139.

27. Roland M, Fairbank J.The Roland-Morris Disability Questionnaire and the Oswestry Disability Questionnaire Spine. 2000: 25:3115-3124

28. Bouhassira D, Attal $N$, Alchaar $H$, Boureau $F$, Brochet $B$, Bruxelle $J$, Cunin $G$, Fermanian $J$, Ginies $P$, Grun-Overdyking A, Jafari-Schluep H, Lanteri-Minet M, Laurent B, Mick G, Serrie A, Valade D, Vicaut E. Comparison of pain syndromes associated with nervous or somatic lesions and development of a new neuropathic pain diagnostic questionnaire (DN4). Pain. 2005; 114:29-36.

29. Bennett M. The LANSS Pain Scale: the Leeds assessment of neuropathic symptoms and signs. Pain. 2001; 92:147-157.

30. Gallizzi M, Gagnon C, Harden RN, Stanos S, Khan A. Medication Quantification Scale Version III: internal validation of detriment weights using a chronic pain population. Pain Pract. 2008; 8:1-4.

31. Hays RD, Morales LS. The RAND-36 measure of health-related quality of life. Ann Med. 2001; 33:350-357.

32. Hosmer D, Lemeshow S. hoofdstuk titel. In: Applied Logistic Regression, Vol.ed. New York: John Wiley \& Sons; 1989. 135-175

33. Datta S, Manchikanti L, Falco FJ, Calodney AK, Atluri S, Benyamin RM, Buenaventura RM, Cohen SP. Diagnostic utility of selective nerve root blocks in the diagnosis of lumbosacral radicular pain: systematic review and update of current evidence. Pain Physician. 2013: 16:SE97-124.

34. Wolff A, Wilder-Smith O. Diagnosis in patients with chronic radiating low back pain without overt focal neurological deficits : what is the value of segmental nerve root blocks? Therapy. 2005; 2:577-585.

35. Xavier AV, Farrell CE, McDanal J, Kissin I. Does antidromic activation of nociceptors play a role in sciatic radicular pain? Pain. 1990; 40:77-79.

36. North RB, Kidd DH Zahurak M Piantadosi S. Specificity of diagnostic nerve blocks: a prospective, randomized study of sciatica due to lumbosacral spine disease. Pain. 1996; 65:77-85.

37. Ramer MS, French GD, Bisby MA. Wallerian degeneration is required for both neuropathic pain and sympathetic sprouting into the DRG. Pain. 1997; 72:71-78.

38. Ramer MS, Thompson SW, McMahon SB. Causes and consequences of sympathetic basket formation in dorsal root ganglia. Pain. 1999; Suppl 6:S111-120

39. Czyrny JJ, Lawrence J. The importance of paraspinal muscle EMG in cervical and lumbosacral radiculopathy: review of 100 cases. Electromyogr Clin Neurophysiol. 1996; 36:503-508.

40. Pinto V. Szucs P. Lima D, Safronov BV. Multisegmental A\{delta $\}$ - and $C$-fiber input to neurons in lamina I and the lateral spinal nucleus. J Neurosci. 2010; 30:2384-2395.

41. Wall PD, Lidierth M, Hillman P. Brief and prolonged effects of Lissauer tract stimulation on dorsal horn cells. Pain. 1999; 83:579-589.

42. Lidierth M. Long-range projections of Adelta primary afferents in the Lissauer tract of the rat. Neurosci Lett. 2007; 425:126-130

43. Li Y,Dorsi MJ, Meyer RA, Belzberg AJ. Mechanical hyperalgesia after an $L 5$ spinal nerve lesion in the rat is not dependent on input from injured nerve fibers. Pain. 2000; 85:493-502. 
Chapter VIII 
TABVLA. III. C LIBRI. I.
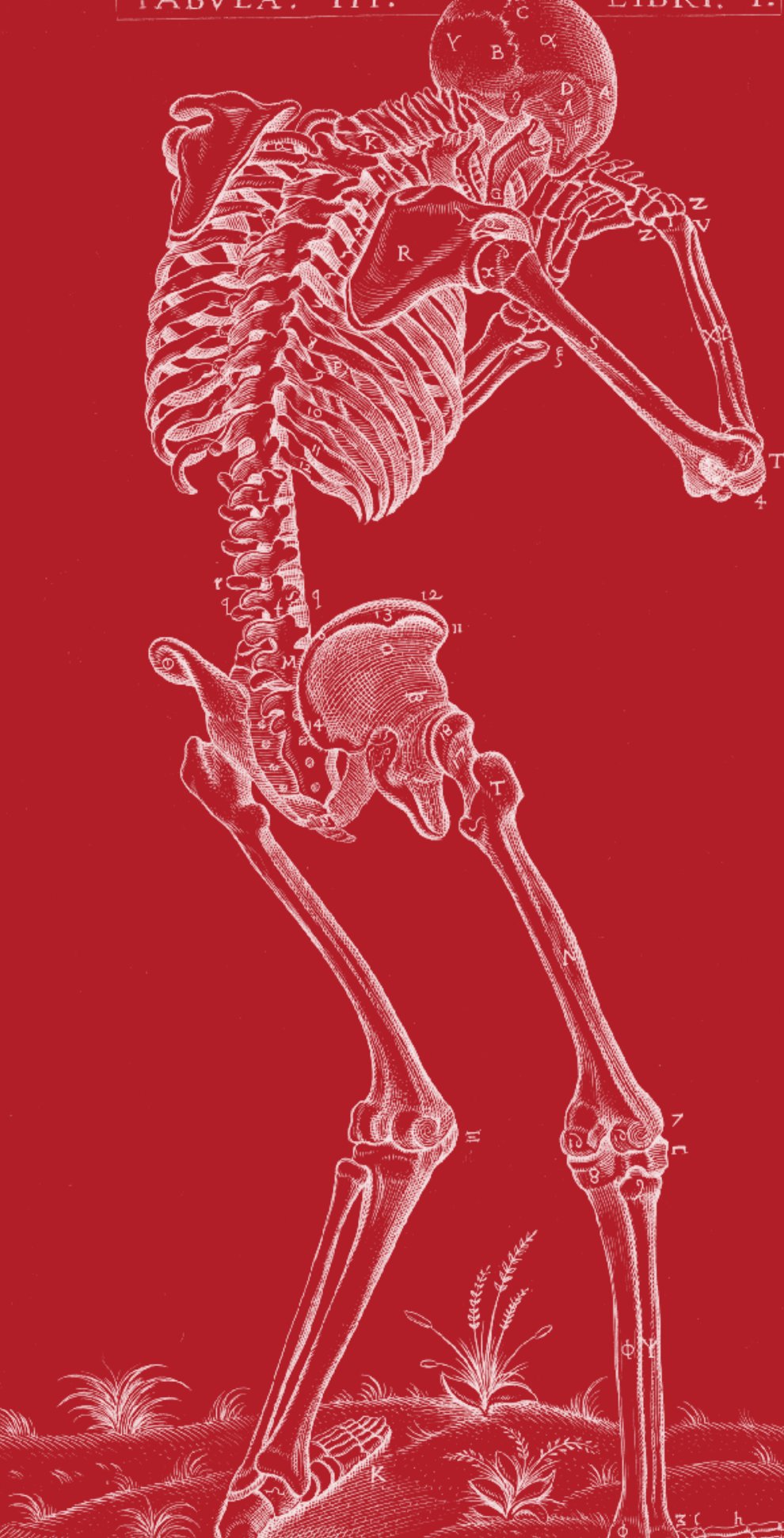

In the 19th century Fuller stated "the history of sciatica is, it must be confessed, the record of pathological ignorance and therapeutic failure". ' From an evidence-based point of view this statement related to efficacy and treatment of lumbosacral radicular pain (LSR) has not lost impact and validity even in the twenty-first ported efficacy of treatments is limited. Only surgery has an evidence-based value compared to conservative treatments, but its efficacy is limited to the first year following discectomy ${ }^{5}$ and is therefore considered a last resort. This means there is a large population with refractory complaints and low quality of life who receive treatments with uncertain efficacy. ${ }^{\circ}$

The aim of this thesis was to evaluate the potential role of pulsed radiofrequency (PRF) treatment adjacent to the dorsal root ganglion (DRG) in patients with chronic lumbosacral radicular pain (LSR). Research

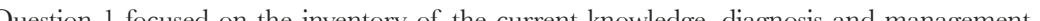
Q based on insights into the underlying mechanisms, basic research on PRF and LSR is reviewed (see Research Question 2). In view of clinical application of interventional treatments of chronic pain patients often problems are encountered in the design of the study, an issue which is addressed under Research Question 3. Finally clinical studies were performed in order to answer Research Questions 4: Does PRF treatment adjacent to the DRG in patients with refractory lumbosacral radicular pain result in pain relief? In addition to this Research Question 5: Is it possible to determine predictive factors for successful outcome of PRF
treatment adjacent to the DRG in chronic LSR patients?

\section{RESEARCH QUESTION 1}

What is the current knozeledge on epidemiology, diagnosis and management of lumbosacral radicular pain?

A review was presented on the current knowledge on epidemiology, diagnosis and management of lumbosacral radicular pain (chapter II). The diagnosis of lumbosacral radicular pain relies in the first place on a thorough history taking to determine the radiation pattern of pain and paresthesia. ${ }^{7}$ Unfortunately current evidence indicates poor diagnostic performance of most physical tests (paresis, sensory loss or loss of reflexes) if used to identify lumbar disc herniation. Better performance may be obtained when various physical tests are combined. ${ }^{8}$

Medical imaging can confirm the presence of a herniated disc or nerve root compression. ${ }^{9}$ The link between documented disc herniation and lumbosacral radicular pain can, however not be made, nor can the presence of a nerve root compression or disc extrusion predict treatment outcome. ${ }^{10} \mathrm{~A}$ diagnostic nerve root block is a commonly used technique for determining the level of the radicular pain, there is, however, uncertainty concerning its sensitivity and specificity. The scientific support for the conservative treatment, consisting of exercise therapy and pharmacologic treatment, is limited. ${ }^{11}$

Clearly a general complication in clinical studies on sciatica, ischias, radicular pain, radiculopathy or lumbosacral radicular pain is still related to a lack of consensus on the terminology of radiating pain emerging from the DRG.12 In this thesis the term "lumbosacral radicular pain" was consistently used as it is more accurate and explanatory of the presenting condition. ${ }^{13-15}$ The lack of a gold standard for diagnosing LSR pain can lead to a heterogeneous patient inclusion, with negative impact on the outcome in clinical studies.

studies. to a fine tuning of diagnostic criteria for LSR pain. This will eventually result in an inclusion of more homogenous populations which then increases the possibility to compare outcomes between individual studies. 


\section{RESEARCH QUESTION 2:}

Which pathophysiological processes underlie acute and chronic LSR pain and how might pulsed radiofrequency modulate these processes?

An in depth literature review on the cellular and molecular changes in radicular pain and the mechanism of PRF is presented in Chapter III. Basically radicular pain is characterized by a divergen pain transmission and spinal segmental spreading of the afferent nociceptive input combined with complex cellular and molecular processes that initiate and maintain the increased nociceptive signa input. The spread of radicular pain to adjacent spinal segments has been demonstrated (figure 1 page 52). ${ }^{16,17}$ Trauma to nerve roots and the DRG lead to significant changes in ion-channels at both injured and adjacent uninjured DRGs and this leads to ectopic firing. Ectopic discharges that reach the dorsal horn can activate postsynaptic pain neurons due to an increase in synaptic efficacy, also referred to a central sensitization. ${ }^{17}$ The mode of action of key molecules and cells involved in radicular pain, like glutamate, BDNF and microglial cells, in relation to their timing and localization is shown in figure 2 (page 55).

As PRF is an interventional treatment that creates a stronger electro-magnetic field than conventional $\mathrm{RF}$, it might potentially affect the pathophysiological processes underlying radicular pain in a larger area. Limited data suggest that PRF results in behaviorally detectable pain relief in experimental animal models of radicular and neuropathic pain, which is accompanied by cellular changes at the DRG and spinal horn. The precise interference of PRF with the cellular and molecular changes a noted in radicular pain is still unknown. Future research should be aimed at the further elucidation of this interference with special emphasis at the modulation of PRF on 1) inflammatory response induced by a herniated disc and Wallerian degeneration; 2) enhanced ectopic firing at the DRG; 3 central sensitization and release of BDNF in the spinal dorsal horn.

Knowledge on how PRF modulates the pain signal is limited and slowly progressing as the exact mechanism is not yet established. The major research question at the moment is, if and how PRF-induced modulation of the cellular and molecular changes in radicular pain affects the divergent pain transmission and spinal segmental spreading? In line with this, the question remains if we use the optima settings and approach for PRF to ensure a maximal interference with the complex cellular and molecular processes of pain transmission and spreading of the signal?

In view of these major research questions a first prerequisite would be the availability of good animal models. Unfortunately at present still many experimental studies on radicular pain are using chronic neuropathic pain models instead of a set-up which mimics the typical features and characteristics of lumbosacral radicular pain. The chronic compression of the dorsal root ganglion (CCD) model, bes mimics disc herniation and lateral foraminal stenosis. With CCD a metal rod is introduced into the intervertebral foramen ${ }^{18}$, which induces both nerve root compression and secondary inflammation ${ }^{19,20}$, thereby mimicking a herniated lumbar disc or foraminal stenosis. The CCD model has been shown to produce electrophysiological and behavioral changes indicative of radicular pain. This makes it an attractive model for evaluating effects of treatment modalities. A first pilot study in our laboratory revealed that this CCD model might result in behavioral pain responses as assessed with von Frey / Catwalk. However, the low reproducibility of the lesion and thus the high variability on the various pain parameters significantly complicate the correct interpretation of the results of this pilot study. Future studies with this CCD model should focus on the optimization of the reproducibility of the lesion and its effect on pain parameters in this model.
It needs no further comment that a better understanding of the cellular and molecular changes as presented in radicular pain and unraveling the mechanism induced by PRF to reverse these changes, may lead to a more optimal use of PRF. Here both localization of the PRF treatment, which could be at the DRG, at the peripheral nerve or trancutaneous, bet a so the PRF (the become future subject of investigation. Standardization of those PRF-parameters in an experimental model for lumbosacral radicular pain would greatly benefit the interpretation.

\section{RESEARCH QUESTION 3:}

Is it possible to further improve the design of clinical studies on interventional pain therapy and how?

Conducting randomized controlled trials on interventional pain management techniques may be complicated by several factors, as described in chapter IV. RCTs on interventional pain management techniques face methodological problems often leading to power problems because an inadequate number of subjects can be recruited. Unfortunately the results of those underpowered studies arc included in systematic reviews and meta-analyses and they may negatively influence the general recommendations.

An additional problem related to RCT's in interventional pain management techniques is the lack of a diagnostic gold standard for chronic (spinal) pain, which might lead to inclusion of patients who may not benefit from the treatment. Obviously heterogeneous patient groups limit the comparison of outcome between studies.

The information provided to potential participants in a randomized sham controlled trial also describes a substantial chance of receiving an ineffective treatment. The latter results in a proportion of alerted patients, who do not agree to provide consent. The selected comparative treatment may not be appealing to patients.

Several alternative trial designs have been proposed to deal with this inclusion problem. The prerandomization design (or Zelen or post-consent design) is a way of avoiding contamination by linding the control group and may offeran alternative that may be worth testing in interventional pain Then all patients are asked permission to prospectively collect their data for research purposes and an informed consent is obtained. After randomization, patients assigned to the experimental group will immediately receive all information related to the experimental treatment, followed by a second informed consent. Patients assigned to conservative standard treatment will receive full information, including the information on the experimental treatment, only after completing the trial period and completing the study they also will be oiven the opportunity to receive the experimental treatment. This design is especially interesting when the experimental treatment seems very attractive, leading to non-adherence in the control group. ${ }^{2}$

Although the pre-randomization- or Zelen-design is still controversial it is now accepted by mos medical ethical committees in the UK and the Netherlands, and this resulted in an adaptation of legal regulations in these countries. ${ }^{23}$ In Belgium this design was not approved by the ethical committee due to unadapted regulations. 


\section{RESEARGH QUESTION 4:}

Does $P R F$ treatment adjacent to the DRG in patients with refractory lumbosacral radicular pain result in pain relief?

We studied the effect of PRF adjacent to the lumbar DRG for the management of refractor lumbosacral radicular pain both in a clinical audit (Chapter V) as well as in a prospective trial (Chapter VI)

The inclusion of patients into the clinical audit was based on the presence of LSR at one single level, concordant with the MRI or CT findinos and responding to a selective diagnostic nerve root block demonstrated a $50 \%$ pain relief in $22.9 \%$ of cases after 6 months. Furthermore the PRF-treatment significantly reduced pain medication in the success group compared to the non-success group. These findings let us suggest that PRF treatment adjacent to the lumbar DRG may be considered a treatmen option for lumbosacral radicular pain although the outcome in this clinical audit was less significan than previously reported. ${ }^{24-27}$ This discrepancy may be related to the fact that in this clinical audit basically only a single intervention at one level was performed as compared to other studies with repeat interventions or treatments on more than one level.

Although clinical audits provide some level of evidence and can be used in recommendation for a treatment in clinical practice Randomized Clinical Trials (RCT) are still needed. It is generally acknowledged that RCT's provide the highest quality evidence also in the treatment of LSR. In view of a treatment for LSR the selection of a comparator poses a problem. The only evidence based therapy available is surgery. ${ }^{5}$ It was documented that early surgery as compared to prolonged conservative care with possible surgery provides a more rapid pain relief and improvement of functionality At 1 year follow-up, however no significant difference between groups was noted anymore. ${ }^{5}$ As PRI may potentially produce a long-term pain reduction this intervention may avoid the need for surgery. However the use of surgery as comparator necessitates a follow-up period of at least 1 year. On the other hand, as the efficacy of PRF is not yet clear and optimal modalities are not known, the use of surgery as comparator was not feasible.

We performed a prospective trial (Chapter VI) which was initially planned to be a randomized controlled tial conventional medical management alone. The multicenter trial in hospitals in The Netherlands and Belgium was initially set up following the pre-randomization design, which, although accepted in The Netherlands was refused in Belgium by the ethical committee. Therefore this multicenter study had to be changed into a non-randomized prospective outcome study.

In absence of a gold standard for the diagnosis of LSR, patients are mainly selected when MRI or CT findings correlate with clinical symptoms and radiation pattern. ${ }^{5,28}$ The specificity of the combination and clinical symptoms is unknown. We handled stringent patient inclusion criteria to compensate for the lack of a diagnostic tool with a high specificity, in order to select patients with a "pure" lumbosacral radicular pain. Patients had to report unilateral and mono-segmental radiating pain down the leg, into the foot to the hallux (L5) or lateral side of the foot (S1), suggesting involvemen of the lumbar spinal nerve along the affected nerve root concordant with the MRI or CT scan findings. ${ }^{29-32}$ This pain distribution had to be present for at least 3 months. ${ }^{33,34}$ The working hypothesis was that in this population the likelihood of dealing with a chronic inflammation of the DRG is very high, consequently forming an ideal population to study LSR. These selection criteria, together with a mono-segmental distribution significantly slowed down the inclusion rate of the clinical trial. In our non-randomized prospective outcome study a PRF treatment at the level concordant with clinical symptoms was performed independent of the result of a selective nerve root block. If a clinically insufficient pain relief was reported at the 6 -week evaluation a single repeat PRF procedure was treat analycis, $56.9 \%, 52.3 \%$ and $55.4 \%$ of a total of 65 included patients had clinical success on the global perceived effect (GPE) or numerical rating scale (NRS) at 6 weeks, 3 and 6 months follow-up respectively. The DN4, the Oswestry Disability Index and the physical component for the RAND-36 quality of life improved significantly while the mental component remained unchanged.

In view of future research in interventional pain management it is obvious that there is a need for an alternative study design, allowing the comparison of PRF treatment with standard care. The concept tation if Belgian Hospitals are involved. A possible alternative is the use of more pragmatic trials. ${ }^{35}$ To further improve the quality and impact of clinical research on the effect of PRF in LSR patients standardized strict selection criteria should be used to include a more homogenous patient population and allow more accurate evaluation of the treatment effects.

The value of a repeat PRF treatment is worth exploring. A repeat intervention at the same or at an adjacent level may consolidate an early effect. This can be supported by findings of animal studies and anatomical observations. The changes in the dorsal root ganglion and dorsal horn observed in animal studies $^{36}$ may indeed be transient after a single treatment. Moreover, a spreading of the radicular signal (see RQ2/Chapter III) occurs in electrophysiological studies, obscuring the efficacy of a single treatment at a single segmental level.

Because of this phenomenon, the simultaneous administration of PRF at multiple levels should be studied with regard to potential improvement of the efficacy due to coverage of a larger part of the afferent incoming signal. Hence, a randomized trial is necessary to evaluate the added value of PRF relative to a control group in LSR patients.

\section{RESEARGH QUESTION 5:}

Is it possible to determine predictive factors for successful outcome of PRF treatment adjacent to the $D R G$ in chronic LSR patients ?

adjacent to the DRG in chronic LSR patients ?
Our study revealed that a successful outcome after PRF adjacent to the DRG in intractable LSR is more likely to occur in patients $\geq 55$ years (Chapter VII). A diagnostic nerve root block has a limited predictive value as the specificity of a nociceptive blockade of the nerve root distal to the etiology for the diagnosis of radicular pain is unknown.

In order to increase the value of the diagnostic block as a predictive factor of successful outcome of PRF in LSR and the fact that a diagnostic block at one level evaluated by the global perceived effect results in a fairly high number of false negatives, two suggestions for future research can be made. The first is to use a NRS as evaluation of the diagnostic block, because the number of false negatives was much lower than with the GPE. The second suggestion is to assess the accuracy of a diagnostic block at multiple levels to increase sensitivity. 


\section{GENERAL GONGLUSION}

The aim of this thesis was to evaluate the potential role of pulsed radiofrequency treatment adjacent to the DRG in patients with chronic LSR.

Although the spreading of the radicular afferent signal is a complex phenomenon, a certain sequence in the inflammatory cascade is apparent. Beginning with the disc degenerating nerve, pro-inflammatory cytokines are released at the site of lesion which causes ectopic firing at the DRG, leading to an increased release of neurotrophins and continuous firing at the dorsal horn, potentially leading to central sensitization. The spread of radicular pain to adjacent spinal seements has implications for future research on interventional pain treatments.

A clinical audit demonstrated clinical success at 6 months after a single PRF adjacent to the DRO in patients with chronic LSR in $29.5 \%$. A prospective trial in patients with refractory symptoms of LSR and strict inclusion criteria, demonstrated clinical success in $55.4 \%$ at 6 months. The DN4, the Oswestry Disability Index and the physical component for the RAND-36 quality of life also improved significantly. Younger patients and those with a high disability at baseline probably will have a lower success rate. The diagnostic nerve root block has a limited predictive value.

Although the studies presented in this thesis demonstrate clinical success, RCTs are needed to furthe confirm and provide solid scientific evidence for PRF treatment adjacent to the DRG in patients with chronic LSR
References

1. Fuller H. On Rheumatism, Rheumatic Gout and Sciatica: The Phatology, Symptoms and Treatment. London: John Churchill; 1852

2. Khoromi S, Patsalides A, Parada S, Salehi V, Meegan JM, Max MB. Topiramate in chronic lumbar radicular pain. J Pain. 2005; 6:829-836.

3. Dworkin RH, O'Connor AB, Backonja M, Farrar JT, Finnerup NB, Jensen TS, Kalso EA, Loeser ID, Miaskowski C, Nurmikko TJ, Portenoy RK, Rice AS, Stacey BR, Treede RD, Turk DC, Wallace MS. Pharmacologic management of neuropathic pain: evidence-based recommendations. Pain. 2007, 132:237-251.

4. Bala M, Bekkering T, Riemsma R, Harker J, Huygen F, Kleijnen J. Epidemiology of chronic pain in the Netherlands Rotterdam CvpvEMC- ed. York-United Kingdom: Kleinen Systematic Reviews Ltd; 2011

5. Peul WC, van Houwelingen HC, van den Hout WB, Brand R, Eekhof JA, Tans JT, Thomeer RT Koes BW. Surgery versus prolonged conservative treatment for sciatica. $N$ Engl J Med. 2007; 356:2245-2256.

6. Doth AH, Hansson PT, Jensen MP, Taylor RS. The burden of neuropathic pain: a systematic review and meta-analysis of health utilities. Pain. 2010; 149:338-344.

7. Tarulli AW, Raynor EM. Lumbosacral radiculopathy. Neurol Clin. 2007; 25:387-405.

8. van der Windt DA, Simons $E$, Riphagen, II, Ammendolia $C$, Verhagen AP, Laslett $M$, Deville $W$, Deyo RA, Bouter LM, de Vet HC, Aertgeerts B. Physical examination for lumbar radiculopathy due to disc herniation in patients with low-back pain. Cochrane Database Syst Rev. 2010; 2:CD007431.

9. Koes BW, van Tulder MW, Peul WC. Diagnosis and treatment of sciatica. BMJ. 2007; 334:1313-1317.

10. el Barzouhi A, Vleggeert-Lankamp CL, Lycklama a Nijeholt GJ, Van der Kallen BF, van den Hout WB, Jacobs WC, Koes $B W$, Peul WC. Magnetic resonance imaging in follow-up assessment of sciatica. N Engl J Med. 2013; 368:999-1007.

11. Luijsterburg PA, Lamers LM, Verhagen AP, Ostelo RW, van den Hoogen HJ, Peul WC, Avezaat CJ, Koes BW. Cost-effectiveness of physical therapy and general practitioner care for sciatica. Spine. 2007; 32:1942-1948

12. Lin CW, Verwoerd AJ, Maher CG, Verhagen AP, Pinto RZ, Luijsterburg PA, Hancock MJ. How is radiating leg pain defined in randomized controlled trials of conservative treatments in primary care? A systematic review. Eur J Pain. 2013.

13. Waddell G. The Back Pain Revolution. New York: Churchill Livingstone; 2004

14. Fairbank JC. Sciatic: An archaic term. BMJ. 2007; 335:112.

15. Peul WC, Brand R, Thomeer RT, Koes BW. Influence of gender and other prognostic factors on outcome of sciatica. Pain. 2008; 138:180-191

16. Nygaard OP, Mellgren SI. The function of sensory nerve fibers in lumbar radiculopathy. Use of quantitative sensory testing in the exploration of different populations of nerve fibers and dermatomes. Spine. 1998; 23:348-352.

17. Woolf CJ, King AE. Dynamic alterations in the cutaneous mechanoreceptive fields of dorsal horn neurons in the rat spinal cord. J Neurosci. 1990; 10:2717-2726.

18. Hu SJ, Xing JL. An experimental model for chronic compression of dorsal root ganglion produced by intervertebral foramen stenosis in the rat. Pain. 1998; 77:15-23.

19. White FA, Sun J, Waters SM, Ma C, Ren D, Ripsch M, Steflik J, Cortright DN, Lamotte RH, Miller RJ. Excitatory monocyte chemoattractant protein-1 signaling is up-regulated in sensory neurons after .

20. Xiang Z, Xiong Y, Yan N, Li X, Mao Y, Ni X, He C, LaMotte RH, Burnstock G, Sun J. Functional upregulation of $P 2 X 3$ receptors in the chronically compressed dorsal root ganglion. Pain. 2008; 140:23-34. 
21. Zelen M. A new design for randomized clinical trials. N Engl J Med. 1979; 300:1242-1245.

22. Schellings R, Kessels AG, Sturmans F. [Pre-randomisation in study designs: getting past the taboo]. Ned Tijdschr Geneeskd. 2008; 152:2053-2056.

23. Schellings $R$, Kessels $A G$, Ter Riet $G$, Kleijnen $J$ Leffers $P$ Knottnerus JA, Sturmans F. Members of research ethics committees accepted a modification of the randomized consent design. J Clin Epidemiol. 2005; 58:589-594.

24. Abejon D, Garcia-del-Valle S, Fuentes ML, Gomez-Arnau JI, Reig E, van Zundert J. Pulsed radiofrequency in lumbar radicular pain: clinical effects in various etiological groups. Pain Pract. 2007; 7:21-26.

25. Teixeira A, Grandinson M, Sluijter M. Pulsed Radiofrequency for radicular pain due to a herniated intervertebral disc - an initial report. Pain Practice. 2005; 5:111-115.

26. Chao SC, Lee HT, Kao TH, et al. Percutaneous pulsed radiofrequency in the treatment of cervical and lumbar radicular pain. Surg Neurol. 2008; 70:59-65.

27. Simopoulos TT, Kraemer J, Nagda JV, Aner M, Bajwa ZH. Response to pulsed and continuous radiofrequency lesioning of the dorsal root ganglion and segmental nerves in patients with chronic lumbar radicular pain. Pain Physician. 2008; 11:137-144.

28. Peul WC, van den Hout WB, Brand R, Thomeer RT, Koes BW. Prolonged conservative care versus early surgery in patients with sciatica caused by lumbar disc herniation: two year results of a randomised controlled trial. BMJ. 2008; 336:1355-1358.

29. Vroomen PC, de Krom MC, Knottnerus JA. Diagnostic value of history and physical examination in patients suspected of sciatica due to disc herniation: a systematic review. J Neurol. 1999; 246:899906.

30. Kerr RS, Cadoux-Hudson TA, Adams CB. The value of accurate clinical assessment in the surgical management of the lumbar disc protrusion. J Neurol Neurosurg Psychiatry. 1988; 51:169-173.

31. Attal N, Perrot S, Fermanian J, Bouhassira D. The neuropathic components of chronic low back pain: a prospective multicenter study using the DN4 Questionnaire. J Pain. 2011; 12:1080-1087.

32. Murphy DR, Hurwitz EL, Gerrard JK, Clary R. Pain patterns and descriptions in patients with radicular pain: Does the pain necessarily follow a specific dermatome? Chiropr Osteopat. 2009, 17:9.

33. Weber H, Holme I, Amlie E. The natural course of acute sciatica with nerve root symptoms in a double-blind placebo-controlled trial evaluating the effect of piroxicam. Spine. 1993: 18:1433-1438.

34. Hofstee DJ, Gijtenbeek JM, Hoogland PH, van Houwelingen HC, Kloet A, Lotters F, Tans JT Westeinde sciatica trial: randomized controlled study of bed rest and physiotherapy for acute sciatica. J Neurosurg. 2002; 96:45-49.

35. Rowbotham MC, Gilron I, Glazer C, Rice AS, Smith BH, Stewart WF, Wasan AD. Can pragmatic trials help us better understand chronic pain and improve treatment? Pain. 2013; 154:643-646.

36. Van Boxem K, Huntoon M, Van Zundert J, Patijn J, van Kleef M, Joosten E. Pulsed radiofrequency: a review of the basic science as applied to the pathophysiology of radicular pain. A call for clinical translation Reg Anesth Pain Med.2014, 39: 149-159. 
Chapter IX

Summary

Samenvatting 
SUMMARY

TABVLA. III. CO LIBRI. I.

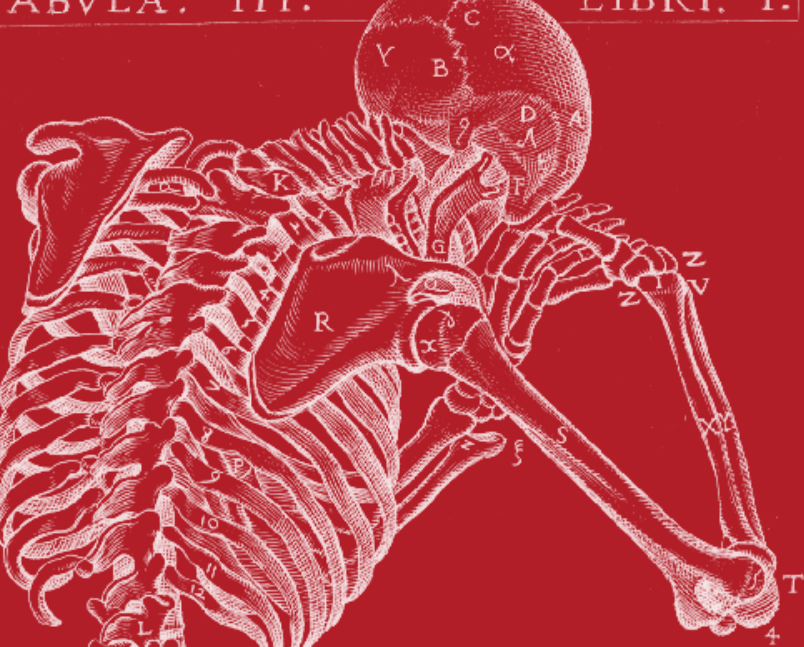

ค

"12.

15

Nit: $: 2(2)$

In

1.
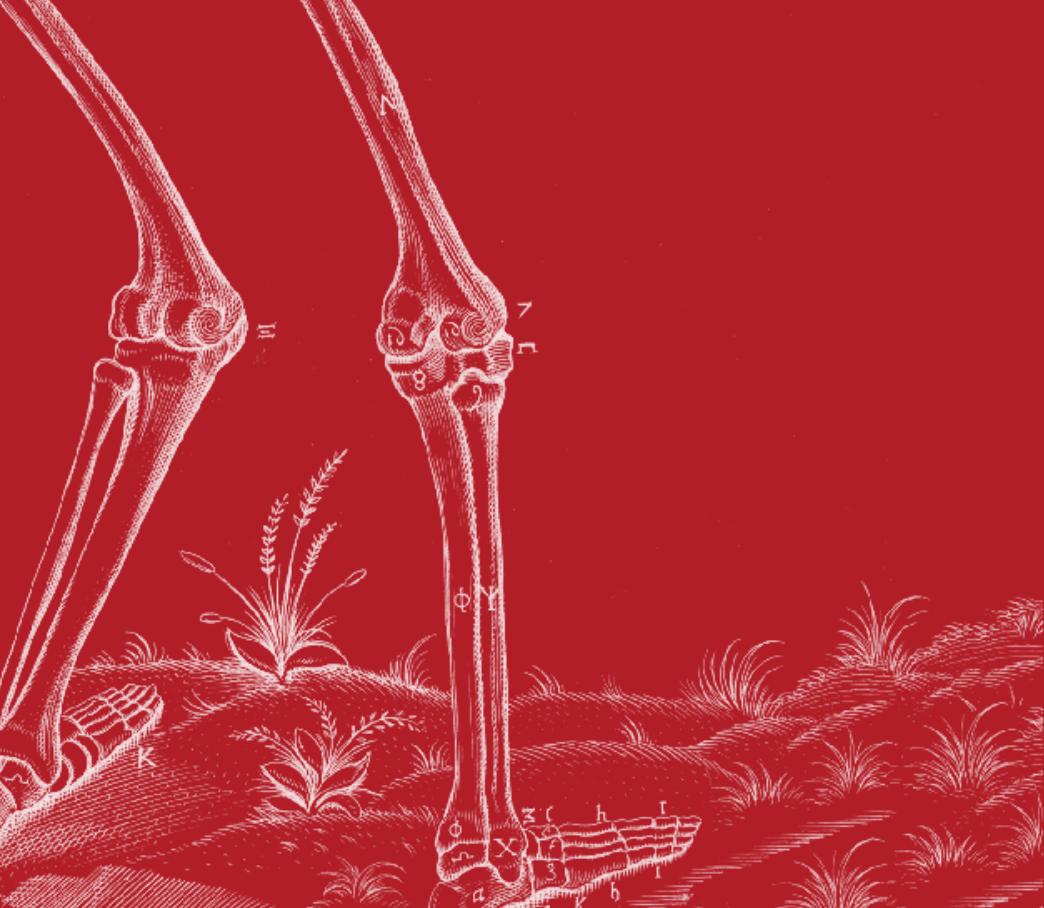

The aim of this thesis was to evaluate the role of pulsed radiofrequency (PRF) treatment adjacent to the dorsal root ganglion (DRG) for the management of refractory lumbosacral radicular pain (LSR). The first chapter of this thesis aimed at defining lumbosacral radicular pain. Furthermore this introductory chapter provides the reader with a description of the epidemiology as well as a summary of available treatments for lumbosacral radicular pain. The latter with special emphasis to interventional techniques including radiofrequency $(\mathrm{RF})$ and Pulsed Radiofrequency.

In chapter II the diagnostic process, the use and value of additional examinations and the potential treatment options for lumbosacral radicular pain are described. It is concluded that the present diagnostic procedure of lumbosacral radicular pain is troubled by a lack of consensus on the definition and by the lack of a gold standard.

To further optimize the use of PRF for the management of (cervical and lumbosacral) radicular pain a better translation between basic science and clinical experience is needed (chapter III). As radicular pain is a complex phenomenon with an important divergence and spreading of the afferent nociceptive signal, leading to the sensitization of the neurotransmission at DRG and in the spinal dorsal horn at vais lo losy. The pathophysiology and the underlying mechanism of action of radicular pain are described in detail in chapter III. It is mentioned that in radicular pain ectopic discharges reach the dorsal horn and are able to activate postsynaptic pain neurons. Then increased neurotrophin release (e.g. BDNF) in the spinal dorsal horn induces a cascade of mechanisms that sensitize the transmission of afferent nociceptive input.

$\mathrm{PRF}$ is an interventional treatment and a good candidate for the management of radicular pain, and has been reported to generate a stronger electro-magnetic field than conventional RF, thereby potentially disrupting the pathophysiological processes underlying radicular pain in a much larger area. Limited data suggest that PRF results in behaviorally detectable pain relief in experimental animal models of radicular and neuropathic pain models, which is accompanied by cellular changes at the DRG and spinal horn.

The efficacy of a treatment is best assessed by means of a randomized, placebo controlled trial where patient and care giver are blinded to the treatment given. In chapter IV the problems and pitfalls of research on interventional pain management techniques are discussed. The pre-randomization or Zelen design is suggested as a way of avoiding contamination by blinding the control group that may offer an alternative that may be worth testing in interventional pain management. Chapter $\mathrm{V}$ describes the result of a clinical audit on the use of PRF adjacent to the DRG for patients with LSR. Here $50 \%$ pain relief was still present in $22.9 \%$ of the cases after 6 months. The success rate of $22.9 \%$ as obtained in this series, compared to carlier studies where repeted RF or PRF procedures have been executed, suggest that performing a repeated procedure at the same or an adjacent level might increase the likelihood of success. Therefore the possibility of performing a repeat intervention was included into the protocol of the cohort study that is reported in chapter VI.

In a prospective trial consecutive patients with refractory unilateral lumbosacral radicular pain of L5 or S1 received a PRF treatment adjacent to the DRG (Chapter VI). Fifty five point four percent of Ditily I in this population of PRF treated LSR patients, while the mental component remained unchanged. 
The success rate of 55.4\% in PRF treated LSR patients as noted in our prospective trial may be improved if predictive factors for success or failure are identified. This urged us to further analyze the data of the prospective trial in order to test if predictors of success could be identified (chapter VII)

Then, successful outcome after PRF adjacent to the DRG, in patients with intractable chronic lumbosacral radicular pain was shown to be more likely in patients $\geq 55$ years, whereas younger patients and those with a high disability showed a lower success rate. Furthermore, from this detailed analysis it was concluded that a diagnostic nerve root block has a limited predictive value Combination of various factors (positive diagnostic block, age $\geq 55$ years are positive predictors and high degree of disability is a negative predictor) resulted in a fair predictive value of success in PR treatment of LSR patients.

It is suggested that based on the positive findings as reported in this thesis on the clinical succes of PRF adjacent to the DRG in treatment of chronic LSR, RCT's are needed to provide further scientific evidence.

\section{SAMENVATTING}

Deze thesis heeft als objectief een evaluatie te maken van de rol van gepulseerde radiofrequente (PRF) behandeling ter hoogte van het ganglion spinale, beter gekend als dorsaal wortel ganglion [dorsal root ganglion (DRG)], voor de behandeling van refractair lumbosacraal radiculair lijden (LSR).

Het eerste hoofdstuk van dit proefschrift heeft als doel lumbosacraal radiculair lijden te definiëren. Dit inleidend hoofdstuk geeft de lezer een overzicht van de epidemiologie van LSR en de beschikbare behandelingen. Hierbij wordt speciaal aandacht besteed aan interventionele technieken zoals radiofrequente en PRF behandelingen.

In hoofdstuk II worden het diagnostische proces, het gebruik en de waarde van bijkomende onderzoeken en de mogelijke behandelopties beschreven. De diagnostische procedure voor LSR wordt gehinderd door het gebrek aan een consensus omtrent de definitie en het gemis aan een gouden diagnostisch standaard.

Om de toepassing van PRFbijpatiënten met (cervicaal en lumbosacraal) radiculair lijden te optimaliseren is een betere correlatie tussen basis wetenschappelijk onderzoek en klinische ervaring nodig (hoofdstuk III). Radiculaire pijn is een complex fenomeen met belangrijke afwijkingen en spreiding van het afferent nociceptief signaal, dat aanleiding geeft tot sensitisatie van de neurotransmissie ter hoogte van het DRG en in de spinale dorsale hoorn op verschillende niveaus. De ontwikkeling van een goed diermodel om dit probleem te bestuderen is niet vanzelfsprekend. Er zijn aanwijzingen dat bij radiculaire pijn ectopische ontladingen ontstaan die de dorsale hoorn bereiken en de post-synaptische neuronen kunnen activeren. De toegenomen vrijstelling van neurotrofines (b.v. BDNF) in de spinale dorsale hoorn induceert een cascade van mechanismen die de transmissie van de afferente nociceptieve input sensitiseren.

PRF is een interventionele behandeling en een mogelijke optie voor de behandeling van radiculaire pijn. PRF genereert een sterker elektromagnetisch veld dan conventionele RF, waardoor de onderliggende pathofysiologische mechanismen van radiculaire pijn in een groter gebied kunnen beïnvloed worden. Er zijn beperkte gegevens die aantonen dat PRF een vermindering geeft van het pijngedrag in experimentele diermodellen voor radiculaire en neuropathische pijn. Dit gaat gepaard met cellulaire veranderingen in het DRG en de spinale hoorn.

De doeltreffendheid van een behandeling wordt het best geëvalueerd door een gerandomiseerde placebo gecontroleerde studie, waarin de patiënt en de zorgverlener niet weten welke behandeling gegeven wordt. In hoofdstuk IV werden de problemen en valkuilen van het onderzoek naar interventionele pijn behandelingstechnieken besproken. De pre-randomisatie of Zelen design wordt voorgesteld als een manier om problemen te voorkomen door de controle groep initieel niet te informeren over een alternatieve behandeling die het proberen waard kan zijn.

In hoofdstuk $\mathrm{V}$ worden de resultaten van een klinische audit over het gebruik van PRF ter hoogte van het DRG bij patiënten met LSR beschreven. In deze groep werd in $22.9 \%$ van de gevallen nog steeds $50 \%$ pijnvermindering genoteerd na 6 maanden. Dit succes ratio van $22.9 \%$ is minder gunstig dan deze gerapporteerd in vroegere studies waar een herhalingsbehandeling van RF of PRF uitgevoerd werd. Deze bevinding suggereert dat een herhalingsbehandeling op hetzelfde of een aanpalend niveau de kans op succes zou kunnen verhogen. Daarom werd de mogelijkheid om een herhalingsbehandeling uit te voeren opgenomen in het protocol van de cohort studie die besproken wordt in hoofdstuk 
In een prospectieve studie werden opeenvolgendepatiënten metrefractair unilateraal lumbosacraal lijden van L5 of S1 behandeld met een PRF interventie ter hoogte van het DRG (hoofdstuk VI) Vijfenvijftig komma vier percent van een totaal aantal van 65 patiënten die in de studie opgenomen werden hadden een klinisch succes na 6 maanden, bepaald met het GPE of de NRS. De Diswestry Disability Index en de fysische component vanc verbeterden significant in deze populatie van LSR patiënten die met PRF werden behandeld. De mentale component van de RAND-36 bleef onveranderd.

De 55.4\% succes ratio bij LSR patiënten die met PRF werden behandeld, zoals in onze prospec tieve studie werd gevonden, zou kunnen verbeteren indien de predictieve factoren voor succes of falen kunnen bepaald worden. Daarom hebben wij de gegevens van de prospectieve studie verder geanalyseerd om na te gaan of er predictoren voor succes kunnen bepaald worden. De resultaten werden in hoofdstuk VII weergegeven. De kans op een goed resultaat na PRF ter hoogte van het DRG, bij patiënten met chronisch lumbosacraal lijden was groter bij patiënten $\geq 55$ jaar, terwijl bij jongere patiënten en personen met sterke beperkingen een kleinere kans hadden op succes. Verder bleek uit deze gedetailleerde analyse dat een diagnostisch wortel block een beperkte predictieve waarde heeft. De combinatie van verschillende factoren heeft (positief diagnostisch block en ouder dan 55 jaar zijn positieve predictieve factoren, een sterke beperking is een negatieve predictor) een vijj goede predictieve waarde voor succes van een PRF behandeling bij patiënten met LSR

De positieve bevindingen voor klinisch succes van PRF ter hoogte van het DRG bij patiënten met chronisch LSR lijden die in dit proefschrift werden gerapporteerd, suggereren dat gerandomiseerde, gecontroleerde studies nodig zijn om meer wetenschappelijk bewijs te genereren.

\section{Co-authors and affiliations}




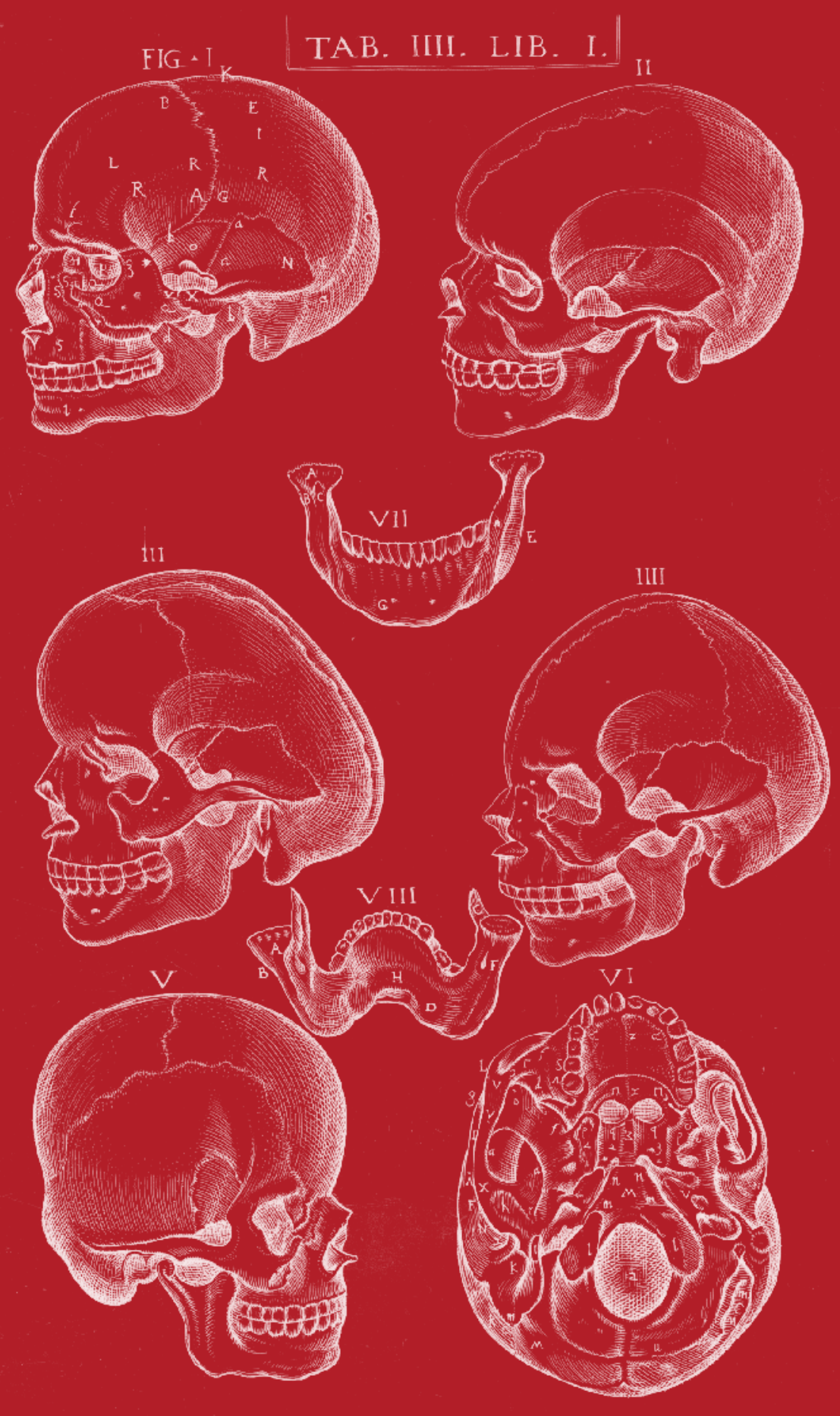

Jianguo Cheng

Department of Pain Management,

Cleveland Clinic

Cleveland Ohio

USA

\section{Nelleke de Meij}

Department of Anesthesiology and Pain Medicine

Maastricht University Medical Centre

Maastricht

The Netherland

\section{Andreas Herrler}

Department of Anatomy and Embryology

Maastricht University

Maastricht

The Netherlands

Marc Huntoon

Division of Pain Management

Vanderbilt University

Nashville

USA

\section{Elbert A Joosten}

School of Mental Health and Neuroscience

University Maastricht

Maastricht

The Netherlands

\section{Alfons Kessels}

Clinical Epidemiology and Medical Technology Assessment

Maastricht University Medical Centre

Maastricht

The Netherlands

\section{Arno Lataster}

Department of Anatomy, Critical Care, Emergency Medicine and Embryology Maastricht University

Maastricht

The Netherlands 
Cleveland Ohio

USA

Jacob Patijn

Department of Anesthesiology and Pain Medicine

Maastricht University Medical Centre

Maastricht

The Netherlands

Bibliography

Joselien van Bilsen

Department of Anesthesiology and Pain Medicine

Maastricht University Medical Centre

Maastricht

The Netherland

Maarten van Kleef

Department of Anesthesiology and Pain Medicine

Maastricht University Medical Centre

Maastricht

The Netherlands

\section{Jan Van Zundert}

Department of Anesthesiology and Multidisciplinary Pain Centre

Ziekenhuis Oost-Limburg

Genk/Lanaken

Belgium 
TABVLA. III. C LIBRI. I.
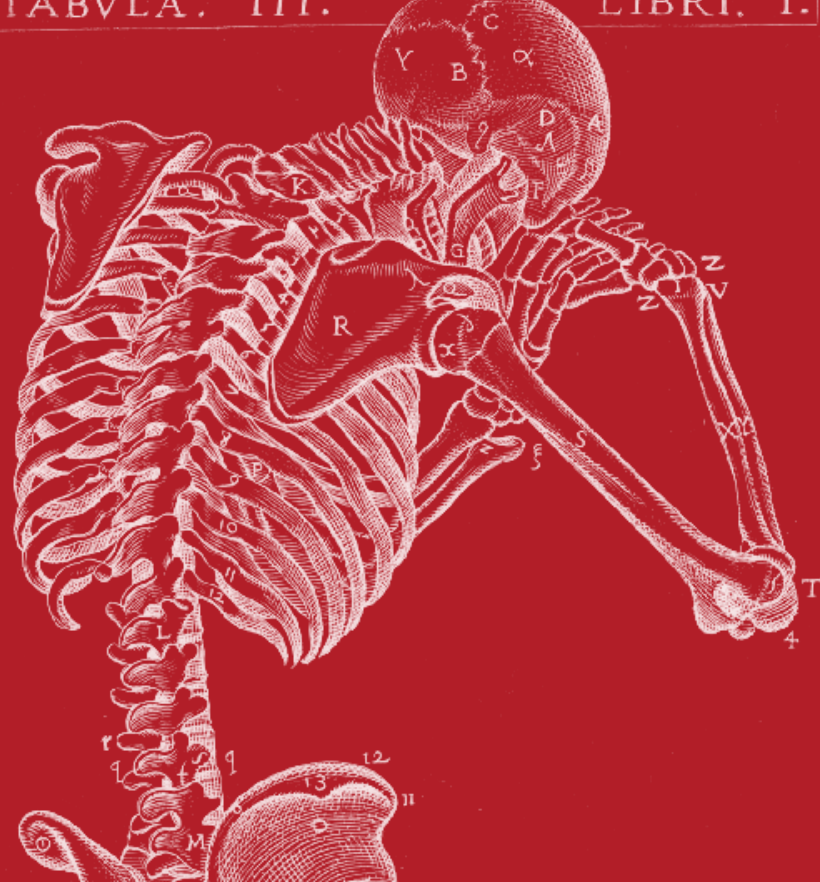

$+29$
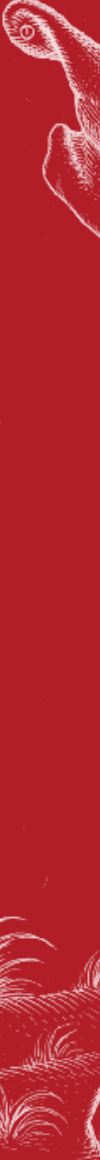

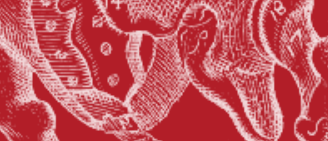

- va
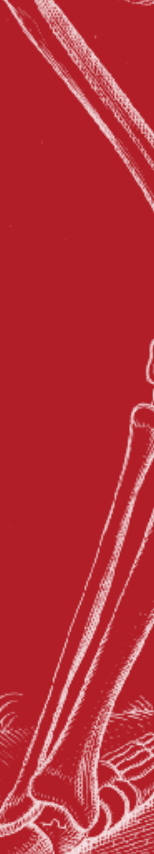
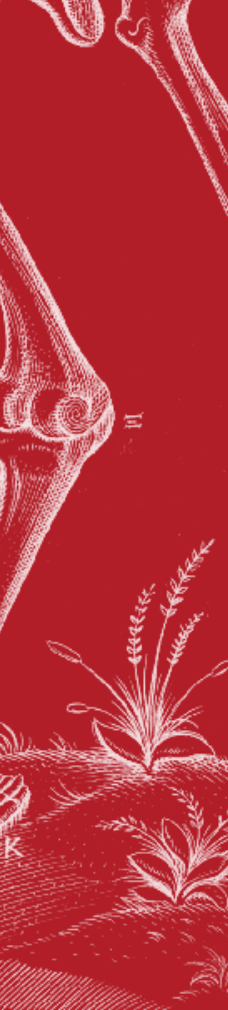
19. Bauer CS, Nieto-Rostro M, Rahman W, Tran-Van-Minh A, Ferron L, Douglas L, Kadurin I, Sri Ranjan Y, Fernandez-Alacid L, Millar NS, Dickenson AH, Lujan R, Dolphin AC. The increase trafficking of the calcium channel subunit alpha2delta-1 to presynaptic terminals in neuropathic pain is inhibited by the alpha2delta ligand pregabalin. J Neurosci. 2009; 29:4076-4088

20. Benedetti F, Carlino E, Pollo A. How Placebos Change the Patient's Brain. Neuropsychopharmacology 2010 36, 339-354

21. Bennett MI, Closs J. Methodological issues in nonpharmacological trials for chronic pain. PAIN Clinical updates. 2010; XVIII:1-6

22. Bennett MI, Smith BH, Torrance N, Potter J. The S-LANSS score for identifying pain of predominantly neuropathic origin: validation for use in clinical and postal research. J Pain. 2005; 6:149158

23. Benzon HT, Chew TL, McCarthy RJ, Benzon HA, Walega DR. Comparison of the particle sizes of different steroids and the effect of dilution: a review of the relative neurotoxicities of the steroids. Anesthesiology. 2007; 106:331-338

24. Bilir A, Gulec S. Cauda equina syndrome after epidural steroid injection: a case report.J Manipulative Physiol Ther. 2006; 29:492 e491-493

25. Bland J, Altman D. Survival probabilities (the Kaplan-Meier method). BMJ. 1998; 317:1572

26. Bogduk N. Epidural steroids. Spine. 1995; 20:845-848

27. Bogduk N. Lumbar transforaminal injections of corticosteroids. In: Bogduk N, ed. International Spine Intervention Society Practice Guidelines for Spinal Diagnoses and Treatment, Vol. ed. San Francisco, USA: ISIS; 2004

28. Boswell MV, Trescot AM, Datta S, Schultz DM, Hansen HC, Abdi S, Sehgal N, Shah RV, Singh V, Benyamin RM, Patel VB, Buenaventura RM, Colson JD, Cordner HJ, Epter RS, Jasper JF, Dunbar EE, Atluri SL, Bowman RC, Deer TR, Swicegood JR, Staats PS, Smith HS, Burton AW, Kloth DS, Giordano J, Manchikanti L. Interventional techniques: evidence-based practice guidelines in the management of chronic spinal pain. Pain Physician. 2007; 10:7-111

29. Botwin K, Gruber R, Bouchlas C, Torres-Ramos F, Freeman TWK. Complications of fluoroscopically guided transforaminal lumbar epidural injections. Arch Phys Med Rehabil. 2000; 81:1045-1050

30. Bouhassira D, Attal N, Alchaar H, Boureau F, Brochet B, Bruxelle J, Cunin G, Fermanian J, Ginie P, Grun-Overdyking A, Jafari-Schluep H, Lanteri-Minet M, Laurent B, Mick G, Serrie A, Valade D, Vicaut E. Comparison of pain syndromes associated with nervous or somatic lesions and development of a new neuropathic pain diagnostic questionnaire (DN4). Pain. 2005; 114:29-36

31. Cahana A, Van Zundert J, Macrea L, van Kleef M, Sluijter M. Pulsed Radiofrequency: Current Clinical and Biological Literature Available. Pain Medicine. 2006; 7:411-423

32. Cahana A, Vutskits L, Muller D. Acute differential modulation of synaptic transmission and cell survival during exposure to pulsed and continuous radiofrequency energy. J Pain. 2003; 4:197-202

33. Carette S, Leclaire R, Marcoux S, Morin F, Blaise GA, St-Pierre A, Truchon R, Parent F, Levesque J, Bergeron V, Montminy P, Blanchette C. Epidural corticosteroid injections for sciatica due to herniated nucleus pulposus. N Engl J Med. 1997; 336:1634-1640

34. CBO. Het Lumbosacrale radiculaire syndroom. In: Toetsing CBvdI, ed. Consensus richtlijnen, Vol. Utrecht: CBO; 1996.

35. Chao SC, Lee HT, Kao TH, Yang MY, Tsuei YS, Shen CC, Tsou HK. Percutaneous pulsed radiofrequency in the treatment of cervical and lumbar radicular pain. Surg Neurol. 2008; 70:59-65.

36. Chien SQ, Li C, Li H, Xie W, Pablo CS, Zhang JM. Sympathetic Fiber Sprouting in Chronically Compressed Dorsal Root Ganglia Without Peripheral Axotomy. J Neuropathic Pain Symptom Palliation. 2005; 1:19-23
37. Cho HK, Cho YW, Kim EH, Sluijter ME, Hwang SJ, Ahn SH. Changes in pain behavior and glial activation in the spinal dorsal horn after pulsed radiofrequency current administration to the dorsal root ganglion in a rat model of lumbar disc herniation: laboratory investigation. J Neurosurg Spine. 2013; 19:256-263

38. Chou R, Atlas SJ, Stanos SP, Rosenquist RW. Nonsurgical interventional therapies for low back pain: a review of the evidence for an American Pain Society clinical practice guideline. Spine (Phila Pa 1976). 2009; 34:1078-1093

39. Cluff R, Mehio AK, Cohen SP, Chang Y, Sang CN, Stojanovic MP. The technical aspects of epidural teroid injections: a national survey. Anesth Analg. 2002; 95:403-408

40. Cosman EJ, Cosman ES. Electric and thermal field effects in tissue around radiofrequency electrodes. Pain Medicine. 2005; 6:405-424

41. Dashfield AK, Taylor MB, Cleaver JS, Farrow D. Comparison of caudal steroid epidural with targeted steroid placement during spinal endoscopy for chronic sciatica: a prospective, randomized, double-blind trial. Br J Anaesth. 2005; 94:514-519

42. Delauche-Cavallier MC, Budet C, Laredo JD, Debie B, Wybier M, Dorfmann H, Ballner I. Lumbar disc herniation. Computed tomography scan changes after conservative treatment of nerve root compression. Spine. 1992; 17:927-933

43. Dellemijn PL, van Duijn H, Vanneste JA. Prolonged treatment with transdermal fentanyl in neuropathic pain.J Pain Symptom Manage. 1998; 16:220-229

44. DePalma MJ, Bhargava A, Slipman CW. A critical appraisal of the evidence for selective nerve root injection in the treatment of lumbosacral radiculopathy. Arch Phys Med Rehabil. 2005; 86:1477-1483

45. Deville WL, van der Windt DA, Dzaferagic A, Bezemer PD, Bouter LM. The test of Lasegue: systematic review of the accuracy in diagnosing herniated discs. Spine. 2000; 25:1140-1147

46. Dilke TF, Burry HC, Grahame R. Extradural corticosteroid injection in management of lumbar nerve root compression. BMJ. 1973; 2:635-637

47. Dionne CE, Dunn KM, Croft PR, Nachemson AL, Buchbinder R, Walker BF, Wyatt M, Cassidy JD, Rossignol M, Leboeuf-Yde C, Hartvigsen J, Leino-Arjas P, Latza U, Reis S, Gil Del Real MT, Kovacs FM, Oberg B, Cedraschi C, Bouter LM, Koes BW, Picavet HS, van Tulder MW, Burton K, Foster NE, Macfarlane GJ, Thomas E, Underwood M, Waddell G, Shekelle P, Volinn E, Von Korff M. A consensus approach toward the standardization of back pain definitions for use in prevalence studies. Spine. 2008; 33:95-103

48. Doth AH, Hansson PT, Jensen MP, Taylor RS. The burden of neuropathic pain: a systematic review and meta-analysis of health utilities. Pain. 2010; 149:338-344

49. Dreiser RL, Le Parc JM, Velicitat P, Lleu PL. Oral meloxicam is effective in acute sciatica: two randomised, double-blind trials versus placebo or diclofenac. Inflamm Res. 2001; 50 Suppl 1:S17-23

50. Dworkin RH, O'Connor AB, Audette J, Baron R, Gourlay GK, Haanpaa ML, Kent JL, Krane EJ, Lebel AA, Levy RM, Mackey SC, Mayer J, Miaskowski C, Raja SN, Rice AS, Schmader KE, Stacey B, Stanos S, Treede RD, Turk DC, Walco GA, Wells CD. Recommendations for the pharmacological management of neuropathic pain: an overview and literature update. Mayo Clin Proc. 2010; 85:S3-14

51. Dworkin RH, O’Connor AB, Backonja M, Farrar JT, Finnerup NB, Jensen TS, Kalso EA, Loeser D, Miaskowski C, Nurmikko TJ, Portenoy RK, Rice AS, Stacey BR, Treede RD, Turk DC, Wallace MS. Pharmacologic management of neuropathic pain: evidence-based recommendations. Pain. 2007; 132:237-251

52. Dworkin RH, Turk DC, Peirce-Sandner S, Baron R, Bellamy N, Burke LB, Chappell A, Chartier K, Cleeland CS, Costello A, Cowan P, Dimitrova R, Ellenberg S, Farrar JT, French JA, Gilron I, Hertz S, Jadad AR, Jay GW, Kalliomaki J, Katz NP, Kerns RD, Manning DC, McDermott MP, McGrath 
PJ, Narayana A, Porter L, Quessy S, Rappaport BA, Rauschkolb C, Reeve BB, Rhodes T, Sampaio C, Simpson DM, Stauffer JW, Stucki G, Tobias J, White RE, Witter J. Research design considerations for confirmatory chronic pain clinical trials: IMMPACT recommendations. Pain. 2010; 149:177-193

53. el Barzouhi A, Vleggeert-Lankamp CL, Lycklama a Nijeholt GJ, Van der Kallen BF, van den Hout WB, Jacobs WC, Koes BW, Peul WC. Magnetic resonance imaging in follow-up assessment of sciatica. N Engl J Med. 2013; 368:999-1007

54. Enck P, Benedetti F, Schedlowski M. New insights into the placebo and nocebo responses. Neuron. 2008; 59:195-206

55. Erdine S, Bilir A, Cosman ER, Cosman ER, Jr. Ultrastructural changes in axons following exposure to pulsed radiofrequency fields. Pain Pract. 2009; 9:407-417

56. Erdine S, Yucel A, Cimen A, Aydin S, Sav A, Bilir A. Effects of pulsed versus conventional radiofrequency current on rabbit dorsal root ganglion morphology. Eur J Pain. 2005; 9:251-256

57. Eslberg $\mathrm{C}$. The extradural ventral on ondromas (eccondroses) their favourite sites, the spinal cord and root symptoms they produce and their surgical treatment. Bull Neurosurg Inst New York. 1931; I:350366

58. Fairbank JC. Sciatic: An archaic term. BMJ. 2007; 335:112

59. Fairbank JC, Pynsent PB. The Oswestry Disability Index. Spine. 2000; 25:2940-2952.

60. Fan N, Sikand P, Donnelly DF, Ma C, Lamotte RH. Increased Na+ and K+ currents in small mouse dorsal root ganglion neurons after ganglion compression. J Neurophysiol. 2011; 106:211-218

61. Farrar JT,Jr.JPY, LaMoreaux L, Werth JL, Poole RM. Clinical importance of changes in chronic pain intensity measured on an 11-point numerical scale. Pain. 2001; 94:149-158

62. Finn KP, Case JL. Disk entry: a complication of transforaminal epidural injection--a case report. Arch Phys Med Rehabil. 2005; 86:1489-1491

63. Finnerup NB, Otto M, McQuay HJ, Jensen TS, Sindrup SH. Algorithm for neuropathic pain treatment: an evidence based proposal. Pain. 2005; 118:289-305

64. Finnerup NB, Sindrup SH, Jensen TS. The evidence for pharmacological treatment of neuropathic pain. Pain. 2010; 150:573-581

65. Finniss DG, Kaptchuk TJ, Miller F, Benedetti F. Biological, clinical, and ethical advances of placebo effects. Lancet. 375:686-695

66. Forst J. Contribution a l'étude clinique de la sciatique. Paris: Université de Paris; 1881

67. Freeman BJ, Ludbrook GL, Hall S, Cousins M, Mitchell B, Jaros M, Wyand M, Gorman JR. Randomized, Double-blind, Placebo-Controlled, Trial of Transforaminal Epidural Etanercept for the Treatment of Symptomatic Lumbar Disc Herniation. Spine (Phila Pa 1976). 2013; 38:1986-1994

68. Fuller H. On Rheumatism, Rheumatic Gout and Sciatica: The Phatology, Symptoms and Treatment. London: John Churchill; 1852

69. Furman MB, Lee TS, Mehta A, Simon JI, Cano WG. Contrast flow selectivity during transforamina lumbosacral epidural steroid injections. Pain Physician. 2008; 11:855-861

70. Gallagher J, Vadi PLP, Wesley JR. Radiofrequency facet joint denervation in the treatment of low back pain-a prospective controlled double-blind study in assess to efficacy. Pain Clinic. 1994; 7:193-198

71. Gallizzi M, Gagnon C, Harden RN, Stanos S, Khan A. Medication Quantification Scale Version III internal validation of detriment weights using a chronic pain population. Pain Pract. 2008; 8:1-4

72. Geng SJ, Liao FF, Dang WH, Ding X, Liu XD, CaiJ, Han JS, Wan Y, Xing GG. Contribution of the spinal cord BDNF to the development of neuropathic pain by activation of the NR2B-containing NMDA receptors in rats with spinal nerve ligation. Exp Neurol. 2010; 222:256-266

73. Geurts JW, Kallewaard JW, Richardson J, Groen GJ. Targeted methylprednisolone acetate/hyaluronidase/clonidine injection after diagnostic epiduroscopy for chronic sciatica: a prospective, 1-year follow-up study. Reg Anesth Pain Med. 2002; 27:343-352

74. Geurts JW, van Wijk RM, Stolker RJ, Groen GJ. Efficacy of radiofrequency procedures for the treatment of spinal pain: a systematic review of randomized clinical trials. Reg Anesth Pain Med. 2001; 26:394-400

75. Geurts JW, van Wijk RM, Wynne HJ, Hammink E, Buskens E, Lousberg R, Knape JT, Groen GJ. Radiofrequency lesioning of dorsal root ganglia for chronic lumbosacral radicular pain: a randomised, double-blind, controlled trial. Lancet. 2003; 361:21-26

76. Gibson JN, Waddell G. Surgical interventions for lumbar disc prolapse: updated Cochrane Review. Spine. 2007; 32:1735-1747

77. Gillespie G, MacKenzie P. Epiduroscopv--a review. Scott Med J. 2004; 49:79-81

78. Glaser SE, Falco F. Paraplegia following a thoracolumbar transforaminal epidural steroid injection. Pain Physician. 2005; 8:309-314

79. Goodman BS, Bayazitoglu M, Mallempati S, Noble BR, Geffen JF. Dural puncture and subdural injection: a complication of lumbar transforaminal epidural injections. Pain Physician. 2007; 10:697705

80. Grovle L, Haugen AJ, Keller A, Ntvig B, Brox JI, Grotle M. Prognostic factors for return to work in patients with sciatica. Spine J. 2013; 13(12):1849-57

81. Guigui P, Cardinne L, Rillardon L, Morais T, Vuillemin A, Deburge A. [Per- and postoperative complications of surgical treatment of lumbar spinal stenosis. Prospective study of 306 patients]. Rev Chir Orthop Reparatrice Appar Mot. 2002; 88:669-67

82. Guyatt G, Gutterman D, Baumann MH, Addrizzo-Harris D, Hylek EM, Phillips B, Raskob G, Lewis SZ, Schunemann H. Grading strength of recommendations and quality of evidence in clinical guidelines: report from an american college of chest physicians task force. Chest. 2006; 129:174-181

83. Hagen KB, Jamtvedt G, Hilde G, Winnem MF. The updated cochrane review of bed rest for low back pain and sciatica. Spine. 2005; 30:542-546

84. Hagiwara S, Iwasaka H, Takeshima N, Noguchi T. Mechanisms of analgesic action of pulsed radiofrequency on adjuvant-induced pain in the rat: roles of descending adrenergic and serotonergic systems. Eur J Pain. 2009; 13:249-252

85. Hahne AJ, Ford JJ. Functional restoration for a chronic lumbar disk extrusion with associated radiculopathy. Phys Ther. 2006; 86:1668-1680

86. Hamann W, Abou-Sherif S, Thompson S, Hall S. Pulsed radiofrequency applied to dorsal root ganglia causes a selective increase in ATF3 in small neurons. Eur J Pain. 2006; 10:171-176

87. Haugen AJ, Brox JI, Grovle L, Keller A, Natvig B, Soldal D, Grotle M. Prognostic factors for nonsuccess in patients with sciatica and disc herniation. BMC Musculoskelet Disord. 2012; 13:183

88. Hays RD, Morales LS. The RAND-36 measure of health-related quality of life. Ann Med. 2001; 33:350-357

89. Heavner J, Chokhavatia S, Kizelshteyn G. Percutaneous evaluation of the epidural and subarachnoid space with a flexible fiberscope. Reg Anesth 1991; 15(S):85

90. Heavner JE, Racz GB, Raj P. Percutaneous epidural neuroplasty: prospective evaluation of $0.9 \%$ $\mathrm{NaCl}$ versus 10\% NaCl with or without hyaluronidase. Reg Anesth Pain Med. 1999; 24:202-207

91. Heliovaara M, Impivaara O, Sievers K, Melkas T, Knekt P, Korpi J, Aromaa A. Lumbar disc syndrome in Finland. J Epidemiol Community Health. 1987; 41:251-258

92. Higuchi Y, Nashold BS, Jr., Sluijter M, Cosman E, Pearlstein RD. Exposure of the dorsal root ganglion in rats to pulsed radiofrequency currents activates dorsal horn lamina I and II neurons. Neurosurgery. 2002; 50:850-855

95. Hofstee DJ, Gijtenbeek JM, Hoogland PH, van Houwelingen HC, Kloet A, Lotters F, Tans JT. West- 
einde sciatica trial: randomized controlled study of bed rest and physiotherapy for acute sciatica. J Neurosurg. 2002; 96:45-49

94. Hooten WM, Mizerak A, Carns PE, Huntoon MA. Discitis after lumbar epidural corticosteroid injection: a case report and analysis of the case report literature. Pain Med. 2006; 7:46-51

95. Horng S, Miller FG. Is placebo surgery unethical? N Engl J Med. 2002; 347:137-139

96. Hosmer D, Lemeshow S, Sturdivant R. Applied logistic regression, 3 rd edition Hosmer DW, Lemeshow S, RX S ed. New York: John Wiley \& Sons; 2013

97. Houten JK, Errico TJ. Paraplegia after lumbosacral nerve root block: report of three cases. The Spine Journal. 2002; 2:70-75

98. Hrobjartsson A, Gotzsche PG. Is the placebo powerless? Update of a systematic review with 52 new randomized trials comparing placebo with no treatment. J Intern Med. 2004; 256:91-100

99. Hu SJ, Xing JL. An experimental model for chronic compression of dorsal root ganglion produced by intervertebral foramen stenosis in the rat. Pain. 1998; 77:15-23

100. Huntoon MA, Martin DP. Paralysis after transforaminal epidural injection and previous spinal surgery. Reg Anesth Pain Med. 2004; 29:494-495

101. Hurley RW, Adams MC, Benzon HT. Neuropathic pain: treatment guidelines and updates. Curr Opin Anaesthesiol. 2013; epub ahead of print:Aug 29

102. Igarashi T, Hirabayashi Y, Seo N, Saitoh K, Fukuda H, Suzuki H. Lysis of adhesions and epidura injection of steroid/local anaesthetic during epiduroscopy potentially alleviate low back and leg pain in elderly patients with lumbar spinal stenosis. Br J Anaesth. 2004; 93:181-187

103. Jacobs WC, van Tulder M, Arts M, Rubinstein SM, van Middelkoop M, Ostelo R, Verhagen A, Koe B, Peul WC. Surgery versus conservative management of sciatica due to a lumbar herniated disc: systematic review. Eur Spine J. 2011; 20:513-522

104. Janssen SP, Truin M, Van Kleef M, Joosten EA. Differential GABAergic disinhibition during the development of painful peripheral neuropathy. Neuroscience. 2011; 184:183-194

105. Jensen MC, Brant-Zawadzki MN, Obuchowski N, Modic MT, Malkasian D, Ross JS. Magnetic resonance imaging of the lumbar spine in people without back pain. N Engl J Med. 1994; 331:69-73

106. Jensen MP, McFarland CA. Increasing the reliability and validity of pain intensity measurement in chronic pain patients. Pain. 1993; 55:195-203

107. Ji RR, Kohno T, Moore KA, Woolf CJ. Central sensitization and LTP: do pain and memory share similar mechanisms? Trends Neurosci. 2003; 26:696-705

108. Jonsson B, Stromqvist B. Motor affliction of the L5 nerve root in lumbar nerve root compression syndromes. Spine. 1995; 20:2012-2015

109. Jonsson B, Stromqvist B. Clinical characteristics of recurrent sciatica after lumbar discectomy. Spine 1996; 21:500-505

110. Kabbara A, Rosenberg SK, Untal C. Methicillin-resistant Staphylococcus aureus epidural absces after transforaminal epidural steroid injection. Pain Physician. 2004; 7:269-272

111. Karppinen J, Malmivaara A, Kurunlahti M, Kyllonen E, Pienimaki T, Nieminen P, Ohinmaa A, Tervonen O, Vanharanta H. Periradicular infiltration for sciatica: a randomized controlled trial. Spine. 2001; 26:1059-1067

112. Karppinen J, Ohinmaa A, Malmivaara A, Kurunlahti M, Kyllonen E, Pienimaki T, Nieminen P, Tervonen $\mathrm{O}$, Vanharanta $\mathrm{H}$. Cost effectiveness of periradicular infiltration for sciatica: subgroup analysis of a randomized controlled trial. Spine. 2001; 26:2587-2595

113. Kennedy DJ, Dreyfuss P, Aprill CN, Bogduk N. Paraplegia Following Image-Guided Transforaminal Lumbar Spine Epidural Steroid Injection: Two Case Reports. Pain Med. 2009; 10:1389-1394

114. Kerr BJ, Bradbury EJ, Bennett DL, Trivedi PM, Dassan P, French J, Shelton DB, McMahon SB,
Thompson SW. Brain-derived neurotrophic factor modulates nociceptive sensory inputs and NMDAevoked responses in the rat spinal cord. J Neurosci. 1999; 19:5138-5148

115. Kerr RS, Cadoux-Hudson TA, Adams CB. The value of accurate clinical assessment in the surgical management of the lumbar disc protrusion. J Neurol Neurosurg Psychiatry. 1988; 51:169-173

116. Khoromi S, Cui L, Nackers L, Max MB. Morphine, nortriptyline and their combination vs. placebo in patients with chronic lumbar root pain. Pain. 2007; 130:66-75

117. Khoromi S, Patsalides A, Parada S, Salehi V, Meegan JM, Max MB. Topiramate in chronic lumbar radicular pain. J Pain. 2005; 6:829-836

118. Kim SH, Chung JM. An experimental model for peripheral neuropathy produced by segmental spinal nerve ligation in the rat. Pain. 1992; 50:355-363

119. Klusakova I, Dubovy P. Experimental models of peripheral neuropathic pain based on traumatic nerve injuries - an anatomical perspective. Ann Anat. 2009; 191:248-259

120. Kobayashi S, Mwaka ES, Baba H, Takeno K, Miyazaki T, Matsuo H, Uchida K, Meir A. Microvascular system of the lumbar dorsal root ganglia in rats. Part I: a 3D analysis with scanning electron microscopy of vascular corrosion casts. J Neurosurg Spine. 2010; 12:197-202

121. Kobayashi S, Mwaka ES, Baba H, Kokubo Y, Yavama T, Kubota M, Nakajima H, Meir A. Microvascular system of the lumbar dorsal root ganglia in rats. Part II: neurogenic control of intraganglionic blood flow. J Neurosurg Spine. 2010; 12:203-209

122. Kobayashi S, Shizu N, Suzuki Y, Asai T, Yoshizawa H. Changes in nerve root motion and intraradicular blood flow during an intraoperative straight-leg-raising test. Spine (Phila Pa 1976). 2003; 28:1427-1434

123. Kobayashi S, Uchida K, Kokubo Y, Takeno K, Yayama T, Miyazaki T, Nakajima H, Nomura E, Mwaka E, Baba H. Synapse involvement of the dorsal horn in experimental lumbar nerve root compression: a light and electron microscopic study. Spine (Phila Pa 1976). 2008; 33:716-723

124. Koes B, Scholten RJ, Mens JMA, Bouter LM. Efficacy of epidural steroid injections for low-back pain and sciatica: a systematic review of randomized clinical trials. Pain. 1995; 63:279-288

125. Koes BW, Scholten RJPM, Mens JMA, Bouter LM. Epidural Steroid Injections for Low Back Pain and Sciatica: An updated Systematic Review of Randomized Clinical Trials. Pain Digest. 1999; 9:241-247

126. Koes BW, van Tulder MW, Peul WC. Diagnosis and treatment of sciatica. BMJ. 2007; 334:1313-1317

27. Konstantinou K, Dunn KM Sciatica: review of epidemiological studies and prevalence estimates. Spine (Phila Pa 1976). 2008; 33:2464-2472

128. Kumar K, Buchser E, Linderoth B, Meglio M, Van Buyten JP. Avoiding Complications from spinal cord stimulation: Practical recommendations from an international panel of experts. Neuromodulation. 2007; 10:24-33

129. Kumar K, Taylor RS, Jacques L, Eldabe S, Meglio M, Molet J, Thomson S, O’Callaghan J, Eisenberg E, Milbouw G, Buchser E, Fortini G, Richardson J, North RB. Spinal cord stimulation versu conventional medical management for neuropathic pain: a multicentre randomised controlled trial in patients with failed back surgery syndrome. Pain. 2007; 132:179-188

130. Laboureyras E, Rivat C, Cahana A, Richebe P. Pulsed radiofrequency enhances morphine analgesia in neuropathic rats. Neuroreport. 2012; 23:535-539

131. Le Bars D. The whole body receptive field of dorsal horn multireceptive neurones. Brain Res Brain Res Rev. 2002; 40:29-44

132. Leclaire R, Fortin L, Lambert R, Bergeron YM, Rossignol M. Radiofrequency facet joint denervation in the treatment of low back pain: a placebo-controlled clinical trial to assess efficacy. Spine. 2001; $26: 1411-1416$

133. Li Y, Dorsi MJ, Meyer RA, Belzberg AJ. Mechanical hyperalgesia after an L5 spinal nerve lesion in the 
rat is not dependent on input from injured nerve fibers. Pain. 2000; 85:493-502

134. Lidierth M. Long-range projections of Adelta primary afferents in the Lissauer tract of the rat Neurosci Lett. 2007; 425:126-130

135. Likert R. A technique for the measurement of attitudes. Archives of Psychology. 1932; 22:140

136. Lin CW, Verwoerd AJ, Maher CG, Verhagen AP, Pinto RZ, Luijsterburg PA, Hancock MJ. How is radiating leg pain defined in randomized controlled trials of conservative treatments in primary care? A systematic review. Eur J Pain. 2013;

137. Liu CN, Wall PD, Ben-Dor E, Michaelis M, Amir R, Devor M. Tactile allodynia in the absence of C-fiber activation: altered firing properties of DRG neurons following spinal nerve injury. Pain. 2000; 85:503-521

138. Lou L, Racz G. Spinal Decompressive Neuroplasty via the Caudal and Cervical Approaches. In: Beltrutti D, Benzon HT, Erdine S, Heavner JE, Niv D, Racz GB, et al., eds. Raj: Textbook of Regional Anesthesia, 1st ed. Vol. MD Consult. ed. Philadelphia, Pennsylvania, US. Churchill Livingstone; 2002

139. Luijsterburg PA, Lamers LM, Verhagen AP, Ostelo RW, van den Hoogen HJ, Peul WC, Avezaat CJ, Koes BW. Cost-effectiveness of physical therapy and general practitioner care for sciatica. Spine 2007; 32:1942-1948

140. Luijsterburg PA, Verhagen AP, Ostelo RW, van den Hoogen HJ, Peul WC, Avezaat CJ, Koes BW. Physical therapy plus general practitioners' care versus general practitioners' care alone for sciatica: a randomised clinical trial with a 12-month follow-up. Eur Spine J. 2008; 17:509-517

141. Luijsterburg PA, Verhagen AP, Ostelo RW, van Os TA, Peul WC, Koes BW. Effectiveness of conservative treatments for the lumbosacral radicular syndrome: a systematic review. Eur Spine J. 2007; 16:881-899

142. Lyders EM, Morris PP. A case of spinal cord infarction following lumbar transforaminal epidural steroid injection: MR imaging and angiographic findings. AJNR Am J Neuroradiol. 2009; 30:1691-1693

143. Maigne JY, Rime B, Deligne B. Computed tomographic follow-up study of forty-eight cases of nonoperatively treated lumbar intervertebral disc herniation. Spine. 1992; 17:1071-1074

144. Manchikanti L, Boswell MV, Rivera JJ, Pampati VS, Damron KS, McManus CD, Brandon DE Wilson SR. [ISRCTN 16558617] A randomized, controlled trial of spinal endoscopic adhesiolysis in chronic refractory low back and lower extremity pain. BMC Anesthesiol. 2005; 5:10

145. Manchikanti L, Pakanati R, Bakhit CE, Pampati V. Role of adhesiolysis and hypertonic saline neurolysis in management of low back pain. Evaluation of modification of Racz protocol. Pain Digest. 1999:91-96

146. Manchikanti L, Pampati V. Role of One Day Epidural Adhesiolysis in Managemnt of Chronic Low Back Pain: A radomized Clinical Trial. Pain Physician. 2001; 4:153-166

147. Manchikanti L, Pampati V, Bakhit CE, Pakanati RR. Non-endoscopic and endoscopic adhesiolysis in post-lumbar laminectomy syndrome: a one-year outcome study and cost effectiveness analysis. Pain Physician. 1999; 2:52-58

148. Manchikanti L, Rivera JJ, Pampati V, Damron KS, McManus CD, Brandon DE, Wilson SR. One day lumbar epidural adhesiolysis and hypertonic saline neurolysis in treatment of chronic low back pain: a randomized, double-blind trial. Pain Physician. 2004; 7:177-186

149. Matsuoka Y, Yang J. Selective inhibition of extracellular signal-regulated kinases $1 / 2$ blocks nerve growth factor to brain-derived neurotrophic factor signaling and suppresses the development of and reverses already established pain behavior in rats. Neuroscience. 2012; 206:224-236

150. McGovern D, Summerskill W, Levi M. Evidence-based medicine in general practice. Oxford: Bios Scientific Publishers; 2001

151. McQuay HJ, Moore RA. Epidural corticosteroids for sciatica McQuay HJ, Moore RA ed. Oxford-
New York- Tokyo: Oxford University Press; 1998

152. Merrill DG, Rathmell JP, Rowlingson JC. Epidural steroid injections. Anesth Analg. 2003; 96:907-908

153. Merskey H, Bogduk N. Classification of Chronic Pain: Descriptions of Chronic Pain Syndromes and Definitions of Pain Terms. Merksey H, Bogduk N ed. Seattle: Wash: IASP Press; 1994

154. Michael GJ, Averill S, Nitkunan A, Rattray M, Bennett DL, Yan Q, Priestley JV. Nerve growth factor treatment increases brain-derived neurotrophic factor selectively in TrkA-expressing dorsal root ganglion cells and in their central terminations within the spinal cord. J Neurosci. 1997; 17:8476-8490

155. Millan MJ. Descending control of pain. Prog Neurobiol. 2002; 66:355-474

156. Mixter W, Barr J. Rupture of the intervertebral dics with involvement of the spinal canal. New Engl J Med 1934:210-215

157. Modic MT, Obuchowski NA, Ross JS, Brant-Zawadzki MN, Grooff PN, Mazanec DJ, Benzel EC. Acute low back pain and radiculopathy: MR imaging findings and their prognostic role and effect on outcome. Radiology. 2005; 237:597-604

158. Modic MT, Ross JS, Obuchowski NA, Browning KH, Cianflocco AJ, Mazanec DJ. Contrast-enhanced MR imaging in acute lumbar radiculopathy: a pilot study of the natural history. Radiology. 1995; 195:429-435

159. Morshed S, Bhandari M. Clinical trial design in fracture-healing research: meeting the challenge. J Bone Joint Surg Am. 2008; 90 Suppl 1:55-61

160. Munglani R. The longer term effect of pulsed radiofrequency for neuropathic pain. Pain. 1999; 80:437-439

161. Murphy DR, Hurwitz EL, Gerrard JK, Clary R. Pain patterns and descriptions in patients with radicular pain: Does the pain necessarily follow a specific dermatome? Chiropr Osteopat. 2009; 17:9

162. Myers RR, Shubayev VI The ology of neuropathy: an integrative review of the role of neuroinflam-

163. Nath S, Nath CA, Pettersson K. Percutaneous lumbar zygapophysial (Facet) joint neurotomy using radiofrequency current, in the management of chronic low back pain: a randomized double-blind trial. Spine. 2008; 33:1291-1297

164. Ng L, Chaudhary N, Sell P. The efficacy of corticosteroids in periradicular infiltration for chronic radicular pain: a randomized, double-blind, controlled trial. Spine. 2005; 30:857-862

165. Niemisto L, Kalso E, Malmivaara A, Seitsalo S, Hurri H. Radiofrequency denervation for neck and back pain: a systematic review within the framework of the cochrane collaboration back review group. Spine. 2003: 28:1877-1888

166. North RB, Kidd DH, Zahurak M, Piantadosi S. Specificity of diagnostic nerve blocks: a prospective, randomized study of sciatica due to lumbosacral spine disease. Pain. 1996; 65:77-85

67. Novak S, Nemeth WC. The basis for recommending repeating epidural steroid injections for radicular low back pain: a literature review. Arch Phys Med Rehabil. 2008; 89:543-552

168. Nygaard OP, Mellgren SI. The function of sensory nerve fibers in lumbar radiculopathy. Use of quantitative sensory testing in the exploration of different populations of nerve fibers and dermatomes. Spine, 1998; 23:348-352

169. Nykvist F, Hurme M, Alaranta H, Kaitsaari M. Severe sciatica: a 13-year follow-up of 342 patients. Eur Spine J. 1995; 4:335-338

170. O'Donnell C, Cano W, D'Eramo G. Comparison of triamcinolone to dexamethasone in the treatment of low back and leg pain via lumbar transforaminal epidural steroid injection. In: ISIS, ed. North American Spine Society 23rd Annual Meeting, Vol. Toronto: ISIS; 2008.

171. Obata K, Tsujino H, Yamanaka H, Yi D, Fukuoka T, Hashimoto N, Yonenobu K, Yoshikawa H, Noguchi K. Expression of neurotrophic factors in the dorsal root ganglion in a rat model of lumbar 
disc herniation. Pain. 2002; 99:121-132

172. Onda A, Murata Y, Rydevik B, Larsson K, Kikuchi S, Olmarker K. Immunoreactivity of brainderived neurotrophic factor in rat dorsal root ganglion and spinal cord dorsal horn following exposure to herniated nucleus pulposus. Neurosci Lett. 2003; 352:49-52

173. Owlia MB, Salimzadeh A, Alishiri G, Haghighi A. Comparison of two doses of corticosteroid in epidural steroid injection for lumbar radicular pain. Singapore Med J. 2007; 48:241-245

174. Ozsoylar O, Akcali D, Cizmeci P, Babacan A, Cahana A, Bolay H. Percutaneous pulsed radiofrequency reduces mechanical allodynia in a neuropathic pain model. Anesth Analg. 2008; 107:14061411

175. Park HW, Ahn SH, Son JY, Kim SJ, Hwang SJ, Cho YW, Lee DG. Pulsed radiofrequency application reduced mechanical hypersensitivity and microglial expression in neuropathic pain model. Pain Med. 2012; 13:1227-1234

176. Perkins WJ, Davis DH, Huntoon MA, Horlocker TT. A retained Racz catheter fragment after epidural neurolysis: implications during magnetic resonance imaging. Anesth Analg. 2003; 96:1717-1719

177. Perret DM, Kim DS, Li KW, Sinavsky K, Newcomb RL, Miller JM, Luo ZD. Application of pulsed radiofrequency currents to rat dorsal root ganglia modulates nerve injury-induced tactile allodynia. Anesth Analg. 2011;113:610-616

178. Persson AK, Gebauer M, Jordan S, Metz-Weidmann C, Schulte AM, Schneider HC, Ding-Pfennigdorff D, Thun J, Xu XJ, Wiesenfeld-Hallin Z, Darvasi A, Fried K, Devor M. Correlational analysis for identifying genes whose regulation contributes to chronic neuropathic pain. Mol Pain. 2009; 5:

179. Petrovic P. Placebo analgesia and nocebo hyperalgesia--two sides of the same coin? Pain. 2008; 136:5

180. Peul WC, Brand R, Thomeer RT, Koes BW. Influence of gender and other prognostic factors on outcome of sciatica. Pain. 2008; 138:180-191

181. Peul WC, van den Hout WB, Brand R, Thomeer RT, Koes BW. Prolonged conservative care versu early surgery in patients with sciatica caused by lumbar disc herniation: two year results of a randomised controlled trial. BMJ. 2008; 336:1355-1358

182. Peul WC, van Houwelingen HC, van den Hout WB, Brand R, Eekhof JA, Tans JT, Thomeer RT, Koe BW. Surgery versus prolonged conservative treatment for sciatica. N Engl J Med. 2007; 356:22452256

183. Pevzner E, David R, Leitner Y, Pekarsky I, Folman Y, Gepstein R. [Pulsed radiofrequency treatment of severe radicular pain]. Harefuah. 2005; 144:178-180, 231

184. Pinto RZ, Maher CG, Ferreira ML, Ferreira PH, Hancock M, Oliveira VC, McLachlan AJ, Koes B Drugs for relief of pain in patients with sciatica: systematic review and meta-analysis. BMJ. 2012; 344:e497

185. Pinto RZ, Maher CG, Ferreira ML, Hancock M, Oliveira VC, McLachlan AJ, Koes B, Ferreira PH. Epidural corticosteroid injections in the management of sciatica: a systematic review and meta-analysis. Ann Intern Med. 2012; 157:865-877

186. Pinto V, Szucs P, Lima D, Safronov BV. Multisegmental A $\{$ delta $\}$ - and C-fiber input to neurons in lamina I and the lateral spinal nucleus. J Neurosci. 2010; 30:2384-2395

187. Polgar S, Ng J. Ethics, methodology and the use of placebo controls in surgical trials. Brain Res Bull. 2005; 67:290-297

188. Postacchini F, Giannicola G, Cinotti G. Recovery of motor deficits after microdiscectomy for lumbar disc herniation. J Bone Joint Surg Br. 2002; 84:1040-1045

189. Protasoni M, Reguzzoni M, Sangiorgi S, Reverberi C, Borsani E, Rodella LF, Dario A, Tomei G, Dell'Orbo C. Pulsed radiofrequency effects on the lumbar ganglion of the rat dorsal root: a morpho- logical light and transmission electron microscopy study at acute stage. Eur Spine J. 2009; 18:473-478

190. Quintero N, Laffont I, Bouhmidi L, Rech C, Schneider AE, Gavardin T, Dizien O. [Transforaminal epidural steroid injection and paraplegia: case report and bibliographic review]. Ann Readapt Med Phys. 2006; 49:242-247

191. Radhakrishnan K, Litchy WJ, O'Fallon WM, Kurland LT. Epidemiology of cervical radiculopathy. A population-based study from Rochester, Minnesota, 1976 through 1990. Brain. 1994; 117 ( Pt 2):325335

192. Raffaeli W, Righetti D. Surgical radio-frequency epiduroscopy technique (R-ResAblator) and FBSS treatment: preliminary evaluations. Acta Neurochir Suppl. 2005; 92:121-125

193. Ramanavarapu V, Simopoulos TT. Pulsed radiofrequency of lumbar dorsal root Ganglia for chronic post-amputation stump pain. Pain Physician. 2008; 11:561-566

194. Ramer MS, French GD, Bisby MA. Wallerian degeneration is required for both neuropathic pain and sympathetic sprouting into the DRG. Pain. 1997; 72:71-78

195. Ramer MS, Thompson SW, McMahon SB. Causes and consequences of sympathetic basket formation in dorsal root ganglia. Pain. 1999; Suppl 6:S111-120

196. Rathmell JP, Benzon HT. Transforaminal injection of steroids: should we continue? Reg Anesth Pain Med. 2004; 29:397-399

197. Richebe P, Rathmell JP, Brennan TJ. Immediate early genes after pulsed radiofrequency treatment: neurobiology in need of clinical trials. Anesthesiology. 2005; 102:1-3

98. Richter H. Is the so-called epidural neuroplasty (Racz catheter) a harmless procedure? In: Neurochirurgie DGf, ed. Deutsche Gesellschaft fur Neurochirurgie Vol. Strasbourg, Germany: Deutsche Gesellschaft fur Neurochirurgie 2005.

199. Riew KD, Park JB, Cho YS, Gilula L, Patel A, Lenke LG, Bridwell KH. Nerve root blocks in the treatment of lumbar radicular pain. A minimum five-year follow-up. J Bone Joint Surg Am. 2006; 88:1722-1725

200. Riew KD, Yin Y, Gilula L, Bridwell KH, Lenke LG, Lauryssen C, Goette K. The effect of nerve-root injections on the need for operative treatment of lumbar radicular pain. A prospective, randomized, controlled, double-blind study. J Bone Joint Surg Am. 2000; 82-A:1589-1593

201. Roland M, Fairbank J. The Roland-Morris Disability Questionnaire and the Oswestry Disability Questionnaire. Spine. 2000; 25:3115-3124

202. Rong R, Meng BL, Jiang N, Hu LQ, Wang TH. Roles of BDNF in spinal neuroplasticity in cats subjected to partial dorsal ganglionectomy. Growth Factors. 2011; 29:263-270

203. Rowbotham MC, Gilron I, Glazer C, Rice AS, Smith BH, Stewart WF, Wasan AD. Can pragmatic trials help us better understand chronic pain and improve treatment? Pain. 2013; 154:643-646

204. Ruetten S, Meyer O, Godolias G. Endoscopic surgery of the lumbar epidural space (epiduroscopy): results of therapeutic intervention in 93 patients. Minim Invasive Neurosurg. 2003; 46:1-4

205. Saarto T, Wiffen PJ. Antidepressants for neuropathic pain. Cochrane Database Syst Rev. 2007: 4 , CD005454

206. Sackett DL. Why randomized controlled trials fail but needn't: 1. Failure to gain "coal-face" commitment and to use the uncertainty principle. CMAJ. 2000; 162:1311-131

207. Sakai T, Aoki H, Hojo M, Takada M, Murata H, Sumikawa K. Adhesiolysis and targeted steroid/ local anesthetic injection during epiduroscopy alleviates pain and reduces sensory nerve dysfunction in patients with chronic sciatica. J Anesth. 2008; 22:242-247

208. Savettieri G, Salemi G, Rocca WA, Meneghini F, D’Arpa A, Morgante L, Coraci MA, Regrio A, Grigoletto F, Di Perri R. Prevalence of lumbosacral radiculopathy in two Sicilian municipalities. Sicilian Neuro-Epidemiologic Study (SNES) Group. Acta Neurol Scand. 1996; 93:464-469 
209. Schellings R, Kessels AG, Sturmans F. [Pre-randomisation in study designs: getting past the taboo]. Ned Tijdschr Geneeskd. 2008; 152:2053-2056

210. Schellings R, Kessels AG, Ter Riet G, Kleijnen J, Leffers P, Knottnerus JA, Sturmans F. Member of research ethics committees accepted a modification of the randomized consent design. J Clin Epidemiol. 2005; 58:589-594

211. Schellings R, Kessels AG, ter Riet G, Sturmans F, Widdershoven GA, Knottnerus JA. Indications and requirements for the use of prerandomization. J Clin Epidemiol. 2009; 62:393-399

212. Schwarzer AC, Wang SC, Bogduk N, McNaught PJ, Laurent R. Prevalence and clinical features of lumbar zygapophysial joint pain: a study in an Australian population with chronic low back pain. Ann Rheum Dis. 1995; 54:100-106

213. Severeijns R, van den Hout MA, Vlaeyen JW, Picavet HS. Pain catastrophizing and general health status in a large Dutch community sample. Pain. 2002; 99:367-376

214. Shah RV. The problem with diagnostic selective nerve root blocks. Spine (Phila Pa 1976). 2012 37:1991-1993

215. Sheth RN, Dorsi MJ, Li Y, Murinson BB, Belzberg AJ, GriffinJW, Meyer RA. Mechanical hyperalgesia after an L5 ventral rhizotomy or an L5 ganglionectomy in the rat. Pain. 2002; 96:63-72

216. Simopoulos TT, Kraemer J, Nagda JV, Aner M, Bajwa ZH. Response to pulsed and continuou radiofrequency lesioning of the dorsal root ganglion and segmental nerves in patients with chronic lumbar radicular pain. Pain Physician. 2008; 11:137-144

217. Simopoulos TT, Kraemer JJ, Glazer P, Bajwa ZH. Vertebral osteomyelitis: a potentially catastrophic outcome after lumbar epidural steroid injection. Pain Physician. 2008; 11:693-697

218. Slappendel R, Crul BJ, Braak GJ, Geurts JW, Booij LH, Voerman VF, de Boo T. The efficacy of radiofrequency lesioning of the cervical spinal dorsal root ganglion in a double blinded randomized study: no difference between 40 degrees $\mathrm{C}$ and 67 degrees C treatments. Pain. 1997; 73:159-163

219. Sluijter ME. Radiofrequency part I: Flivopress, Meggen, Switzerland; 2001

220. Sluijter ME, Cosman ER, Rittman IIWB, van Kleef M. The effects of pulsed radiofrequency field applied to the dorsal root ganglion - a preliminary report. The Pain Clinic. 1998; 11:109-117

221. Somayaji HS, Saifuddin A, Casey AT, Briggs TW. Spinal cord infarction following therapeutic computed tomography-guided left L2 nerve root injection. Spine (Phila Pa 1976). 2005; 30:E106-108

222. Song XJ, Hu SJ, Greenquist KW, Zhang JM, LaMotte RH. Mechanical and thermal hyperalgesia and ectopic neuronal discharge after chronic compression of dorsal root ganglia. J Neurophysiol. 1999; 82:3347-3358

223. Suri P, Rainville J, Hunter DJ, Li L, Katz JN. Recurrence of radicular pain or back pain after nonsurgical treatment of symptomatic lumbar disk herniation. Arch Phys Med Rehabil. 2012; 93:690-695

224. Takei Y, Laskey R. Interpreting crosstalk between TNF-alpha and NGF: potential implications for disease. Trends Mol Med. 2008; 14:381-388

225. Talu G, Erdine S. Complications of epidural neuroplasty: a retrospective evaluation. Neuromodulation. 2003:237-347

226. Tanaka N, Yamaga M, Tateyama S, Uno T, Tsuneyoshi I, Takasaki M. The effect of pulsed radiofrequency current on mechanical allodynia induced with resiniferatoxin in rats. Anesth Analg. 2010; 111:784-790

227. Tarulli AW, Raynor EM. Lumbosacral radiculopathy. Neurol Clin. 2007; 25:387-405

228. Taylor RS, Van Buyten JP, Buchser E. Spinal cord stimulation for chronic back and leg pain and failed back surgery syndrome: a systematic review and analysis of prognostic factors. Spine. 2005; 30:152160

229. Teixeira A, Grandinson M, Sluijter M. Pulsed Radiofrequency for radicular pain due to a herniated intervertebral disc - an initial report. Pain Practice. 2005; 5:111-115

230. Terashima Y, Kawamata M, Takebayashi T, Tanaka S, Tanimoto K, Yamashita T. Changes in synaptic transmission of substantia gelatinosa neurons in a rat model of lumbar radicular pain revealed by in vivo patch-clamp recording. Pain. 2011;152:1024-1032

231. Thomas E, Cyteval C, Abiad L, Picot MC, Taourel P, Blotman F. Efficacy of transforaminal versus interspinous corticosteroid injectionin discal radiculalgia - a prospective, randomised, double-blind study. Clin Rheumatol. 2003; 22:299-304

232. Thoomes EJ, Scholten-Peeters W, Koes B, Falla D, Verhagen AP. The Effectiveness of Conservative Treatment for Patients With Cervical Radiculopathy: A Systematic Review. Clin J Pain. 2013; 29:1073-1086

233. Tubach F, Beaute J, Leclerc A. Natural history and prognostic indicators of sciatica. J Clin Epidemiol. 2004; 57:174-179

234. Tullberg T, Svanborg E, Isaccsson J, Grane P. A preoperative and postoperative study of the accuracy and value of electrodiagnosis in patients with lumbosacral disc herniation. Spine. 1993; 18:837-842

235. Tun K, Cemil B, Gurcay AG, Kaptanoglu E, Sargon MF, Tekdemir I, Comert A, Kanpolat Y. Ultrastructural evaluation of Pulsed Radiofrequency and Conventional Radiofrequency lesions in rat sciatic nerve. Surg Neurol. 2009; 72:496-500; discussion 501

236. Tweede kamer der Staten-Generaal TLCotDP. Evaluatie Wet medisch-wetenschappelijk onderzoek met mensen [Evaluation of The Medical Research Involving Human Subjects Act]. In, Vol. 29963 The Hague; 2006-2007.

237. Vad VB, Bhat AL, Lutz GE, Cammisa F. Transforaminal epidural steroid injections in lumbosacral radiculopathy: a prospective randomized study. Spine. 2002; 27:11-16

238. Vallejo R, Tilley DM, Williams J, Labak S, Aliaga L, Benyamin RM. Pulsed radiofrequency modulates pain regulatory gene expression along the nociceptive pathway. Pain Physician. 2013; 16:E601-613

239. Van Boxem K, Cheng J, Patijn J, van Kleef M, Lataster A, Mekhail N, Van Zundert J. 11. Lumbosacral radicular pain. Pain Pract. 2010; 10:339-358

240. Van Boxem K, Huntoon M, Van ZundertJ, Patijn J, van Kleef M, Joosten EA. Pulsed radiofrequency: a review of the basic science as applied to the pathophysiology of radicular pain: a call for clinical translation. Reg Anesth Pain Med. 2014; 39:149-159

241. van Boxem K, Joosten EA, van Kleef M, Patijn J, van Zundert J. Pulsed radiofrequency treatment for radicular pain: where do we stand and where to go? Pain Med. 2012; 13:351-354

242. Van Boxem K, van Bilsen J, de Meij N, Herrler A, Kessels F, Van Zundert J, van Kleef M. Pulsed radiofrequency treatment adjacent to the lumbar dorsal root ganglion for the management of lumbosacral radicular syndrome: a clinical audit. Pain Med. 2011; 12:1322-1330

243. van der Windt DA, Simons E, Riphagen, II, Ammendolia C, Verhagen AP, Laslett M, Deville W, Deyo RA, Bouter LM, de Vet HC, Aertgeerts B. Physical examination for lumbar radiculopathy due to disc herniation in patients with low-back pain. Cochrane Database Syst Rev. 2010; 2:CD007431

244. van Kleef M, Barendse GA, Kessels F, H.M.Voets, Weber WE, de Lange S. Randomized trial of radiofrequency lumbar facet denervation for chronic low back pain. Spine. 1999; 24:1937-1942

245. van Kleef M, Liem L, Lousberg R, Barendse G, Kessels F, Sluijter M. Radiofrequency lesion adjacent to the dorsal root ganglion for cervicobrachial pain: a prospective double blind randomized study. Neurosurgery. 1996; 38:1127-1131

246. van Kleef M, Mekhail N, van Zundert J. Evidence-based guidelines for interventional pain medicine according to clinical diagnoses. Pain Pract. 2009; 9:247-251

247. van Kleef M, Spaans F, Dingemans W, Barendse GAM, Floor E, Sluijter ME. Effects and side effects of a percutaneous thermal lesion of the dorsal root ganglion in patients with cervical pain syndrome. Pain. 1993; 52:49-53 
248. van Wijk RM, Geurts JW, Wynne HJ, Hammink E, Buskens E, Lousberg R, Knape JT, Groen GJ. Radiofrequency denervation of lumbar facet joints in the treatment of chronic low back pain: randomized, double-blind, sham lesion-controlled trial. Clin J Pain. 2005; 21:335-344

249. Van Zundert J. Clinical research in interventional pain management techniques: the clinician's point of view. Pain Pract. 2007; 7:221-229

250. Van Zundert J, de Louw AJ, Joosten EA, Kessels AG, Honig W, Dederen PJ, Veening JG, Vles JS, van Kleef M. Pulsed and continuous radiofrequency current adjacent to the cervical dorsal root ganglion of the rat induces late cellular activity in the dorsal horn. Anesthesiology. 2005; 102:125-131

251. Van ZundertJ, Harney D, Joosten EA, Durieux ME, PatijnJ, Prins MH, Van Kleef M. The role of the dorsal root ganglion in cervical radicular pain: diagnosis, pathophysiology, and rationale for treatment. Reg Anesth Pain Med. 2006; 31:152-167

252. Van Zundert J, Lamé IE, de Louw A, Jansen J, Kessels F, Patijn J, van Kleef M. Percutaneous Pulsed Radiofrequency Treatment of the Cervical Dorsal Root Ganglion in the Treatment of Chronic Cervical Pain Syndromes: A Clinical Audit. Neuromodulation. 2003; 6:6-14

253. Van Zundert J, le Polain de Waroux B. Safety of epidural steroids in daily practice: evaluation of more than 4000 administrations. In: Monitor TI, ed. XX Annual ESRA Meeting, Vol. 12 Rome: ESRA; 2000. 122.

254. Van Zundert J, Patijn J, Kessels A, Lame I, van Suijlekom H, van Kleef M. Pulsed radiofrequency adjacent to the cervical dorsal root ganglion in chronic cervical radicular pain: a double blind sham controlled randomized clinical trial. Pain. 2007; 127:173-182

255. Van Zundert J, Van Boxem K, Joosten EA, Kessels A. Clinical trials in interventional pain management: Optimizing chances for success? Pain. 2010; 151:571-574

256. Van ZundertJ, Van Boxem K, Vanelderen P, Puylaert M, De Vooght P, Mestrum R, Heylen R, Visser $\mathrm{K}$, Van Kleef M. Establishing the diagnosis of low back pain: patient selection for interventional pain medicine. Pain Manage. 2013; 3:1-8

257. Veihelmann A, Devens C, Trouillier H, Birkenmaier C, Gerdesmeyer L, Refior HJ. Epidural neuroplasty versus physiotherapy to relieve pain in patients with sciatica: a prospective randomized blinded clinical trial. J Orthop Sci. 2006; 11:365-369

258. Verwoerd AJ, Luijsterburg PA, Lin CW, Jacobs WC, Koes BW, Verhagen AP. Systematic review of prognostic factors predicting outcome in non-surgically treated patients with sciatica. Eur J Pain. 2013; 17:1126-1137

259. Vroomen PC, de Krom MC, Knottnerus JA. Diagnostic value of history and physical examination in patients suspected of sciatica due to disc herniation: a systematic review. J Neurol. 1999; 246:899-906

260. Vroomen PC, de Krom MC, Knottnerus JA. Predicting the outcome of sciatica at short-term follow-up. Br J Gen Pract. 2002; 52:119-123

261. Vroomen PC, de Krom MC, Slofstra PD, Knottnerus JA. Conservative treatment of sciatica: a systematic review. J Spinal Disord. 2000; 13:463-469

262. Vroomen PC, de Krom MC, Wilmink JT, Kester AD, Knottnerus JA. Diagnostic value of history and physical examination in patients suspected of lumbosacral nerve root compression. J Neurol Neurosurg Psychiatry. 2002; 72:630-634

263. Waddell G. The Back Pain Revolution. New York: Churchill Livingstone; 2004

264. Wagner KJ, Sprenger T, Pecho C, Kochs EF, Tolle TR, Berthele A, Gerdesmeyer L. [Risks and complications of epidural neurolysis -- a review with case report]. Anasthesiol Intensivmed Notfallmed Schmerzther. 2006; 41:213-222

265. Waldman. Interventional Pain Management: Saunders, W.B; 2001

266. Wall PD, Lidierth M, Hillman P. Brief and prolonged effects of Lissauer tract stimulation on dorsal horn cells. Pain. 1999; 83:579-589

267. Ware JE, Jr. SF-36 health survey update. Spine (Phila Pa 1976). 2000; 25:3130-3139

268. Watts RW, Silagy CA. A Meta-Analgysis on the efficacy of epidural corticosteroids in the treatment of sciatica. Anaesth Intens Care. 1995; 23:564-569

269. Weber H. The natural course of disc herniation. Acta Orthop Scand Suppl. 1993; 251:19-20

270. Weber H, Holme I, Amlie E. The natural course of acute sciatica with nerve root symptoms in a double-blind placebo-controlled trial evaluating the effect of piroxicam. Spine. 1993; 18:1433-1438

271. Weinstein JN, Tosteson TD, Lurie JD, Tosteson AN, Hanscom B, Skinner JS, Abdu WA, Hilibrand AS Boden SD, Deyo RA. Surgical vs nonoperative treatment for lumbar disk herniation: the Spine Patient Outcomes Research Trial (SPORT): a randomized trial. JAMA. 2006; 296:2441-2450.605

272. White FA, Sun J, Waters SM, Ma C, Ren D, Ripsch M, Steflik J, Cortright DN, Lamotte RH, Miller RJ. Excitatory monocyte chemoattractant protein-1 signaling is up-regulated in sensory neurons after chronic compression of the dorsal root ganglion. Proc Natl Acad Sci USA. 2005; 102:14092-14097

273. Wiesel SW, Tsourmas N, Feffer HL, Citrin CM, Patronas N. A study of computer-assisted tomography I. The incidence of positive CAT scans in an asymptomatic group of patients. Spine. 1984; 9:549-551

274. Wilmink J. In: Lumbar spinal imaging in radicular pain and related conditions, Vol. ed. Berlin - Heidelberg: Springer-Verlag; 2010. 79

275. Wilson-MacDonald J, Burt G, Griffin D, Glynn C. Epidural steroid injection for nerve root compression. A randomised, controlled trial. J Bone Joint Surg Br. 2005; 87:352-355

276. Wolff A, Wilder-Smith O. Diagnosis in patients with chronic radiating low back pain without overt focal neurological deficits : what is the value of segmental nerve root blocks? Therapy. 2005; 2:577-585

277. Wolff AP, Groen GJ, Crul BJ. Diagnostic lumbosacral segmental nerve blocks with local anesthetics: a prospective double-blind study on the variability and interpretation of segmental effects. Reg Anesth Pain Med. 2001; 26:147-155

278. Wolff AP, Groen GJ, Wilder-Smith OH. Influence of needle position on lumbar segmental nerve root block selectivity. Reg Anesth Pain Med. 2006; 31:523-530

279. Wolff AP, Wilder Smith OH, Crul BJ, van de Heijden MP, Groen GJ. Lumbar segmental nerve blocks with local anesthetics, pain relief, and motor function: a prospective double-blind study between lidocaine and ropivacaine. Anesth Analg. 2004; 99:496-501

280. Wong GY, Schroeder DR, Carns PE, Wilson JL, Martin DP, Kinney MO, Mantilla CB, Warner DO, Effect of neurolytic celiac plexus block on pain relief, quality of life, and survival in patients with unresectable pancreatic cancer: a randomized controlled trial. JAMA. 2004; 291:1092-1099

281. Woolf CJ, Allchorne A, Safieh-Garabedian B, Poole S. Cytokines, nerve growth factor and inflammaory hyperalgesia: the contribution of tumour necrosis factor alpha. Br J Pharmacol. 1997; 121:417424

282. Woolf CJ, Bennett GJ, Doherty M, Dubner R, Kidd B, Koltzenburg M, Lipton R, Loeser JD, Payne R, Torebjork E. Towards a mechanism-based classification of pain? Pain. 1998; 77:227-229

283. Woolf CJ, King AE. Dynamic alterations in the cutaneous mechanoreceptive fields of dorsal horn neurons in the rat spinal cord. J Neurosci. 1990; 10:2717-2726

284. World Medical Association. World Medical Association Declaration of Helsinki: ethical principles for medical research involving human subjects. JAMA. 2000; 284:3043-3045

285. Wu B, Ni J, Zhang C, Fu P, Yue J, Yang L. Changes in spinal cord met-enkephalin levels and mechanical threshold values of pain after pulsed radio frequency in a spared nerve injury rat model. Neurol Res. 2012; 34:408-414

286. Xavier AV, Farrell CE, McDanal J, Kissin I. Does antidromic activation of nociceptors play a role in sciatic radicular pain? Pain. 1990; 40:77-79 
287. Xiang Z, Xiong Y, Yan N, Li X, Mao Y, Ni X, He C, LaMotte RH, Burnstock G, Sun J. Functional up-regulation of P2X 3 receptors in the chronically compressed dorsal root ganglion. Pain. 2008; 140:23-34

288. Yabuki S, Kikuchi S, Olmarker K, Myers RR. Acute effects of nucleus pulposus on blood flow and endoneurial fluid pressure in rat dorsal root ganglia. Spine (Phila Pa 1976). 1998; 23:2517-2523

289. Yezierski RP. The effects of age on pain sensitivity: preclinical studies. Pain Med. 2012; 13 Suppl 2:S27-36

290. Yildirim K, Kataray S. The effectiveness of gabapentin n patients with chronic radiculopathy. The Pain Clinic. 2003; 15:213-218

291. You HJ, Morch CD, Arendt-Nielsen L. Electrophysiological characterization of facilitated spinal withdrawal reflex to repetitive electrical stimuli and its modulation by central glutamate receptor in spinal drawal reflex to retitive electrical stimuli and its

292. Younes M, Bejia I, Aguir Z, Letaief M, Hassen-Zrour S, Touzi M, Bergaoui N. Prevalence and risk factors of disk-related sciatica in an urban population in Tunisia. Joint Bone Spine. 2006; 73:538-542 293. Young WF. Transient blindness after lumbar epidural steroid injection: a case report and literature review. Spine. 2002; 27:E476-477

294. Zang R, Muller HJ, Kielbassa K, Marks F, Gschwendt M. Partial purification of a type eta protein kinase $\mathrm{C}$ from murine brain: separation from other protein kinase $\mathrm{C}$ isoenzymes and characterization. Biochem J. 1994; 304 ( Pt 2):641-647

295. Zelen M. A new design for randomized clinical trials. N Engl J Med. 1979; 300:1242-1245

\section{Dankwoord}




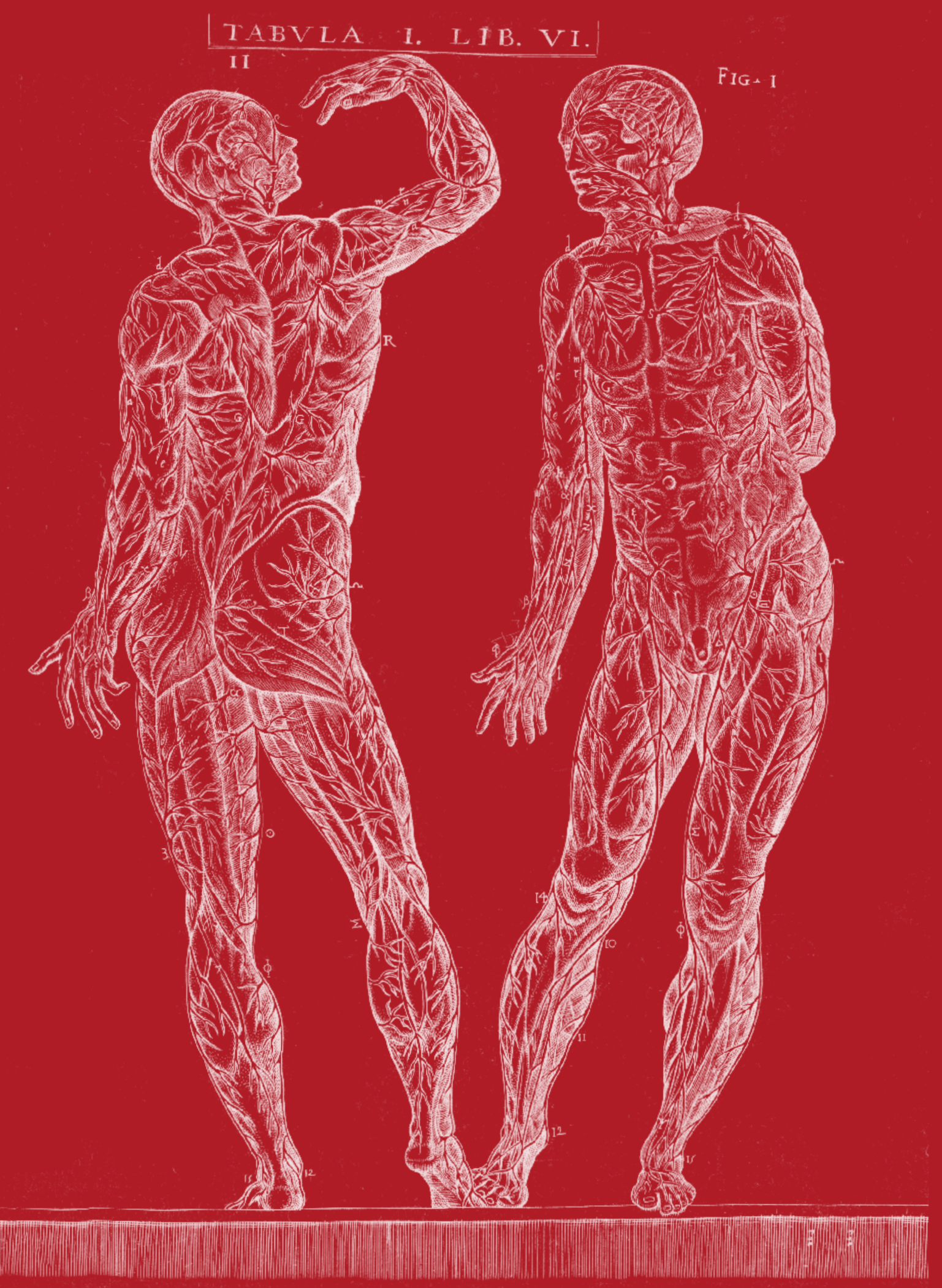

DANKWOORD

"Er zijn 2 zaken die je moet starten zonder er teveel over na te denken: de ene is kinderen kopen en de andere is een proefschrift maken. " Aan deze wijze woorden van dr. Patijn, neuroloog, heb ik vaak gedacht de laatste jaren.

Mijn dank gaat in eerste instantie uit naar mijn promotoren Prof. dr. van Kleef en Prof. dr. Joosten. Beste Maarten, ik had reeds weet van je bibliografische kennis, maar je hebt me tijdens dit traject een paar keer verbluft door je helicopterview op die jungle van literatuur.

Beste Bert, bedankt voor je hartelijke steun en je analytisch vermogen om structuur te brengen in manuscripten. Mijn dank gaat eveneens uit naar mijn copromotor dr. Van Zundert. Jan, als geen andere vind je hiaten in een redenering of moeilijke overgangen in een manuscript. Je opmerkingen andere vind je hiaten in een reden
en suggesties waren steeds welkom.

Dr. Patijn, beste Jaap, jouw visie op het klinisch onderzoek vormde een essentieel onderdeel in de uitgevoerde klinische studies. Hiervoor mijn oprechte dank.

Achter de sterke positie van Maastricht in het publicatielandschap staat een sterk team. Dr. Kessels, methodoloog/statisticus en Mevr. de Meij, datamanager, Fons en Nelleke jullie hulp was onmisbaar voor de realisatie van de publicaties. Met e-mail en telefonisch contact konden we de af tand tusen onze vaste werkplekken overbrugren. Een frisse pint is ook altijd een aanrader om terug helder te zien als data ons zicht vertroebelt. Wiel Honig, Robbie Jaken, Ronald Deumens, Anouk Lindelauf en vele anderen wens ik te danken voor de begeleiding en hulp bij onze pogingen om het dierexperimentele CCD model te reproduceren. Ik heb mogen ondervinden dat wetenschappelijk onderzoek $1 \%$ inspiratie is en $99 \%$ transpiratie. Em. Prof. dr. Wilmink, hoogleraar neuroradiologie, wens ik te danken voor het bijschaven van mijn radiologische kennis over discus hernia. Hermina en José dank ik omdat ze me deskundig doorheen de administratie van de universiteit loodsten.

Voorts wens ik mijn bijzondere waardering uit te drukken voor de leden van de beoordelingscommissie : Prof. dr. van Oostenbrugge als voorzitter, Prof. dr. van Overbeeke, Prof. dr. Buhre, Prof. dr. Vissers en Prof. dr. Hans voor het beoordelen van mijn proefschrift. Ik besef dat dit geconcentreerd werk dikwijls buiten de reguliere uren valt, waarvoor mijn dank.

Het afronden van dit proefschrift is een eindstation na een lange reis.

Tijdens mijn verblijf in Parijs inspireerden dr. Lamine Abdennour et Prof. dr. Louis Puybasset me. Ik ben het team van neuro-anesthesie van het Hôpital Pitié-Salpêtrière dan ook erkentelijk voor hun enthousiasme. Hun toewijding aan het wetenschappelijk onderzoek heeft me enorm beïnvloed. Je suis reconnaissant à l'équipe de neuro-anesthésie de l'Hôpital Pitié-Salpêtrière à Paris. Dr. Lamine Abdennour et Prof. Louis Puybasset j'étais stupéfié par votre enthousiasme pour l'éducation. Votre dévouement pour la recherche scientifique m’a infecté, dans une des plus belles villes du monde. Merci pour allumer ma curiosité.

Mijn eerste stappen zette ik in de pijnwereld onder supervisie van Prof. dr. Adriaensen en Prof. dr. Hans in het Universitair Ziekenhuis Antwerpen. Hun bezieling motiveerde me om te kiezen voor deze jonge subdiscipline. Dit leidde me naar het Ziekenhuis Oost-Limburg met het dynamische team Vissers - Van Zundert - Puylaert. Het bleek een beslissende stap en een etsende leerschool op medisch, menselijk en leidinggevend vlak. Mijn dankbaarheid voor de Limburgse kennis en hartelijkheid is groot, met respect voor dr. Heylen, die met visie een prachtteam rond zich wist te verzamelen. Met de hulp van het huidige pijnteam in het ZOL kon de klinische studie in dit proefschrift afgerond worden. Dank hiervoor aan Dr. Pieter De Vooght, dr. Roel Mestrum, dr. Martine Puylaert en 
dr. Pascal Vanelderen. Ook dank aan dr. Koen Lauwers, dr. Mirella Dingens en dr. Bob Ickx van he Klina ziekenhuis te Brasschaat voor het selecteren van patiënten voor de klinische studie.

Graag wil ik de collega's danken van het AZ Nikolaas te Sint-Niklaas, de vroegere Stadskliniek, voor de mogelijkheid die ik kreeg om mee te helpen met de uitbouw van een pijncentrum. In het bijzonder $\mathrm{dr}$. Thiessen en dr. Willekens van het toenmalige pijnteam. Zeker de levendige anesthesie vergaderingen blijven me bij. Ze werden steevast beklonken met een glas lekkere wijn.

Deze promotie werd tevens mogelijk door de steun van mijn collega's anesthesie van de Sint-

Jozefkliniek Bornem \& Willebroek. De groene oevers van de Schelde zorgen voor een uniek fiets- en werkklimaat met een goede verstandhouding tussen het operatiekwartier, intensieve zorgen en het (voormalig) diens worden, ik voelde me hierdoor altijd gesterkt. Dank aan dr. Luc Van Overberge, dr. Wojciech Pisarek, dr. Godelieve Van Den Abeele en dr. Katrien Vandewiele, mijn collega's anesthesie die mijn passie voor pijnbestrijding dulden. In het bijzonder dank aan de verpleegkundigen en artsen van ons multidisciplinair pijncentrum dr. Gudrun De Clerck en dr. Freija Raps. Op enkele jaren tijd hebben we een hele weg afgelegd, met "effenaf" een mooi team als resultaat.

Dr. Van Zundert en Mevr. Van den Hecke. Jan en Nicole, zonder jullie steun weet ik niet of ik het eindstation had bereikt. Jan, je onbegrensde energie verwonderde me en werkte tegelijk aanstekelijk. Nicole, met je luisterend oor en je vlekkeloze coördinatie was je een wijze gids in een onherbergzaam landschap. Jullie hielden mijn locomotief aan de praat toen het flink bergop ging, ik kan jullie hier nie genoeg voor danken.

Anneleen, ik zie ons nog altijd in de auto zitten, na de inaugurale reden van prof. dr. Vissers. Tot mijn stomme verbazing gaf je spontaan aan dat ik je goedkeuring had om te promoveren, je kent me beter dan ik mezelf ken. Het laatste decennium was ik dikwijls (mentaal) afwezig, met mijn continue stroom van projecten, maar er is een kentering op til. We hebben samen al heel wat watertjes doorzwommen, ik dank je voor je blijvende steun en liefde.

Arno en Wout, mijn boekje is klaar! Ik kan nu eindelijk mijn 'cel' verlaten, een eindhalte is bereikt. 
GV and publications 
7. Van Boxem K, Joosten EA, van Kleef M, Patijn J, van ZundertJ. Pulsed radiofrequency treatment for radicular pain: where do we stand and where to go? Pain Med. 2012; 13:351-354

8. Van Zundert J Van Boxem K, Vanelderen P, Puylaert M, De Vooght P, Mestrum R, Heylen R, Vissers K, Va Kleef M. Establishing the diagnosis of low back pain: patient selection for interventional pain medicine. Pain Manage. 2013; 3:1-8

9. Vanelderen P, Van Boxem K, Van ZundertJ. Epiduroscopy: the missing link connecting diagnosis and treatment? Pain Pract. 2012 Sep;12(7):499-501

10. Van Boxem K, Huntoon M, Van Zundert J, Patijn J, van Kleef M, Joosten EA.Pulsed radiofrequency: a review of the basic science as applied to the pathophysiology of radicular pain: a call for clinical translation. Reg Anesth Pain Med. 2014; 39:149-159

\section{Letters to the editor}

1. Van Boxem K, Van Zundert J, Van Zundert J, Patijn J, van Kleef M. Pseudoradicular and radicular low-back pain: How to diagnose clinically? Pain. 2008; 135:311-312; author reply 313-315

2. Van Boxem K, Van ZundertJ, van Kleef M. Injection therapy: too broad for one conclusion Spine. 2009; 3415 1628-1629 author reply 1629

3. Van ZundertJ, Van Boxem K, van Kleef M. Methodologists are not qualified to write clinical guidelines.Lancet. 2009; 374:1326; author reply 1327.

4. Van Boxem K, Van ZundertJ, van Kleef M. Injection therapv: too broad for one conclusion Spine 2009; 34; 15 1628-1629

5. Van Boxem K, Cahana A, Van Zundert J. Injection therapy and denervation procedures for chronic low back pain: a systematic review-clinical value?Eur Spine J. 2011 May;20(5):820-1; author reply 822-3

\section{In congress proceedings}

1. Van Boxem K, Van Zundert J, Puylaert M, Heylen R, Vissers K. Pulsed radiofrequency treatment of the Gasserian ganglion in trigeminal neuralgia.IMRAPT. 2002; 14:abstr; No. 189

2. Van Boxem K. Interventional Pain Management Techniques in Cervical Pain. In: Society BB, ed. Annual conference of BBS, Vol. Liège: BBS; 2006.

3. Van Zundert J, Puylaert M, Van Boxem K, Vanelderen P, Vissers K, Heylen R. Interventional pain management techniques. In: EFIC, ed. Pain in Europe V, 5th congress of the European Federation of IASP, Vol. Refresher courses. Istanbul, Turkey: EFIC; 2006.

4. Van Boxem K, Joosten E, Van Zundert J, Honig W, Van Kleef M.Chronic compression injury of the DRG: A model for the study of radicular pain.Pain Pract. 2009; 9:25-26 PA 26

5. Van Boxem K, Van Zundert J, Van Kleef M. The role of radiofrequency in lumbosacral radicular pain.Pain Pract. 2009; 9:15 TS 50
6. Van ZundertJ, Van Boxem K, Van Kleef M. Radiofrequency: an expanding role in interventional pain medicine.Pain Pract. 2009; 9:15 TS 51

7. Van Boxem K· Honig W, Van Zundert J, van Kleef M, Joosten E. Pulsed radiofrequency treatment of the lumbar dorsal root ganglion minimizes the development of experimental radicular pain in the rat. Abstract and poster presentation NeuPSIG congres Athens, May 26-29 2010.

8. Vanelderen P., K. Van Boxem, M. van Kleef, J. Van Zundert; Evidence-based injection therapy for low back pain. "Highlights in Regional Anesthesia and Pain Therapy, 31st Annual ESRA Congress 2012, Bordeaux, France."

9. Van Boxem. Pulsed radiofrequency: Translating animal research. Pain Practice 2012; 12: 10 TS 33.

10. K. Van Boxem, J. Van Zundert, W. Honig, M. van Kleef, E. Joosten. Pulsed radiofrequency treatment of the lumbar dorsal root ganglion prevents the development of experimental radicular pain in the rat. Pain Practice 2012; 12: 32 PP112.

11. K. Van Boxem, J. van Bilsen, N. de Meij, A. Herrler, F.Kessels, J. Van Zundert, M. van Kleef. Pulsed radiofrequency treatment adjacent to the lumbar dorsal root ganglion for the management of lumbosacral radicular syndrome: a clinical audit. Pain Practice 2012; 12: 162 PP606.

\section{Book chapters}

1. Van Boxem K, Van Zundert J. Lumbosacraal radiculaire pijn. In: Van Zundert J, Huygen F, Patijn J, van Kleef M eds. Praktische richtlijnen anesthesiologische pijnbestrijding gebaseerd op klinische diagnosen, Maastricht: 2009. 103-116.

2. Vissers K, Besse K, Van Boxem K, Brabant S, Verhagen C. Farmacologische behandeling van pijn bij kanker. In Van Zundert J, Huygen F, Patijn J, van Kleef M, eds. Praktische richtlijnen anesthesiologische pijnbestrijding, gebaseerd op klinische diagnosen, Maastricht: 2009. 279-290.

\section{In journals published in Dutch}

1. Van Boxem K, Van Zundert J.Interventionele pijnbestrijdingstechnieken bij de behandeling van chronische cervicale pijn. Neuron.Neuron. 2007; 12:216-219

2. Van Boxem K.Value of the Magnetic Resonance Imaging in Patients with painful lumbar spinal stenosis (LSS) undergoing lumber epidural steroid injections (comments).NTPP. 2008.

3. Van Boxem K. Peripheral Nerve Pathways of Afferent Fibers Innervating the Lumbar Spine in Rats (comments) NTPP 2009.

4. Van Boxem K. Changes in synaptic transmission of substantia gelatinosa neurons in a rat modelof lumbar radicular pain revealed by in vivo patch-clamp recording (comments) NTPP 2011.

5. Van Boxem K. Physical Exercise Induces Excess Hsp72 Expression and Delays the Development of Hyperalgeia and Allodynia in Painful Diabetic Neuropathy Rats (comments) NTPP 2013. 
List of abbreviations 
TABVLA. III. LIBRI. I.

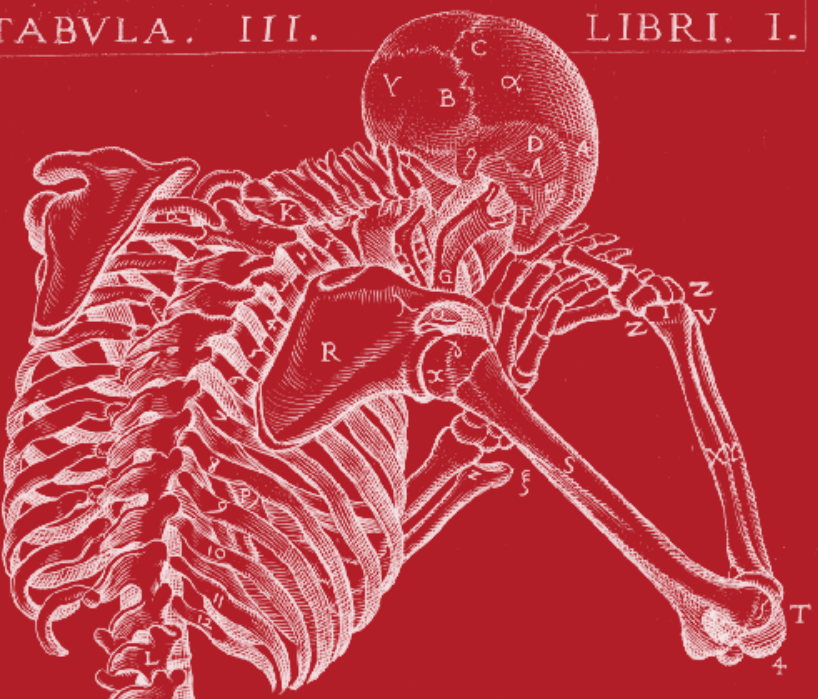

(2)

52

- $:-62$

y.

n.

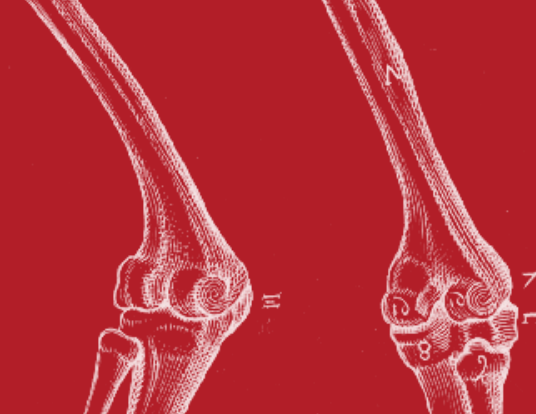

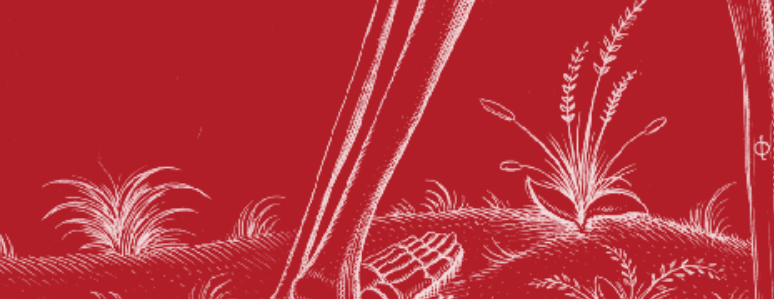

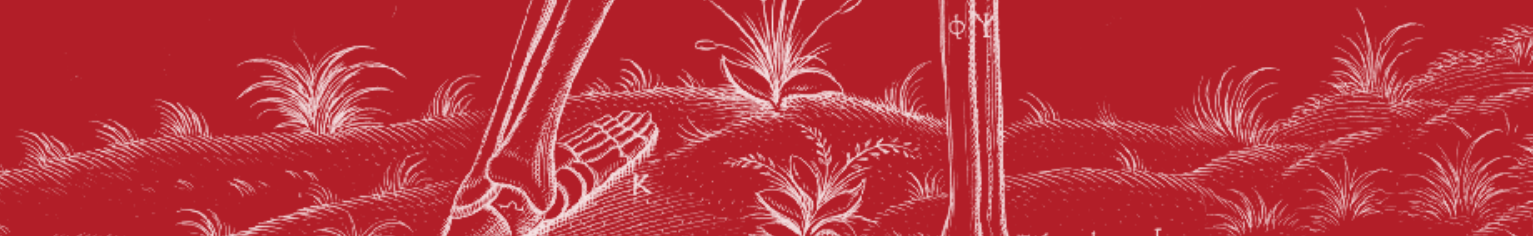

AP view

ATF-3

AUC

BDNF

G-arm

CCD

CGI

c-Fos

CMM

COX-2

CRF

CT

DH

DN4

DRG

EBM

EMG

FBSS

FCA

GPE

GRADE

HD

HIV
Antero-Posterior

Activating Transcription Factor

Area Under the Curve

Brain-Derived Neurotrophic Factor

Image intensifyer in the form of a $\mathrm{C}$

Chronic Compression of the Dorsal Root Ganglion

Chronic Constriction Injury

An immediate early gene

Conventional Medical Management

Cyclo-oxygenase-2

Conventional radiofrequency

Computed Tomography

Dorsal Horn

Douleur Neuropathique 4 question

Dorsal Root Ganglion (ganglion spinale)

Evidence-Based Medicine

Electromyography

Failed Back Surgery Syndrome

Freund's complete adjuvant

Global Perceived Effect

Grading of Recommendations Assessment, Development and Evaluation

Herniated Disc

Human Immunodeficiency Virus 


\section{Health-Related Quality of Life}

International Association for the Study of Pain

LA

LANSS

LSR

M-ENK

$\mathrm{MH}$

MQS

MRI

NCS Nerve Conduction Studies

NGF Nerve Growth Factor

NMDA N-methyl-D-aspartate

NP Nucleus Pulposus

NRS Numeric Rating Scale

NSAID Non-Steroidal Anti-Inflammatory Drug

NNT Number Needed to Treat

ODI Oswestry Disability Index

pERK phosphorylated Extracellular signal-Regulated Kinases

PRF Pulsed Radiofrequency

QST Quantitative sensory testing

RAND-36

\section{Local Anesthetic}

assessment of neuropathic symptoms and signs

$\begin{array}{ll}\text { RCT } & \text { Randomized controlled trial } \\ \text { RF } & \text { Radiofrequency } \\ \text { RQ } & \text { Research question } \\ \text { s } & \text { second } \\ \text { SCS } & \text { Spinal Cord Stimulation } \\ \text { SD rats } & \text { Sprague Dawley rats } \\ \text { SD } & \text { Standard Deviation } \\ \text { SLR } & \text { Straight-Leg-Raising test } \\ \text { SNL } & \text { Spinal Nerve Ligation } \\ \text { SS } & \text { Spinal Stenosis } \\ \text { TCA } & \text { Tricyclic antidepressant } \\ \text { TH } & \text { Thermal Hypersensitivity } \\ \text { TNF-a } & \text { Tumor Necrosis Factor-a } \\ \text { trkB } & \text { Otyrosine kinase receptor B } \\ \text { V } & \text { Volt } \\ \text { VAS } & \text { Visual Analogue Scale } \\ \text { VAVP } & \text { Vlaamse Anesthesiologische Vereniging voor Pijnbestrijding } \\ \text { WD } & \text { Wallerian Degeneration } \\ \text { WHO } & \text { World Health Organization } \\ \text { Z-ray } & \end{array}$


Illustrations 
TABVLA. III. IIBRI. I.

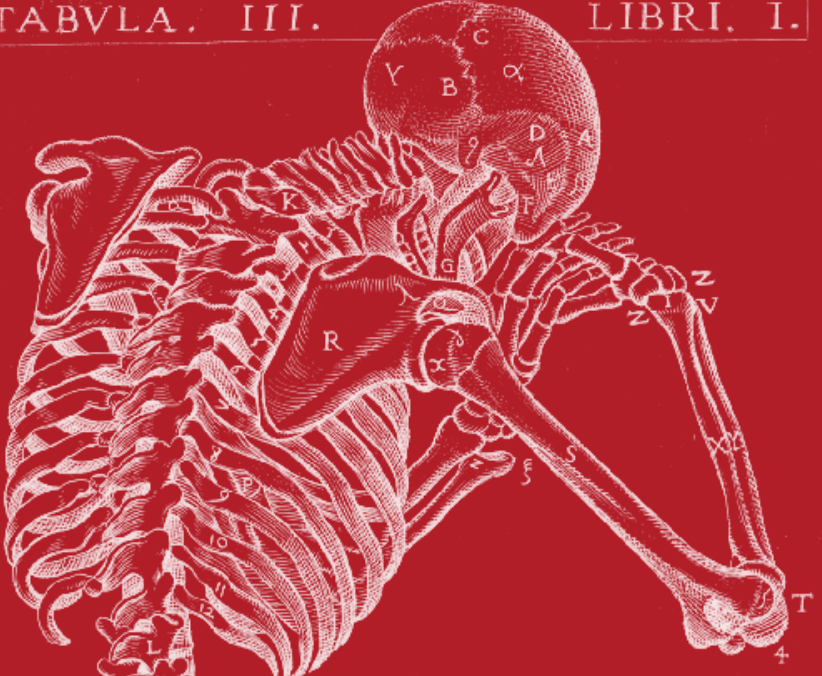

(9)

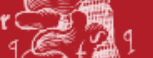

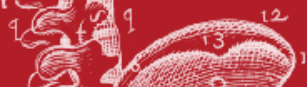
an

$\cos (2)$

Hi: :

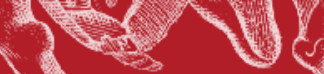
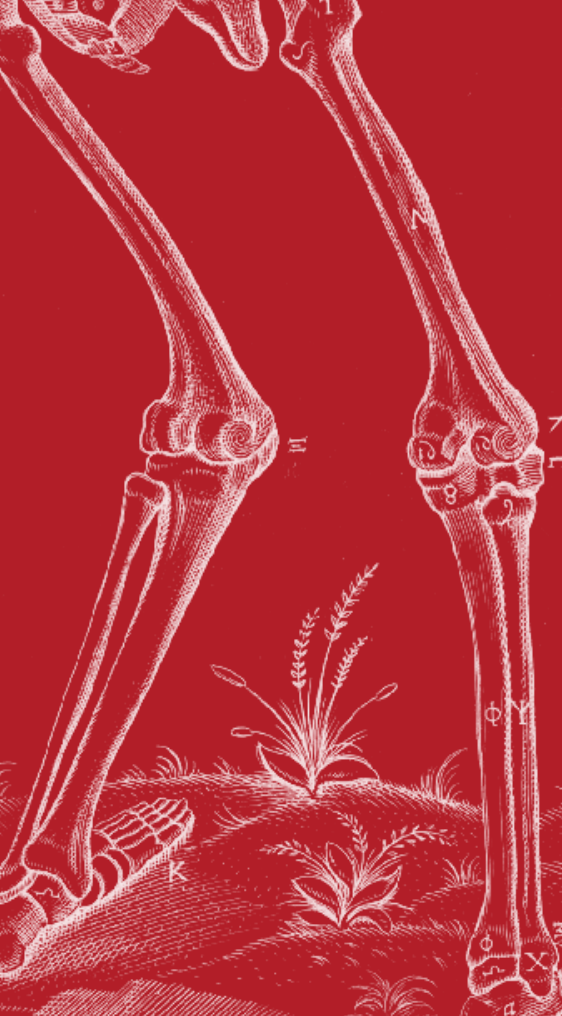

THE PLANTIN-MORETUS MUSEUM

UNESCO WORLD HERITAGE

www.museumplantinmoretus.be

The Plantin-Moretus Museum is the former residential house of the Plantin-Moretus family. The oldest printing presses in the world are there. They bear witness to the first industrial distribution of knowledge and image. The rich art collection is located in the historical residence, including paintings from family friend Peter Paul Rubens. The residence as well as the printing establishment is on UNESCO's prestigious World Heritage list.

Christoffel Plantin published Vivae imagines corporis humani by the Spanish physician Juan Valverda. This work was first published by Plantin in 1566 and is illustrated with engravings based on wood-cuts from the anatomical work by Andreas Vesalius ${ }^{\circ} 1514-\uparrow 1564$ ). The book is still fascinating today, particularly as the museum is now presenting it in Analysing anatomy. Plantin as a publisher of medical work from the perspective of several question

\section{Illustrations}

All the anatomical illustrations used in this publication were etched by the brothers Huys for Plantin in 1564 and were published in the Dutch edition: Juan Valverde de Amusco, Anatomie, oft levende beelden vande deelen des menschelicken lichaems, Antwerpen: Christoffel Plantijn, 1568, $2^{\circ}$ (MPM R 44.12). Plantin printed this Dutch translation mainly for barbers and surgeons who didn't understand Latin. The original "Anatomie" is digitalized and can be freely consulted online.

Photography : Peter Maes 

